\title{
DIEU D'EAU
}

Entretiens avec Ogotemmêli

\author{
par \\ Marcel GRIAULE (1898-1956)
}

\section{8}

Un document produit en version numérique par Pierre Palpant, collaborateur bénévole

Courriel : ppalpant@uqac.ca

Dans le cadre de la collection : "Les classiques des sciences sociales" dirigée et fondée par Jean-Marie Tremblay, professeur de sociologie au Cégep de Chicoutimi

Site web : http : //classiques.uqac.ca/
Une collection développée en collaboration avec la Bibliothèque Paul-Émile-Boulet de l’Université du Québec à Chicoutimi Site web : http : //bibliotheque.uqac.ca/


Un document produit en version numérique par Pierre Palpant, collaborateur bénévole,

Courriel : ppalpant@uqac.ca

à partir de :

\section{DIEU D'EAU, entretiens avec Ogotemmêli par Marcel GRIAULE (1898-1956)}

Librairie Arthème Fayard, Paris, 1975, 224 pages.

Police de caractères utilisée : Verdana, 12 points.

Mise en page sur papier format Lettre (US letter), 8.5'x11"

Édition complétée le $1^{\mathrm{er}}$ mars 2006 à Chicoutimi, Québec. 

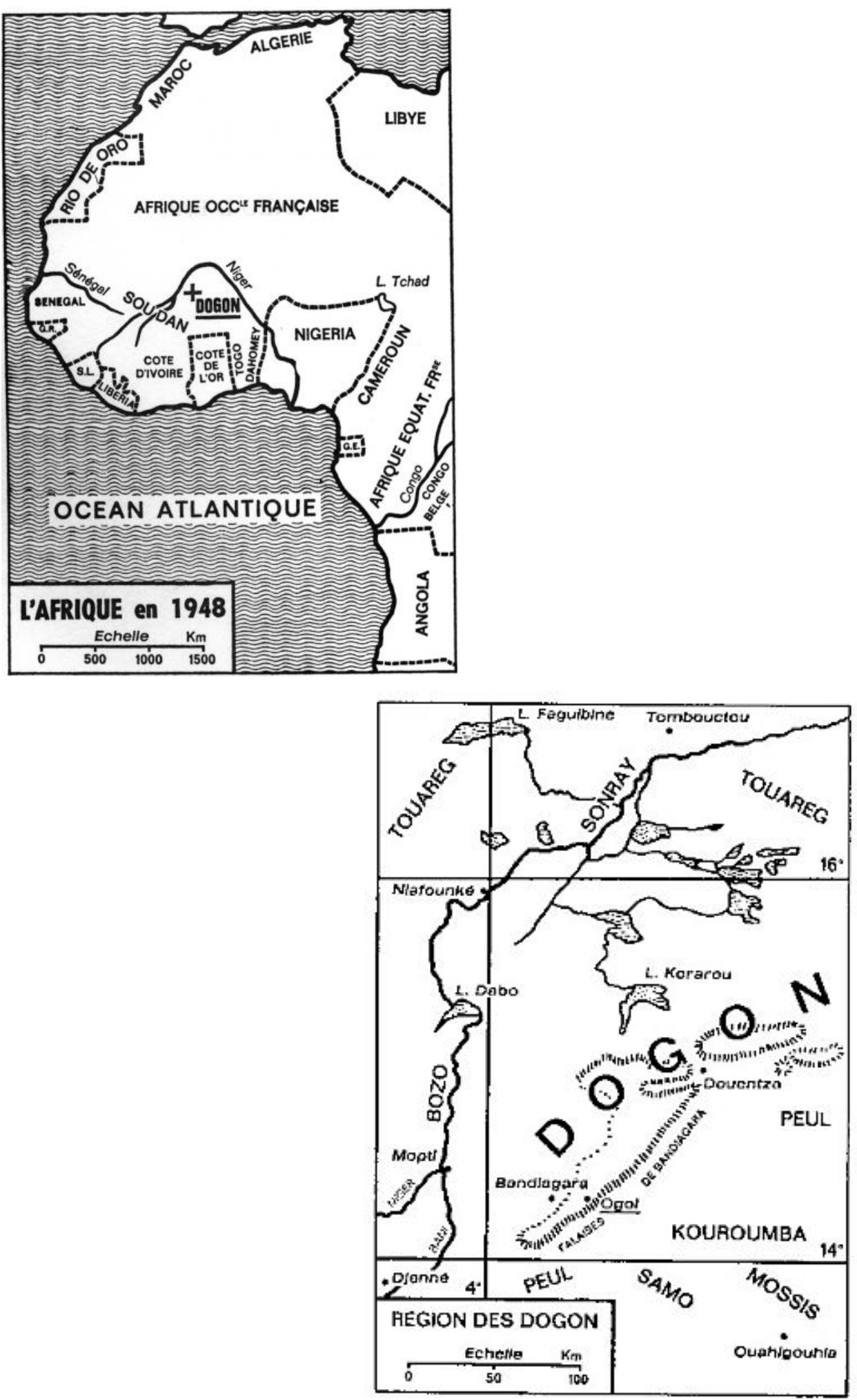


\section{T A B L E D E S M A T I È R S \\ $\underline{\text { Préface }}-\underline{\text { Bibliographie }}-\underline{\text { Index }}$}

Les Ogol.

Première J ournée. - Ogotemmêli.

Seconde J ournée. - La première parole et la jupe de fibres.

Troisième Journée. - La seconde parole et le tissage.

Quatrième Journée. - La troisième parole et le grenier de terre pure.

Cinquième Journée. - La troisième parole et le classement des choses.

Sixième Journée. - La troisième parole, la descente du grenier de terre pure et la mort.

Septième Journée. - La troisième parole et le vomissement du système du monde.

Huitième J ournée. - La troisième parole et les travaux de rédemption.

Neuvième Journée. - La troisième parole et les tambours.

Dixième Journée. - Le verbe et le métier à tisser.

Onzième Journée. - Le verbe et les travaux des champs.

Douzième Journée. - Le verbe, la parure et l'amour.

Treizième J ournée. - La Forge. La Poterie.

Quatorzième Journée. - La grande maison de famille.

Quinzième Journée. - Le Sanctuaire.

Seizième Journée. - Le Sanctuaire et les peintures de façade.

Dix-septième Journée. - Le Sanctuaire et les peintures de façade (suite).

Dix-huitième Journée. - Le culte du Lébé.

Dix-neuvième Journée. - Le culte des Binou.

Vingtième Journée. - Le Sacrifice.

Vingt et unième Journée. - La parole fécondante.

Vingt-deuxième Journée. - Le sang des femmes.

Vingt-troisième Journée. - Le sang des femmes et le battage de Digitaria.

Vingt-quatrième Journée. - La double âme et la circoncision.

Vingt-cinquième Journée. - Les autels personnels.

Vingt-sixième J ournée. - Invention de la mort. 
Vingt-septième Journée. - Le culte des morts, les boissons fermentées. Les morts-vivants.

Vingt-huitième Journée. - La danse.

Vingt-neuvième J ournée. - Le culte du feu.

Trentième Journée. - Les jumeaux et le commerce.

Trente et unième J ournée. - Les jumeaux et le commerce (suite).

Trente-deuxième J ournée. - Les signes du Zodiaque.

Trente-troisième J ournée. - Adieu à Ogotemmêli.

Septembre, 1947.

$\underline{\text { Tableau des correspondances }}$

(9) 


\section{P R É F A C E}

Dans l'un des chaos de roches les plus étonnants de I'Afrique, vit une population de paysans-guerriers qui fut l'une des dernières du domaine français à perdre son indépendance.

Pour la plupart des Blancs de l'Afrique occidentale, les Dogon sont de dangereux hommes, sinon les plus arriérés de la Fédération. Ils passent pour pratiquer encore des sacrifices humains et pour se défendre d'autant mieux contre les influences extérieures qu'ils habitent un pays difficile. Des littérateurs ont raconté leurs petites peurs lors d'excursions supposées téméraires. D'après ces légendes et sous prétexte de révoltes dues souvent à des malentendus, on a parfois tenu en exil des villages entiers.

En bref, les Dogon représenteraient l'un des plus beaux exemples de primitivité farouche et cette opinion est partagée par certains Noirs musulmans qui, intellectuellement, ne sont pas mieux outillés que les Blancs pour apprécier ceux de leurs frères fidèles aux traditions ancestrales. Seuls les fonctionnaires qui ont assumé la lourde tâche d'administrer ces hommes ont appris à les aimer.

L'auteur de ce livre et ses nombreux coéquipiers fréquentent les Dogon depuis une quinzaine d'années. Ils ont publié sur ces hommes des travaux qui en font actuellement le peuple le mieux connu du Soudan français: Les Ames des Dogon (G. DIETERLEN, 1941), Les Devises (S. DE GANAY 1941), Les Masques (M. GRIAULE, 1938) ont apporté à l'érudition la preuve que les Noirs vivaient sur des idées complexes, mais ordonnées, sur des systèmes d'institutions et de rites où rien n'est laissé au hasard ou à la fantaisie. Ces travaux, il y a déjà dix ans, attiraient l'attention sur des faits nouveaux concernant la «force vitale » dont les sociologues nous entretiennent depuis un demi-siècle. Ils démontraient l'importance primordiale de la notion de personne, elle-même liée à celle de société, d'univers, de divinité. 
Ce faisant, l'ontologie dogon ouvrait des horizons aux ethnologues et plaçait le problème sur un plan plus vaste.

Par ailleurs tout récemment (1945), un livre retentissant sur La Philosophie bantoue (R. P. TEMPELS) analysait des notions comparables et posait la question de savoir si l'on doit « prêter à la pensée bantoue un système philosophique ».

Par effets de persévérance et de méthode, quinze années après les premiers pas faits dans les rochers des Falaises de Bandiagara, à cette question il peut être répondu en ce qui concerne les Dogon: ces hommes vivent sur une cosmogonie, une métaphysique, une religion qui les mettent à hauteur des peuples antiques et que la christologie elle-même étudierait avec profit.

Cette doctrine, un homme vénérable l'a confiée à l'auteur. Ogotemmêli, d'Ogol-du-Bas, chasseur devenu aveugle par accident, devait à son infirmité d'avoir pu longuement et soigneusement s'instruire. D'une intelligence exceptionnelle, d'une habileté physique encore visible malgré son état, d'une sagesse dont le prestige s'étendait dans tout son pays, il avait compris l'intérêt des travaux ethnologiques des Blancs et il avait attendu pendant quinze ans l'occasion de révéler son savoir. II voulait sans doute que ces Blancs fussent déjà au fait des institutions, des coutumes et des rites les plus importants.

En octobre 1946, il manda chez lui l'auteur et, durant trente trois journées, des entretiens inoubliables se déroulèrent, mettant à nu l'ossature d'un système du monde dont la connaissance bouleversera de fond en comble les idées reçues concernant la mentalité noire comme la mentalité primitive en général.

On serait tenté de croire qu'il s'agit d'une doctrine ésotérique. D'aucuns ont même avancé, à première vue et sans attendre de précisions, qu'il y avait là spéculation individuelle d'intérêt secondaire. Ce sont d'ailleurs les mêmes qui jugent bon de passer une vie sur les idées apparemment personnelles de Platon ou de Julien d'Halicarnasse.

Bien qu'elle ne soit connue, dans son ensemble, que des anciens et de certains initiés, cette doctrine n'est pas 
ésotérique puisque chaque homme parvenu à la vieillesse peut la posséder.

D'autre part, des prêtres totémiques de tous âges connaissent les parties correspondant à leur spécialité. Bien plus, les rites afférant à ce corps de croyances sont pratiqués par le peuple entier.

Certes, ce peuple n'a pas toujours la connaissance profonde de ses gestes et de ses prières, mais en cela il ressemble à tous les peuples. On ne saurait taxer d'ésotérisme le dogme chrétien de la transsubstantiation sous prétexte que I'homme de la rue ignore ce mot et n'a que des lueurs sur la chose.

Une réserve de même sorte pourrait être faite concernant la valeur explicative et représentative de cette doctrine, concernant la mentalité noire en général. On pourrait avancer que ce qui vaut pour les Dogon ne vaut point pour les autres populations du Soudan.

A cela, l'auteur et ses coéquipiers répondent avec assurance: la pensée Bambara repose sur une métaphysique aussi ordonnée, aussi riche et dont les principes de base sont comparables à ceux qu'utilisent les Dogon. Les travaux de Mme G. Dieterlen et de Mme de Ganay en apportent le témoignage. II en est de même des Bozo, pêcheurs du Niger, des Kouroumba, cultivateurs du centre de la Boucle, des énigmatiques Forgerons des mêmes régions, chez lesquels les enquêtes ne font que commencer.

II ne s'agit donc point ici d'un système de pensée insolite, mais bien du premier exemple d'une suite qui sera longue.

Ce faisant, l'auteur souhaite atteindre deux buts : d'une part, mettre sous les yeux d'un public non spécialiste, et sans l'appareil scientifique habituel, un travail que l'usage réserve aux seuls érudits; d'autre part, rendre hommage au premier Noir de la Fédération occidentale qui ait révélé au monde Blanc une cosmogonie aussi riche que celle d'Hésiode, poète d'un monde mort, et une métaphysique offrant l'avantage de se projeter en mille rites et gestes sur une scène où se meut une multitude d'hommes vivants. 


\section{Les Ogol}

p.7 Le soleil s'était brusquement levé de la plaine du Gondo et dominait les terrasses d'Ogol-du-bas. Les oiseaux s'étaient tus, lui donnant la parole. Dans la cour du caravansérail qu'est tout campement soudanais, les dernières minutes de paix s'écoulaient. Autour d'un plat oublié où restait, la veille, quelque nourriture, des traces de sabots d'âne indiquaient les visites de la nuit. Quatre boules de crottin, nettes comme des exemples, auraient pu être recueillies pour les collections du Muséum (Laboratoire de Mammalogie): elles n'étaient pas encore, à cette heure, un centre attractif de bousiers.

Un grand rocher gris-rose, incliné, formait une table basse, dans la cour de service, devant le bâtiment cubique en terre craquelée qui, tournant le dos au soleil levant, béait de toutes ses ouvertures sur la vallée de Dolo.

Aucune montagne ne surgissait dans aucun horizon, sauf peut-être à l'Orient : en montant sur une terrasse, on aurait pu voir l'éperon discret de Nînou dominant les éboulis de Banani.

On était bien enfoncé dans une mer de grès figée en pleine tourmente, avec ses longs creux de vallées sablonneuses et ses vagues aplaties de rochers reflétant la lumière. On était protégé par des épaisseurs de pays, au sec, visage et corps briqués par les quintaux de sable que charrient les airs.

Dans la pénombre ouverte à tous vents de l'édifice sans battants de portes ni de fenêtres, l'agitation minuscule du petit matin commençait. Quatre Européens allongés sous des moustiquaires-cercueils échangeaient les quolibets ordinaires. Côté cour, dans l'inondation rose-jaune passé de la lumière, un noyé ${ }_{\text {p. } 8}$ de soleil apparut entre les deux pilastres du mur d'enceinte. II s'arrêta un instant pour contempler les scènes intérieures organisées par la nuit ; il vit l'écuelle, les traces d'âne; il vit aussi, renversée dans la poussière, la barrière de nattes défendant la cuisine. 
Enfin son regard s'arrêta sur la fenêtre du réduit et nota le désordre des tiges de mil destinées à repousser les chats.

Mênyou était un doux Noir d'Ogol-du-Haut qui servait avec affection les quatre étrangers, connus de lui depuis longtemps. Il étouffa un juron, bras ballants dans sa lévite blanche à vastes manches, et s'avança vers les désastres.

Le mouvement s'organisa. Le serveur Apourali avait échangé les interminables salutations avec son collègue. D'autres Dogon arrivaient, peuplant la cour : des femmes, enfant au dos, pour des soins d'yeux; une fille blessée au crâne. Des bambins nus, ventre en avant, s'installaient pour le spectacle long d'un jour. Sur les murs, sur le rocher central, sur les marches de la maison, les informateurs, les interprètes étaient en position d'attente. Par groupes, ils entraient à l'appel de leur nom. Et cette scène répétait toutes les autres, celles de la veille et de l'avant-veille, toutes celles qui depuis quinze ans, à chaque séjour des Blancs, animaient l'éperon méridional d'Ogoldu-Haut.

Dans un coin retiré de la véranda, un Européen reprenait l'enquête de la veille sur un obscur sacrifice offert dans une faille des gorges d'l. Il s'était, la veille, enfoncé dans les cavernes et les entonnoirs de grès, avait suivi les corniches en déversoir, avait atteint des ruines où régnait une odeur de fauve et de chauve-souris. Un vieux Dogon répondait par bribes, livrant une vérité démantelée, abandonnant peu à peu ses positions, poussant quelques mensonges, penaud ou rieur, accroupi le dos au mur, cramponné à ses mystères. Son bonnet phrygien, terre de

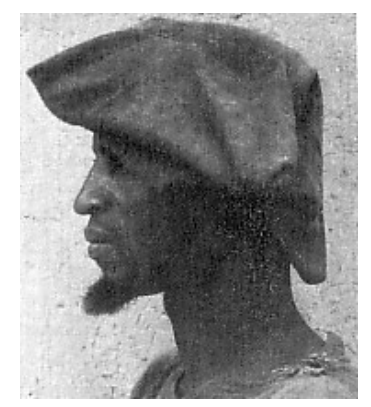

Sienne, retombait sur une oreille, en cachant sa face noir délavé, aux lèvres peu épaisses, au nez mince, aux yeux sans cils. 
Dans la galerie nord, les gesticulations étaient plus vives. Une jeune Européenne orchestrait un chœur de quatre Dogon appartenant à des familles diverses parlant chacune un dialecte. Les vocabulaires étant riches et les verbes expressifs nombreux, c'étaient bientôt quatre acteurs ardents qui mimaient les attitudes et criaient les exemples.

La pièce du nord ressemblait plutôt à un confessionnal ; des prêtres du culte des Ancêtres y parlaient avec modération à une Européenne pleine de patience et d'entêtement.

p.9 Galerie sud enfin, une autre blanche écrivait, sous la dictée d'un Bambara aux yeux vifs, les prières au Komo :

- Komo! tueur de morts gras !

- Linceul des vivants !

Les quatre points cardinaux étaient donc pleins des rumeurs habituelles, des éclats passagers, des détentes de chaque jour.

Pourtant, une petite nouvelle s'avançait vers l'édifice, sur le remblai large d'une main séparant deux champs de haut mil. Elle était dans la cervelle de I'honnête Gana, fils du Hogon, le plus vieil homme des Ogol, donc le chef religieux. Gana tenait entre ses lèvres un bâtonnet frottedents qu'il prenait à la main pour saluer les connaissances. Sa culotte à large fond, sa tunique ample mettaient dans les tiges une note pain brûlé.

Le sentier se heurtant à la roche d'Ogol-du-Haut, il l'escalada. II suivit une ligne que mille et mille pieds avaient polie sur le grès.

Ayant salué à la cantonade, il pénétra dans la cour et finalement surgit devant le Blanc. II sourit et ses oreilles se rapprochèrent de son petit crâne :

- Un chasseur veut vous voir.

- Il est malade ?

En général ce sont les malades qui demandent pareille chose, chez les Noirs. Dans tout autre cas, voir un Blanc ne présente aucun intérêt.

- Non ! il veut vous vendre une amulette. 
- Laquelle ?

- Une amulette que vous aviez commandée il y a dix ans, contre les balles.

- Je n'ai pas souvenir de cette...

Le Blanc se mordit les lèvres. II avait soudain compris l'insolite de la démarche. II dit: «Bien!», continua l'entretien avec le sacrificateur et envoya Gana pour chercher l'objet.

Gana, frotte-dents à la bouche, reprit la piste luisante, sauta du rocher d'Ogol-du-Haut, traversa le mil, se perdit dans l'enchevêtrement d'Ogol-du-Bas, pénétra dans une cour et parla à voix basse devant une porte béante. Une main maigre sortit de l'ombre pour lui tendre un cuir en trapèze, couvert de sang coagulé. Gana refit en sens inverse le même chemin, se présenta au Blanc.

- Et la formule? As-tu la formule?

- Quelle formule?

- Fabrication et usage ! Va la chercher !

- p.10 Je la connais, confia le sacrificateur, Iorsque Gana eut le dos tourné.

Et il la récita incontinent au Blanc qui l'écrivit.

Gana et ses dix-sept ans savaient à quoi s'en tenir sur les histoires entre grandes personnes. II sauta encore le rocher d'Ogol-du-Haut, mais cette fois il resta planté tout raide sur la piste après avoir retiré vivement son frottedents : une épine lui était entrée dans le pied. Boitillant il repartit, retrouva la cour dans le dédale des ruelles et s'étant assis sur le seuil noir, il parla longuement, en retirant une écharde de son orteil. Une voix lente lui répondit, qu'il écouta avec déférence. Puis il reprit la route avec un léger soupir, et se retrouva dans la véranda, devant le Blanc seul. Retirant son frotte-dents, il débita la formule en oubliant trois versets que son interlocuteur, lisant ses notes, lui récita. D'étonnement, Gana laissa pendre un instant la mâchoire.

- Mais qui est ce vieux chasseur ? lui demandait-on.

II se méprit et crut qu'on voulait connaître la devise de I'homme : 
- Vizê, dit-il, vizê karandiang !

C'est-à-dire : Ecarteur! Ecarteur terrible !

(a) 


\section{Première journée}

\section{Ogotemmêli}

Ogol-du-Bas, comme tout village dogon, entassait ses maisons et ses greniers. Terrasses de glaise et toits de paille coniques alternaient. A se faufiler dans ses ruelles d'ombre et de lumière, entre les pyramides tronquées, les prismes, les cubes ou cylindres des greniers et maisons, les portiques rectangulaires, les autels rouges ou blancs en hernies ombilicales, on se sentait nain perdu dans un puzzle. Tout était craquelé sous les pluies et les chaleurs; les parois de torchis se fissuraient comme des peaux de pachydermes. Par-dessus les murs des courettes, on voyait, sous les fondations des greniers, les poules, les chiens jaunes et parfois les grosses tortues, symboles des patriarches. A un détour de la ruelle, on arrivait devant une porte taillée à p.11 la hache et qui, même neuve, n'aurait pu obstruer l'entrée faite de pylônes de terre et d'un fronton de rondins. Porte large comme deux épaules, avec les veines du bois creusées par les pluies d'hiver, ondulantes, et des nœuds ouvrant leurs yeux dans les vagues. La sécheresse, les mains accrocheuses, les museaux des chèvres avaient rétréci le battant qui grinçait sur son pivot, s'appliquait contre le mur avec un bruit de gong et découvrait la courette misérable de l'homme le plus étonnant des plaines et des roches, depuis Oropa jusqu'à Nimbé, Asakarba et Tintam.

Le Blanc s'avança sur un fumier maigre de vieillard sans enfants. Une façade à logettes, percée d'une porte basse au rez-de-chaussée et d'un panneau surbaissé à l'étage, se dressait au milieu de la cour, cachant le bâtiment principal. Sur le fronton s'ouvraient dix trous d'hirondelles; huit cônes coiffés de pierres plates ornaient l'arête. A droite et à gauche s'alignaient, comme de grands dés, six greniers dont deux tournaient le dos, appartenant au voisin. Sur les quatre constructions, l'une était vide, l'autre disloquée, la troisième coupée par le travers comme un fruit mordu. Une seule vivait, à demi-pleine de grains. 
En face, entre l'édifice principal et les greniers, une maison basse fermait la cour, recelant la légère rumeur de la vie. Sur la droite, dans un réduit à ciel ouvert, des duvets tournaient indéfiniment, entraînés par un tourbillon sans violence.

L'homme qui accompagnait le Blanc lança les formules de salut. Aussitôt une voix où les mots sonnaient distinctement répondit :

- Dieu vous amène ! Dieu vous amène !

- Salut ! comment va ton corps ?

La voix s'approchait lentement. De l'ombre intérieure venaient des frottements de mains aux murs et aux bois des chambranles. Un bâton tâtonnait les parois; une poterie sonna creux ; des poussins minuscules sortirent un à un de la chatière, poussés par une grande vie qui avançait.

Enfin une tunique brune apparut, tirée aux coutures, effrangée par l'usage comme un drapeau des guerres d'autrefois; puis une tête se courba sous l'architrave et I'homme se redressa de toute sa taille, tournant sa face indescriptible vers l'étranger :

- Salut à ceux qui ont soif ! dit-il.

Les lèvres épaisses parlaient la plus pure langue de Sanga. On ne voyait qu'elles. Elles seules vivaient. Le reste était comme replié, d'autant que dès les premiers mots, la tête s'était p.12 penchée vers la terre. Les joues, les pommettes, le front, les paupières n'étaient qu'un seul et même ravage; ils étaient plissés de cent rides qui leur donnaient un rictus douloureux, comme d'un visage inondé d'une trop grande lumière ou qui recevrait continûment une grêle de pierres. Ils étaient sous le coup d'une décharge à bout portant et les yeux étaient morts.

Comme les deux visiteurs venaient du dehors et qu'ils étaient censés avoir travaillé à la chaleur, l'homme, appuyé sur son bâton, leur dit enfin :

- Salut ! Salut de fatigue ! Salut de soleil ! 
Le plus long, ce premier jour, fut le choix du lieu, de la place étroite, de la pierre des entretiens. Devant la maison habitée, même en laissant le vieil Ogotemmêli à l'intérieur, même en poussant la tête vers lui et en parlant comme à confesse, on risquait, selon lui, de dresser les oreilles éternelles des femmes. De l'autre côté de la maison à façade, dans la courette exiguë battue par les vents du nord, on pouvait être épié par les enfants cachés dans le grenier en ruine. Restait la cour elle-même, avec son fumier de misère, sa pierre creuse, ses cendres et son mur calamiteux échancré au centre, à hauteur de curieux.

Ogotemmêli hésita encore; il y avait beaucoup à dire sur l'incommodité de la cour pour les conversations entre hommes mûrs. Le Blanc n'ouvrait la bouche que pour approuver ; il insista même sur l'indiscrétion des murailles, sur la sottise des hommes et, naturellement, sur l'inconcevable curiosité des femmes, sur leur soif inextinguible de nouvelles. II était intéressé par toutes ces précautions qui semblaient disproportionnées avec une simple vente d'amulette.

Enfin Ogotemmêli s'assit sur le seuil de la porte inférieure de la grande façade; il se replia sur lui-même, le visage penché vers la terre, et croisant les mains audessus de sa tête, coudes appuyés aux genoux, il attendit.

Le Blanc comprenait peu à peu que la vente de l'amulette n'était qu'un prétexte. II n'en fut pas question dans les entretiens qui suivirent et la raison profonde du geste du vieil homme ne devait jamais être découverte.

Mais à divers détails, il apparut dans la suite qu'Ogotemmêli voulait donner à l'étranger, dont le premier séjour dans le pays p.13 remontait à quinze ans et en qui il avait confiance, l'instruction qu'il avait lui-même reçue de son grand-père, puis de son père.

Ogotemmêli attendait. II était lui-même perplexe devant ce cas qu'il avait provoqué, devant cet homme qu'il ne pouvait voir. Non pas que ce fût pour lui un inconnu : depuis quinze ans il entendait parler de ces groupes de Blancs qui venaient sous sa conduite dormir sur la dure et chevaucher dans les falaises pour y étudier les coutumes. 
Il avait même suivi leurs travaux depuis le début, car il était très lié avec le vieil Ambibê Babadyé, grand dignitaire des Masques, leur informateur attitré, mort depuis peu. A plusieurs reprises, au cours de ces quinze années, Ambibê était venu lui demander conseils et renseignements. Au travers de ses dires, et selon les rapports des uns et des autres, il s'était fait une idée juste des intentions de cet interlocuteur qui passait pour acharné dans la recherche.

Mais le cas était unique. Comment instruire un Blanc? Comment le mettre de plain-pied avec les choses, les rites, les croyances ? Et d'ailleurs, ce Blanc avait déjà démonté les Masques ; il en connaissait la langue secrète ; il avait parcouru le pays en tous sens et pour certaines institutions il en savait autant que lui. Alors ?

Le Blanc le tira d'embarras :

- Lorsque votre fusil vous a éclaté au visage, sur quoi tiriez-vous?

- Sur un porc-épic.

Le Blanc voulait, par un biais, en venir aux affaires de la chasse, aux règles concernant le monde animal et, de là, verser dans le totémisme.

- C'est un accident, déclara le vieillard. Mais c'était aussi le dernier avertissement. La divination m'avait dit qu'il me fallait cesser de chasser si je voulais conserver mes enfants. La chasse, qui est un travail de mort, attire la mort. J'ai eu vingt et un enfants. II m'en reste cinq.

Le grand drame de la mortalité noire se dressait, et aussi les débats profonds de ces hommes, sans défense devant la mort, accrochés à leurs croyances comme tous les hommes de la terre, croyances qui consolent et expliquent, mais qui n'évitent pas l'épreuve.

Sur ce plan de malheur la personnalité d'Ogotemmêli apparut, en elle-même et dans ses rapports avec les puissances p.14 surnaturelles. Dès l'âge de quinze ans il avait été initié aux mystères de la religion par son grandpère. Son père avait continué son instruction après la mort du vieillard. II semblait que ces «leçons » avaient été données pendant plus de vingt ans et que la famille 
d'Ogotemmêli était de celles où ces choses n'étaient pas prises à la légère.

Sans doute aussi Ogotemmêli avait-il fait preuve, très tôt, d'un esprit éveillé et d'une grande adresse. Jusqu'à son aveuglement, il était le chasseur prodigieux qui, bien que borgne depuis son enfance par suite de la variole, revenait les mains pleines alors que les autres peinaient encore dans les gorges. II projetait dans sa technique sa connaissance profonde de la nature, des animaux, des hommes et des dieux. Après son accident, il avait appris davantage encore. Replié sur lui-même, sur ses autels et sur chaque parole entendue, il était devenu l'un des plus puissants esprits des Falaises.

De fait, son nom et sa devise étaient connus du plateau et des éboulis. «Le plus petit gosse les dit ! » affirmait-on, et les consultants affluaient à sa porte, chaque jour et même la nuit.

Comme des bonnets phrygiens se haussaient derrière les murs et que les femmes, de loin, faisaient des signes, il fallut partir et laisser la place aux clients. Mais le contact était pris et les entretiens devaient s'organiser par accord tacite, sur une sorte de programme et à des heures convenables. 


\section{Seconde journée}

\section{La première parole et la jupe de fibres}

Ogotemmêli s'étant assis sur son seuil, racla sa tabatière de peau rigide et posa sur sa langue une poussière jaune :

- Le tabac, dit-il, donne l'esprit juste.

Et il entreprit de décomposer le système du monde.

Car il fallait commencer à l'aurore des choses.

Ogotemmêli repoussa comme détail sans intérêt !a formation des quatorze systèmes solaires dont parle le peuple, à terres plates et circulaires disposées en pile. II ne voulait traiter que du système solaire utile. II consentait à prendre en p.15 considération les étoiles bien qu'elles jouassent un rôle secondaire :

- Il est bien vrai, disait-il, que dans la suite des temps les femmes décrochaient les étoiles pour les donner à leurs enfants. Ceux-ci les perçaient d'un fuseau et faisaient tourner ces toupies de feu pour se montrer à eux-mêmes comment fonctionnait le monde. Mais ce n'est là qu'un jeu.

Les étoiles provenaient de boulettes de terre lancées dans l'espace par le dieu Amma, dieu unique. II avait créé le soleil et la lune selon une technique plus compliquée, qui ne fut pas la première connue des hommes mais qui est la première attestée chez Dieu : la poterie. Le soleil est, en un sens, une poterie portée au blanc une fois pour toutes, entourée d'une spirale à huit tours de cuivre rouge. La lune a même forme et son cuivre est blanc. Elle n'est chauffée que par quartier. Sur leur mouvement, les explications viendraient plus tard. Pour le moment, il convenait de tracer les grandes lignes d'un décor et d'en venir aux acteurs.

Toutefois, Ogotemmêli voulut donner une idée de la grandeur du soleil. 
- Certains, dit-il, l'estiment grand comme le campement, ce qui lui ferait trente coudées. II est en réalité plus grand. II dépasse en surface le canton de Sanga.

Et après avoir hésité, il ajouta :

- Il est peut-être même plus grand encore.

Quant aux dimensions de la lune, il refusa de s'y attarder. II ne les donna jamais. La lune n'avait qu'un rôle moyen. On en reparlerait. II indiqua cependant que si les Noirs étaient des créatures de lumière extraites en plein soleil, c'était au clair de lune qu'avaient été créés les Blancs, d'où leur aspect larvaire.

Ce disant Ogotemmêli cracha son tabac. II n'avait rien contre les Blancs. II ne disait pas non plus qu'il les plaignait. II les laissait à leur destinée, dans les terres du nord.

Le Dieu Amma ayant donc pris un boudin de glaise, il le serra dans sa main et le lança comme il avait fait pour les astres. La glaise s'étale, gagne au nord qui est le haut, s'allonge au sud qui est le bas, bien que tout se passe à I'horizontale.

- La terre est couchée mais le nord est en haut.

Elle s'étend à l'orient et à l'occident, séparant ses membres comme un fœtus dans la matrice. Elle est un corps, c'est-à-dire une chose dont les membres se sont écartés d'une masse centrale.

p.16 Et ce corps est femme, orienté nord-sud, posé à plat, face au ciel. Une fourmilière est son sexe, une termitière son clitoris. Amma, qui est seul et veut s'unir à cette créature, s'approche d'elle.

C'est alors que se produisit le premier désordre de I'Univers.

Ogotemmêli se tut. Mains croisées au-dessus de sa tête, il tâtait les sons divers venant des cours et des terrasses. Il en était à l'origine des calamités, à la maladresse primordiale de Dieu.

- Si I'on m'entendait, j'aurais un bœuf d'amende ! 
Au moment où Dieu s'approche, la termitière se dresse, barre le passage et montre sa masculinité. Elle est l'égale du sexe étranger, l'union n'aura pas lieu.

Pourtant, Dieu est tout-puissant. II abat la termitière rebelle et s'unit à la terre excisée. Mais l'incident originel devait marquer à jamais la marche des choses: de l'union défectueuse naquit, au lieu des jumeaux prévus, un être unique, le Thos aureus, le chacal, symbole des difficultés de Dieu.

Ogotemmêli parlait de plus en plus bas. II n'était plus question des oreilles des femmes. D'autres tympans, immatériels, pouvaient vibrer à ces paroles considérables. Le Blanc et son assistant noir, le sergent Koguem, étaient penchés vers le vieillard comme pour d'effroyables complots.

Mais comme on arrivait aux gestes bénéfiques de Dieu, le ton redevint normal.

Dieu eut d'autres rapports avec sa femme et cette fois rien ne vint troubler leur union, car l'excision avait fait disparaître la cause du premier désordre. L'eau, semence divine, pénétra donc au sein de la terre et la génération poursuivit le cycle régulier de la gémelliparité. Deux êtres se modelèrent.

- Dieu les a créés comme de l'eau. Ils étaient de couleur verte, en forme de personne et de serpent. De la tête aux reins ils étaient humains ; le bas était serpent.

Les yeux rouges étaient rendus comme ceux des hommes et leur langue fourchue comme celle des reptiles. Les bras, souples, n'avaient pas d'articulations. Tout leur corps était vert et lisse, glissant comme une surface d'eau, garni de poils courts et verts, annonce des végétations et germinations.

Ces génies, dits Nommo, étaient donc deux produits p.17 homogènes de Dieu, d'essence divine comme lui, conçus sans aventures et développés selon les normes dans la matrice terrestre. Leur destinée les conduisit au ciel où ils reçurent les instructions de leur père. Non pas que Dieu ait eu à leur enseigner la Parole, cette chose indispensable à 
tous les êtres, comme au système universel : le couple était né complet et parfait ; par ses huit membres, son chiffre était huit, symbole de la parole.

II possédait aussi l'essence de Dieu, car il était fait de sa semence, qui est à la fois le support, la forme et la matière de la force vitale du monde source de mouvement et de persévérance dans l'être. Et cette force est l'eau. Le couple est présent dans toute eau, il est l'eau, celle des mers, des confins, des torrents, des orages, de la cuillerée qu'on boit.

Ogotemmêli employait indifféremment les termes « eau » et « Nommo ».

- Si ce n'est grâce au Nommo, disait-il, on ne pouvait pas même créer la terre, car la terre fut pétrie et c'est par l'eau (par le Nommo) qu'elle reçut la vie.

- Quelle vie est dans la terre ? demanda le Blanc.

- La force vitale de la terre est l'eau. Dieu a pétri la terre avec de l'eau. De même, il fait le sang avec de l'eau. Même dans la pierre il y a cette force, car l'humidité est dans tout.

Mais si le Nommo est l'eau, il produit aussi du cuivre. Dans le ciel couvert on voit se matérialiser les rayons du soleil sur l'horizon de brume; ces rayons, excréments des génies, sont de cuivre et sont lumière. Ils sont aussi d'eau, car ils supportent I'humidité terrestre dans son cheminement ascendant. Le couple excrète de la lumière parce qu'il est aussi lumière.

Ogotemmêli cherchait, depuis quelques moments, des choses dans la poussière. II finit par recueillir plusieurs petits cailloux. D'un geste rapide il les lança dans la cour, par-dessus ses deux interlocuteurs qui n'eurent pas même à baisser la tête. Les projectiles tombèrent juste à la place où venait de chanter, quelques secondes auparavant, le coq du Hogon.

- Ce coq est une bourrasque. II détruit les conversations.

Et comme la bête chantait à nouveau de l'autre côté du mur, Ogotemmêli délégua Koguem pour lui jeter un bois. 
Koguem revenu, il lui demanda si le coq était sorti des limites du quartier de Tabda.

- Il est dans le champ du Hogon, dit Koguem, et je le fais surveiller par quatre enfants.

- p.18 C'est bien, dit Ogotemmêli avec un petit rire, qu'il profite de son reste: on m'a dit qu'il serait mangé à la prochaine Bière-des-Jumeaux.

II revint à l'affaire des Génies Nommo, du Nommo, comme il disait plus couramment, car ce couple de jumeaux représentait l'union parfaite, l'unité idéale.

Le Nommo, du haut du ciel, vit sa mère, la Terre, nue et sans parole, ce qui était sans doute la conséquence du premier incident survenu lors des rapports avec le Dieu Amma. Il fallait mettre fin à ce désordre. Le Nommo descendit sur la Terre, apportant des fibres tirées de plantes déjà créées dans les régions célestes. II en sépara dix poignées correspondant à ses dix doigts et en toronna cinq pour les placer devant et cinq pour les placer derrière. Aujourd'hui encore, les hommes masqués portent ces accessoires qui pendent jusqu'à leurs pieds en épaisses vrilles.

Mais le rôle de ce vêtement n'était pas seulement de pudeur. II présentait au monde terrestre le premier acte d'ordonnance universelle et le signe hélicoïdal qui se projette sur un plan sous forme de ligne brisée serpentante.

Les fibres, en effet, tombaient en torsades, symbole des tornades, des méandres des torrents, des tourbillons des eaux et des vents, de la marche ondulante des reptiles. Elles rappelaient aussi les spirales à huit tours du soleil pompeur d'humidité. Elles étaient elles-mêmes un cheminement d'eau parce que gorgées des fraîcheurs prises aux plantes célestes. Elles étaient pleines de l'essence du Nommo, elles étaient le Nommo lui-même, en mouvement, comme l'indiquait la ligne ondulée qui peut se prolonger à l'infini.

Mais le Nommo, lorsqu'il parle, émet comme tout être une buée tiède porteuse de verbe, verbe elle-même. Et cette buée sonore, comme toute eau, se meut sur une ligne hélicoïdale. Les torsades du vêtement étaient donc un 
chemin de prédilection pour la parole que le génie voulait révéler à la Terre. II incantait ses mains en les portant à ses lèvres tandis qu'il tressait; ainsi sa parole humide se lovait avec les tresses humides; la révélation spirituelle pénétrait l'enseignement technique.

Par ces fibres pleines d'eau et de paroles, le Nommo était donc continuellement présent devant le sexe de sa mère.

Ainsi vêtue la Terre avait un langage, le premier de ce monde, p.19 le plus fruste de tous les temps. Syntaxe élémentaire, verbe rare, vocabulaire sans grâce. Les mots étaient des souffles peu différenciés, mais cependant porteurs de force. Telle quelle, la parole sans nuances convenait aux grands travaux des commencements.

Au milieu d'un mot, Ogotemmêli poussa un grand cri : il répondait à la devise de chasse lancée dans l'échancrure du mur par la face prudente d'Akoundyo, prêtre des femmes mortes en couches et des enfants mort-nés.

Akoundyo avait d'abord craché de côté, l'œil rivé sur le groupe d'hommes. Il portait un bonnet phrygien grenat, enserrant les oreilles, avec une pointe relevée en uréus sur la racine du nez, à la manière dite «le vent souffle». Pommettes en saillie, dents luisantes, il déclamait les congratulations que le vieillard lui renvoyait aussitôt. Les formules alternées atteignirent un premier palier d'exaltation.

- Que Dieu! s'exclama Ogotemmêli, que Dieu maudisse celui qui ne t'aime pas dans Ogol du-Bas !

L'agitation grandit dans le cœur d'Akoundyo qui parvint au comble de la surenchère.

- Que Dieu! s'écrie enfin l'aveugle, que Dieu me maudisse moi-même si je ne t'aime pas! Les quatre hommes respirèrent. Ils plaisantèrent sur la spéciale maigreur du gibier dans la vallée d'l. Enfin Akoundyo s'éloigna en déclarant, dans un français de tirailleur, qu'il allait « se mettre sur le chemin du cabinet du porc-épic », animal retors et estimé. 
On revint à la Parole. Son rôle était d'organisation : elle était donc une bonne chose ; pourtant elle déclencha tout d'abord le désordre.

En effet le chacal, fils déçu et décevant de Dieu, désira la posséder et mit la main sur les fibres qui la portaient, c'est-à-dire sur le vêtement de sa mère. Celle-ci résista, car c'était là geste incestueux. Elle s'enfonça dans son propre sein, dans la fourmilière, sous l'apparence d'une fourmi. Mais le chacal la suivait ; il n'y avait d'ailleurs pas d'autre femme à désirer dans le monde. Le trou qu'elle forait n'était jamais assez profond et finalement elle dut s'avouer vaincue. Ainsi étaient préfigurées les luttes équilibrées des hommes et des femmes qui se terminent pourtant par la victoire masculine.

L'inceste fut de grande conséquence: il donna d'abord la p.20 parole au Chacal, ce qui devait lui permettre, pour l'éternité, de révéler aux devins à venir les desseins de Dieu.

De plus, il fut la cause de l'apparition du sang menstruel qui teignit les fibres. L'état de la terre, devenue impure, était incompatible avec le règne de Dieu. Celui-ci se détourna de cette épouse et résolut de créer directement des êtres vivants. Ayant modelé une matrice dans une argile humide, il la plaça sur la terre et, du haut du ciel, la coiffa d'une boulette jetée dans l'espace. II fit de même pour un sexe d'homme: l'ayant posé au sol, il lança une sphère qui se ficha dessus.

Aussitôt les deux masses s'organisèrent; leur vie s'étala; des membres se séparèrent du noyau, des corps apparurent et un couple humain surgit des glèbes.

C'est alors qu'entra en scène, pour de nouvelles tâches, le couple des Nommo; il prévoyait que la règle fondamentale des naissances doubles allait être abolie et qu'il pourrait en résulter des fautes comparables à celles du Chacal, né unique. Car c'est à cause de sa solitude que le premier fils de Dieu agit ainsi.

- Né seul, disait Ogotemmêli, le Chacal, à cause de cela, a fait plus de choses que la bouche n'en peut dire.

Le génie dessina sur le sol deux silhouettes superposées, deux âmes dont l'une était mâle et l'autre 
femelle. L'homme s'étendit sur ses ombres et les prit toutes deux. II fut fait de même pour la femme.

Ainsi, chaque être humain, dès l'origine, fut nanti de deux âmes de sexes différents, ou plutôt de deux principes correspondant à deux personnes distinctes à l'intérieur de chacun. Pour l'homme, l'âme femelle siégea dans le prépuce. Pour la femme, l'âme mâle fut supportée par le clitoris.

Mais la prescience du Nommo lui montra sans doute les inconvénients de ce pis-aller. La vie des hommes ne pouvait s'accommoder de ces êtres doubles; il fallait décider chacun à verser dans le sexe pour lequel il était apparemment le mieux fait.

Le Nommo circoncit donc I'homme, rayant ainsi en lui toute la féminité du prépuce. Mais celui-ci se métamorphosa en un animal qui n'est «ni serpent, ni insecte, mais qui est classé avec les serpents ».

Cet animal porte le nom de nay. II s'agirait d'une sorte de lézard noir et blanc comme la couverture des morts. Son nom signifie aussi «quatre», chiffre féminin et « soleil », entité femelle.

p.21 Le nay symbolisait la douleur de la circoncision et la nécessité où était le mâle de souffrir lui aussi dans son sexe, comme la femme.

Alors l'homme s'unit à sa compagne. Plus tard, elle accoucha des deux premiers enfants d'une série de huit qui devaient être les ancêtres du peuple dogon. A ce moment, la souffrance de la parturition se concentra dans son clitoris qui, excisé par une main invisible, se détacha d'elle et s'éloigna, métamorphosé en scorpion. La poche et le dard symbolisaient l'organe, le venin étant l'eau et le sang de la douleur.

En rentrant par le champ couvert de mil, l'Européen se demandait le sens de toutes ces marches et contremarches, de tous ces à-coups de la pensée mythique: un Dieu manque sa première création; les choses se rétablissent par l'excision de la terre puis par la naissance d'un couple de génies, ingénieux et ingénieurs 
du monde, qui apportent une première parole ; un inceste détruit l'ordre et compromet les naissances de jumeaux ; l'ordre se rétablit par création d'un couple humain; la gémelliparité est remplacée par une âme double (Pourquoi la gémelliparité ?) ; mais cette âme double est un danger : un homme doit être mâle et une femme femelle. Circoncision et excision remettent encore les choses en ordre. (Mais pourquoi ce nay, pourquoi ce scorpion?).

Les réponses devaient venir plus tard. Elles allaient s'inscrire dans l'immense édifice que l'aveugle faisait surgir peu à peu des brumes millénaires.

Au-dessus des têtes de l'Européen et de Koguem, les grappes de mil violâtres se détachaient sur le plomb du ciel. Ils traversaient un champ d'épis lourds, haut brandis, immobiles à la brise. Quand le mil est mal venu, clairsemé, si ses épis sont légers, il s'agite aux moindres souffles et bruit. Les champs maigres sont sonores. Au contraire le champ de l'abondance pèse dans le vent et s'offre en silence. 


\section{Troisième journée}

\section{La seconde parole et le tissage}

p.22 En pénétrant dans la cour, on bousculait les agencements. La cour étriquée où les milans, les plus fins acrobates de l'air, ne pouvaient saisir les volailles. Il y avait dans la pierre creuse un reste de bière de mil, une lie à vrai dire, bue par poulets, coq et poule et poussins. Et aussi par un chien tigré, blanc et jaune, à queue en faucille comme un sabre éthiopien. Au coup de gong de la porte, tout ce monde s'était dispersé, laissant la place aux hommes.

Ogotemmêli s'encastra dans sa porte, et se mit au dénombrement des huit ancêtres primordiaux nés du couple pétri par Dieu. Les quatre aînés étaient mâles, les quatre autres femelles. Mais par l'effet d'une grâce qui ne devait échoir qu'à eux, ils pouvaient se féconder euxmêmes, étant doubles et des deux sexes.

D'où la descendance des huit familles dogon.

Car I'humanité s'organisait dans le pis-aller. La naissance unique, calamité permanente, s'amendait faiblement par l'octroi de l'âme double que le Nommo dessinait au sol près des parturientes. On les plaquait au nouveau-né en le tenant par les hanches au-dessus des lieux, mains et pieds posés sur la terre. Puis l'âme encombrante était rognée à la circoncision et l'humanité poursuivait cahin-caha son destin obscur.

Or les soifs célestes de perfection n'étaient pas éteintes. Le couple Nommo, qui prenait peu à peu la place de Dieu son père, méditait les rédemptions. Mais il fallait, pour bonifier les statuts humains, conduire les réformes et les enseignements sur les plans humains. Le Nommo craignait les contacts effarants entre créatures charnelles et purs esprits. Il fallait des actes compréhensibles, déroulés au plus près des bénéficiaires, dans leur climat. II fallait que les hommes, après régénération, soient attirés dans l'idéal comme un paysan dans un champ gras. 
Les Nommo descendirent donc sur la Terre et pénétrèrent dans la fourmilière, sexe dont ils étaient issus. Ils étaient ainsi à même, entre autres travaux, de défendre leur mère contre les ${ }_{\text {p.23 }}$ entreprises possibles de leur aîné, le Chacal incestueux. Ils purgeaient aussi par leur présence humide, lumineuse et parlante, celle qui restait à jamais souillée pour Dieu, mais sur laquelle pouvait gagner, par plaques, la pureté nécessaire aux travaux de vie.

Dans ce sexe, le Nommo mâle prit la place de la masculinité exclue jadis lors de l'excision du clitoris termitière. La femelle se substitua à la féminité et sa matrice vint dans celle de la terre.

Ainsi le couple pouvait-il procéder à l'œuvre de régénération qu'il entendait mener, d'accord avec Dieu, au lieu de Dieu.

- Le Nommo, à la place d'Amma, «travaillait» le travail d'Amma, disait l'aveugle.

Dans ces temps brumeux de l'évolution du monde, les hommes ne connaissaient pas la mort. Les huit ancêtres issus du premier couple humain vivaient donc indéfiniment. Ils procréèrent huit descendances distinctes, chacun se reproduisant pour soi-même, car chacun était à la fois mâle et femelle:

- Les quatre mâles et les quatre femelles, à cause de leur bas (de leur sexe) étaient huit doubles. Les quatre hommes étaient homme et femme, les quatre femmes étaient femme et homme. Chez les hommes, c'était I'homme qui était responsable; chez les femmes, la femme. Ils se sont accouplés eux-mêmes; se sont engrossés chacun pour soi ; ont procréé.

Mais quand les temps furent révolus, un obscur instinct poussa l'aîné vers la fourmilière investie par les Nommo. II portait sur la tête, en guise de coiffure et comme pour se garantir du soleil, l'écuelle de bois dans laquelle il mettait sa nourriture. Plaçant ses deux pieds dans l'orifice du sein terrestre, il s'enfonça lentement, comme pour une parturition à rebours. 
II pénétra ainsi tout entier dans la terre et sa tête ellemême disparut. Mais il laissa sur le sol, comme témoin de son passage dans ce monde, l'écuelle qui avait été retenue par les bords de la fente. II ne restait plus sur la fourmilière qu'un hémisphère de bois, imprégné des nourritures et des gestes du disparu, symbole de son corps, symbole de sa nature humaine comme l'est de la nature animale le fourreau que les reptiles abandonnent après la mue.

p.24 Délivré de sa condition terrestre, l'ancêtre fut pris en charge par le couple régénérateur. Le mâle le conduisit au fond de la terre, dans les eaux matricielles de sa compagne. II se replia comme un fœetus, se réduisit comme un germe, atteignit la qualité d'eau, semence de Dieu, essence des deux génies.

Et tout ce labeur était de verbe : le mâle accompagnait de la voix la femelle qui se parlait à elle-même, qui parlait à son propre sexe. Le verbe entrait en elle, s'enroulait autour de la matrice en une hélice à huit spires. Et de même que la bande hélicoïdale de cuivre entourant le soleil lui donne son mouvement diurne, de même la spirale de verbe donnait à la matrice le mouvement régénérateur.

Achevé en paroles et eau, le nouveau génie, expectoré, montait au ciel. Les huit ancêtres devaient accomplir dans leur ordre cette transsubstantiation. Mais quand vint le tour du septième, la mutation fut marquée par un événement considérable.

En effet, le septième rang est de perfection. Bien qu'égal en qualité aux autres, il est la somme de la féminité, 4 , et de la masculinité, 3. II est l'aboutissement de la série parfaite, le symbole de l'union totale du mâle et de la femelle, c'est à-dire, proprement, de l'unité. Et ce tout homogène a notamment le rang de la maîtrise de la parole. L'entrée en terre de son tenant devait être le prélude de bouleversements bénéfiques.

Dans le sein, il devint comme les autres, eau et génie. II se développa comme les autres au rythme des paroles que prononçaient les deux transformateurs.

- Les paroles que le Nommo femelle se parlait à luimême, dit Ogotemmêli, se tournaient en hélice et 
entraient dans son sexe. Le Nommé mâle l'aidait. Ce sont ces paroles qu'apprenait l'ancêtre septième à l'intérieur du ventre.

Ces paroles, les autres les possédaient à égalité, par l'effet de leur passage dans le même milieu; mais leur rang n'était pas de maîtrise ni leur rôle d'exploitation. Le septième reçut donc la connaissance parfaite d'un verbe le second que la terre entendait - plus clair que le premier, non plus, comme le premier, réservé à quelquesuns, mais destiné à l'ensemble des hommes. Ainsi pouvaitil apporter un progrès au monde. Notamment, il permettait de prendre le pas sur le mauvais fils de Dieu, le Chacal; celui-ci restait en possession, certes, de la première parole; il pouvait encore, par elle, divulguer aux devins p. 25 certains desseins célestes; mais dans le futur ordre des choses, il ne devait plus être qu'un traînard de la révélation.

Cette parole efficace développa la puissance de son nouveau porteur; pour lui, la régénération dans le sein terrestre se transforma peu à peu en investissement de ce sein. II occupa lentement tout le volume de l'organisme et s'y disposa comme il convenait pour ses travaux: ses lèvres se confondirent avec les bords de la fourmilière qui devint bouche et s'épanouit. Des dents appointées surgirent. On en compta sept pour chaque lèvre, puis dix, chiffre des doigts, puis quarante; enfin quatre-vingts, soit dix par ancêtre.

L'apparition de ces nombres indiquait les rythmes futurs de la multiplication des familles; la pousse des dents était le signe que le temps du nouvel enseignement approchait.

Mais là encore se manifesta le scrupule des génies : ce ne fut pas directement aux hommes que le Septième donna l'instruction mais à la fourmi, avatar de la terre, familière des lieux.

Le jour venu, à la lumière du soleil, le Septième génie expectora quatre-vingts fils de coton qu'il répartit entre ses dents supérieures utilisées comme celles d'un peigne de métier à tisser. Il forma ainsi la plage impaire de la chaîne. Il fit de même avec les dents inférieures pour constituer le plan des fils pairs. En ouvrant et refermant 
ses mâchoires, le génie imprimait à la chaîne les mouvements que lui imposent les lices du métier. Et comme tout son visage participait au labeur, ses ornements de nez représentaient la poulie sur laquelle ces dernières basculent; la navette n'était autre que l'ornement de la lèvre inférieure.

Tandis que les fils se croisaient et se décroisaient, les deux pointes de la langue fourchue du génie poussaient alternativement le fil de trame et la bande se formait hors de la bouche, dans le souffle de la deuxième parole révélée.

En effet, le génie parlait. Comme avait fait le Nommo lors de la première divulgation, il octroyait son verbe au travers d'une technique, afin qu'il fût à la portée des hommes. II montrait ainsi l'identité des gestes matériels et des forces spirituelles ou plutôt la nécessité de leur coopération.

Le génie déclamait et ses paroles colmataient tous les interstices de l'étoffe; elles étaient tissées dans les fils et faisaient corps avec la bande. Elles étaient le tissu luimême et le tissu était le verbe. Et c'est pourquoi étoffe se dit soy, qui signifie p.26 « c'est la parole ». Et ce mot veut dire aussi 7 , rang de celui qui parla en tissant.

Durant l'accomplissement du travail, la fourmi allait et venait sur les bords de l'orifice, dans le souffle du génie, entendant et retenant les paroles. Nantie de cette nouvelle instruction, elle la communiqua aux hommes qui hantaient les parages et qui avaient déjà suivi la transformation du sexe de la terre.

Jusqu'au moment de l'enfoncement des ancêtres, ils habitaient des excavations creusées comme des tanières dans le sol horizontal. Lorsque leur attention fut attirée par les écuelles abandonnées, ils observèrent les formes de la fourmilière qu'ils trouvèrent mieux agencée que leurs trous. Ils les imitèrent en ouvrant des galeries, en disposant des chambres abritées de la pluie et ils commencèrent à engranger des provisions faites de produits de cueillette.

Ils s'acheminaient ainsi vers une vie moins rudimentaire et quand ils remarquèrent la pousse de dents autour de 
l'orifice, ils les imitèrent pour édifier une protection contre les fauves : ayant pétri de grands crocs de glaise, ils les firent sécher et les encastrèrent autour de leurs entrées.

Au moment de l'octroi de la seconde instruction, les hommes habitaient donc des repaires qui étaient déjà, en quelque sorte, une préfiguration de la révélation et du sein dans lequel chacun d'eux, le moment venu, descendrait se régénérer. Et cette fourmilière humaine était aussi, avec ses occupants et ses chambres à grains, l'image rudimentaire d'un système du monde qui, beaucoup plus tard, devait parvenir du ciel sous la forme d'un grenier merveilleux.

Ces obscures ébauches des temps futurs avaient préparé les hommes à recevoir les conseils de la fourmi. Celle-ci, après la démonstration, avait emmagasiné des fibres de coton; elle les avait filées et, devant les hommes, tirait les fils entre les dents de l'orifice, comme avait fait le génie. A mesure que la chaîne sortait, les hommes passaient le fil de trame en le jetant de droite et de gauche, au rythme des mâchoires qui avaient repris leur mouvement; la bande obtenue s'enroulait sur un bois, ébauche de l'ensoupleau.

Dans le même temps la fourmi divulguait les paroles et les hommes les répétaient. Ainsi était reconstitué sur les lèvres de terre le climat de vie en mouvement, de forces transposées, de souffles efficaces que l'ancêtre septième avait créé.

p.27 Ainsi les entrecroisements de la chaîne et de la trame enserraient les mêmes paroles, nouvel enseignement qui devenait l'héritage des hommes et que les tisserands transmettaient de génération en génération, aux claquements de la navette et au bruit aigre de la poulie du métier dite « grincement de la parole ».

Tout ceci se passait à la lumière du jour, car filage et tissage sont labeurs diurnes. Travailler de nuit serait tisser des bandes de silence et d'ombre. 


\section{Quatrième journée}

\section{La troisième parole et le grenier de terre pure}

Ogotemmêli n'avait pas une limpide idée de ce qui s'était passé au ciel après la métamorphose des huit ancêtres en Nommo. Certes, ces huit, ayant quitté la terre tous travaux accomplis, avaient gagné les régions où régnait le couple aîné, auteur de leur transformation. Certes, ces aînés avaient le pas sur les autres et ils ne s'étaient pas fait faute de leur imposer aussitôt une organisation et des règles de vie.

Mais il n'apparut jamais clairement pourquoi ce monde céleste s'agita jusqu'à rupture, ni pourquoi ces désordres entraînèrent une réorganisation du monde humain qui n'était pour rien dans ces querelles. Car finalement les huit redescendirent sur terre dans un attirail gigantesque de symboles où prenait place une troisième et définitive parole nécessaire au fonctionnement du monde moderne.

Si I'on avait écouté Ogotemmêli avec résignation, on n'eût obtenu que cette réponse évasive :

- Les génies ne tombent du ciel que par colère ou bousculade.

Manifestement, Ogotemmêli avait conscience de la complication infinie des vues de Dieu ou des génies qui le remplaçaient, et il répugnait à s'en expliquer.

Pourtant, un tableau modeste mais satisfaisant fut dressé de cette période obscure.

Le couple Nommo avait reçu au ciel les huit transformés. Mais bien qu'ils fussent tous de même essence, les aînés avaient p.28 sur les nouveaux les droits de la génération supérieure et ils les organisèrent dans un réseau de règles dont la plus grave était la séparation les uns des autres et l'interdiction de se fréquenter. 
En effet, à l'image des sociétés humaines où le nombre est facteur de troubles, la société céleste serait allée au désordre du fait du nombre si tous avaient été réunis.

Garantie par cette règle, la nouvelle génération de Nommo devait pourtant bouleverser sa destinée en la violant.

En effet, Dieu avait donné aux huit un ensemble de huit graines destinées à leur nourriture et dont le Premier ancêtre était responsable. Sur ces huit graines, la dernière, la Digitaria, avait été publiquement méprisée par le destinataire, sous le prétexte de sa petitesse et de l'incommodité de sa préparation. II était même allé jusqu'à jurer qu'il n'en mangerait jamais.

Arriva pourtant une période critique où toutes les graines vinrent à épuisement, sauf la dernière. Le Premier et le Second ancêtres, qui d'ailleurs avaient déjà rompu l'interdit de séparation, se réunirent pour consommer l'ultime provision. Ce geste p.29 mit le comble à la démesure : il consacrait en effet la première faute par une rupture de parole. Les deux ancêtres devinrent de ce fait impurs pour le monde des cieux, c'est-à-dire d'une essence incompatible avec la vie céleste. Ils résolurent de quitter ces régions où ils se sentaient étrangers, et les six autres, solidaires, se tinrent dans les mêmes dispositions. De plus, ils voulaient s'enfuir en prenant avec eux tout ce qui pouvait être utile aux hommes qu'ils allaient retrouver.

C'est alors que, sans doute sous l'œil bienveillant de Dieu et peut-être avec son aide, le premier ancêtre commença les préparatifs du départ.

II reçut un panier tressé, à ouverture circulaire et à fond carré, qui devait servir au transport de la terre et du pisé nécessaire à l'édification d'un système du monde dont il allait être l'un des moniteurs. Ce panier servit d'abord de modèle à une autre vannerie de grandes dimensions; l'ancêtre la construisit dans la position renversée, le fond carré de 8 coudées de côté formant terrasse, l'ouverture de 20 coudées de diamètre posée au sol ; la hauteur était de 10 coudées.

p. 30 Sur cette armature fut appliqué du pisé fait de terre célestielle, et dans l'épaisseur fut ménagé, à partir du 
centre de chaque côté du carré, un escalier de 10 degrés orientés vers l'un des points cardinaux. Dans le sixième degré de l'escalier nord, était ménagée une porte permettant d'accéder à l'intérieur où huit compartiments se répartissaient en deux étages.

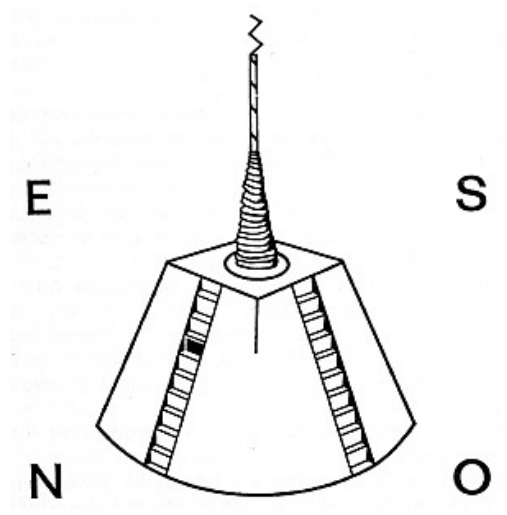

SYSTÈME DU MONDE

Symboliquement, l'édifice ainsi construit avait la signification suivante :

- la base circulaire représentait le soleil ;

- la terrasse carrée rappelait le ciel ;

- un cercle, au centre de la terrasse, figurait la lune ;

- chaque marche horizontale étant femelle et chaque contre-marche mâle, l'ensemble des quatre escaliers de 10 degrés préfigurait les huit dizaines de familles issues des huit ancêtres.

Chaque escalier supportait une catégorie d'êtres et était en rapport avec une constellation :

- l'escalier septentrional, correspondant aux Pléiades, supportait des hommes et des poissons ;

- l'escalier méridional, Baudrier d'Orion, recevait les animaux domestiques ;

- l'escalier oriental, Vénus, était occupé par les oiseaux ;

- l'escalier occidental, étoile dite «à grande queue », portait les animaux sauvages, les végétaux et les insectes.

A vrai dire, l'image du système n'avait pas surgi d'un seul coup et sans peine des explications d'Ogotemmêli. 
- Quand l'ancêtre est descendu du ciel, avait-il dit d'abord, il était debout sur un morceau de ciel carré, pas très grand... à peu près comme une natte à dormir. Un peu plus grand tout de même.

- Comment tenait-il ce morceau de ciel ?

- C'était un morceau de terre de ciel.

- Ce morceau était-il épais ?

- Oui, comme une maison. II avait dix coudées de haut, avec des escaliers de chaque côté indiquant les quatre points cardinaux.

L'aveugle avait relevé la tète, qu'il tenait presque toujours penchée vers le sol. Comment expliquer ces formes géométriques, ces degrés, ces dimensions précises ? L'Européen avait d'abord cru comprendre qu'il s'agissait d'un haut prisme flanqué de 4 escaliers en croix ; il revenait constamment à cette forme qu'il voulait saisir et son interlocuteur, sans impatience, p.31 perdu dans ses ténèbres, tâtonnait de nouvelles précisions.

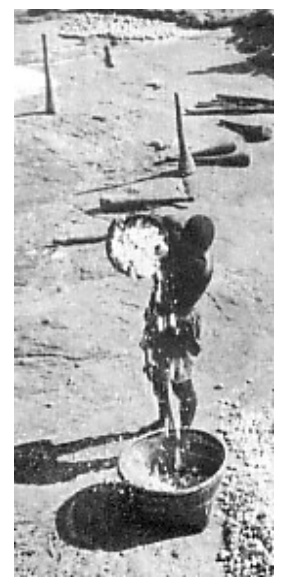

Panier du système du monde

Enfin, une sorte de sourire débrida la face ravagée: Ogotemmêli avait trouvé. Se penchant dans le corps de sa maison, presque allongé sur le dos, il chercha parmi les objets qui crissaient, sonnaient creux, raclaient le sol sous sa main. Ses genoux maigres et ses pieds accrochés à la roche de la cour restaient seuls de lui dans l'embrasure. Le reste disparaissait dans l'ombre. La haute façade était comme un énorme visage appuyé par la bouche sur deux tibias minuscules. 
Après quelques arrachements, une chose sortit du tréfonds et vint s'encadrer dans le chambranle. C'était une vannerie noircie par les poussières et les suies de l'intérieur, un panier d'entrée ronde et de fond carré, défoncé, égueulé, une proie pour la misère.

La chose se déposa devant la porte en perdant quelques tigelles et l'aveugle réapparut en entier, la main sur l'exemple récalcitrant.

- II ne sert plus qu'à enfermer les poulets, dit-il.

Et passant lentement les mains sur ces décombres, il expliqua le système du monde. 


\title{
Cinquième journée
}

\author{
La troisième parole \\ et le classement des choses
}

Le panier avait été honteusement relégué.

II était rentré dans le mystère, derrière le dos d'Ogotemmêli et personne n'y fit plus jamais allusion. II y avait eu, dans l'exhibition au soleil de cet effondrement, comme un défi à la vanité du monde. Au demeurant, il avait rempli son office. Tout était devenu clair et la géométrie divine se précisa. On put entamer l'énumération détaillée des êtres échelonnés aux quatre points cardinaux de l'édifice.

L'escalier occidental était occupé par les animaux sauvages. Du premier degré du haut au dernier du bas figuraient les antilopes, les hyènes, les chats (sur deux marches), les reptiles et sauriens, les singes, les gazelles, les marmottes, le lion, l'éléphant.

p.32 A partir du $6^{\mathrm{e}}$ degré apparaissaient les arbres, depuis le baobab jusqu'au Lannea acida, et sur chacun de ces végétaux étaient les insectes que l'on y trouve communément aujourd'hui.

Sur l'escalier méridional s'étageaient les animaux domestiques. En premier lieu les gallinacés; puis les ovidés, les capridés, les bovidés, les caballins, les canidés, les chats.

Aux huitième et neuvième degrés les chéloniens : les grandes tortues qui, dans chaque famille, remplacent aujourd'hui les patriarches durant leurs absences, et les petites, qui sont lentement mises à mort dans les sacrifices de purification territoriale.

Au dixième rang venaient les mus, souris et rats de maison et de brousse.

L'escalier oriental était occupé par les oiseaux; sur le premier degré les grands rapaces et les calaos; sur le 
second les autruches et cigognes; sur le troisième les petites outardes et vanneaux; sur le quatrième les vautours. Venaient ensuite les petits rapaces, puis les hérons. En septième position venaient les pigeons, en huitième les tourterelles, en neuvième les canards et enfin les grandes outardes blanches et noires.

L'escalier septentrional était celui des hommes et des poissons.

II présentait sans doute des complications car Ogotemmêli dut s'y prendre à plusieurs fois avant d'en donner une description satisfaisante.

Il pensait bien que les hommes étaient des Bozo, ces premiers occupants du Niger, aujourd'hui encore reconnus par tous gens de la Boucle comme les seuls vrais pêcheurs. Mais leur répartition sur les marches l'embarrassait et ce n'est qu'au second entretien, en fin de journée, qu'il arrêta une version définitive.

Sans doute avait-il pris, entre-temps, l'avis de quelque vieillard.

Sur chacun des deux premiers degrés se tenait un Bozo mâle, un poisson accroché au nombril et pendant entre les jambes.

De cet accrochement, Ogotemmêli avait une idée claire, mais elle ne put être saisie par l'Européen : le nombril de I'homme était pincé entre les branchies, c'est-à-dire que le poisson restait en entier en dehors du ventre. Par ailleurs, le nom même qui est donné au Bozo par les Dogon indiquerait, selon Ogotemmêli, que le poisson était en instance de pénétration dans le corps de son porteur.

En effet le terme de sologonon, ou sorogonon, qui a donné ${ }_{\text {p. } 33}$ Sorko, autre nom des Bozo, signifie littéralement «qui n'est pas complètement passé ». Et ce mot s'appliquerait au poisson, c'est-à-dire, finalement, au Bozo lui même, car tous deux sont frères jumeaux comme l'indique cette jonction ombilicale.

Sur chacune des deux marches suivantes stationnait une femme bozo accolée également à un poisson.

Sur la cinquième marche, une femme bozo se tenait seule. 
Enfin les cinq dernières marches étaient vides.

Une question était venue à l'enquêteur :

- Sur l'édifice, il n'y avait qu'une partie des animaux et des végétaux. Où étaient les autres ?

- Chacun de ceux dont on a parlé est comme un chef de file. Derrière lui se tiennent tous ceux qui sont de même espèce. L'antilope de la première marche de l'ouest est la walbanou, la rouge. Ensuite viennent l'antilope blanche, la noire et l'antilope kâ. Sur la première marche du sud, où perche la poule, sont aussi la pintade, la perdrix, la poule-de-rochers.

- Comment toutes ces bêtes tenaient-elles sur un degré d'une coudée d'emmarchement et d'une coudée de hauteur?

L'Européen avait également calculé, d'après la déclivité des parois, que le giron de chaque marche mesurait $6 / 10^{e}$ de coudée de profondeur. Mais il ne mentionna pas cette dimension, par politesse, afin de ne pas avoir l'air d'éplucher le céleste.

- Tout cela se dit en paroles, rétorqua Ogotemmêli. Tout est symbole. Sur les marches étaient le symbole des antilopes, le symbole des vautours chauves, le symbole de I'hyène tachetée.

Et il ajouta, après un silence :

- Tout ce qui s'exprime par symbole peut tenir sur une marche d'une coudée.

II employait, pour le mot symbole, une expression composée dont le sens littéral était «parole de ce bas monde ».

Ogotemmêli ayant qualifié l'édifice de grenier, il entreprit d'en décrire l'ordonnance.

- L'ensemble de la chose aux escaliers, dit-il, se nomme «Grenier du Maître de la Terre Pure ». Il est divisé en huit compartiments, quatre en bas, quatre en haut. La porte s'ouvre au nord, à la sixième marche. Elle est comme la bouche et le grenier est comme le ventre, l'intérieur du monde. 
p. 34 L'édifice s'avérant le modèle des greniers modernes, l'Européen, pour se remettre dans l'œil l'agencement du système, s'ouvrit à voix basse, à l'oreille de son aide Koguem, de la nécessité de revoir l'une de ces constructions.

A vrai dire la cour était ceinturée, sur presque la moitié de son pourtour, par une demi-douzaine d'exemplaires. Mais passer la tête dans une porte de grenier, c'est se glisser dans un giron, crisper la famille, détailler des entrailles. Scruter les denrées, graines ou épis macérant dans l'ombre, c'est compter des forces en instance, s'insinuer dans les digestions futures.

Koguem s'en ouvrit à l'aveugle, en suggérant une visite dans une maison abandonnée qu'il avait remarquée à Dyamini-Kouradondo, village d'une autre famille. Mais peut être pouvait-on trouver un exemple plus proche.

Ogotemmêli réfléchit. II passait manifestement en revue, dans ses ténèbres, les greniers démolis possibles de la région. En fin de liste figuraient sans doute les siens propres, car il en désigna deux dans l'arrière-cour.

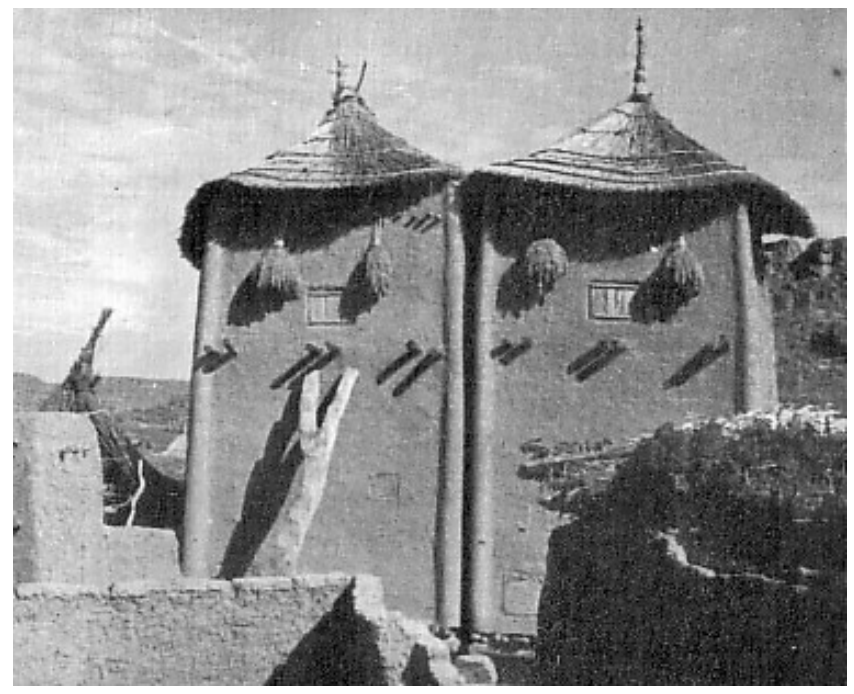

Celui du fond était détruit ; c'est là que Koguem lançait des pierres, dix fois par jour, sur les enfants qui venaient tendre leurs oreilles aux mystères des entretiens. L'autre était en bon état, vide, mais fermé. II fallut deux houes pour l'ouvrir, la porte étant serrée comme dans une mâchoire. Ogotemmêli attendait sur son seuil, les mains croisées, comme toujours, au dessus de sa tête. Koguem, 
de temps à autre l'informait des progrès du travail. Quand la porte eut cédé, l'Européen se plaça dans l'embrasure, d'où sortaient des odeurs de vieilles graines.

Les quatre compartiments inférieurs d'un grenier dogon sont séparés par deux cloisons en croix dont la rencontre forme une cupule de terre pouvant recevoir une poterie sphérique. Cette poterie, qui contient des graines ou des objets précieux, forme le centre de l'ensemble de la construction. La porte débouche au-dessus de ces compartiments; elle est étroite et permet à un corps humain de passer avec effort.

Au-dessus de la porte se développe l'étage des quatre autres casiers ; deux occupent, sur la même ligne, la paroi du fond ; les deux autres longent les deux parois latérales. Ils forment une sorte de corniche à trois côtés dégageant l'espace de l'entrée et permettant à un homme de se tenir accroupi au dessus des compartiments inférieurs, les épaules à hauteur du balcon.

p. ${ }_{35}$ Dans l'édifice céleste, ces compartiments avaient un ordre : le premier était celui de droite en entrant, à l'étage inférieur; le second, celui de droite au fond, et ainsi en tournant. Le cinquième était celui du haut à droite et ainsi de suite jusqu'au huitième qui était celui de gauche en haut.

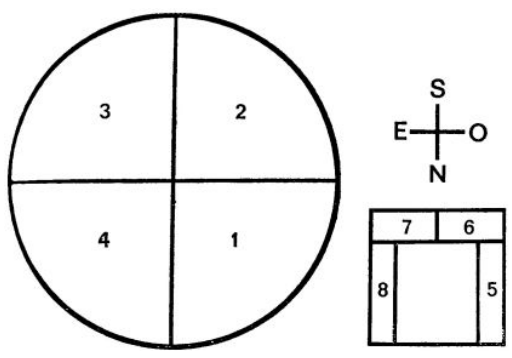

\section{PLAN DE LA BASE - PLAN DE L'ÉTAGe}

Chacun d'eux avait reçu l'une des huit graines données par Dieu aux huit ancêtres, dans l'ordre suivant: le petit mil, le mil blanc, le mil d'ombre, le mil femelle, le haricot, l'oseille, le riz, la Digitaria.

Avec chacune de ces graines étaient toutes celles de même espèce.

Mais les huit divisions ne servaient pas que de réceptacle des graines à répandre chez les humains. Elles 
étaient aussi l'image des huit principaux organes du Génie de l'eau, comparables à ceux des hommes et auxquels s'ajoutait le gésier, car le génie a la vitesse des oiseaux.

Ces organes étaient répartis dans l'ordre suivant: estomac, gésier, cœur, petit foie, rate, intestins, grand foie, vésicule biliaire.

$\mathrm{Au}$ centre, une poterie sphérique symbolisait la matrice; une autre poterie, plus petite, obturait la première. Elle contenait de I'huile de Lannea acida et représentait le fœtus. Elle était obturée par une autre plus petite encore qui contenait du parfum. Et sur cette dernière figurait une cupule double.

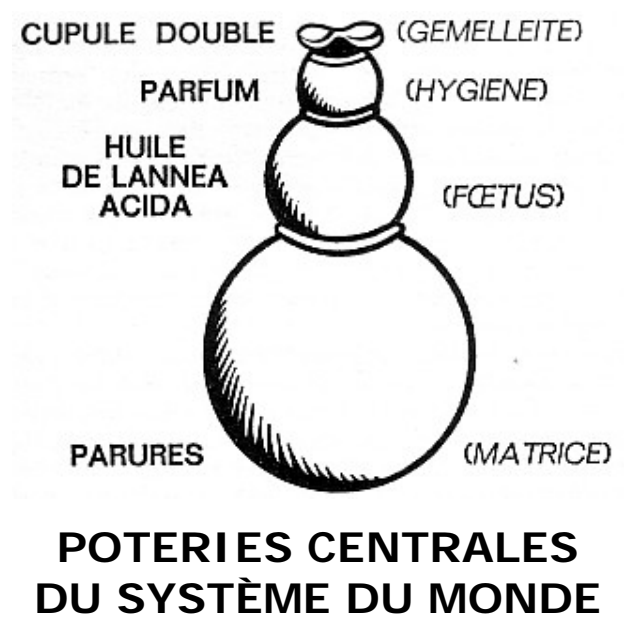

L'ensemble de ces organes était maintenu par les parois et les cloisons intérieures qui symbolisaient le squelette. Les quatre montants aboutissant aux angles du carré de la terrasse étaient les quatre membres. Ainsi le grenier était comme une femme, couchée sur le dos, lequel était le soleil, bras et jambes levés, maintenant la terrasse, image du ciel. Les deux jambes étaient placées côté nord, et le sexe était marqué par la porte de la sixième marche.

Le grenier et tout ce qu'il supportait était donc l'image du système du monde de l'ordre nouveau et sa marche était représentée par celle des organes intérieurs. Ceux-ci absorbaient des nourritures symboliques qui suivaient la filière de la digestion et de la diffusion sanguine. Des compartiments 1 et 2 (estomac, gésier), elles allaient au 6 (intestins), et de là dans tous les autres, sous forme de sang et finalement de souffle, qui aboutit au foie et à la 
vésicule biliaire. Ce souffle est une vapeur, une eau qui supporte et qui est le principe de vie.

p. ${ }_{36}$ A la voix sourde d'Ogotemmêli, la misère du grenier abandonné s'animait, aidée par le soleil tombant qui défonçait l'ouest, au-delà des gorges d'l. Ses parois devenaient rosâtres et réverbéraient des lueurs sur les plans de grès et les pailles du fumier. Coiffant la terrasse, une botte d'oseille amarante se dressait comme un feu. L'instant s'avançait où les Ogol du Haut et du Bas allaient flamber de tous leurs torchis occidentaux. L'édifice participait aux débauches de lumières de toute la surface visible. Dans son ombre intérieure revivaient les prodiges.

L'aveugle, le visage vers la terre, les mains à la nuque, s'enfonçait dans le passé des cieux. Il atteignit enfin la dernière couche de symboles qui faisaient de l'univers, condensé dans le grenier primordial, un corps gorgé de vie déglutissant les nourritures:

- Ce qui est mangé, dit-il, c'est la lumière du soleil. L'excrément, c'est la nuit. Les souffles de la vie sont les nuages, et le sang est la pluie qui tombe sur le monde. 


\section{Sixième journée}

\section{La troisième parole, la descente du grenier de terre pure et la mort}

@

p.37 Ogotemmêli avait omis de situer, dans son système, le scorpion et le nay. II les plaça sous le grenier, dans le cercle symbolisant le soleil.

L'ancêtre constructeur avait rassemblé sur la terrasse les outils et appareils d'une forge. Car son rôle futur était d'apporter aux hommes le fer pour leur permettre de cultiver.

Le soufflet était fait de deux vases de terre crue triturée avec du poil de mouton blanc; ces vases étaient fixés l'un à l'autre comme deux jumeaux : leur large ouverture était fermée avec une peau. De chacun d'eux partait un conduit de terre aboutissant à la tuyère.

La masse avait la forme d'une grande navette de fer, conique côté manche, quadrangulaire côté frappe. L'enclume, de forme comparable, était fixée dans une traverse de bois.

L'ancêtre Forgeron était armé d'un arc de fer et de flèches-fuseaux. II en lança une dans la terrasse du grenier, au centre du cercle figurant la lune; il entoura la tige d'un long fil de la Vierge qui forma bobine. Ainsi l'édifice entier était une énorme fusaïole. Prenant une seconde flèche à laquelle il attacha l'autre extrémité du fil, il la décocha dans la voûte du ciel pour servir de point d'appui.

Ce qui allait descendre était une somme de symboles:

Au premier chef, le grenier merveilleux était le système du monde orienté, classé en catégories d'êtres.

Il était le panier tressé qu'avait imité son constructeur et dont les hommes devaient faire leur unité de volume. L'unité de longueur était l'emmarchement, ou la contremarche du degré des escaliers, soit une coudée. 
L'unité de surface était donnée par la terrasse de huit coudées de côté. Les deux figures géométriques fondamentales se manifestaient par la terrasse carrée et par le cercle de base qui, dans le panier, est en réalité l'ouverture.

p.38 II était le grenier modèle dans lequel les hommes allaient engranger leurs récoltes.

Il était, de ce fait, la réalisation idéale et dernière de l'agencement de la fourmilière, laquelle avait déjà servi de modèle aux hommes pour transformer leurs habitations souterraines.

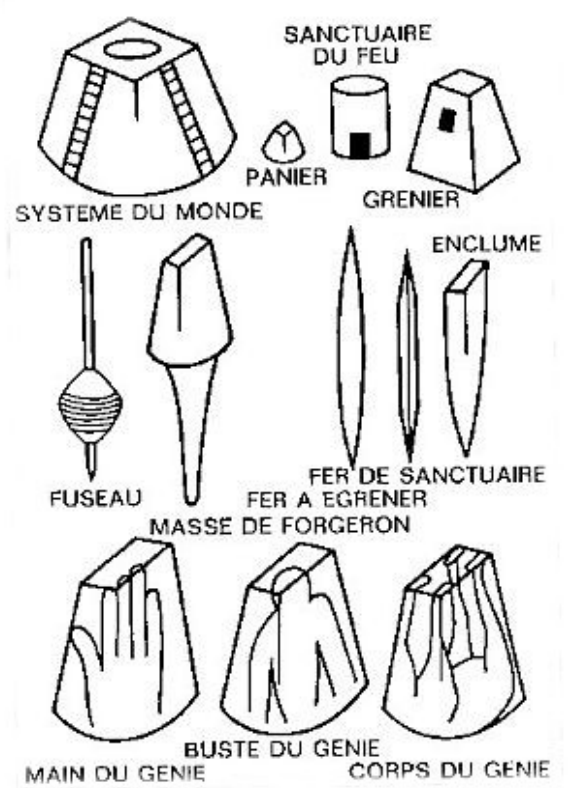

Il était la fusaïole, masselotte du fuseau que le Forgeron avait décoché dans sa terrasse et qui servait d'axe au bobinage du fil de descente.

II donnait symboliquement la forme du fer à égrener le coton, navette bi-tronconique dont la silhouette est apparentée à celle de la masse du Forgeron.

Il était le haut de la masse. Dans la croyance populaire, c'est dans sa masse que le Forgeron avait apporté les graines aux hommes.

II était aussi l'enclume quadrangulaire, femelle, forgée à l'imitation de la masse qui est le mâle. 
Il était la main palmée du Nommo, dont la masse donne l'image.

Il était le haut du corps du Nommo, dont cette même masse est aussi le symbole: deux faces opposées représentant la poitrine et le dos; les deux autres étant les bras.

II était enfin le corps même de la féminité du Forgeron qui, comme tous les êtres, était double.

Tout était prêt pour le départ. Mais le feu de forge manquait. L'ancêtre se glissa dans l'atelier des grands Nommo qui sont les forgerons du ciel et il vola un morceau de soleil sous forme de braise et de fer incandescent. II le saisit à l'aide d'un «bâton de voleur» dont la crosse recourbée se terminait par une fente ouverte comme une bouche. Perdant des braises, revenant sur ses pas pour les reprendre, il s'enfuit vers l'édifice dont il ne retrouva plus les issues dans son émoi. Il en fit plusieurs fois le tour avant d'escalader les degrés et de gagner la terrasse où il cacha son larcin dans l'une des peaux du soufflet en disant :

- Gouyo!

C'est-à-dire « volé ».

Ce nom, depuis, est resté dans la langue et signifie grenier. II rappelle que sans le feu de la forge, sans le fer des boues, il n'y aurait pas de récolte à engranger.

Sans perdre un instant, le Forgeron lança le tronc-decône-pyramide le long d'un arc-en-ciel Sans que l'édifice tournât sur p.40 lui-même, le fil se déroulait en serpentin, image du cheminement de l'eau.

Sa masse et son arc en mains, le Forgeron se tenait debout, prêt à se défendre contre l'espace. Mais l'attaque fut inattendue: dans un bruit de tonnerre, un brandon lancé par le Nommo femelle atteignit la terrasse. Le Forgeron, pour se protéger, saisit l'une des peaux du soufflet et la brandit au-dessus de sa tête, créant ainsi le bouclier. La peau, par le fait qu'elle avait reçu le morceau de soleil, était devenue d'essence solaire et le feu du ciel ne prévalait pas contre elle. Puis l'ancêtre éteignit avec l'eau de son outre le bois enflammé qui incendiait l'édifice. 
Ce bois, nommé bazou, devait être à l'origine du culte du feu femelle.

Un autre coup de foudre suivit le premier, lancé cette fois par le Nommo mâle. Mais il n'eut pas plus d'effet. Le Forgeron éteignit le second brandon, nommé anakyê, sur lequel devait être fondé plus tard le culte du feu mâle.

L'édifice poursuivit donc sa route le long de l'arc-en-ciel. Il allait seulement plus vite, du fait de la poussée donnée par les foudroiements.

Sur la terrasse, le Forgeron avait repris sa garde, mais il était fatigué de tenir sa masse serrée dans sa main et il la posa en travers de ses bras légèrement relevés vers l'avant. Quant à l'enclume, il la portait en bandoulière à l'aide d'un long cuir qui passait autour de son cou et retombait derrière lui par-dessus ses épaules. La traverse de bois dans laquelle était enfoncé le fer lui battait les jambes.

Dans cette descente, l'ancêtre avait encore la qualité de génie de l'eau et son corps, bien qu'ayant gardé une apparence humaine du fait qu'il s'agissait d'un homme régénéré, était pourvu de quatre membres souples comme des serpents, à l'image des bras des grands Nommo.

Le sol approchait rapidement. L'ancêtre était toujours debout, bras en avant, masse et enclume en travers des membres. Survint l'impact final qui se produisit au bout de l'arc-en ciel, là où il touchait la terre. Le choc dispersa dans un nuage de poussière les animaux, les végétaux et les hommes échelonnés sur les marches.

Quand le calme fut revenu, le Forgeron était encore sur la terrasse, debout, face au nord, ses outils en même place. Mais dans le choc, la masse et l'enclume lui avaient brisé les bras et ${ }_{p .41}$ les jambes, à hauteur des coudes et des genoux qu'il n'avait pas jusque-là. II recevait ainsi les articulations propres à la nouvelle forme humaine qui allait se répandre sur la terre et qui était vouée au travail.

- En vue du travail, son bras s'est plié.

En effet, les membres souples étaient impropres aux tâches de la forge et des champs. Pour frapper le fer rouge et pour creuser la terre, il fallait le levier de l'avant-bras. 
En prenant contact avec le sol, l'ancêtre était donc prêt pour son œuvre civilisatrice. II descendit par l'escalier septentrional et délimita un champ carré de dix fois huit coudées de côté orienté comme la terrasse sur laquelle il était descendu et qui donnait les mesures de la parcelle unitaire.

Ce champ fut divisé en 80 fois 80 carrés d'une coudée qui furent répartis entre les huit familles descendant des ancêtres, et qui avaient poursuivi leur destinée sur la terre. Selon la médiane nord-sud du carré, huit maisons d'habitation furent construites, avec de la terre à laquelle on avait mélangé du torchis pris au grenier. Au nord de cette ligne, la forge s'établit.

- On avait mis aussi du torchis céleste dans le champ, dit Ogotemmêli. Ainsi le sol fut purifié. Et plus tard, lorsque le défrichement s'étendit, l'impureté de la terre a reculé.

L'aveugle insistait toujours sur cette affaire de l'impureté du sol, cause du premier désordre :

- Autrefois, lors de la création, la terre était pure. La boule lancée par Dieu était de glaise pure. Mais la faute avec le Chacal a souillé la terre et cette affaire a dérangé le monde. C'est pourquoi le Nommo est venu le réorganiser. La terre qui est sortie des cieux et qui est descendue était une terre pure. Dans le lieu où elle s'est posée, elle a fait passer cette pureté, comme dans tous les lieux défrichés. Dans tous les lieux où a gagné la culture, l'impureté a reculé.

La rénovation de la terre n'était pas la seule œuvre à mener.

- Le grenier est descendu plein de nourritures nouvelles. Elles étaient destinées à la régénération, au renouvellement des hommes.

Mais le début de ces travaux devait être marqué par d'autres événements.

Le Forgeron, ex-Nommo, ne pouvait suffire à la tâche de moniteur. Son rôle était d'ailleurs surtout de technicien et d'autres enseignements étaient nécessaires. 
p.42 Aussitôt après le Forgeron, premier ancêtre, les sept autres descendirent. L'ancêtre des Cordonniers, I'ancêtre des Trouvères suivirent un fil. Ils avaient chacun leurs outils ou attributs. Les autres vinrent ensuite, selon leur rang.

C'est alors que se produisit l'incident qui devait orienter la réorganisation :

Le Huitième ancêtre, rompant l'ordre des préséances, descendit avant le Septième, Maître de la Parole. Celui-ci, courroucé, se retourna contre les autres en arrivant au sol et, sous la forme d'un grand serpent, il se précipita dans le grenier pour y prendre les graines.

Selon une autre version, il mordit la peau du soufflet déjà installé dans la forge pour disperser les graines qui y avaient été déposées.

Selon d'autres encore, il était descendu en même temps que le Forgeron, sous la forme du grenier lui-même; il avait pris, au sol, le corps d'un grand serpent et une querelle avait éclaté entre les deux génies.

Quoi qu'il en soit, le Forgeron, à la fois pour se débarrasser d'un adversaire et poursuivre les grands desseins de Dieu, conseilla aux hommes de tuer le serpent, d'en manger le corps et de lui en confier la tête.

- Selon d'autres, dit Ogotemmêli, qui attachait la plus haute importance à ce tournant de l'histoire du monde et qui voulait exposer scrupuleusement l'attitude des génies, selon d'autres, le Forgeron, en arrivant au sol, trouva les hommes des huit familles et installa son atelier auprès d'eux. Comme il avait déposé les peaux du soufflet, le grand serpent surgit, se précipita sur elles, dispersant le mil alentour. Les hommes, ayant vu ce nouveau venu, surpris par son geste, le tuèrent. Le Forgeron les remercia, leur donna le corps pour qu'ils le mangent et garda la tête.

Mais tout le monde était d'accord sur la suite donnée au meurtre :

- Quand il eut la tête, le Forgeron la porta vers la pierre qui lui servait de siège pour frapper le fer, fit un trou, l'enterra et la couvrit avec la pierre. 
- Alors, dit l'Européen, le Nommo-ancêtre Septième est dans toute forge d'aujourd'hui ?

- Oui, répondit l'aveugle, tout forgeron, lorsqu'il travaille, est comme assis sur la tête du serpent.

p.43 Mais il y avait encore d'autres dédales à ce mystère.

- Le Nommo-ancêtre Septième a été tué par les hommes sous sa forme de serpent et sa tête enterrée. Mais on peut dire aussi qu'il était le grenier descendu des cieux, qu'il a été brisé et divisé, que la terre des parois a été répandue dans le champ primordial, mélangée à celle des habitations, que les graines de son ventre, au moment des semailles, ont été enfouies dans le sol. On peut dire que le Septième a été tué et détruit et inhumé comme Serpent, comme grenier, comme graines.

- Et pourquoi lui ?

- Parce qu'il était le Maître de la Parole.

- Et pourquoi lui fallait-il mourir ?

Ogotemmêli ne répondit pas directement.

II avait posé son menton sur ses genoux remontés contre sa poitrine; les mains aux joues, il regardait dans sa nuit.

- Il est mort vers la mi-novembre, dit-il.

L'Européen prit congé. L'absence de réponse, chez son partenaire, était toujours pleine de promesse. Et il se souvenait que l'avant-veille, à la demande :

- Qu'y a-t-il dans le grenier ?

le vieil homme avait répondu :

— Wolo ! c'est-à-dire : Rien ! 


\section{Septième journée}

\section{La troisième parole et le vomissement du système du monde}

Dans la cour d'Ogotemmêli, on vivait au ras des volailles, dont les peurs et les sagesses ne duraient qu'un temps. Une terreur générale, inspirée par un jet de pierre ou de bois, n'était suivie que de quelques minutes de paix.

C'est que, dans les villages noirs, les poulets sont rarement gorgés. Leur vie est une incessante frénésie de recherche des nourritures, d'autant que les surfaces à explorer sont limitées aux cours et aux ruelles. En effet, le maigre poids de ces bêtes en fait des proies faciles pour les milans; elles ne peuvent se défendre que dans les volumes encombrés des habitations où les piqués et les vols rasants sont impossibles.

p.44 Dès qu'Ogotemmêli était assis sur son seuil et l'Européen absorbé par l'enquête, la basse-cour s'organisait. Les poussins basculaient dans les calebasses pleines de lie de bière, dérapaient dans la pierre creuse, couraient au mur à la moindre ombre passant au zénith. Certains, aux heures chaudes, venaient dormir sur les espadrilles de l'étranger qui n'osait plus remuer un orteil.

Les poussins, avec leurs voix fluettes, étaient de bonne compagnie. Mais les coqs, et spécialement le coq du Hogon, jetaient le trouble dans les cosmogonies, coupaient les phrases, déclenchaient des cris et des gesticulations. Ogotemmêli, le buste dressé dans l'embrasure, les maudissait avec véhémence, sans omettre le souhait de les voir cuits.

II reprenait l'instant d'après, sur un ton monocorde, l'entretien sectionné en plein foudroiement du Forgeron, en pleine mécanique céleste.

Cette septième journée ogotemmêlienne avait été séparée de la sixième par une grande semaine de travaux poursuivis dans les régions du Nord. L'Européen avait hâte 
de renouer. Il s'assit sur la pierre habituelle, posa son casque au sol et jeta dedans les goyaves de son déjeuner.

- A partir du moment où le Forgeron fut sur la terre, dit Ogotemmêli, les hommes eurent des articulations. Ils avaient jusque-là des os souples qui ne se pliaient pas assez. Le bras souple ne permet pas le bon travail.

D'autre part, les bras seuls et les mains nues ne pouvaient accomplir que des tâches limitées; c'est pourquoi le Forgeron donna, dans les mois qui suivirent, le fer en forme de houe qu'il emmancha. La houe était un bras qui prolongeait celui de l'homme.

L'apparition de la houe devait donner le signal des travaux agricoles. Jusqu'alors, il n'y avait que quelques végétaux sur la terre, comme le coton, qui était récolté pour le tissage, mais non cultivé. De même, il n'y avait, avant la descente du grenier céleste, que quelques animaux comme la fourmi, le termite, le chacal, peut-être le scorpion et le lézard dit « soleil ».

Mais la présence sur la terre de la houe défonceuse et des graines ne pouvait suffire à déclencher l'agriculture ; il fallait la pluie abondante.

Il fallait aussi que les hommes s'organisent, que la totalité des desseins de Dieu s'accomplisse.

p.45 Huit familles, descendant des huit ancêtres, vivaient sur la terre et le plus vieux de tous les hommes appartenait à la huitième.

Or le rang huit, tout en étant égal aux autres, a un privilège particulier :

- Sept, dit Ogotemmêli, est le rang du maître de la parole. 1 s'ajoute à 7 et c'est 8 . Le huitième rang est celui de la parole elle-même. La parole est en dehors du Septième qui l'enseigne. Elle est le Huitième ancêtre. Le Huitième est le support de la parole qu'avaient les sept premiers et que le Septième enseignait.

Le plus vieil homme vivant alors était donc, du fait qu'il appartenait à la huitième famille, l'être terrestre le plus représentatif de la parole.

II avait nom Lébé. 
Or les hommes étaient en possession d'une parole ancienne, la seconde, apprise lors du tissage et qui devait céder la place à la troisième. L'enseignement de cette nouvelle parole devait être le fait du Nommo-ancêtre Septième, tué par les hommes et dont la tête reposait sous le siège de la forge dans la partie nord du champ primordial.

Il fallait que le vieil homme mourût pour qu'il passe dans le même monde que le Septième et pour permettre la réalisation des desseins de Dieu.

Le vieil homme mourut donc.

- Mais, fit remarquer Ogotemmêli, il mourut en apparence. On dit aux hommes du commun que le vieillard était mort. On leur dit aussi que le Septième avait été tué et consommé. En réalité, ni l'un ni l'autre ne sont morts. Le vieillard ne pouvait pas mourir puisque la mort ne devait apparaître que plus tard. Le Septième ne pouvait pas mourir puisqu'il était Nommo.

l'Européen.

- Et pourquoi tromper les hommes? demanda

- Pour leur mieux faire comprendre les choses, répondit l'aveugle.

Et il passa outre.

Le vieil homme étant mort, on le déposa sur la terre pendant qu'on creusait, dans le champ, non loin de la forge, une tombe orientée nord-sud. On l'y enfouit à plat dos, tête au nord, dans p.46 la position de la terre et dans son nombril même, c'est-à-dire en son centre.

Si on le mit à plat dos, ce fut pour l'accomplissement des desseins de Dieu et aussi parce que les hommes ignoraient la mort et les rites funéraires. Dans la suite des temps, quand les hommes périrent, on les coucha dans le fond des tombes ou dans les cavernes, la tête au nord, les mâles sur le côté droit, les femmes sur le côté gauche, dans la position où ils dorment, sur le terre-plein de la deuxième chambre. On omit aussi de lui replier les membres pendant quelques instants, comme on devait le faire plus tard à tous les morts, pour leur donner 
fugitivement la forme du fœtus et préfigurer la régénération.

Ainsi le champ primordial contenait d'une part le corps du plus vieil homme et cet homme appartenait à la famille huitième, rang de la parole. II contenait d'autre part, sous la pierre du Forgeron, la tête du Septième ancêtre.

Alors retentit le premier bruit de la forge.

Il se répercuta dans les profondeurs de la terre et atteignit le Septième ancêtre tué par les hommes.

A la cadence du soufflet double activant le feu et de la masse frappant l'enclume, le Septième Nommo prit sa forme de génie à tronc humain terminé en reptile. Puis se dressant sur sa queue, avec des gestes réguliers de ses bras portés en avant, avec des à-coups rythmés du corps, il nagea la première danse qui le conduisit souterrainement dans la tombe du vieillard.

Au rythme du travail de forge, le Septième se présenta au nord du corps, côté crâne, et le déglutit; il le reçut dans sa matrice et le régénéra. Enfin, sur les mêmes battements, il vomit dans la tombe avec un torrent d'eau le produit de la métamorphose.

Cette eau, symbole des torrents et des mares, forma sur l'ancienne place du corps une nappe centrale d'où s'échappèrent, dans les cinq directions de la tête et des membres, cinq rivières.

Cette eau était aussi celle de la parturition : la matrice du Nommo avait transformé en pierres de couleur les os de l'homme et elle les émit dans le fond de la tombe en dessinant un squelette posé à plat dos, la tête au nord, sur le lieu occupé auparavant par le corps.

- Le Septième Nommo, dit Ogotemmêli, a avalé le vieil p.47 homme par la tête et il a rendu les pierres dougué en les plaçant dans le même ordre que le corps étendu. C'était comme un dessin d'homme fait avec les pierres.

Le tracé rappelait aussi celui que fait de l'âme d'un homme le Nommo à chaque naissance. Et il indiquait, par l'emplacement des pierres, l'ordonnance de la société humaine. 
- Il a organisé le monde en vomissant les dougué qui silhouettaient une âme d'homme.

II déposa les pierres une à une, en commençant par celle de la tête et par les huit dougué principaux, un par ancêtre, marquant les articulations du bassin, des épaules, des genoux et des coudes; la priorité était donnée à la droite; les pierres des quatre ancêtres mâles étaient placées aux articulations du bassin et des épaules, c'est-àdire dans le haut des membres; celles des quatre femelles aux quatre autres.

(9)

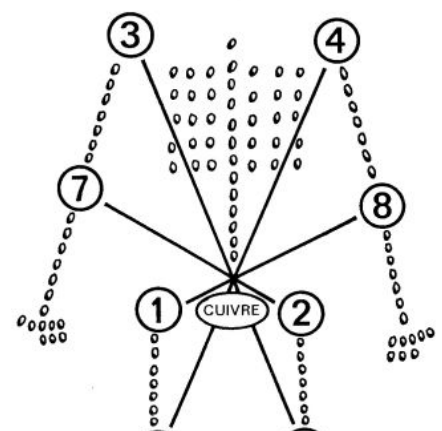

$\begin{array}{cc}5 & 6 \\ 0 & 0 \\ 0 & \vdots \\ 0 & \vdots \\ 0 & \vdots \\ 0 & \vdots \\ 00000 & 0000 \\ 00000 & 0000\end{array}$

\section{LE SYSTÈME SOCI AL DE LA $3^{\mathrm{e}}$ PAROLE}

- L'articulation, déclara l'aveugle, est ce qu'il y a de plus important dans l'homme.

Ensuite les pierres de second ordre, émanation des huit premières, dessinèrent les os longs, la colonne vertébrale, les côtes.

Tous ces dougué étaient les pierres d'alliance que devaient plus tard porter au cou les prêtres totémiques. Elles étaient les gages d'affection des Huit Ancêtres, les réceptacles de leur force vitale qu'ils voulaient remettre en circulation dans leur descendance.

- Les dougué étaient huit, comme les ancêtres étaient huit, comme les graines étaient huit. Les dougué représentaient les huit vieux du début de l'humanité. Et les 
huit hommes, les huit graines, les huit articulations sont dans le même ordre que les dougué.

Toutes les couleurs de l'arc-en-ciel le long duquel le Forgeron était descendu étaient représentées, mais non dans leur ordre naturel ; la jambe gauche était presque noire ; la droite et le bras gauche tiraient sur le rouge et le bras droit sur le blanc. Mais on ne pouvait déterminer que la teinte dominante de chaque membre : le squelette, dans son entier, était multicolore.

Les couleurs des huit dougué principaux, affectés respectivement à l'ancêtre de même rang, rappelaient soit celles des organes du grenier céleste, soit celles des graines correspondantes:

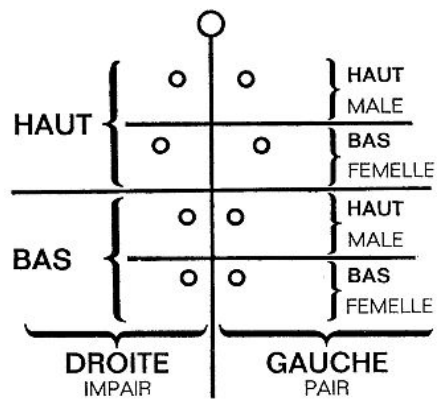

- La première pierre, jaune-marron, comme le vêtement dogon, rappelait l'estomac ( ler compartiment) ;

- p.49 La deuxième, rougeâtre, traversée d'un trait blanc, avait la couleur du gésier (2e compartiment) ;

- La troisième était rouge comme le cœur $\left(3^{\mathrm{e}}\right.$ compartiment) ;

- La quatrième blanchâtre comme le mil femelle (4e compartiment) ;

- La cinquième bronzée comme le haricot $\left(5^{\mathrm{e}}\right.$ compartiment) ;

- La sixième noire comme l'oseille écrasée $\left(6^{\mathrm{e}}\right.$ compartiment) ;

- La septième rose comme le foie ( $7^{\mathrm{e}}$ compartiment) ;

- La huitième verte et blanche comme la bile $\left(8^{\mathrm{e}}\right.$ compartiment). 
Le Nommo expectora également les ongles du mort sous forme de cauris, à raison de huit par main et par pied. II les déposa à la place des mains et des pieds en commençant par la droite et dans l'ordre suivant :

- Un cauris sur le majeur, un autre sur l'index pour rappeler la qualité de jumeaux des deux premiers ancêtres ; unique ;

- p.50 Un sur le pouce, le troisième ancêtre étant né

- Un sur l'annulaire, un sur l'auriculaire, pour les quatrième et cinquième ancêtres également jumeaux ;

- Un sur le pouce, l'index et le majeur, à nouveau, pour les sixième, septième et huitième ancêtres.

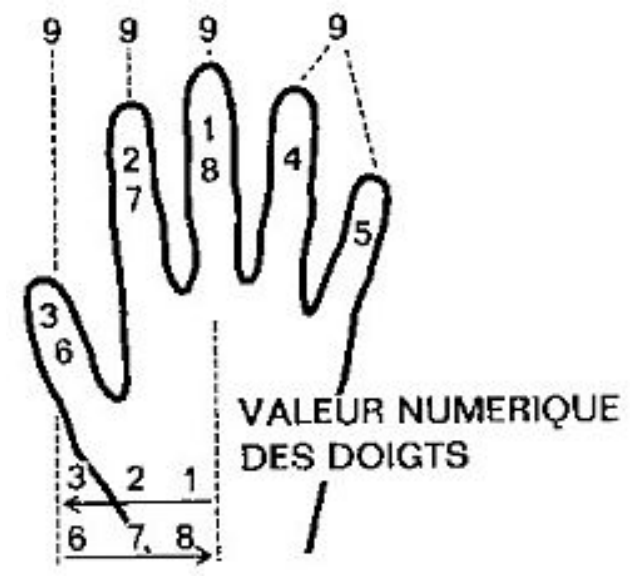

L'Européen nota en passant que les cauris de rangs 7 et 8 , chiffres se rapportant à la parole, étaient posés sur deux doigts (index et majeur) qui, chez les Dogon, « séparent » les paroles.

Ogotemmêli ne s'expliqua guère sur ce sujet. II dit pourtant que le majeur, dans les cas de mort suspecte, était laissé hors du suaire, légèrement courbé, afin d'indiquer et $d^{\prime}$ ' accrocher » le criminel.

Mais il revenait aux cauris.

- Plus tard, quand fut inventé le commerce, on devait poser les cauris par huit, dans l'ordre des doigts. On comptait au-delà, autant de fois huit cauris qu'il y avait d'ongles dans les deux mains, soit 80 . Et huit fois 80 , soit 640, marquait le bout du compte. 
Entre les jambes de la silhouette, le Nommo déposa le cuivre $_{p .51}$ résultat de sa digestion, métal qui devait servir à confectionner des bracelets pour les usages rituels.

La disposition des huit pierres des articulations détermina dans la suite le système des alliances selon le principe de l'alternance de la gauche et de la droite, du haut et du bas, du pair et de l'impair, du mâle et du femelle, soit :

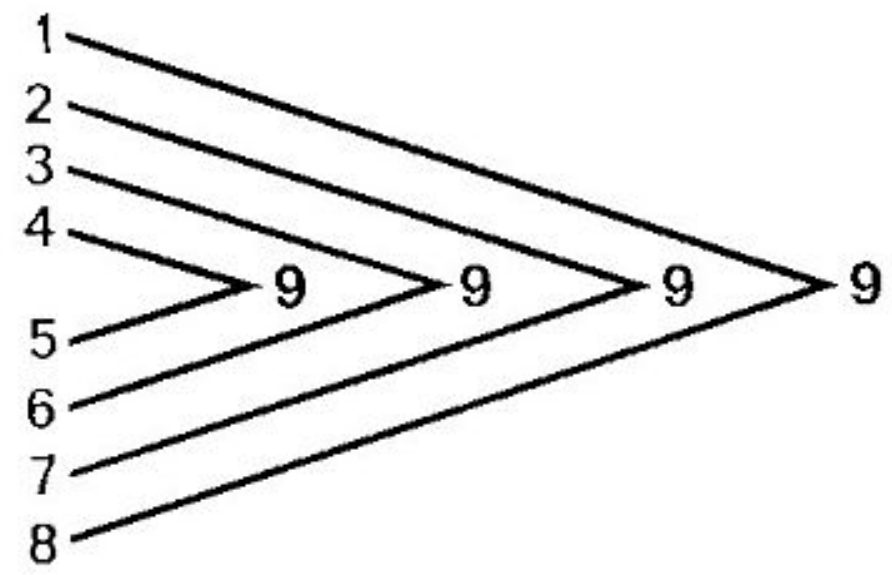

$-1^{\mathrm{e}}$ famille (cuisse droite, mâle) avec $8^{\mathrm{e}}$ (avant-bras gauche, femelle).

$-3^{\mathrm{e}}$ famille (bras droit, mâle) avec $6^{\mathrm{e}}$ (jarret gauche, femelle).

- $5^{\mathrm{e}}$ famille (jarret droit, femelle) avec $4^{\mathrm{e}}$ (bras gauche, mâle).

$-7^{\mathrm{e}}$ famille (avant-bras droit, femelle) avec $2^{\mathrm{e}}$ (cuisse gauche, mâle).

Ces alternances étaient poussées si loin que, dans le cas du haut et du bas par exemple, ce n'était pas seulement haut et bas du corps qui étaient unis mais encore haut et bas de membre. Ainsi une cuisse (bas du

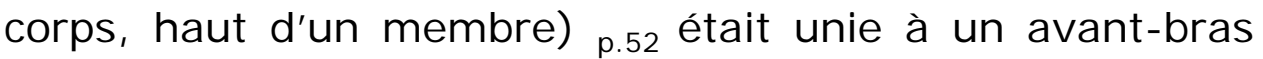
(haut du corps, bas d'un membre).

Ces alliances étaient réparties de telle sorte que la somme des rangs des deux familles était toujours 9, rang de la chefferie. 
Quant à la pierre posée à la place du crâne, elle avait également le rang 9, car elle devait être affectée à la chefferie dans chaque famille.

Le système d'alliance était aussi inscrit ailleurs : dans le dépôt des cauris à la place des doigts, le majeur avait rang un et huit ; l'index avait rang deux et sept, le pouce trois et six.

C'était montrer que l'appariement des rangs se faisait sur un seul doigt. Apparier et marier, c'était unir en un.

Par le 4 et le 5 annulaire et auriculaire, c'était apparier deux jumeaux de sexes opposés, donc deux êtres ne formant qu'un. (En effet, les Ancêtres 4 mâle, et 5 femelle, étaient jumeaux.)

L'exposé d'Ogotemmêli n'était pas allé sans à-coups. II s'était d'abord longuement embarrassé dans les articulations. Comme on ne pouvait pas dessiner dans la poussière, il concrétisait ses calculs par des tapes sur ses cuisses ou ses avant-bras.

De plus, les poulets, les chiens et les femmes indiscrètes avaient rompu vingt fois l'entretien. Notamment, lorsque l'aveugle décrivait la danse souterraine de résurrection, Koguem s'était précipité à corps perdu dans la cour, agitant les bras, soufflant comme un serpent. II était revenu à l'Européen en lui tendant une goyave déchiquetée que la poule aux six poussins avait dérobée dans le casque :

- Pauvres bêtes ! avait répondu le Blanc en rejetant le fruit à la couvée qui s'enfuit, le prenant pour une pierre.

- Que se passe-t-il ? avait demandé l'aveugle.

Koguem ayant expliqué la scène, Ogotemmêli s'indigna, buste haut dans l'embrasure.

Tendant les mains, il se fit remettre le fruit qu'il partagea en trois et distribua :

- La poule, grommela-t-il, n'a pas l'autorité pour manger la goyave. 


\section{Huitième journée}

\section{La troisième parole et les travaux de rédemption}

p.53 Depuis longtemps la récolte du mil était faite. Entre les deux Ogol, dans le champ du Hogon, les tiges sèches claquaient au moindre tourbillon. La terre allait attendre pendant toute une saison de vents et de soleil qu'on lui ouvre à nouveau le ventre. On n'entendrait pas avant longtemps les paysans nommer le mil d'après sa hauteur, tout au long d'une croissance anxieusement observée, encouragée par le sang des volailles sur les autels, par les prières infinies, par les précautions compliquées. On n'entendrait pas avant des mois appeler «nez poussé » la première apparition des tigelles, «queue de coq »la première courbure de la feuille caressée par le vent, «mottes cachées» la disparition de la terre sous la verdure, «avale bêtes» les tiges assez hautes pour masquer un mouton.

L'Européen marchait sur les pistes en remblai des tristes champs d'après récolte où se dressaient, dans leur peau vert-rosissant au soleil levant, les baobabs. II connaissait par leur nom propre tous ceux des Ogol et l'ordre chronologique de plantation pour les vingt plus vieux. II admirait de loin le huitième de la liste, Adama, le plus vaste: neuf hommes, les bras en croix collés à son tronc en auraient fait à peine le tour. II passait devant Baobab-Gravier dont les graines ressemblaient à du sable, devant Baobab-Filant dont les fruits donnaient une crème coulant comme du fromage, devant Haut, Rugueux-deI'Ancêtre, devant Minces-Graines, Haute-Poitrine, PetitGros et Plac-Plac dont les fruits fragiles éclataient en tombant. Puis il entrait dans les ruelles, s'installait dans la cour d'Ogotemmêli et jetait un coup d'œil à la cime, visible par-dessus les terrasses, de celui qui s'appelait simplement Baobab, ancêtre de tout le verger monstrueux. 
- Le vieillard mangé par le Nommo Septième, dit Ogotemmêli, s'appelait le Lébé. Les pierres qui pendent au cou de tous les prêtres sont ses os.

p.54 Mais les hommes ne connurent pas les résurrections souterraines au moment où elles eurent lieu; ils n'entrèrent pas en possession du trésor de pierres aussitôt qu'il fut déposé. Ils ne surent pas la cause des pluies qui se mirent à tomber et qui étaient le signal du défrichement du champ délimité par le Forgeron.

Ces premières pluies, en effet, avaient un rôle de purification. Le Nommo Septième, génie pur, en ingérant le vieillard avait assimilé la nature humaine impure et la seconde parole périmée. Dans le vomissement rythmé par les coups sur l'enclume, il avait éjecté à la fois les pures pierres d'alliance et une eau qui charriait la souillure. Cette eau s'était répandue en mares et rivières, se frayant des vallées et pesant sur les creux. II fallait la balayer et la remplacer par une eau pure et bénéfique. Ce fut le rôle de la pluie que les grands Nommo célestes envoyèrent pour aider le Nommo Septième dans ses travaux.

Mais l'eau du ciel ne fit pas que repousser le flot des rivières : elle humecta le champ primordial, permettant au Forgeron d'enseigner les gestes des semailles.

C'est bien plus tard, selon certains, que les hommes connurent le déroulement des événements prodigieux du sous-sol. Les terres étant devenues trop étroites, ils décidèrent l'émigration en masse. Mais comme ils voulaient s'amarrer au passé et piétiner les mêmes humus, ils creusèrent la tombe du Lébé dans l'idée d'en prélever les ossements et la terre pour les emporter en d'autres lieux.

C'est à ce moment qu'ils découvrirent le système de pierres vomi par le Nommo Septième et ce génie luimême, sous sa forme de serpent.

Selon d'autres, cette découverte eut lieu dans la première année de la culture, lorsque vint le temps de la première façon à donner au champ.

Enfin, d'autres disent qu'on a enterré le Lébé et semé les graines le même jour. A la récolte, les hommes 
creusèrent la tombe, pensant que le vieillard était ressuscité, comme le mil lui-même.

Ainsi donc l'organisation spirituelle et l'organisation matérielle allaient de pair. Comme pour les première et seconde paroles, l'enseignement en cours de la troisième s'imbriquait dans les techniques.

- Mais pourquoi, demanda le Blanc qui revenait à son idée, p.55 pourquoi le meurtre du Septième ? Et pourquoi le Septième dévore-t-il le Lébé en tant qu'homme descendant du Huitième?

- Le Nommo Septième a dévoré le Lébé pour que les hommes croient que les pierres vomies étaient ses os digérés et transformés. Pour que la chose soit une chose d'homme et non une chose du ciel. Pour faire passer dans la nature humaine une chose qui était du ciel. Pour faire croire aux hommes que le vieux Lébé, le plus vieux, le plus respectable de tous, et lui seul, était dans les pierres d'alliance. C'est pour que les hommes comprennent toutes les choses qu'il a faites qu'il est descendu sur un squelette d'homme.

- Vous dites « faire croire ». Y avait-il donc un secret à leur cacher?

- Si I'on voulait expliquer cet événement à un homme qui l'ignore, à un homme du commun, on dirait qu'une puissance du ciel est venue pour manger le vieux père et pour transformer ses os en des pierres bénéfiques.

- Mais quelle est la vérité ?

- Si I'on veut vous l'expliquer, à vous, Nazaréen, on dira que quelqu'un est descendu des cieux comme femme, avec ses parures et accessoires, qu'elle a mangé le vieux père, mais que les pierres ne sont pas les os de l'homme : ce sont ses parures à elle.

Il s'agissait des pierres et cauris contenus dans la poterie-matrice placée au croisement des cloisons, au centre du grenier.

- Mais pourquoi, insistait le Blanc, le Septième a-t-il été tué ? II n'obtint pas de réponse. 
- Le Nommo Septième, disait Ogotemmêli comme se parlant à lui-même, s'est sacrifié. Lui seul pouvait le faire. Le Septième est le maître des paroles, il est maître du monde, il est capable de faire toutes choses. Sans le Septième, rien ne pouvait être réorganisé. Le Septième pourrait dire - il ne l'a pas dit, mais il pourrait le dire - : la chose que je faisais, le travail que je travaillais, la parole que je parlais, c'est : « ku ma inné déga dâ bébadou ».

C'est-à-dire :

- Ma tête est tombée à cause des hommes pour les sauver.

- Et le Lébé a été dégluti comme descendant du huitième ancêtre, de la famille de la parole. La parole est la chose la plus importante au monde. En mangeant le Lébé, le Nommo Septième, maître du Verbe, a pris ce qu'il y avait de bon dans la parole ancienne et l'a introduit dans les pierres. Tout ce ${ }_{\text {p.56 }}$ qui était impur a été rejeté avec l'eau et emporté par les pluies.

- Le Septième, mort en apparence, a mangé le Lébé, mort en apparence. En mangeant I'homme il en a pris ce qui était bon. Mais il a, de son côté, donné sa force vitale à la chair de l'homme, c'est-à-dire aux hommes. Car en le faisant pour le plus vieux, il le faisait pour toute I'humanité.

Ainsi le Septième et le Lébé, descendant de son frère Huitième, en vertu de la manducation de l'un par l'autre, confondaient leurs forces vitales.

- Et leurs âmes ? Que devenaient leurs âmes ?

- Leurs âmes se sont jointes et tout en restant distinctes : elles ne se séparent jamais. Chaque année, au grand sacrifie en l'honneur du Lébé, les hommes qui mangent la victime représentant l'Ancêtre demandent qu'il en soit toujours ainsi. II se rendent au sanctuaire et disent :

«Que Nommo et Lébé ne cessent pas d'être la même chose, qu'ils restent la même chose bonne, qu'ils ne se séparent pas de cette qualité d'être la même chose. »

- En somme, se dit l'Européen, c'est la nature humaine indissolublement liée à la nature céleste. 
Mais il ne prenait jamais un grand intérêt à ses propres spéculations.

- Pourtant, remarqua Ogotemmêli, le Lébé nouveau du vomissement, celui qui est honoré de nos jours...

II se reprit. La chose était difficile à expliquer. D'autre part la femme du Hogon venait d'entrer dans la cour et saluait. Une vieille à voix douce et brisée à certains mots par des battement trop rapides du cœur. Elle penchait sa petite tête ronde en avant, bouche ouverte et les yeux grands, très attentive à ce que lui disait l'Européen :

- Dieu vous amène! répondait-elle, donnez-moi un remède pour mon cœur.

- C'est de la vieillerie, expliquait-il, comment refaire du neuf avec du vieux?

II lui répétait cette plaisanterie chaque fois qu'ils se rencontraient, car il savait qu'elle en riait aux larmes.

Ogotemmêli s'était tu après les interminables salutations. II garda le silence pendant tout le temps des allées-venues de la vieille dans la cour et jusqu'à ce qu'il l'eût entendue sortir. Hogon.

- On ne peut, dit-il, parler du Lébé devant la femme du

p.57 Le Hogon est en effet le prêtre du Lébé, le plus vieil homme du groupe, le plus haut dignitaire religieux.

- Les femmes ont des oreilles, chuchota-t-il sur le ton de la plus étonnante des confidences.

Cette scène se répétait dix fois par jour. C'était tantôt la femme du Hogon, tantôt une femme de prêtre totémique, tantôt une fille non excisée, tantôt un vieillard méfiant, tantôt un forgeron qui pénétrait dans la cour ou plaçait la tête devant l'échancrure du mur de pierres.

On ne pouvait parler du Lébé devant la femme du Hogon, des Huit ancêtres devant une femme de prêtre, du Nommo devant le forgeron, ni de rien devant les sots.

- Le Lébé, reprit l'aveugle, était une sorte de chose nouvelle qui n'entrait pas encore dans le compte des Huit. 
Il entendait par là que huit était, en une certaine manière, le bout du compte des symboles, qu'il n'y en avait pas au-delà. II entendait aussi par Lébé, non pas le vieillard dans son ancien être, mais l'élément nouveau obtenu par l'union de ce vieux et du Nommo.

- Le Lébé vient en quelque sorte en neuvième position, comme s'il était la création du Septième Nommo et du descendant du Huitième.

II voulait dire aussi que ce descendant était comme le Huitième lui-même. Or, dans la série des Nommoancêtres, les Septième et Huitième sont femelles.

- Le Lébé, c'est une nouvelle parole créée par deux femmes. Ce Neuvième, de ce fait, est le père inconnu, comme un bâtard. On ne sait lequel, du Septième ou du Huitième, a joué le rôle de l'homme.

Mais Ogotemmêli fit remarquer qu'il s'agissait là de manière de parler, qu'il voulait seulement faire comprendre au Nazaréen cette absence de père. Cependant le principe de l'être gémellaire pouvait expliquer cette création. Tout être étant double et des deux sexes, avec prédominance de l'un ou de l'autre, peut procréer, mais à la condition, semble-t-il, qu'intervienne un autre être. Ainsi dans le cas des deux Nommo-ancêtres Septième et Huitième considérés comme femelles, mais dotées d'un principe mâle non prédominant, il était possible que la féminité de l'un fut fécondée par la masculinité (même non prédominante) de l'autre.

- Le Lébé, concluait Ogotemmêli, procédant du Septième et ${ }_{\text {p.58 }}$ du Huitième, a le rang 9. C'est le rang de la chefferie. Sa marque est la pierre déposée dans la tombe à la place du crâne, elle provient de la métamorphose de la poterie centrale du grenier. Elle est à la fois le crâne et la poterie-matrice qui contenait les huit autres pierres.

A ce moment Allaye, camarade de Koguem, apporta une calebasse remplie de dix francs de lait dont ledit Koguem avait payé la moitié.

- Bois d'abord, dit Allaye. 
Koguem but à longs traits, les yeux révulsés vers le haut pour ne rien perdre du visage de l'autre qui le surveillait sévèrement.

- Assez! lui cria Allaye en reprenant le récipient, assez ! Je connais la limite de cinq francs de lait !

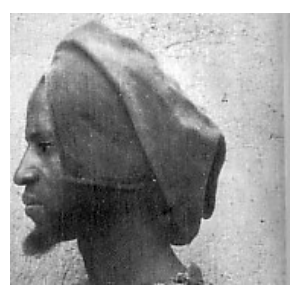

@ 


\section{Neuvième journée}

\section{La troisième parole et les tambours}

A des signes imperceptibles on sentait que c'était jour de marché. La semaine dogon étant de cinq jours - les doigts de la main - le marché revenait selon un rythme qui, pour un Européen, brisait très heureusement les cadres du comput. Le jour de marché, depuis la phase tranquillement sournoise du lever jusqu'à la détente du coucher, en passant par la puissante rumeur du midi, avait ses bruits et ses silences, ses lumières, ses silhouettes. Dans la nuit précédente, on pouvait voir, du côté de Gôna, sur les tables de grès coulant vers le pays de Kamma, les feux maigres des marchands. L'horizon était cerné de marchandises encore enveloppées dans des peaux, de rumeurs, d'ânes gras déchargés, de rêves de gains. Au lever du soleil, les hommes et les peaux, dans le bruit mat des sabots sans fer, déferleraient vers les Ogol.

Il y avait aussi, dans les abords, un décalage sensible des aboiements: les éventails de chiens se fermaient sur les cours des bouchers, à cause des filets de sang sous les portes ou dans les regards des murs.

Dès la troisième heure du jour, le vaste rocher luisant de Dolo était investi par les hommes et par le soleil. Pas un arbre $_{\text {p.59 }}$ ne portait la moindre ombre sur les pierres qui délimitaient grossièrement les emplacements des vendeurs. Vers l'ouest, le sol s'inclinait brusquement dans la vallée aux tables plates entre lesquelles coulaient des filets tièdes. Les hommes et les femmes s'agrippaient à cette sorte de déversoir pour se hisser sur la place gorgée de lumière, de chaleur, d'odeurs de condiments et qui vomissait son trop-plein de relents dans le bas-fond.

Tous portaient leurs plus beaux vêtements de bandes de coton blanc ou pain-brûlé.

Les hommes se balançaient dans leur tunique ample à larges manches, échancrée sur le col où pendaient les pierres rituelles. Les adultes avaient leur culotte courte 
serrée aux mollets, le fond vaste ballottant de droite et de gauche. Les plus vieux la portaient plus longue et plus profonde. Enfin les hommes de poids traînaient des fonds immenses qui toutefois n'atteignaient jamais les dimensions de celui du Hogon, l'intouchable qui ne sortait jamais du village. Les fonds variaient avec l'honorabilité.

Les jeunes garçons étaient vêtus de longues chasubles blanches dont certaines, ouvertes sur les côtés, laissent les flancs libres et se nomment «Mère prends-moi! » car elles facilitent la prise dans les bras.

Toutes les femmes, torse nu, seins flasques ou provocants, étaient ceintes du pagne à quatre bandes, bracelets à la saignée du bras et au poignet, collier de perles vertes ou rouges, l'oreille bordée des huit boutons de métal, le lobe garni de la pendeloque rouge en triangle.

Comme depuis quelques années il y avait eu quelques difficultés au-delà des mers, on voyait peu de ces costumes à falbalas, de ces parapluies sans objet, de ces lunettes inutiles que les tristes commerces déversent en ces pays. Les guerres lointaines avaient, pour un temps, purgé les contrées de la chienlit envahissante.

Le marché secouait les entrailles de tous les hommes et de bon nombre de bêtes depuis Kamma jusqu'à Yougo. Vers midi, tous se plongeaient dans son énorme murmure, le feu aux oreilles et l'œil inquisiteur pour des achats modestes mais véhéments.

Le remue-ménage ne se limitait pas à la place du marché ni aux pistes; les remous et à-coups atteignaient les fonds et tréfonds des maisons. Les vieillards trop dignes pour aller traîner leurs désirs dans la foule, le Hogon attaché aux roches habitées connaissaient heure par heure les grands et menus faits de p.60 Dolo. Et Ogotemmêli, en temps ordinaire - lorsqu'il ne connaissait pas de Nazaréen -, était au centre des nouvelles.

II recevait, en effet, des clients qui profitaient de leur déplacement pour se faire soigner. II avait ainsi des échos frais de Yènndoumman, de Mendéli, de Nînou, de Pêguê. La plaine, le plateau, les éboulis suaient leurs malades et leurs chasseurs en peine de recettes pour tuer à coup sûr un céphalopode. Ogotemmêli donnait à tout ce monde des 
conseils et des poudres et sa devise ne cessait de retentir dans la ruelle et la cour : «Écarteur ! écarteur terrible !

Le Nazaréen étant là, le flot d'impétrants avait reculé jusqu'aux carrefours, perplexe. Déjà lors de la quatrième journée qui était tombée un jour de marché, les gens n'avaient même pas approché le quartier de Tabda. Mais cette fois, quelques unités courageuses s'étaient hasardées jusqu'à l'échancrure du mur, avaient lancé les saluts; la présence insolite avait définitivement décontenancé les uns, effrayé les autres.

Il avait fallu convenir d'un modus vivendi pour ces jours insignes où tout palpitait.

Dans le brouhaha, l'entretien avait pu reprendre. Ogotemmêli exposait l'octroi de la troisième parole incluse dans les travaux de culture et de résurrection.

- Le plus important de tous les tambours, dit-il, est le tambour d'aisselle. C'est le Nommo qui l'a fait.

II s'agit de deux coupes hémisphériques de bois reliées en leur pôle par un cylindre de petit diamètre. II rappelle un sablier dont l'étranglement serait très allongé. Plaçant l'instrument entre le bras gauche et l'aisselle, le joueur, en appuyant plus ou moins fortement sur la cage de lanières ainsi formée, exerce une tension plus ou moins forte sur les peaux, modifiant la tonalité.

- C'est le Nommo qui l'a fait. Il en a donné l'image avec ses doigts, comme font aujourd'hui les enfants avec les jeux de ficelles.

Écartant les mains, il passa dix fois le fil dans chacun des quatre doigts, le pouce n'étant pas utilisé. II obtint ainsi dans chaque main quarante boucles qui faisaient quatre-vingts fils, nombre même des dents d'une de ses mâchoires. Ses mains, palmées, figuraient les peaux des extrémités. Symboliquement, frapper sur le tambour, c'est frapper sur les mains du Nommo. Mais que représentent-elles?

p.61 Plaçant les deux paumes en cornet derrière ses oreilles, Ogotemmêli rappela que le génie n'avait pas de pavillons, mais seulement des trous auditifs : 
- Ses mains lui servent d'oreilles, dit-il, pour entendre, il les place toujours de chaque côté de sa tête. Battre le tambour, c'est battre les mains palmées du Nommo, c'est battre ses oreilles.

Tenant devant lui le jeu de ficelles qui figurait une trame, le génie, à l'aide de sa langue, fit passer dans les fils une sorte de chaîne sans fin composée d'une mince bande de cuivre; il la fit tourner en hélice, lui donnant quatre-vingts spires et durant tout ce travail il parlait comme il avait fait lors de l'enseignement du tissage.

Mais sa parole était nouvelle; elle était la troisième qu'il révélait aux hommes.

Car la technique de construction du tambour était semblable à celle du tissage et, dans la main de l'artisan, le poinçon pour percer le bord des peaux et faire passer la corde de tension est le symbole de la navette et de la langue du génie.

Et frapper le tambour est aussi tisser: le son, sous les coups de la baguette, bondit d'une peau à l'autre à l'intérieur du cylindre, comme glissent la navette et son fil d'une main à l'autre entre les deux plages croisées par les lices.

- Mais pourquoi les spires de cuivre? Les tambours ordinaires n'en comportent pas.

- Le tambour avec l'enroulement de cuivre se fait mieux entendre du Nommo. Il est réservé à la chefferie des Arou et ne se trouve pas entre les mains des autres gens. De plus, il n'est battu qu'en de rares occasions.

Quant au rôle de ce cuivre en hélice, il est de conduite du son, de conduite de la parole. Battre la peau anime le cuivre et le verbe que le Nommo a pris dans les entrecroisements des tendeurs et de la bande de métal. Du cuivre, le son va au tambour; puis il revient dans la bande et de là se répercute dans les oreilles du génie déjà alertées du fait que les peaux les représentent.

Mais le tambour n'était pas seulement destiné à relier les hommes au Nommo; il leur apprenait la nouvelle parole complète et claire des temps modernes. 
Or le tambour d'aisselle ne pouvait suffire pour l'enseignement de cette parole qui devait être multiforme et répondre aux besoins divers des hommes. Chaque chef des huit familles, sur p.62 les indications du Nommo Septième, confectionna un tambour propre à son groupe.

Pour la taille du sien et la tension de la peau, le forgeron de la première famille prit modèle sur son soufflet. Le corps donna l'idée de la caisse sonore et le cuir de soufflerie, avec son système d'attache, servit d'exemple pour la peau à battre.
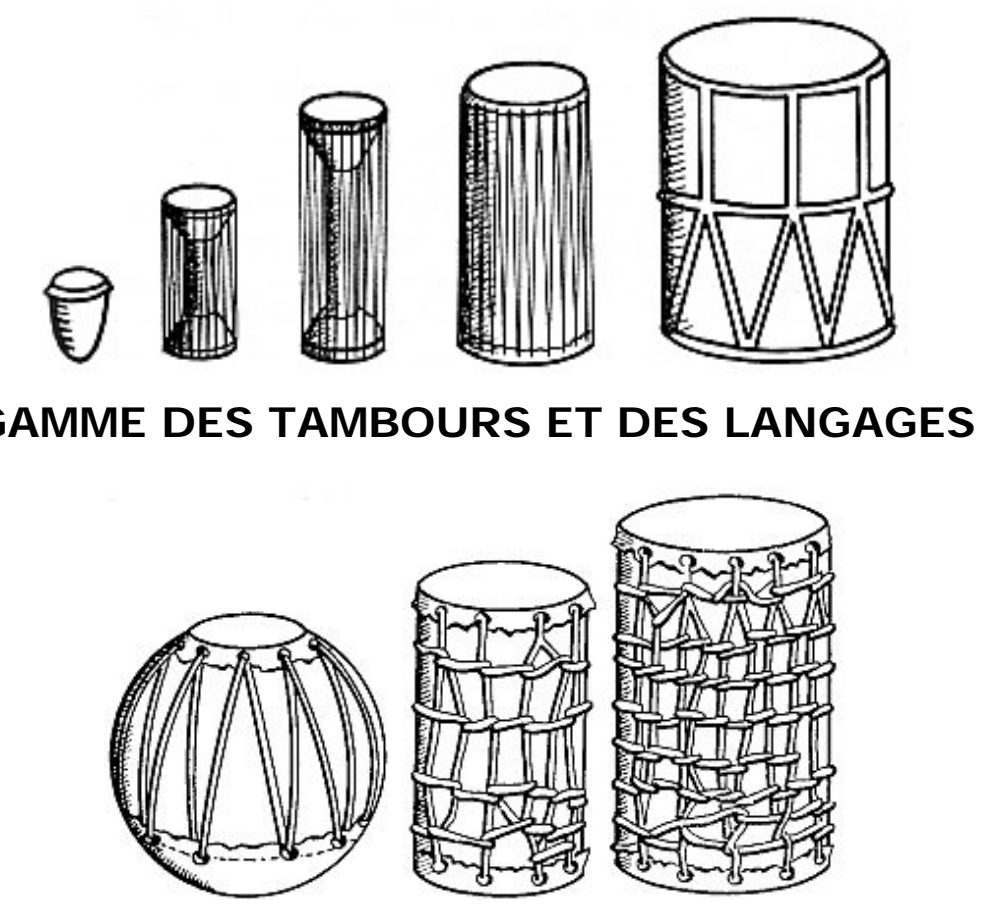

Ainsi fut fait le tambour en demi-fruit de baobab sur lequel était tendue une peau de batracien. II ressemble à un sein et son bruit imite celui que fait l'enfant tétant sa mère.

Sur ce tambour, le forgeron battit les premiers rythmes qu'il avait trouvés sur la double peau du soufflet lorsqu'il animait son feu, au temps de la résurrection souterraine du Nommo.

La seconde famille eut un tambour d'aisselle de petit modèle. La troisième reçut celui qui avait été enseigné par le Nommo. 
La quatrième confectionna une caisse cylindrique rappelant la petite taille des premiers hommes.

La cinquième fit de même dans un tronc plus grand. Elle obtint ainsi une voix puissante comme celle du lion.

La sixième tendit une peau sur l'ouverture d'une grande calebasse sphérique, image d'un ventre de femme. Le son qu'elle donne rappelle les plaintes de la parturition.

La septième tailla une caisse dans un tronc, lui donnant une dimension ne correspondant pas à celle de la cinquième.

La huitième eut la plus grande caisse. Elle ressemble au ventre de la vache et du fait de sa taille donne un grand roulement.

A chaque tambour correspondit une voix particulière. Ainsi chaque famille reçut son langage propre et c'est ce qui explique les langues diverses d'aujourd'hui.

Les deux premières familles, établies au sud, parlèrent deux toro, assez proches, la troisième le mendéli, la quatrième le sanga, la cinquième un autre toro, la sixième le bamba, la septième l'iréli.

Enfin la huitième reçut une langue comprise dans toute la falaise.

- De même que le huitième tambour domine tous les autres, de même la langue est entendue en tous pays.

Ainsi les hommes reçurent la parole définitive, complète et multiple qui convenait aux temps nouveaux. Elle était intimement liée, comme les deux premières, et plus qu'elles, à des p.63 matériels. Et le Nazaréen se faisait à part lui une curieuse remarque :

La première parole, fruste, était associée à une technique simple sans doute la plus archaïque, qui avait donné le vêtement élémentaire: la fibre. Cette fibre non nouée, non tissée, se coulait selon une ligne serpentante, selon, pourrait-on dire, une seule dimension.

La seconde parole, plus déliée, émanait du tissage, poursuivi sur une chaîne large recevant des fils perpendiculaires, selon une surface, c'est-à-dire deux dimensions. 
Enfin la troisième parole, claire et parfaite, se développait dans un réseau cylindrique au travers duquel passait un p.64 serpentin de cuivre, c'est-à-dire selon un volume, selon trois dimensions. L'étranger pensait aussi que ces trois techniques dont la ligne ondulée ou en chevrons était le cheminement fondamental, étaient marquées chacune par trois phénomènes :

- humidité des fibres, garantissant la fraîcheur nécessaire à la procréation,

- lumière du tissage, travail diurne interdit de nuit sous peine d'aveuglement,

- sonorité du tambour.

On passait aussi, du point de vue matériel, de l'écorce dégrossie au fil de coton, du fil aux lanières de cuir et au ruban de cuivre.

Ogotemmêli, durant les entretiens de ce jour, avait semblé distrait. II devait être relié par des lignes invisibles à toute la gesticulation commerciale et politique de la région. II devait suivre aussi par la pensée les personnes de confiance qu'il avait chargées de quelque achat. Entre autres, l'intime qui devait lui apporter du tabac.

La conversation de la matinée avait été plusieurs fois marquée par cette préoccupation, et des allusions aux services insignes que rend le tabac avaient sectionné l'exposé concernant le troisième verbe.

Dans la soirée, la préoccupation avait fait place à une imperceptible impatience : Ogotemmêli avait bien reçu son tabac, mais il eût souhaité le préparer. Car il convenait de réduire les feuilles en poudre en les frappant à petits coups sur une pierre et en les écrasant comme des graines.

Finalement l'aveugle n'y tint plus et fit remarquer qu'il aurait une amende.

- Une amende ?

- N'est-il pas interdit de frapper le sol de nuit ?

L'étranger avait en effet oublié cette règle : de nuit, le silence doit régner, et surtout aucun coup ne doit retentir contre le sol; dans les pierres creuses ou dans les 
mortiers, aucun grognement des moutures ne doit être entendu.

Le tabac, éclaircisseur d'idées, valait bien un arrêt du débit cosmogonique.

Le Blanc prit congé. II fit un détour par les ruelles enchevêtrées et s'enfonça dans celle qui coupait par le travers les cinq quartiers du village. C'était I'heure de fatigue d'après marché, l'heure des rassasiements, des bonnes affaires ruminées. Dans toutes les cours, on digérait une journée de paroles. 


\section{Dixième journée}

\section{Le verbe et le métier à tisser}

@

p.65 La veille, l'Européen n'était pas allé chez Ogotemmêli. Il avait voulu donner, dans d'autres milieux, des coups de sonde pour les vérifications, les mises au point indispensables. II s'était rendu chez Ongnonlou, homme de poids habitant le quartier de Dodyou, père du prêtre non encore intronisé du sanctuaire élevé à Ogoïné.

Chez Ongnonlou, on entrait par une pièce basse donnant sur une remise sous auvent, laquelle s'ouvrait sur le fumier. Toutes les maisons dogon semblent construites pour des gens de petite taille. Koguem s'était assis sur une pierre, puis sur un poulailler en forme d'ombilic où gloussait une couveuse. Ongnonlou était accroupi sur un bois posé en travers du fumier qui tenait toute la cour. L'Européen siégeait sur une touque de fer blanc, objet honorable. Dix-sept moutons et agneaux passaient et repassaient sans arrêt, comme des vagues battant une grève. Aucun d'eux ne se décidait à entraîner les autres par la ruelle vers les lieux de liberté. De temps à autre, le jusant de laine se bloquait dans un angle, laissant un répit aux hommes.

Ongnonlou s'était révélé excellent informateur. D'imperceptibles réticences apparaissaient bien quand la conversation abordait quelque rivage réservé, mais dans l'ensemble l'homme avait donné de magnifiques recoupements.

Les moutons passaient comme dans un goulet entre le Blanc et Koguem, distants de moins de deux coudées. Le flot s'évasait un instant, se rétrécissait à nouveau entre deux femmes qui filaient, hésitait sur lui-même et finalement s'engouffrait dans l'étroite porte de la maison d'habitation. Mais les femmes et Ongnonlou étaient si occupés à parler au Blanc, à le scruter du coin de l'œil, à cuver sa présence, qu'ils ne pensaient pas aux bêtes. 
Ongnonlou exposait le mystère de la mort, la parade des hommes et l'invention des matériels. Soudain il dressa l'oreille; son visage sombre, un peu crispé en un sourire aimable, se détendit et se tourna vers l'arrière-cour. L'homme bondit p.66 vivement en criant et en rattrapant son bonnet phrygien qui glissait. II se précipita, suivi des femmes lâchant les pilons, dans la porte basse béant sur l'ombre du fond. Un grand bruit s'éleva et trois nuages de poussière giclèrent de la porte et des jours latéraux ménagés dans la paroi : un à un les moutons s'éjectèrent et se tinrent cois, éberlués de lumière. Ongnonlou surgit dans le flot de laine, crachant et maugréant, le poussa dans une impasse entre mur et grenier et boucha l'étranglement de l'entrée avec un grand panier.

Ayant fermé la porte de la maison, les acteurs revinrent l'un à sa conversation, les autres à leur mortier.

Soudain, une femme s'arrêta et Ongnonlou s'étant figé un instant, se précipita sur la porte et s'y engouffra. Nouveaux cris et poussières: le plus gros des béliers, que son maître avait enfermé dans sa précipitation, déboucha ; les prisonniers, défonçant le panier, le rejoignirent et tous, chargeant entre le Blanc et Koguem, envahirent l'entrée, s'y arrêtèrent net, urinèrent et se mirent à somnoler.

II y eut un quart d'heure de paix durant lequel Ongnonlou expliqua le symbolisme de la crosse-siège utilisée aux grandes initiations.

Mais deux agneaux étant restés sur le fumier et ne trouvant plus de nourriture, bêlèrent. Les quinze autres rechargèrent aussitôt.

La cour d'Ogotemmêli, comparée à ce chaos, était pleine d'un charme paisible.

Comme les entretiens précédents avaient démontré la prééminence du tissage, l'Européen demanda à l'aveugle de lui parler de cette technique. II avait auparavant revu, pour la vingtième fois depuis qu'il venait en Afrique, un métier en mouvement et des fileuses.

L'armature de l'appareil, faite de quatre bois verticaux enfoncés en terre et reliés par des tiges horizontales, 
délimite un prisme où un homme assis et ses instruments tiennent à l'aise. La chaîne, étroite et interminable, part d'un traîneau couvert de pierres, passe sur un support horizontal et se présente inclinée au tisserand. Dans le secteur actif compris entre ce support et l'ensoupleau autour duquel vient s'enrouler la bande terminée, la chaîne passe dans des lices puis dans la grille du battant, p.67 dont les dents sont faites d'éclats de roseaux. Les lices, mues au pied, alternent à l'aide d'une poulie accrochée à une traverse de l'armature; le battant est balancé au bout d'une cordelette fixée à ses extrémités.

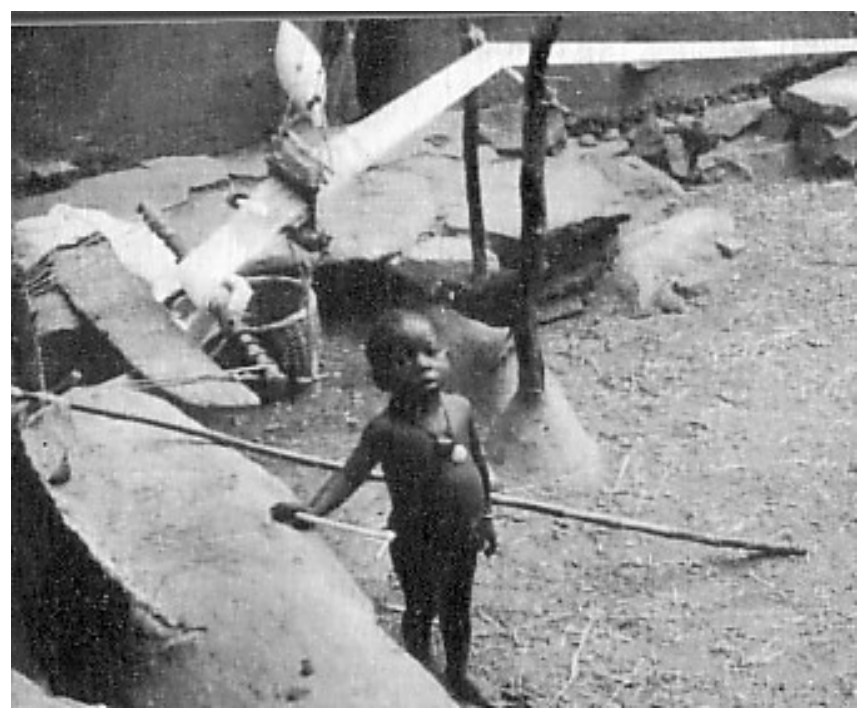

La navette, faite d'une augette de bois dont les extrémités sont taillées en pointe, est lancée à la main.

Le filage, labeur de femme, est pratiqué avec un fuseau composé d'une mince tigelle dont l'une des pointes est enfoncée dans une fusaïole en forme de grosse bille de terre séchée. De la main droite, la femme imprime un mouvement de rotation à son instrument, et égalise le fil au-dessus d'une peau qui protège le tout de la poussière. De la gauche elle tient la masse de fibres d'où part le fil. Elle sèche ses doigts avec la cendre blanche d'une petite calebasse.

Auparavant, elle aura égrené le coton brut en roulant sur les fibres posées sur une pierre plate une tige de fer longue d'une palme, renflée en son milieu. Le cardage se fait avec une baguette. Les graines sont conservées par la femme qui les met à sécher jusqu'aux semailles suivantes, 
dans la maison, sur le linteau de la deuxième porte, symbole de son sexe et de l'humidité propre à la germination.

- La fileuse, dit Ogotemmêli, est le Septième Nommo. Le fer à égrener est, comme la masse du forgeron, symbole du grenier céleste. II est donc en rapport avec les graines. Le bâton pour carder est la baguette avec laquelle le forgeron jette de l'eau sur son feu pour le diminuer.

La peau sur laquelle file la femme est le soleil, car le premier cuir utilisé ainsi a été celui du soufflet de forge qui avait contenu le feu solaire.

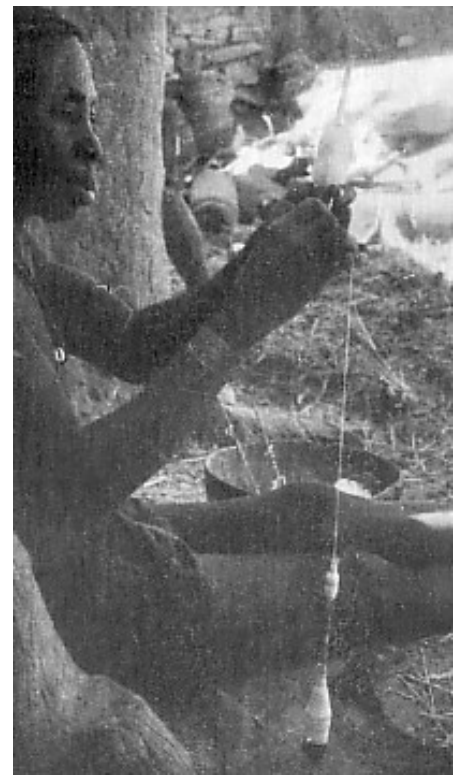

Le tournoiement du fuseau est le mouvement de la spirale de cuivre qui propulse le soleil, spirale que figurent souvent les lignes blanches ornant l'équateur de la fusaïole. Le fil qui descend de la main de la femme et qui s'enroule autour du fuseau est le fil de la Vierge, le long duquel est descendu le système du monde.

Le fuseau lui-même est la flèche transperçant la voûte du ciel et à laquelle est accroché ce fil ; il est aussi la flèche enfoncée dans le grenier céleste.

La calebasse contenant la cendre pour sécher les doigts est le grand Nommo femelle; elle rappelle la calebasse coiffant le bélier céleste, avatar du grand Nommo mâle. La cendre est le ${ }_{\text {p.68 }}$ bélier lui-même et aussi sa semence; le coton bouffant d'où part le fil est sa laine. 
L'écheveau de fil qu'on étend pour former la chaîne est le chemin du Septième Nommo ancêtre; il est aussi ce Nommo lui-même sous sa forme de reptile. La grande bobine dévidée pour ce travail est le soleil roulant dans l'espace.

- Le métier à tisser était-il avec la forge sur le système du monde?

- Oui ! mais symboliquement. L'escalier nord du grenier représentait la chaîne; les quatre poutrelles sortant de la façade à hauteur de l'étage étaient les quatre montants. La poitrine du tisserand était la porte du grenier; la navette est la serrure, qui va et vient. La poulie est le bois triangulaire qui maintient les deux pièces de la porte.

Le métier à tisser, orienté de telle sorte que l'artisan travaille face au sud, est la maison du Septième et le bâti est fait de l'ensemble des huit ancêtres: les quatre montants verticaux (mâles) délimitent la chambre de repos; les quatre montants horizontaux (femelles) dessinent la terrasse.

Le métier est aussi la tombe du Lébé dans le champ primordial. Le siège est le terre-plein sur lequel le cadavre fut déposé avant l'inhumation. Les lices ouvrent et ferment la porte de la tombe, dans laquelle pénètre et dont sort le Septième Nommo, sous la forme du fil de trame figurant un reptile dont la langue est la navette : à l'appui du pied droit correspond le lancé par la main droite, image de l'entrée; l'appui et le lancé gauches sont la sortie du serpent. La serrure de la porte est la poulie à laquelle sont pendues les lices.

Les lices, comportant chacune 80 fils, sont le symbole des mâchoires du Septième. Le peigne, fait de 80 fentes, marque le passage des 80 chefs de famille issus des huit ancêtres et représentés par les 80 fils pairs et les 80 fils impairs.

La bande enroulée sur l'ensoupleau et à laquelle s'appuie le ventre du travailleur figure le serpent déglutissant le cadavre. Car le tisserand est le symbole du Lébé, mort et ressuscité. 
L'œuvre type qui sort du métier est la bande destinée à former la couverture des morts. Elle est faite de carrés noirs et blancs alternés composés par les deux plans de 80 fils pairs et impairs de la chaîne et par 80 va-et-vient de la trame. La couverture compte huit bandes cousues qui devraient comporter chacune quatre-vingts carrés.

p.69 Mais on ne les tisse que de vingt éléments.

La coopération de l'homme et de la femme, lors de la conservation des graines, lors des semailles et de la culture du coton, a le même sens que le filage et le tissage, symboles de l'amour.

- Filer le coton, tisser le vêtement, I'homme et la femme qui rentrent à la maison pour se coucher et procréer, c'est tout un.

Le tisserand, qui représente un mort, est aussi le mâle qui ouvre et ferme la femme, figurée par les lices. La procréation est matérialisée par les fils tendus.

- Les fils de coton des tisserands, les nombreux hommes de ce monde, c'est tout un.

La confection de la bande est l'image de la multiplication des hommes.

- Le métier à tisser, conclut Ogotemmêli, est la tombe de la résurrection, la chambre des époux et la matrice prolifique.

Restait la question de la parole, fond même de la révélation du tissage.

- La parole, dit l'aveugle, est dans le bruit de la poulie et de la navette. Le nom de la poulie signifie « grincement de la parole». Tout le monde entend la parole; elle s'intercale dans les fils, remplit les vides de l'étoffe. Elle appartient aux huit ancêtres; les sept premiers la possèdent, le septième en est le maître ; et elle est le huitième.

II répétait :

- Les paroles des sept ancêtres remplissent les vides et forment le huitième.

La parole, étant eau, chemine selon la ligne chevronnée de la trame. 
- Le tisserand chante en jetant la navette et sa voix entre dans la chaîne, aidant et entraînant celle des ancêtres. Car il est le Lébé, c'est-à-dire celui de la huitième famille, donc parole lui-même.

Et l'aveugle se mit à murmurer, dans une langue archaïque, deux versets d'un chant de funérailles que psalmodient les artisans d'Onndom lorsqu'ils tissent les couvertures des morts.

... la paresse à la nuque informe !

Un seul tambour pour quatre-vingts trouvères !

Le Nazaréen s'en retourna vers la fin du jour, par le quartier p.70 de Dodyou-Oreil, au sud d'Ogol-du-Bas, avancé comme un cap dans l'étang de Bananga. Sur la petite place, de toutes parts défoncée par les angles des maisons, face à l'abri du conseil, s'entassaient quelques métiers. Près d'eux s'élevait un ombilic de terre, autel du Nommo Septième.

Vide de ses hommes et de ses chaînes de fils, la maigre forêt de piquets reliés au sommet par des bois sans grâce semblait une misère repoussée dans une encoignure. Les tisserands, selon la règle, avaient arrêté net leur travail dès que le soleil avait touché l'horizon.

Comme la forge, le tissage est labeur de jour, car la chaîne et la trame symbolisent un être de lumière et de paroles, car le fuseau de la fileuse tourne sur un soleil de peau et sa calebasse de cendres blanches est un soleil fécondé. II convient donc que l'astre luise sur le métier. Tisser la nuit serait composer une bande de silence et d'ombre. Qui tisserait après le coucher du soleil, après que Dieu a fermé la porte du monde, deviendrait aveugle. 


\section{Onzième journée}

\section{Le verbe et les travaux des champs}

- C'est une poule que j'ai achetée en commun avec Amadigné et Gana, disait Koguem.

Koguem avait prêté main forte au premier nommé pour tenter de capturer la bête qui s'était échappée. Après une course folle dans les champs et la rocaille, la poule s'était blottie sous une roche interdite contenant des objets sacrés.

Amadigné s'était donc assis sur les lieux, en attendant que la soif chasse son bien hors du refuge.

On avait quitté le factionnaire en émettant des vœux de succès. Sur l'éperon boursouflé d'Ogol-du-Haut, des moutons, alourdis par deux mille ans de domestication, sautaient courageusement les rochers, la queue en trop ballottant au hasard, en débraillé. Ils fuyaient un berger minuscule couvert d'un chapeau à diamètre de bouclier, armé d'un bâton et d'une gourde-bouteille.

p.71 Laissant Ogol-du-Haut à gauche, on évitait à droite de parler aux femmes écrasant le fruit du Lannea acida, car on eût compromis, par la voix, la limpidité de l'huile. Puis on sautait par une marche rocheuse dans le champ du Hogon, prêtre du Lébé. On laissait en arrière la petite plaque pelée qu'aucune houe ne retourne et qui symbolise la tombe du Lébé. On apercevait, à gauche, escaladant les déversoirs de grès et pénétrant dans le quartier Guèndoumman, la piste luisante par laquelle le Lébé, sous forme de grand serpent brillant, se rend chaque nuit dans le sanctuaire de ville. Plus loin, au bout du champ, se devinait la caverne où il demeure durant le jour.

Il fallait passer aussi à hauteur du tas de pierres qui est l'un des autels principaux du Lébé.

Sans compter les dessous de baobabs qualifiés qui font autant de lieux-dits, il fallait, pour se rendre du campement à la maison d'Ogotemmêli, piétiner ou frôler 
cinq champs ou rochers nommés et strictement délimités : Tenné, Ba Diguilou, Goummo, Ogo Digou, Toummogou. Entré dans Ogol-du-Bas, on écornait trois quartiers: Amtaba, Guinna, Tabda. A vol d'oiseau, du point de départ au point d'arrivée, il n'y avait pas deux cents mètres.

Et chaque surface pouvait se détailler en places restreintes de nom connu. Surtout dans les superficies couvertes d'habitations et de places publiques, on louvoyait entre les interdits; à scruter du haut des airs le village d'Ogol-du-Haut, la bousculade des lieux-dits, pierres, fentes, autels et arbres nommés eût paru inextricable.

Encore était-on en pays de plateau. Dans les falaises, une muraille rocheuse n'est pas une limite : c'est un sol qui se dresse ; les lieux s'étagent à la verticale, certains surplombant les autres, ce qui poserait d'insolubles problèmes de représentation cadastrale.

C'était donc un morcellement infini, une mise au carreau du sol sous les pieds des hommes, comme s'ils l'avaient organisé pierre à pierre, motte à motte, l'imprégnant de leur vie, l'imprégnant de noms, le reconstruisant à leur image, donnant à chaque établissement, symboliquement, l'ordonnance de la première terre organisée autour du point de chute du grenier céleste.

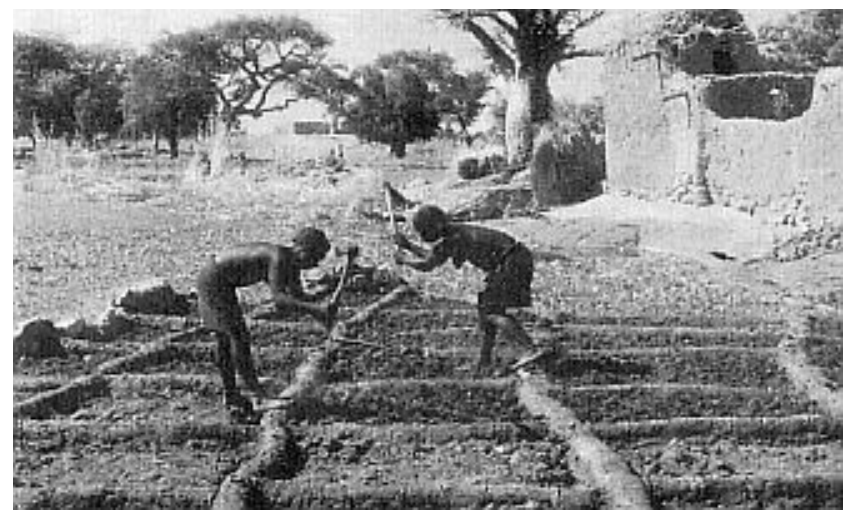

La « mise au carreau » du terrain dogon

En pays de plaine, le sol cultivé est un damier régulier de carrés formés par des diguettes de moins d'une palme de large, p.72 boursouflures plutôt que levées de terre. En pays de rochers, où la terre est tourmentée, les parcelles 
sont irrégulières et, dans Sanga, on cite les champs de Lulli pour être partagés selon la règle.

Mais la mise au carreau atteint son paroxysme dans les jardins d'oignons qui s'étendent à la saison sèche, où les parcelles, d'une à deux coudées de côté, forment une suite de bassins réguliers bordés de levées de terre nettes.

Ainsi l'eau des pluies, ou de l'arrosage, est-elle retenue au pied des plantes, et le sol défendu contre le ruissellement.

L'agencement de base est celui du champ.

- La culture, dit Ogotemmêli, se fait par carrés de huit coudées de côté, entourés d'une levée de terre.

Car la surface de la parcelle unitaire est celle de la terrasse du grenier céleste. Et la parcelle est orientée, chaque côté faisant face à un point cardinal.

- La manière ancienne de cultiver est celle qui rappelle le tissage. On commence du côté nord, en allant de l'est vers l'ouest, puis en revenant de l'ouest à l'est. A chaque ligne, on plante huit pieds et le carré comprend huit lignes rappelant les huit ancêtres et les huit graines.

De plus, à l'intérieur de la ligne, le cultivateur progresse tantôt d'un pied, tantôt de l'autre, changeant sa houe de main à chaque pas: quand le pied droit est en avant, la main droite, sur le manche, est la plus près du fer et inversement au changement de pied.

La culture étant un tissage, le champ est comme une couverture à huit bandes, les carrés noirs et blancs étant figurés par l'alternance des buttes faites à chaque pied et des vides correspondants. Une butte et son ombre forment un carré noir.

L'ensemble des champs, autour du village, et le village lui-même, sont aussi une grande couverture. Les maisons à terrasses éclairées par le soleil sont les carrés blancs; les cours d'ombre les carrés noirs. Les ruelles sont les coutures unissant les bandes.

- Si un homme défriche et ouvre de nouveaux carrés, s'il construit des habitations, son travail est comme un tissage. 
Or le tissage étant une parole, fixant la parole dans le tissu par le va-et-vient de la navette sur la chaîne, la culture, par le mouvement de va-et-vient du paysan sur les parcelles, fait pénétrer le verbe des ancêtres, c'est-à-dire l'humidité, dans la terre p.73 travaillée, fait reculer l'impureté de la terre, étend la civilisation autour des lieux habités.

Mais si cultiver est tisser, il convient de dire que tisser est cultiver. La partie sans trame de la chaîne est la brousse. La bande terminée est le symbole du champ cultivé. Les quatre poteaux du métier sont les arbres et les broussailles qui sont abattus avec la navette, symbole de la hache. Tirer à soi le peigne, c'est tirer le bois pour en faire des fagots.

Et passer le fil de la trame, c'est faire avancer la vie, l'eau et la pureté dans les régions désertes. 


\section{Douzième journée}

\section{Le verbe, la parure et l'amour}

- C'est le fils de Mênyou, dit le grand Allaye; depuis que je lui ai donné du lait, il vient au camp. Il a la tête plate, comme son père.

Ce disant, il lui passa la main sur le crâne, pour appuyer sa description.

Dès le matin, les enfants nus cernaient le camp, dans l'attente des cent miracles qui jalonnent la vie ordinaire des Nazaréens. Ils attendaient également le départ chez Ogotemmêli pour s'emparer des menus objets et ahaner en triomphe devant le Blanc qui ne pouvait pas même conserver son crayon: un être minuscule le portait verticalement, comme une flèche pointée vers le ciel.

La caravane déambulait par les voies ordinaires avec des à-coups provoqués par les porteurs qui se mouchaient dans leurs doigts et s'essuyaient soigneusement à la plante de leur pied gauche. Elle s'étirait dans le champ du Hogon, se coulait dans la ruelle séparant Guinna d'Amtaba et abandonnait, comme un flot vomisseur d'épaves, son menu chargement sur les rochers et pierres creuses de la cour. Puis les grêles corps s'évanouissaient dans Tabda.

- Le premier vêtement tissé, commença Ogotemmêli, fut le pagne de la femme. On l'a cousu lorsqu'on lui a enlevé les fibres.

p.74 Cette pièce, qui a quatre bandes, signe de la féminité, se porte dans le sens transversal, les coutures horizontales. Elle cache le corps entre nombril et genoux et s'enroule sur elle-même sans système de fermeture.

- La femme porte un pagne ouvert, car son sexe est ouvert. S'il en était autrement, elle ne pourrait jamais être fécondée. 
Le second vêtement fut le pantalon de l'homme, comportant trois bandes de fond (chiffre masculin) qui passent entre les jambes, couvrant ventre et reins, et trois bandes de chaque côté pour les cuisses. La taille est donc entourée de quatre fois trois bandes, chiffres de la féminité et de la masculinité.

Le pantalon est fermé à l'aide d'une cordelette, car le sexe de l'homme est clos. Le nœud de fermeture est un symbole de l'amour, le bout droit de la corde étant I'homme, le gauche la femme.

Le troisième habit fut la lévite dite «à manches» composée de quatre longues bandes de dos et de quatre devant, de trois bandes de chaque côté.

Les quatre bandes de dos rappellent les quatre ancêtres mâles ; les quatre antérieures les ancêtres femelles.

- Car l'homme cherche la femme qu'il veut devant lui pour l'union.

Les trois bandes latérales sont le chiffre du mâle.

La quatrième chose tissée a été la couverture des morts, faite de huit bandes de carreaux noirs et blancs qui sont les huit familles multipliées et reproduisent l'agencement des terres productives.

Elle est ainsi un symbole de vie et de résurrection. Le mort y est replié un instant comme un fœtus dans la matrice, pour y être retrempé dans le réseau des vivants et des champs pleins de germes.

En cinquième vint le bonnet à deux bandes, symbole du couple. II a été inventé lors de l'organisation du monde et, à l'origine, il était réservé au Hogon, c'est-à-dire au chef.

- A l'origine, les vêtements étaient blancs, couleur du coton. Puis les hommes eurent peur de pâlir et de ressembler à l'étoffe. Ils la teignirent en jaune safran, couleur terre, pour ressembler à leur sol. Ensuite on a inventé le noir-bleu pour la couverture des morts, pour la première couverture qui enveloppa le corps du Lébé.

Les gens en discutaient et l'accord fut long à établir. Mais p.75 cette teinte fut retenue, car c'était elle qui ressemblait le plus au charbon, lui-même rappelant la 
peau des hommes. Pourtant, les hommes d'autrefois étaient dits banu, c'est-à-dire rouges, ainsi qu'on appelle encore les peaux claires. Mais on pensa aussi à la peau du forgeron, noircie par la poussière du charbon.

Ogotemmêli n'attachait pas autrement d'importance à ces couleurs et à ces chiffres. C'étaient là choses simples.

- Le vêtement, dit-il, le vêtement de l'homme, c'est le Nommo Septième.

Il entendait que mettre un vêtement (soy) c'était se couvrir des paroles (so) du Nommo de rang sept (soy). II entendait aussi, et surtout, que mettre des parures (sey), pour une femme, c'était se travestir en Nommo Septième.

II commença par une déclaration inattendue :

- La bouche de la femme, c'est le matériel à tisser.

Et il rappela l'enseignement donné par le Septième Nommo enfoncé dans la terre, ouvrant au soleil sa bouche-fourmilière d'où partaient les fils de chaîne :

- Les dents limées en pointes sont les dents aiguës du génie, dans lesquelles passaient les fils. La boucle de cuivre accrochée au centre de la lèvre inférieure est la bobine de fil. Les quatre boucles (chiffre féminin) des ailes du nez forment la poutre du métier, la pendeloque de perles de la cloison étant l'axe pivotant.

Si les femmes - et les hommes - se liment les dents, c'est pour rappeler le passage des quatre-vingts fils pairs et des quatre-vingts fils impairs, symboles de la multiplication des familles. Ils marquent ainsi leur respect pour la parole supportée par ces fils, pour la parole humide sortant de la bouche, pour l'eau qu'on boit, essence du maître du verbe. Et la ligne de chevrons que forme chaque rangée est aussi le chemin de l'eau et de la parole.

- C'est aussi toute la parure du génie de l'eau qu'ont les femmes.

II voulait dire que les parures des femmes rappelaient celles du Nommo et surtout certains détails de son corps vert.

Le diadème de perles vertes arrêté aux tempes est le front brillant du Nommo; le collier, les rides de son cou. 
Les deux perles rouges du coin des ailes du nez sont ses yeux.

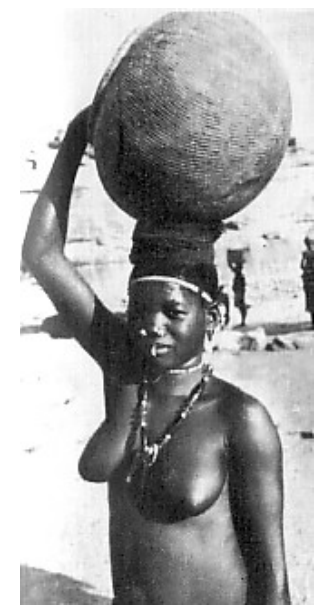

Femme parée des ornements du Nommo

Les bracelets de cuivre des poignets et de la saignée des bras ont la forme et tiennent la place des os circulaires qui font ${ }_{\text {p.76 }}$ gonfler la peau du génie en cette partie des membres. En effet, ses bras sont flexibles quoiqu'ils soient munis d'os longs continus. Ces bracelets sont au nombre de quatre, chiffre de la femme.

Le rang de perles, ou l'anneau de cuivre, de la cheville droite rappelle l'os circulaire du bout de la queue du génie. Régulièrement, la cheville gauche ne devrait pas être ornée.

A l'index, à l'auriculaire et à l'annulaire sont passés les anneaux de cuivre, car seuls ces doigts, dans la main palmée, présentent des bourrelets circulaires à la place des articulations. Ce sont ces bourrelets qui sont imités. Au contraire, le pouce et le majeur restent libres, car, chez le génie, ils sont lisses et souples, ce qui ne permettrait pas à un anneau de s'y fixer.

On ne devrait pas mettre d'anneau d'orteils, le génie n'ayant pas de pied.

Ogotemmêli passa ensuite à l'une des ouvertures du corps les plus importantes: I'oreille.

L'oreille est un sexe double, pour l'homme comme pour la femme. Le pavillon est la verge qui défend le conduit 
auditif, image du sexe féminin. Les pendeloques triangulaires, de couleur rouge, sont les testicules. Les huit boucles de cuivre en forme de croissant obèse accrochées sur le pourtour de l'hélix sont les huit ancêtres.

Le rôle de l'oreille dans la génération devait être évoqué dans un autre entretien.

Quant aux mutilations tégumentaires pratiquées par les femmes, elles reproduisent celles du Nommo. Elles consistent le plus souvent en deux lignes d'incisions dont l'une, verticale, va de la hauteur des seins au nombril et dont l'autre, horizontale, barre le ventre de chaque côté de ce dernier. Ces lignes sont faites d'une double rangée de courtes incisions en biais formant une suite de $V$ sans pointe.

Aux tempes sont pratiquées quatre incisions parallèles (chiffre féminin).

Chacune de ces incisions est un sexe taillé à l'aide d'un rasoir qui symbolise le membre viril. Et toutes sont toujours humides puisqu'elles sont ouvertes au nom du génie de l'eau.

Ainsi la fécondité de la femme est-elle multipliée.

- Et la coiffure, a-t-elle un sens ?

- p.77 Les cheveux de la femme, dit Ogotemmêli, sont ceux du Nommo. La pointe qui sert à les séparer est comme le peigne du métier à tisser qui sépare les fils de la trame. Dans la coiffure dite Kou tari, on devrait avoir 60 raies au milieu et 10 de chaque côté, soit 80 , pour rappeler les huit familles. Mais ce n'est pas possible.

D'ailleurs, les règles de la parure ne sont pas strictes et rares sont les femmes qui portent tous les ornements.

Sur le rôle social du vêtement, Ogotemmêli s'étendit longuement.

- Le pagne est serré, dit-il, pour qu'on ne voie pas le sexe de la femme. Mais il donne à tous l'envie de voir ce qui est dessous. C'est à cause de la parole que le Nommo a mise dans le tissu. Cette parole est le secret de chaque femme et c'est cela qui attire l'homme. II faut qu'une femme ait des parties secrètes pour qu'on les désire. Une 
femme qui se promènerait nue au marché, personne ne courrait derrière elle, même si elle était d'une grande beauté. Si elle n'a rien sur les reins, le cœur de l'homme ne la désire pas. La femme ornée de parures, les hommes la veulent même si elle n'est pas belle. Une femme très belle sans ornements, les hommes s'en détournent.

II réfléchit quelques instants :

- Être nu, dit-il, c'est être sans parole.

Durant le retour au camp, Koguem commentait ce qui avait été dit sur la parure.

- Un vêtement, remarqua-t-il, contente non seulement celui qui le porte, mais encore celui qui le voit. Et c'est vrai qu'on est attiré par la parure de la femme. Mais la femme aussi est attirée par l'homme bien vêtu.

Et il raconta comment le désir de parure privait le pays de nombreux jeunes gens. Tous les ans, en effet, l'Administration déplore, dans les Falaises comme ailleurs, le départ massif de travailleurs en pleine force qui s'en vont à la Côte-de-l'Or pour y gagner un pécule, qui s'y fixent parfois pendant des années, qui parfois aussi y meurent.

- Les jeunes gens qui partent en Gold Coast, ceux qui s'en vont à Bamako ou ailleurs, c'est principalement pour les habits, p.78 dit-il. Ils gagnent de l'argent et ils dépensent tout, la veille du retour, en achats de boubous, de turbans, de parapluies. Quand ils reviennent, ils se pavanent au marché et aux enterrements. L'habit les aide à se marier. Car plus un homme a d'habits, plus ses habits sont élégants, et plus les femmes le désirent.

Lui aussi préférait une femme ordinaire mais ornée de parures - le vêtement proprement dit n'entrant guère en ligne de compte - à une femme jolie, sans perles ni bracelets.

- Ogotemmêli a raison, conclut-il, la parure est un appel à l'amour; elle remplit son office d'attirer l'homme, comme l'a voulu le Nommo. Et s'il y a un rapport entre les 
parures et l'amour, c'est parce que les premières de toutes, celles du Nommo femelle, étaient dans la poterie centrale du grenier céleste sur lequel descendit le forgeron. Or cette poterie est le symbole de la matrice du monde.

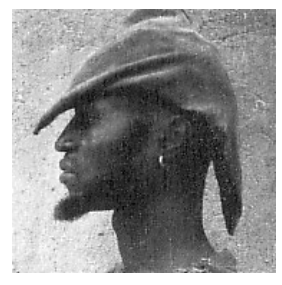

@ 


\section{Treizième journée}

\section{La Forge}

Dans le chaos rocheux formant au sud la grand-place d'Ogol-du-Haut, sur un coin exigu de terre, se cache la forge. Sur un plan vaguement circulaire, elle élève des pans de murette de pierres sèches non jointes, criblée de jours. Sur cet appui s'étale une couche maigre de branchages soutenue en son centre par un poteau et qui n'empêche pas le soleil de faire mille taches dans la pénombre.

Sans ordre apparent, les outils et appareils sont disposés sur le sol, en pleine poussière. Bien que l'artisan vienne de partir, l'atelier semble abandonné depuis des années. Le double soufflet, peaux flasques, braque ses deux conduits sur le feu éteint. L'enclume, comme une énorme épine de fer, est plantée en terre, enfoncée dans une traverse enfouie dans le sol. Contre elle, une pince et quelques bouts de fer informes. La masse, symbole de la main palmée du génie de l'eau, est invisible, cachée ou emportée par le forgeron. Contre le mur, un four, sein de terre glaise au bas duquel s'ouvre un tunnel qui p.79 débouche en cratère au sommet. Tout près, une pierre creuse dont l'eau s'est évaporée.

Écrasé de silence et de soleil, l'atelier apparaît dans toute sa pauvreté. La technique qui a révolutionné le monde, qui s'est précipitée du ciel, dont les outils ont brisé les membres du premier artisan, qui met en œuvre le feu, fragment de soleil, tient dans ce délabrement.

L'Européen avait tenu à faire ce détour avant de mettre Ogotemmêli sur le sujet. II voulait, après avoir étudié le tissage, technique prestigieuse, la première en date, support de la parole, connaître de lui le sens du plus fruste des outillages.

- La forge, dit l'aveugle, est comme une maison d'habitation et comme une personne dont la tête est le four et les deux bras la soufflerie aux deux tuyaux. 
Sur le champ primordial, dans lequel atterrit le grenier-volant, la forge fut installée au nord, à la limite du terrain que ses houes allaient déchirer. Pour cette raison, I'atelier est aujourd'hui édifié au nord de la grand-place, elle-même ménagée au nord du village.

- Vous pouvez voir, dit Ogotemmêli en jetant la tête de côté, vous pouvez voir par-dessus le mur.

La grand-place d'Ogol-du-Bas s'étendait en effet derrière le grenier effondré de l'arrière-cour de gauche. On voyait le haut rocher central, la meule carrée de la maison du conseil, la pierre cubique dite «pierre du brave » et, sur la gauche, en plein nord, une forge, sœur de celle d'Ogol-du-Haut.

Mais ici la règle était respectée, l'autre village présentant une disposition diamétralement opposée.

- A l'origine, dit l'aveugle, le forgeron n'avait pas tous les outils qu'il possède aujourd'hui. II n'avait pas le marteau emmanché, ni la lime, ni la pince. Le fer rouge était pris à la main et c'est une chose qu'on peut voir encore de nos jours lorsque les forgerons se réunissent pour les funérailles. En chantant les chants des morts, ils prennent dans la main un fer rouge, pour rappeler la pratique des premiers artisans.

Le principal outil de main est la masse :

- Le grenier céleste était une masse. Tout le monde croit que c'est dans cet outil que les graines sont descendues des cieux. La masse est la main palmée du génie de l'eau.

p.80 Le bras est le manche conique, la main elle-même est la partie quadrangulaire avec laquelle on frappe.

- La masse est aussi le corps entier du génie de l'eau, du grand Nommo mâle du ciel. Deux côtés opposés forment les bras; les deux autres le dos et la poitrine. Le manche conique est la queue de reptile qui termine le corps vers le bas.

Quant à l'enclume, qui ressemble vaguement à une enclumette de faucheur, elle est la forme femelle de la masse et représente le grand Nommo femelle. Sa table, très étroite, est carrée et son corps se termine en pointe 
mousse. A son extrémité inférieure, elle présente souvent une petite cavité, rappel du rôle joué par la masse, c'est-à-dire par le grenier, dans l'organisation du monde: ce creux est le symbole de l'intérieur de l'édifice, rempli d'organes et de graines.

La traverse dans laquelle est fichée l'enclume est faite d'un tronc moyen d'une coudée de longueur, grossièrement équarri. Ce bois, noyé en terre, est orienté nord-sud comme devraient l'être tous les lits des hommes.

- Le bois de l'enclume est le lit des deux grands génies de l'eau. Quand la masse frappe le fer, le couple s'unit.

Les deux poteries du soufflet sont modelées dans de l'argile à laquelle on mêle des poils de mouton blanc. On obtient ainsi une plus grande cohésion de la matière qui n'est pas cuite, mais lentement séchée à l'air. Les poils de mouton sont l'image de ceux du bélier céleste, avatar du Nommo.

Les deux poteries sphériques sont le symbole du soleil, car elles sont de même forme et les poils que contient leur glaise viennent de la toison du génie, toison de cuivre, excrément de soleil. Elles sont aussi liées à l'astre par les peaux qui les coiffent et dont le maniement envoie l'air dans le foyer. L'une d'elles, en effet, a contenu le morceau de soleil dérobé par le forgeron avant son départ et a de ce fait acquis la qualité de feu. L'autre, brandie au-dessus de la tête du fuyard, et déjà gagnée à l'ignité par son contact avec sa jumelle, a reçu sans dommage la décharge des deux coups de foudre.

Les tuyaux de terre sèche unissant les poteries au foyer donnent passage à l'air refoulé par les peaux. Et cet air est un souffle de soleil qui anime le feu.

Dans la pierre creuse, le forgeron puise avec un bâton l'eau qu'il jette sur le feu pour le réduire. Dans cette flaque demeure le Nommo, comme dans toute eau. II s'y déplace en nageant ${ }_{\text {p.81 }}$ et sa nage est rythmée par les coups sur l'enclume et par les halètements alternés du soufflet.

Le Blanc connaissait déjà depuis des années le rôle prestigieux des bruits de forge. II avait assisté maintes fois à des rites durant lesquels, à point nommé, un forgeron frappait la roche avec sa masse ou son fer d'enclume. En 
faisant sonner le fer dans lequel l'artisan mythique apporta tant de bienfaits, il rappelait aux hommes la puissance suprême d'Amma et du Génie de l'eau, il aidait leur prière, il la fortifiait de son bruit ; il apaisait les courroux possibles des êtres célestes par cette confession de leur prééminence. Dans les querelles entre les hommes, il venait au milieu d'eux, masse en main, frapper les pierres, mettant une note divine dans les désarrois, calmant les colères.

Ogotemmêli, questionné sur ces points, ne répondit pas et suivit son idée :

- Le forgeron, en frappant l'enclume, demande à la terre de lui rendre la force dont il s'est vidé en elle autrefois.

Lorsque le forgeron du grenier céleste arriva sur la terre souillée, il fit pénétrer en elle une grande partie de ses forces pures. II se dépouilla donc, pour donner au sol une force de vie favorable aux grands travaux qu'il allait conduire.

De ce fait, lui et ses descendants furent affectés d'une qualité spéciale qui en faisait des êtres différents des hommes «impurs» (pourou), des hommes « vivants» (omo) ou des hommes «blancs » (pili).

Les «impurs » sont les descendants des premiers initiés au culte du Grand Masque, support des principes spirituels du premier mort.

Les « vivants » sont les autres Dogon.

Les «blancs » sont les gens comme les cordonniers, les trouvères ainsi que les hommes de diverses populations de la plaine.

La caractéristique de la situation des forgerons est une force vitale amoindrie, ce qui les éloigne de la catégorie des «vivants». Mais cet amoindrissement n'est pas comparable à celui de la mort, ce qui les éloigne aussi des « impurs ». Ils ne sont pas comparables non plus aux «blancs », car ceux-ci sont insensibles à certaines causes d'impureté. Quoiqu'ils possèdent, comme les autres, des autels individuels de tête et de corps (koutogolo, djabyé), il leur est nécessaire de pratiquer ${ }_{\text {p.82 }}$ constamment un 
autre procédé d'entretien de soi, qui est l'exercice même de leur métier.

- En frappant sur l'enclume, dit Ogotemmêli, ils font revenir de la terre une partie de la force qu'ils lui ont donnée. En battant, ils récupèrent.

Mais les coups sur le fer doivent être donnés de jour. La forge est un labeur diurne, sans doute parce que son feu, fragment de soleil, ne saurait luire de nuit.

- Et c'est pourquoi il est interdit non seulement au forgeron, mais à tout homme, de frapper, de nuit, le fer, la pierre ou le sol. Aucun coup de masse, aucun coup de pilon, ne doit résonner clairement ou sourdement dans le silence.

Car, frapper de nuit, c'est détruire l'effet des coups diurnes, c'est repousser ce qui a été attiré, c'est faire perdre au forgeron ce qu'il a gagné de jour sur les forces dont il s'était dessaisi autrefois.

Les amendes infligées à ceux qui donnent des coups dans la nuit sont employées à fournir des victimes pour l'autel de fondation du village, autel qui, dans les temps anciens, était « planté » sur un homme enterré debout et qui avait offert ses forces et son corps pour la solidité de l'établissement humain sur la terre nouvelle.

Ainsi rétablit-on l'ordre troublé des échanges entre le sol et celui qui se dépouilla pour le purifier et permettre aux hommes la conduite des travaux de vie.

Dans le champ primordial, le forgeron avait alloué à sa famille l'une des huit parts délimitées autour du point d'impact du grenier. Mais il s'agissait là de marquer ses droits aux produits des cultures, car il ne devait jamais cultiver lui-même.

Son rôle est de forger et jamais son fer n'entre dans le sol par sa main: les houes qu'il façonne sont pour les hommes des sept autres familles et il les leur donne, à charge pour eux de le nourrir. Aussi voit-on chaque année, au moment des récoltes, le forgeron quitter son feu et courir le pays pour prélever les graines sur les parcelles défoncées par son fer. II connaît tous les champs qui lui 
doivent tribut; il n'ignore rien de leur croissance, il flaire les maturités.

Et lorsque le paysan couvert de sueur, ouvrant à la lumière le sol assombri par les tiges, coupe son dernier épi, il aperçoit au bout du champ, assis, outres béantes, le forgeron qui regarde en silence.

\section{La Poterie}

p.83 Dans la forge était née la poterie. La femme du forgeron faisait sécher au soleil un pot qu'elle avait modelé comme l'une des sphères du soufflet. Mais elle trouva que la pâte ne durcissait pas assez vite et elle posa l'objet près du feu. Ayant constaté alors que la terre cuisait et qu'elle devenait dure, elle prit l'habitude de mettre au feu les pots qu'elle modelait.

Son travail se poursuivait sur une petite natte carrée de quatre-vingts cordelettes tramées sur une chaîne de même nombre. Elle composait d'abord une ébauche en tronc de cône renversé dans laquelle elle lançait avec force un galet rond qui s'y ménageait un logement de plus en plus vaste formant finalement une sphère. A mesure que la paroi était frappée de l'intérieur, le dessin de la natte s'imprimait dans la pâte.

Les femmes d'aujourd'hui imitent la potière mythique. Mais cet art n'est plus l'apanage de la femme du forgeron : est potière qui veut.

- La natte sur laquelle travaille la femme, dit Ogotemmêli, est le symbole de celle du premier couple humain. La poterie est comme un être sur une natte. En pétrissant la glaise, la femme imite le travail de Dieu lorsqu'il a modelé la terre et le couple. Elle crée un être et le pot rond est une tête posée sur la natte, une tête ou une matrice. Un pot sans ornement symbolise aussi un homme. Celui qui a deux petits seins est une femme.

Ogotemmêli avait placé devant lui l'un des pots qui servaient à faire bouillir la bière de mil. II passait la main sur la panse, pour sentir le décor imprimé. 




La natte sur laquelle on travaille a quatre-vingts fils dans un sens et autant dans l'autre. Elle est tissée comme un carré de la couverture des morts, non avec du coton, mais avec des fibres de baobab.

Les fibres de baobab sont très employées chez les Dogon pour les cordes et les tressages de tous genres. Des anneaux de deux coudées de hauteur manquent aux troncs des arbres dont on a arraché l'écorce.

- p.85 C'est un travail d'homme qui ressemble au tissage. Les meilleures sont faites à Banani. Les dessins qu'elles impriment sur le pot, c'est comme s'il transportait sa natte pour se reposer partout où il est.

- Et le galet avec lequel on frappe ?

- La pierre que la femme pousse dans la glaise est l'image des aliments qu'on y fera cuire.

- Comment faisait-on cuire la viande avant de connaître le travail de la glaise ?

- Avant la poterie, dit Ogotemmêli, les hommes mangeaient la viande crue.

Dans un entretien précédent, il avait comparé le soleil à une poterie chauffée par quartier. Le symbolisme valait dans l'autre sens. 
- Quand la glaise n'est pas encore mise au feu, l'ouverture de la poterie rappelle le pourtour de la lune; après cuisson, elle est l'image du pourtour du soleil. Cela s'explique, continua-t-il ; on pense que la lune est moins cuite que le soleil.

Ainsi un humble pot était-il un raccourci de l'univers portant sur sa panse sa propre natte. 


\section{Quatorzième journée}

\section{La grande maison de famille}

@

La grande maison d'Ogotemmêli n'était pas un exemple de construction classique. Elle présentait une façade de pauvre, avec des niches poussiéreuses remplies d'autels d'enfants morts. Des maigres tréfonds ne sortait aucune odeur de céréales. Les trous d'hirondelles, seuls, béaient vers l'ouest, dans l'attente des envols futurs.

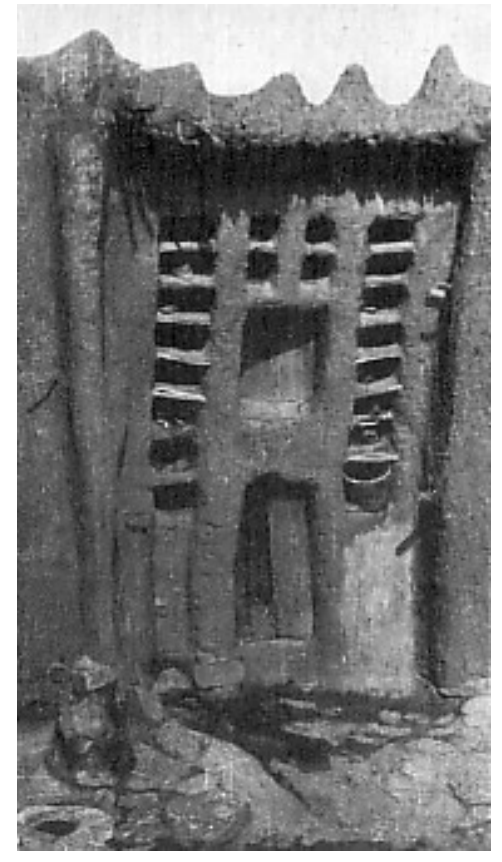

La maison d'Ogotemmêli en 1948

La maison d'Amadigné, au contraire, présentait le damier de creux et de pleins, l'ensemble de portes, de nids et de fleurons coniques traditionnels.

La façade s'étalait sur douze coudées de large et huit de haut. Elle était percée de dix rangées verticales de huit niches carrées d'une palme de côté, qui commençaient au ras du sol et p.86 s'élevaient jusqu'à une ligne horizontale de trous d'hirondelles, laquelle était protégée par un auvent de petits rondins dépassant de moins d'une coudée. Couronnant le tout, une série de colonnettes en 
pain de sucre très élancées s'alignait, chacune coiffée d'une large pierre plate, pour la pluie; mais l'eau fouettante les avait amincies en leur milieu et certaines prenaient l'aspect de sabliers.

Au centre, deux portes superposées séparées par deux niches coupaient le damier en deux registres; celle du rez-de-chaussée, un peu plus large qu'une poitrine et moins haute qu'un homme, faite de deux hautes planches nues. Celle du premier étage, de même largeur, mais beaucoup plus basse, supportait plusieurs rangs de personnages sculptés en relief et se fermait à l'aide d'une serrure apparente surmontée de deux personnages géométriques.

Le plan de l'édifice se présentait sous la forme d'un carré de huit coudées de côté, dimensions de la parcelle unitaire, flanqué de quatre rectangles de même longueur. Ce plan pouvait aussi se comparer à une croix grecque aux branches très épaisses et courtes. Mais dans la maison d'Amadigné, la façade était plus large et ses extrémités abritaient deux réduits dans l'angle disponible.

Le carré délimitait la pièce principale, utilisée pour le repos par le couple et, pour le travail, par la femme. Quatre poteaux, répartis en carré sur les diagonales, soutenaient le plafond. A gauche, un lit de terre surélevé occupait un rectangle contre la paroi. Dans la chambre, au-dessus de la porte, étaient tassées sur le linteau, dans leurs fibres blanches, des graines de coton.

Le rectangle côté façade était occupé par le vestibule, la porte d'entrée faisant face à la porte de la chambre. Celui du fond formait la cuisine; les deux latéraux étaient les magasins.

Ces quatre pièces, qui formaient en réalité des couloirs étroits, communiquaient avec la chambre centrale par des portes ménagées au milieu des parois, celles qui donnaient sur les magasins latéraux n'étant que de simples baies. L'unique entrée, au centre du mur de façade, formait enfilade avec les ouvertures donnant dans la chambre et dans la cuisine. 
Le foyer était composé de deux pierres posées à deux palmes du mur du fond et à deux palmes l'une de l'autre. Une poterie ronde s'appuyait sur elles et sur le mur.

p. 87 Le même plan se répétait à l'étage, sauf pour la cuisine, pièce dont le plafond dépasse la terrasse de l'ensemble et sur laquelle elle prend jour par une ouverture donnant également issue à la fumée.

Comme la plupart des maisons d'Ogol-du-Bas, celle d'Amadigné était orientée vers l'ouest, pour éviter les pluies des vents dominants. Elle formait la paroi d'une ruelle étroite dont l'autre côté était une suite de greniers aux portes soigneusement closes. Mais ceux-ci ouvraient, devant la porte centrale, un passage sur un fumier d'homme riche. En haut de la façade, accrochées à des bois dépassant du torchis, pendaient des grappes rouges mordorées de l'espèce de mil dite « aux yeux exorbités », à cause de ses gros grains ronds.

L'Européen avait l'impression de passer dans un entassement réglé de richesses envahissant les terrasses, les étages, les niches, les casiers.

De fait, des denrées de toutes sortes, en quantités mesurées, séchaient sur les terrasses: piment rouge, oseille aux fruits amarante, mil jaune au son clair lorsqu'il tombe, et qu'on dit « or tintant ».

- La façade aux huit rangées de dix niches, dit Ogotemmêli, représente les huit ancêtres et leur descendance, nombreuse comme les doigts de leurs mains.

Dans le sens vertical, les deux séries de cinq colonnes sont les dix doigts et lorsqu'on regarde une maison de face, on voit deux mains étendues.

Les niches sont les logements des ancêtres qu'ils occupent dans l'ordre de progéniture, en commençant par le rang du haut. II convient de ne jamais les fermer, car il leur faut respirer l'air du dehors.

La porte sculptée du premier étage compte, ou devrait compter, huit rangées de quatre-vingts personnages, images des hommes et des femmes du monde entier issus des premiers ancêtres. 
La serrure est l'autel des ancêtres et les deux personnages qui la surmontent représentent le gardien et sa femme.

Le couple de plus grande taille sculpté parfois en haut du panneau figure le couple humain primordial.
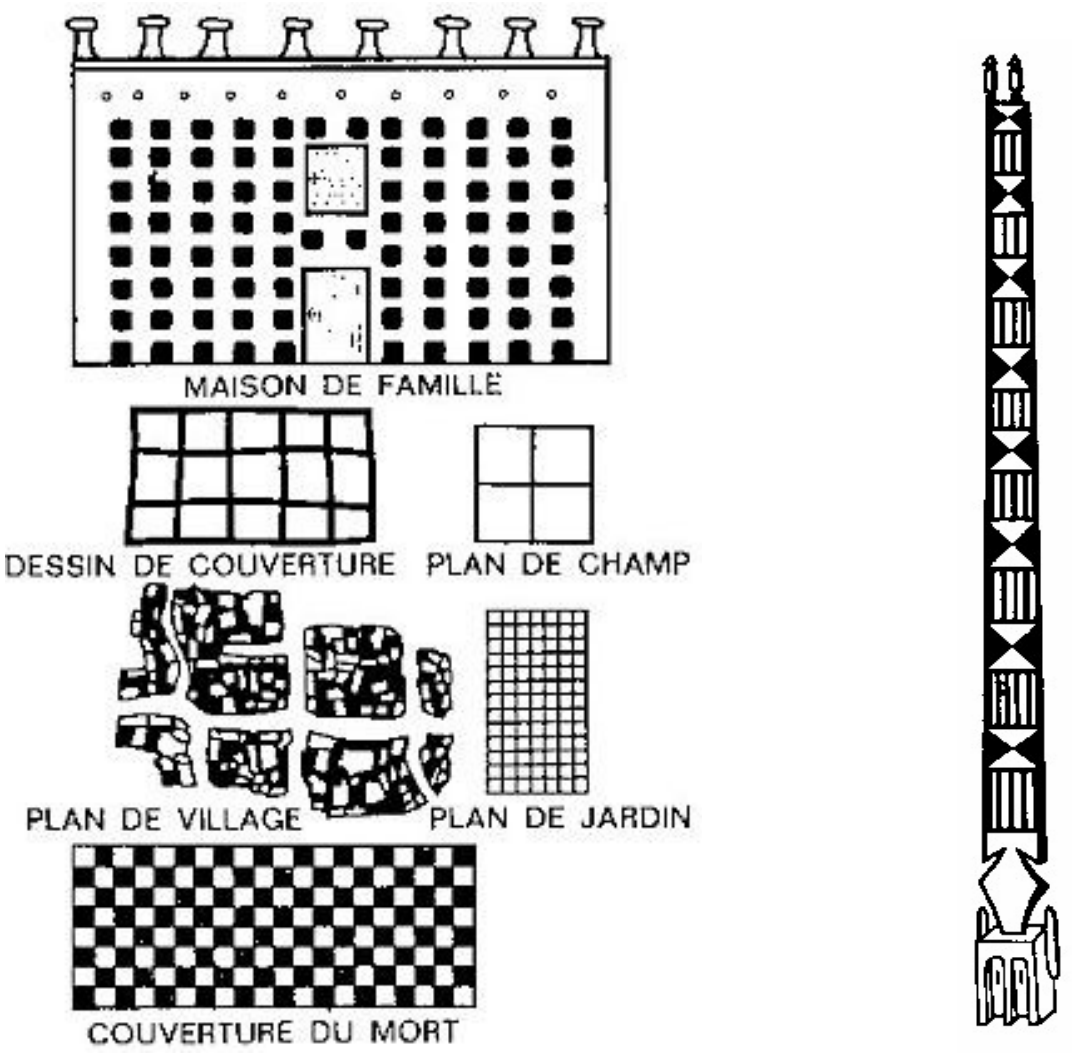

\section{MASQUE \\ MAI SON DE FAMI LLE}

Les trous circulaires du fronton, au nombre de dix, comme les doigts de la main, sont occupés par les nids d'hirondelles, «basse-cour » des ancêtres. Ils portent le nom de «trous p.89 d'hirondelles », qui s'applique également, et par euphémisme, à toutes les niches de la façade, par respect pour les vieux, dont on ne saurait parler à tout propos.

Les huit colonnettes de la crête du mur sont les autels des Ancêtres, le premier se trouvant sur la gauche. Quand la maison est étroite et ne compte que deux ou trois rangs verticaux de niches, les colonnettes sont moins nombreuses; elles dépassent la dizaine dans le cas contraire, mais le nombre traditionnel est de huit, une par ancêtre. 
L'ensemble de la façade avec ses huit rangs de dix trous sombres, séparés par des pleins plus clairs, est le symbole de la couverture des morts, aux huit bandes faites de carreaux noirs et blancs, elle-même image des terres défrichées et délimitées.

Cette façade donne son nom au plus haut des masques dont le faîte s'élève à dix coudées au-dessus de la tête du porteur. Le mât est divisé en dix éléments faits d'une grille rectangulaire ajourée, à quatre ou cinq barreaux; ces éléments sont séparés par des pleins. Ce mât est luimême le symbole de la chaîne du métier à tisser et c'est lui qui est abattu vers l'est et vers l'ouest, pour imiter la marche diurne du soleil.

L'Européen se rappelait des chants d'encouragement psalmodiés au masque «maison à étage » : p.90

On dit que les maisons de Molou, dans Tombo Kê, sont belles

Que les maisons de Molou sont belles

A Molou les maisons ont des étages

Mais ce sont les hommes qui sont beaux

Et non pas les maisons à étages !

- Le sol du rez-de-chaussée, dit Ogotemmêli, est le symbole de la terre et du Lébé, ressuscité dans la terre.

La terrasse, carrée comme celle du grenier volant, est l'image du ciel et le plafond séparant l'étage du rez-de-chaussée est l'espace qui s'étend entre le ciel et la terre. Autour d'elle, les quatre petites terrasses rectangulaires marquent les quatre côtés cardinaux, comme le foyer lui-même.

Le foyer est animé par le feu céleste issu du feu dérobé par le forgeron; quand la maison a la bonne orientation, c'est-à-dire s'ouvre au nord, la poterie posée sur la flamme indique ce même point; les pierres signalent l'est et l'ouest. Le mur, troisième appui du récipient, manifeste le sud.

L'intérieur de la maison, les pièces diverses sont les cavernes de ce monde, habitées par les hommes. 
Le vestibule, pièce du maître, représente le mâle du couple. Son sexe est la porte extérieure.

UNE MAISON

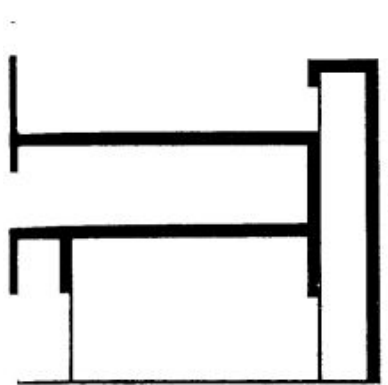

ÉLÉVATION

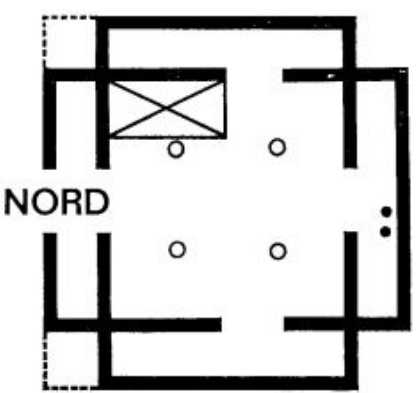

PLAN

La grande pièce centrale est le domaine et le symbole de la femme; les resserres latérales sont ses bras, la porte de communication son sexe. Pièce et resserres exhibent la femme, couchée sur le dos, bras étendus, porte ouverte, prête pour l'union.

La pièce du fond, qui contient le foyer et qui prend jour sur la terrasse, manifeste la respiration de la femme qui est recouverte par le plafond, symbole de l'homme, dont le squelette est fait des poutres. Leur souffle sort par l'ouverture supérieure. Les quatre poteaux (chiffre féminin) sont les bras du couple, ceux de la femme soutenant l'homme qui s'appuie à terre sur les siens. Pour l'accouchement, la parturiente se place au milieu de la pièce, dos au nord, assise sur un tabouret, soutenue par les femmes. L'enfant vient sur le sol et prend possession de son âme là où il a été conçu.

Le terre-plein servant de lit est allongé nord-sud, et le couple y repose, tête au nord, orienté comme la maison elle-même, dont la façade est le visage.

L'homme se couche sur le côté droit, face à l'ouest, la femme ${ }_{p .91}$ sur le côté gauche, face à l'est, dans la position où ils seront dans la tombe.

- L'homme couche sur le côté droit et touche la femme avec la main gauche; il ne la touche jamais avec la droite. La femme couche sur le bras gauche et touche l'homme avec la droite. Jamais on ne se place autrement. La femme 
est enterrée sur le bras gauche, l'homme sur le bras droit, comme ils dorment.

Sur le couple est étalée la couverture des funérailles.

Sous le lit sont placées toutes les graines destinées aux semailles, à l'exception de celles du coton, disposées sur le linteau de la seconde porte, image du sexe féminin.

Dans l'union, I'homme ensemence. II est comme un génie de l'eau qui fait pleuvoir l'eau fécondante sur la terre et la femme, sur les graines des semailles. Ainsi se trouvent liés l'acte agricole et l'acte conjugal.

Si le couple est allongé sous l'étoffe comme dans la mort, p.92 c'est que le lit est aussi une tombe. Il est la tombe du Lébé où pénètre et d'où sort le Septième Nommo en empruntant les deux ouvertures placées entre les portes de la façade.

De même que le Lébé ressuscita dans la terre par le labeur du génie, de même les graines sont promues à la germination et les enfants procréés par l'acte des époux étendus sous la couverture des morts, symbole des nombreuses descendances et des terres cultivées.

Mais la maison n'est qu'un élément du village qui forme un enchevêtrement d'habitations entourées de greniers et de dépendances. Des ruelles courent en tous sens, séparant les blocs. Chaque agglomération se divise en quartiers et dans chaque quartier se trouve une famille au sens large, possédant une grande maison. Chaque quartier a son abri du conseil construit sur une petite place; mais au village est affecté un abri plus important, propriété de I'un des quartiers, construit sur une place plus vaste où se déroulent les grandes cérémonies.

- Le village, dit Ogotemmêli, doit s'étendre du nord au sud, comme un corps d'homme, à plat dos. Ogol-dû-Bas est presque dans la règle. La tête est la maison du conseil, édifiée sur la place principale qui est le symbole du premier champ.

II ressortait toutefois aussi des explications préliminaires de l'aveugle, que le village devrait présenter un plan carré dont l'un des côtés serait face au nord et les ruelles orientées nord-sud et est-ouest. Mais cette 
technique n'est possible qu'en plaine; sur le plateau tourmenté et dans les éboulis des falaises, le village s'adapte au terrain irrégulier.

\section{SCHÉMA DU VI LLAGE}

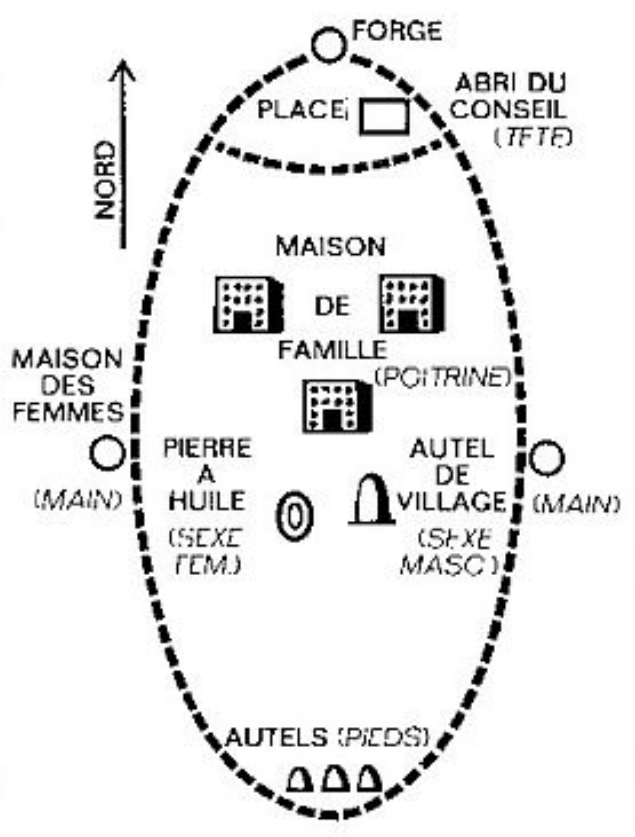

Au nord de la place s'élève la forge, comme était celle du forgeron civilisateur.

Placées à l'est et à l'ouest, les maisons pour les femmes en état de menstruation, rondes comme des matrices, sont les mains. Les grandes maisons de famille manifestent la poitrine et le ventre. Les autels communs, construits au sud, sont les pieds.

Au centre, les pierres à écraser les fruits de Lannea acida forment un sexe de femme. A côté d'elles devrait être placé l'autel de fondation, image du sexe masculin. Mais par respect pour les femmes, cet autel est construit hors des murs.

A l'intérieur du village, chaque quartier forme un tout et doit être disposé de la même manière que l'agglomération, comme un être à part. Vu du haut des airs, le village est l'image de la maison de l'ancêtre, aux quatre-vingts niches, et de la p.94 grande couverture des morts, aux 
carrés noirs et blancs. Les constructions forment les pleins de la façade; les cours et les abords simulent les creux. Les terrasses luisant au soleil et les ombres portées sur le sol donnent les deux couleurs de la couverture.

Les ruelles courant du nord au sud sont les coutures unissant les bandes.

L'abri des hommes, qui s'élève sur chaque place publique et notamment sur la grand-place du village, est d'une construction très différente de celle des habitations. II est fait, à Sanga, d'une meule carrée composée de plusieurs couches entrecroisées de tiges de mil bottelées. Cette masse repose sur une charpente grossière faite de troncs non équarris, équilibrée sur trois rangs parallèles de piliers en pierres sèches ou en bois.

Sous l'abri, les hommes se réunissent aux heures chaudes pour se reposer en devisant. Les vieillards, notamment, y tiennent conseil et prennent les décisions intéressant les affaires publiques. Autrefois, Iorsqu'on fondait un village, l'abri et la maison des femmes étaient les premiers édifiés.

\section{ABRI DU CONSEI L}
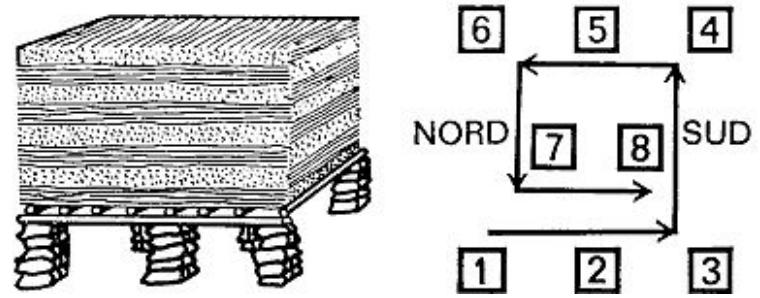

PLAN DES PILIERS

C'est sous une telle construction que délibéraient les huit ancêtres, au temps où ils avaient forme humaine, avant leur métamorphose en génies de l'eau.

Les abris actuels, lorsqu'ils ne sont pas circulaires et surmontés d'une meule en tronc de cône renversé, sont, ou devraient être, orientés selon les côtés cardinaux. Ils p.95 comportent, ou devraient comporter, trois rangs de piliers dans le sens nord-sud, les deux rangs latéraux comptant trois supports, celui du centre, deux, placés en quinconce. 
Ces colonnes trapues, faites de pierres solidement équilibrées que recouvre parfois un enduit de torchis gris-blanc, se dressent comme les troncs des huit ancêtres assis pour les débats, têtes insérées dans la poutraison.

Pour un observateur assis face au nord, au centre de l'édifice, ces colonnes se présentent dans l'ordre numérique, la première étant celle de l'angle nord-ouest, la seconde celle de l'ouest, la troisième au sud-ouest, la quatrième au sud-est et ainsi de suite en tournant. La septième est celle du milieu, côté nord, et la huitième est placée derrière elle.

Ainsi la suite des huit piliers s'inscrit-elle, sur un plan, comme un serpent lové selon une ligne brisée et entourant les symboles de l'ancêtre Septième, maître de la parole, et de l'ancêtre Huitième, qui est la parole elle-même. 


\section{Quinzième journée}

\section{Le Sanctuaire}

@

Ogotemmêli, au cours des entretiens précédents, avait laissé entendre que la maison d'habitation n'avait pas été la première construite. Le tout premier édifice avait été un sanctuaire de Binou élevé dans la région de Dâlé par le prêtre de l'ancêtre Dewa-sorti-du-bâton. C'était très exactement près de la mare Guibêlé de Kounnou que la chose avait eu lieu. Par la suite, les hommes avaient interprété pour les maisons d'habitation la forme de ce sanctuaire.

- Mais, avait dit Ogotemmêli, le sanctuaire est une tombe, tandis que la maison est un endroit où l'on vit.

Le sanctuaire de Binou est élevé en I'honneur d'un ancêtre, Binou ; ce nom est la contraction de deux termes

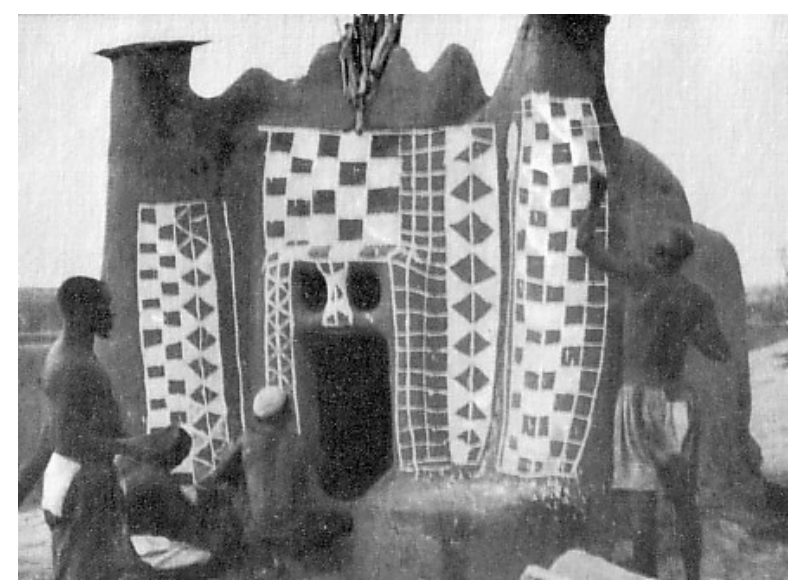

Sanctuaire du binou Sangabilou de Do

dont l'un signifie «parti » et l'autre « revenu». II s'agit d'un ancêtre apparemment mort, c'est-à-dire parti pour un autre monde, puis revenu parmi les hommes, parmi les siens, pour les protéger, pour leur donner aide et assistance.

Les entretiens avec Ogotemmêli supposaient la connaissance de cette institution considérable qu'on peut, dans une certaine mesure, nommer totémique, faute d'un 
meilleur terme. Un p.96 entretien ultérieur devait fortifier l'Européen sur sa position réticente quant au «totémisme » dogon. Mais il était d'avis que ce terme était commode et présentait moins d'inconvénients si on le définissait.

II pensait aussi que seules importaient les idées et représentations qui tournaient dans la tête de son prestigieux informateur et que les siennes propres, pas plus que celles des spéculateurs d'Occident, n'avaient d'intérêt.

Le symbolisme du sanctuaire de Binou était donc à l'ordre du jour de la quinzième journée et l'étranger se rendait avec délectation au fumier des révélations.

II se remémorait les centaines de sanctuaires qu'il avait étudiés au cours de ses déplacements dans les falaises et plateaux. II revoyait notamment les deux grandes tours en obus encadrant la façade du temple du Nommo, de Nandouli, posé sous les baobabs, en haut d'une vallée sèche, dans un décor heurté de création du monde. II lui avait fallu abandonner tout tissu, se mettre nu pour pénétrer dans une troisième tour en forme de couronne blanche de pharaon, où il devait découvrir, parmi un matériel extraordinaire, des outils de forgeron ornés de sonnailles, des sandales de fer et une couronne de fer rappelant celle des Lombards. II était là au cœur même du problème, devant le trône-autel du Dieu de l'eau.

Au sud du plateau, à Dyombolo, il avait vu la maison carrée arrondie aux angles du Binou Arsana, éclatante des couleurs rouges, noires, blanches de ses peintures représentant des masques, un soleil, un soubassement de triangles alternés formant chevrons. Un immense serpent, en relief, au corps moucheté, entrait par un trou du mur, ressortait ailleurs.

Dans les villages d'éboulis, il avait vu, au pied des grandes parois, à Banani, à Yougo Pilou, des temples réduits à des façades plaquées sur un creux de roche, sur un rentré d'auvent. On y accédait par des corniches d'où l'on découvrait l'éboulis dévalant jusqu'à la plaine aux arbres clairsemés comme ceux d'un verger. 
A Yougo Dogorou, tous les autels étaient rassemblés dans une gorge étroite qui allait s'amincissant dans le cœur du massif. Ils étaient comme calfeutrés dans des galeries horizontales ouvertes tout leur long sur le vide, et l'exiguïté des corniches faisait réduire les constructions à de minces décors dont les façades supportaient quelques dessins de chevrons.

p. 97 Alors qu'à Banani le sacrificateur opérait à la vue de tout un pays, à Yougo Dogorou, il s'enfonçait dans les entrailles de la pierre.

Qu'il soit un véritable édifice étalé au soleil ou un réduit de fond de gorge, le sanctuaire comprend toujours une simple chambre carrée (souvent arrondie aux angles) ou ronde. Celui du quartier Sodamma d'Ogol-du-Haut, village regorgeant d'autels, mesure quatre coudées sur cinq. Sa façade est percée d'une porte basse surmontée de deux trous et couronnée de quatre excroissances en pain de sucre arrondi. Il s'agit là d'un édifice construit dans une cour exiguë et tous ceux qui sont ainsi placés sont de dimensions restreintes.

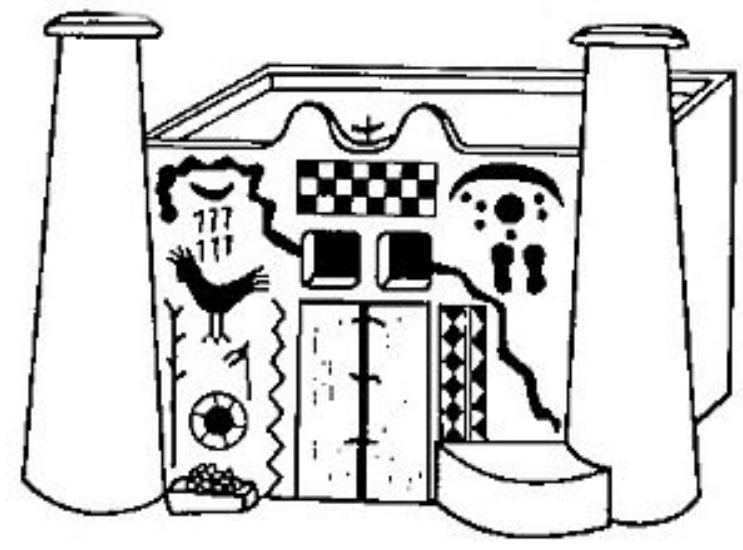

\section{SANCTUAIRE TOTEMI QUE ET SES PEI NTURES}

Le temple du Binou Sangabilou, dans le quartier Do, est au contraire érigé sur une place assez vaste, à l'extérieur des habitations. Cube d'environ six coudées de côté, il présente une façade flanquée aux angles de tours légèrement coniques et coiffée par deux ombilics laissant apparaître entre eux un crochet de fer. La porte d'une coudée sur deux est surmontée de deux niches carrées placées à même hauteur. A droite de ${ }_{\text {p.98 }}$ cette porte est 
ménagé un terre-plein qui sert de siège au prêtre durant les cérémonies. A gauche sont posées des pierres creuses, anciennes pierres à moudre, contenant des haches de pierres ou des galets ronds.

Le toit est fait d'une terrasse dont l'eau s'évacue par une gouttière de bois et les deux tours d'angle sont coiffées d'une large pierre plate débordante qui protège les faîtes contre la pluie.

A l'intérieur du sanctuaire sont placés les accessoires du culte: pierre creuse remplie d'eau ou de pierres de tonnerre, poteries diverses, instruments de fer ou de bois, autels de terre.

- Le sanctuaire, dit Ogotemmêli, devrait s'ouvrir au nord. Mais, comme pour la grande maison, c'est la pluie qui fait décider.

Les deux tours de flanc et les cônes centraux sont les grands et les petits autels de ce monde. Ceux du centre reçoivent les libations de bouillie de mil et le sang sacrificiel. A l'époque des offrandes, le blanc et le rouge ruissellent sur la façade et tombent en longues lignes jusqu'au sol.

- Là où est le crochet de fer, entre les ombilics, c'est là où l'Ancêtre forgeron a commencé à forger, dans le premier champ.

- Mais ce crochet ? traverse.

- Le crochet est l'enclume. II est enfoncé dans une

- Une traverse du toit ?

- Non ! on place un bois court sur le fronton et qui ne se confond pas avec la charpente de la terrasse. C'est l'image de la traverse dans laquelle est plantée l'enclume.

La terrasse du sanctuaire est le symbole du champ primordial et le dessous, l'intérieur de l'édifice, est la tombe du Lébé. 


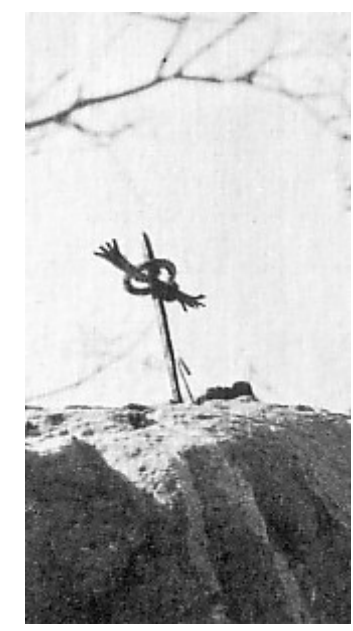

Fronton du sanctuaire

Le terre-plein extérieur est l'emplacement où fut déposé le mort avant sa mise en terre. La porte est le trou d'entrée des hommes lorsqu'ils voulurent exhumer les os pour les emporter dans de nouveaux pays. Les deux niches qui la surmontent sont les passages du Septième ancêtre, mué en serpent : il entra par celle de droite pour aller ingérer le mort et le régénérer; il est sorti par celle de gauche.

A l'intérieur, la pierre creuse remplie d'eau, de galets et de cauris contient le vomissement du Septième, les eaux des torrents et des mares, les os du mort transformés en pierres d'alliances et ses ongles transformés en cauris.

p.99 Le sanctuaire est la chambre de la déglutition où le Septième a consommé la nature humaine et rejeté la silhouette de l'organisation du monde.

Mais le sanctuaire est aussi une forge. Le crochet du fronton est l'enclume, et la pierre creuse de l'extérieur rappelle celle où l'artisan verse de l'eau pour le refroidissement des fers rouges. Les deux autels hémisphériques de l'intérieur, autels personnels du prêtre consacrés à sa tête et à son corps, sont les poteries du soufflet. Ils sont placés contre une tache d'ocre rouge rappelant le feu qu'ils animent.

La masse est figurée par un autel conique.

Mais le plus important de tous les objets est le crochet de fer planté au fronton et qui est l'enclume de la forge. 
Le crochet est le plus fréquemment double, chaque branche se terminant par un enroulement serré. II est le front cornu du bélier céleste dont les volutes retiennent les nuages pluvieux.

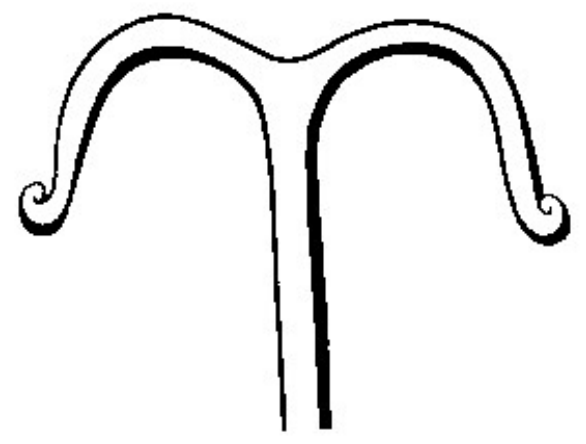

\section{CROCHET DE SANCTUAIRE}

Ces deux enroulements sont aussi compris comme deux mains qui retiendraient I'humidité, qui accrocheraient l'abondance.

Mais le crochet est souvent remplacé par une tige de fer quadrangulaire ou cylindrique de la grosseur du pouce et d'une palme de hauteur, amincie à partir du milieu en tronc de cône terminé par une pointe mousse. A mihauteur, cette tige est traversée par une mince pièce de fer plat qui serait comme deux bras étendus latéralement incurvés vers le haut. Chaque branche se termine en s'évasant en une sorte de main aplatie dont les doigts sont figurés par les dents de scie.

Cet objet, qui est dit également « crochet», rappelle lointainement, par sa tige verticale, à la fois l'enclume et la masse du forgeron. Par ses branches transversales qui sont des bras, il est le symbole du génie de l'eau que cette même masse et cette même enclume représentaient déjà.

Et ces deux bras légèrement relevés ont le même rôle que les mains en volutes des crochets: dans leur courbe, ils retiennent la pluie et les graines nécessaires aux hommes.

C'est à cause de la bienfaisance de ces fers qu'en souvenir des huit ancêtres, les huit épis cueillis lors de la récolte du champ affecté au sanctuaire sont accrochés en haut de la façade. 


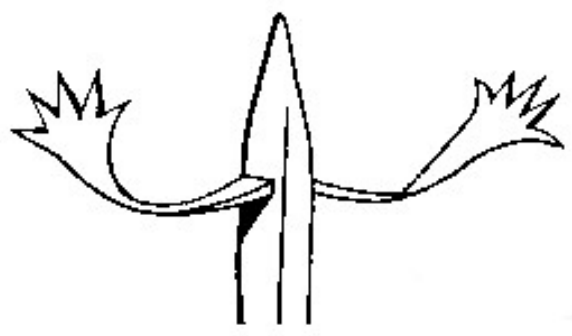

\section{CROCHET A NUAGES}

C'est pour la même raison que sont étalés sur la terrasse, lors p.100 de l'inauguration des semailles, les épis destinés aux ensemencements.

Toutes ces graines s'y imbibent des humidités et des forces de recommencement accrochées dans les volutes des cornes et dans les bras étendus.

Et c'est du haut de cette terrasse, c'est-à-dire du champ primordial, dont les profondeurs furent témoins d'une mort et d'une résurrection, que sont lancés à la foule les épis lourds de vie qu'elle mêlera aux semences. 


\section{Seizième journée}

\section{Le Sanctuaire et les peintures de façade}

Ce Christ de fer planté dans une traverse d'enclume, au fronton d'un tombeau, avait empêché le Nazaréen de dormir.

A vrai dire, les sommeils étaient courts dans la communauté. Entre les révélations du Bambara transplanté à Sanga, les travaux de linguistique, les enquêtes ardues sur les grands cycles de l'activité dogon, il restait peu de temps pour le repos, peu de paix dans les esprits.

L'Européen était revenu du dernier entretien et avait jeté la nouvelle sur ses compagnons :

- p.101 Je comprends maintenant, continua-t-il, la lance d'Orosongo. Vous savez cette lance à fer allongé que nous avons photographiée voilà bientôt dix ans. Eh bien, c'est une variante des crochets, c'est dans l'esprit des crochets.

Il faisait allusion à un objet qui l'intriguait depuis des années et qu'il avait vu dans un temple du plateau de Wazouba. Sur la pointe de l'arme était fixé un personnage humain d'une demi-palme, en fer forgé, les bras en croix.

II restait intrigué par la courbure des bras de ce Christenclume.

- Bien sûr, disait-il, Ogotemmêli y voit un système d'accrochage. C'est pour retenir les eaux et les graines, l'abondance. Elle en a plein les bras, si j'ose dire, l'enclume.

Mais il pensait à la dernière révélation du moniteur Septième, à ce jeu de ficelles entre ses mains palmées, pour la démonstration, qui était un tissage, du tambour d'aisselle. 
Ce fer planté sur une tombe était comme le rappel de la troisième parole, du verbe musical.

Jamais, pourtant, Ogotemmêli ne devait en souffler mot.

Lors du seizième entretien, le Nazaréen demanda pourquoi, dans le sanctuaire-tombeau-forge, les objets et symboles étaient si dispersés qu'il était impossible d'en lire le sens.

- La dispersion des objets, rétorqua l'aveugle, c'est pour cacher le symbolisme à ceux qui voudraient comprendre.

En somme, pour les profanes, l'intérieur et la masse de l'édifice, avec ses accessoires, constituent un rébus inextricable.

Mais un autre rébus se présentait aux yeux des spectateurs: au moment des semailles, la façade des sanctuaires est p.102 transformée en un tableau de figures blanches et parfois rouges et noires. A la bouillie de mil, à l'ocre et au charbon, les sacrificateurs attitrés ornent les parois pour le nouveau cycle des cultures.

Du fait de l'ignorance ou de l'instruction incomplète de ces hommes, et pour d'autres raisons encore, une grande fantaisie semble régner dans le choix des sujets, objets et figures représentés. Mais la règle de ce dispositif était connue d'Ogotemmêli.

Pour un observateur placé devant le temple, la façade se divise en trois zones: la droite, réservée aux êtres et accessoires femelles, la gauche, réservée aux mâles, le dessus de la porte.

La figure principale de la droite est un bélier de profil, urinant, regardant vers la gauche et dominé par une série de taches simulant les étoiles.

- Mais la droite est réservée aux femelles !

Ogotemmêli releva la tête

- II porte entre les deux cornes une calebasse, symbole de la femme et du soleil femelle. C'est à cause de cette femelle que le bélier est à droite. 
II avait déjà fait maintes allusions à cet animal bien connu des Soudanais comme avatar du génie de l'eau. Tout le monde se méfie des béliers rôdant autour des mares, surtout s'ils sont coiffés d'une calebasse luisante à laquelle l'huile de Lannea acida donne des reflets rouges. Certes, cet ustensile lui sert de protection contre les rayons de soleil, mais il l'utilise surtout comme un appât pour attirer les hommes:

- On voit une calebasse entre les cornes d'un bélier; on s'étonne; c'est beau à voir ; c'est pour imiter le soleil. On se demande pourquoi un si bel objet, si brillant, si rouge, se trouve sur un bélier. On s'étonne, on pense qu'il faut le saisir pour empêcher qu'il ne le brise.

Car les Dogon sont pleins d'attention pour le matériel.

Alors l'homme se précipite et, comme dans un rêve, la calebasse, qui a déjà quitté les cornes, flotte sur les eaux, entraînant l'imprudent vers les génies qui boivent son sang par ses narines.

Mais c'était là manifestations terrestres; cent légendes bien localisées sont fondées sur des moutons plantureux attracteurs de filles, qui rôdent au bord des plans d'eau en saison humide et entraînent les infortunées parmi les nénuphars.

- Ce bélier, qui est-ce ? demandait l'étranger.

- C'est le grand Nommo du ciel, le couple de Nommo.

- p.103 Un couple ?

- Le bélier est le mâle, la calebasse la femelle. C'est un bélier d'or. Avant chaque orage, pendant la saison des pluies, on peut le voir se déplacer dans la voûte du ciel.

L'Européen grommelait contre cette nouvelle complication. De l'or? On n'en avait pas encore vu jusqu'à présent.

- L'or, dit le vieillard, est un frère puîné du cuivre.

L'or était donc un sous-produit, un métal de second ordre. 
- En réalité, reprenait Ogotemmêli, la toison est de cuivre. Et le cuivre, c'est le faisceau de rayons sortant des nuages de pluie, quand le soleil est caché. Le cuivre, c'est l'excrément des génies de l'eau qui sont dans l'humidité céleste.

II s'étendait sur le rôle insigne du soleil pompeur de nuages et sur la métamorphose en cuivre des rayons lumineux déféqués par les Nommo.

- Le Bélier-Nommo, dit-il, se roule dans ses excréments.

Quand il apparaît dans le ciel, il porte entre les cornes une calebasse.

- Comme une chéchia. Elle est luisante d'huile de Lannea acida.

Ce bélier est aussi le symbole du système du monde :

- La calebasse est le soleil. Le corps est la terre; le chanfrein la lune. Ses yeux sont les étoiles des cieux.

La toison de cuivre est aussi toison d'eau car le cuivre est rayon humide; elle est aussi toison de feuilles, car l'eau et la végétation sont de même essence.

- Et le nez et la bouche manifestent la respiration de tous les êtres du monde, car il est, par ses pattes postérieures, les grands animaux, par les antérieures les petits, par sa queue les reptiles.

Mais la calebasse est aussi le Nommo femelle, la femme par excellence dont les seins, sur le corps même de la bête, sont les deux excroissances de la gorge.

- Le bélier la met sur sa tête pour la tenir entre ses cornes qui sont des testicules et pour la pénétrer du phallus qui se dresse sur son front.

Dès qu'il se transforme ainsi, le Nommo urine, par son membre inférieur, les pluies et les brouillards. Et par son membre frontal il émet la semence fécondante dans la féminité du soleil, p.104 dans la femme et aussi dans les graines enfouies dans la terre. 
Ogotemmêli voyait dans tout cela l'essentiel du fonctionnement de la vie universelle.

- Les rayons du soleil, reprenait-il, sont feu et excréments du Nommo. Ce sont ces rayons qui donnent sa force au soleil. C'est le Nommo qui anime l'astre, qui est le soleil en quelque sorte.

Sur cette déclaration obscure, il était difficile de s'expliquer. Le Nazaréen avait beau retourner comme une peau, examiner sévèrement cette partie de la cosmogonie ; il ne pouvait trouver la bienheureuse fissure par où comprendre.

II était aussi placé devant des identités inacceptables pour un Blanc, un bon Blanc moyen raisonnant. Et il se sentait agréablement humilié en entendant son interlocuteur faire du feu et de l'eau des compléments et non des contraires.

- Les rais de lumière et de chaleur tirent l'eau, font monter l'eau. Ce sont eux aussi qui la font redescendre sous forme de pluie. C'est une bonne chose. Ce va-et-vient pour créer un mouvement est une bonne chose. Par les rais, le Nommo retire et redonne de la force vitale. C'est ce mouvement même qui fait la vie.

Le vieil homme sentait qu'il était là sur un plexus. Si le Nazaréen ne comprenait pas cette affaire de va-et-vient, il ne comprendrait rien du reste. II voulait dire que ce qui faisait la vie, ce n'était pas tellement des forces, mais bien plutôt des mouvements de forces.

II reprenait l'idée de la navette universelle :

- Les rayons boivent les petites eaux de la terre, les petites eaux des flaques sans épaisseur, les font monter, les font redescendre en pluie.

Puis, il enchaînait, sans plus parler de l'eau :

- Tirer en faisant monter ; tirer en faisant descendre, c'est cela la vie du monde.

Mais on ne pouvait rester éternellement dans les hauteurs de cette métaphysique. Par ailleurs, ce bélier était doué de mouvement ; une fois surgi dans les cieux, il allait, il aboutissait. II n'était pas un urinant sur place; il courait les nues, laissant une trace de quatre couleurs faite 
de la terre secouée de ses sabots. L'antérieur gauche laissait une voie noire, la droite une p.105 voie rouge; les deux autres une jaune et une verte. Cette voie quadruple est dite « trace du Nommo ». II s'agit de l'arc-en-ciel.

Mais l'arc-en-ciel aboutit. Le Bélier d'or descend des cieux et plonge dans les grandes mares de la terre.

- Vous pourrez le voir, par violent orage, tomber dans la mare de Bananga, au sud d'Ogol-du-Bas. Ne l'avez-vous pas vu?

Et le vieillard, tendant sa main sèche vers le sud, ajoutait

- Il plonge dans les nénuphars aux cris de: "L'eau m’appartient ! I'eau m'appartient ! » 


\section{Dix-septième journée}

\section{Le Sanctuaire et les peintures de façade (suite)}

La figure principale de la partie droite de la façade devait donc représenter le Génie de l'eau, le Nommo, sous sa forme prestigieuse de Bélier d'or ou de cuivre, dans un lit d'étoiles.

Ogotemmêli avait oublié un détail qui intéresse les mammalogistes :

- Les cornes de la bête sont droites ou recourbées. Elles peuvent prendre l'une des deux formes. Mais ce sont les secondes qui sont les plus anciennes.

La bouillie de mil, répandue sur le torchis lisse à l'aide de plumes de volailles ou de pinceaux en poils d'âne, devait donner l'impression que la toison était faite de feuillage. Et pour bien ramener la pensée sur les travaux de la germination, la queue, à tête de serpent terminale, dominait un épi de mil dressé.

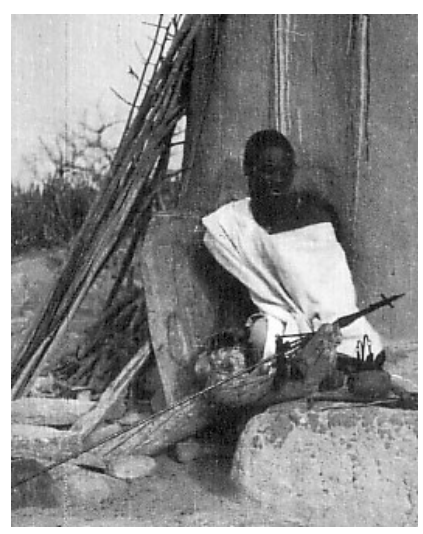

Prêtre du sanctuaire d'Orosongo

A droite de l'animal, deux traces de pas, souvent en relief, figurent à la fois les sandales du prêtre maître du sanctuaire et les marques de pas du premier homme. Elles sont aussi les sandales du couple de Nommo. Le bas de leur corps étant terminé par une queue de reptile, une 
sandale suffit pour chacun ; la gauche pour le mâle, l'autre pour la femelle.

Sur chaque sandale figurent huit taches rappelant les cauris déposés à l'emplacement des pieds de l'ancêtre Lébé, dans le tombeau de la résurrection. Elles manifestent également les huit ancêtres, les huit graines, les huit pierres d'alliance. Elles p.106 sont finalement les huit cauris ornant les sandales d'apparat chaussées par l'impétrant le jour de l'introduction à la prêtrise.

Coiffant le Bélier et les étoiles, trois lignes horizontales, rouge, blanche et bleu-vert se terminant à chaque bout en pointe recourbée vers le bas, figurent l'arc-en-ciel.

C'est donc la grande image du ciel lumineux et pluvieux qui est peinte à droite de la porte.

A gauche, les objets ou êtres évoqués sont terrestres. En premier lieu un serpent qui, à Sanga, est le Septième ancêtre. II est souvent fait d'une ligne ondulée, le chemin de l'eau, qui se trouve à profusion sous forme de lignes chevronnées verticales traçant le cours des ruissellements terrestres et le mode de chute du Nommo lorsqu'il se précipite en pluie du ciel sur la terre.

Et ce cheminement peut être parfois évoqué par le dessin d'une autruche dont le corps aux cercles concentriques est chevronné et dont la marche en zigzag, quand elle est poursuivie, n'est propre à aucun autre volatile de la plaine.

Les lignes en chevrons se présentent aussi sous forme de registres verticaux contenant des dents de scie pleines, en séries simples ou doubles, opposées par les pointes, ce qui donne à l'ensemble l'aspect de sabliers empilés.

Dans le haut de la façade, en pendant à la calebasse de droite, image du soleil, est tracée la lune, ronde ou en croissant. Elle est, à gauche, un rappel des régions célestes.

Sans ordre précis, dans la partie libre du torchis, figurent divers objets et animaux du culte :

le bâton fourchu du prêtre, qui est le symbole à la fois de la masculinité et de la féminité. L'homme est la tige elle-même, qui arrive à hauteur de poitrine ; la femme est 
la fourche terminale, dans laquelle le prêtre appuie l'index figurant lui aussi le mâle ;

le siège du prêtre, fait souvent d'un cercle plein entouré d'une circonférence ;

le bâton droit et court de l'ancêtre qui a donné les masques ;

les crochets, qui figurent par ailleurs réellement sur la terrasse ;

les crosses de jet, symboles des garçons que désire la famille et qui doublent les crosses véritables pendues au fronton ;

une crosse de voleur rituel, dont le manche est orné d'une ligne de chevrons et dont la branche courbe est ouverte comme p.107 une bouche aux lèvres rouges rappelant qu'elles ont tenu le morceau de soleil volé par le forgeron ;

les houes ;

les grappes de gros mil et les épis de petit mil ;

l'animal interdit du culte de l'ancêtre auquel est dédié le sanctuaire ;

un mouton ou un poulet, victime ordinaire des sacrifices offerts sur les autels ;

un oiseau d'eau, rappelant les recherches du prêtre, avant son intronisation, lorsqu'il devait explorer les mares et les torrents pour y trouver la pierre d'alliance cachée à la mort de son prédécesseur ;

une tortue, image de celle que possède toute famille, grande ou petite. En cas d'absence du patriarche, c'est elle qui le remplace pour la consommation de la première bouchée des plats et de la première gorgée d'eau quotidienne. Ce dessin de la tortue est un rappel du patriarche. II rappelle aussi que la carapace représente la région habitée par le Nommo, c'est-à-dire le ciel concave. Les dessins en losanges de l'écaille symbolisent la façade de l'habitation du génie, la couverture à carreaux du mort, les lignes chevronnées, chemins des pluies. 


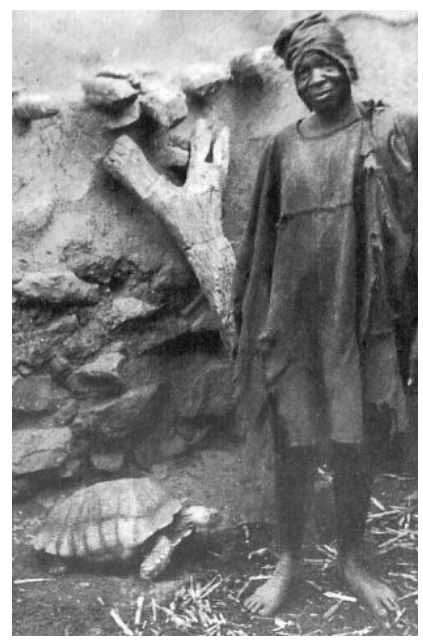

La tortue patriarcale

Des masques tels que la «maison à étage », l'« antilope chevaline», le «déployeur d'ailes de brousse », sont souvent dessinés sur le panneau de gauche. Ce sont des masques de bois, accessoires mâles contenant plus de force que les cagoules tressées.

Si ces dernières contiennent une humidité efficace du fait qu'elles sont confectionnées avec des fibres, les masques de bois sont plus humides encore, car ils tiennent leur qualité à la fois du bois dans lequel ils sont sculptés et des fibres revêtues par les porteurs:

- Ayant plus d'humidité, ils sont plus en rapport avec le Nommo.

Au-dessus de la porte du temple est peint un damier de carreaux blancs alternant avec des carreaux de la couleur du fond de torchis. Régulièrement, il comprend huit bandes, une par ancêtre.

Ce damier est l'image par excellence des « choses de ce monde » et surtout du cadre et des objets de base de l'organisation des hommes.

Il est le symbole :

- de la couverture du mort, aux huit bandes de carreaux p.108 noirs et blancs qui manifestent la multiplication des huit familles ;

- de la façade de la grande maison, aux quatre-vingts niches, habitat des ancêtres ; 
- des champs cultivés, tissés comme la couverture ;

- des villages aux ruelles formant coutures, et plus largement de la région habitée, défrichée ou exploitée par les hommes.

Le damier, comme la couverture, exhibe les huit ancêtres.

A l'intérieur du sanctuaire, outre la tache rouge représentant le feu de forge, sont peints à droite de la porte, en sortant, un serpent, image du Huitième ancêtre, et à gauche un crocodile, qui est le symbole du plus vieil homme connu de la famille.

Cette dernière règle est valable pour Sanga. Chaque région fait représenter l'image des êtres auxquels elle est liée.

C'est donc le système du monde, avec les êtres et accessoires célestes et terrestres, qui est peint sur le temple, à l'aide de bouillie de mil et de riz.

- L'utilité du dessin ? dit Ogotemmêli. II aide les plantes, il aide la germination. La veille du jour où le sacrificateur trempe ses pinceaux, les épis de semence sont étalés sur la terrasse, symbole du premier champ.

II s'agit de prendre les graines encore vierges, à l'aurore du cycle de la végétation, et de les inclure dans le cycle universel, dans le mouvement des nues et des hommes.

Mais une question brûlait les lèvres de l'étranger :

- Jamais, dit-il, je n'ai vu de bélier dessiné sur une façade. Jamais je n'ai vu de temple orné selon la règle.

- Je ne sais, répondit l'aveugle, qui pourrait dessiner le bélier. Si je voyais !... II n'y a plus de temple peint selon la règle.

Au premier chef joue l'ignorance. Le prêtre et son sacrificateur peuvent être très jeunes et n'avoir reçu qu'une instruction restreinte aux rites de leur propre culte. Nombreux sont ceux qui ignorent une grande partie de la symbolique des peintures et notamment l'existence de l'image du bélier céleste. 
Mais la règle serait-elle bien connue de certains prêtres, qu'ils ne s'en abstiendraient pas moins de la suivre.

En effet, les peintures étant efficaces, apportant aux céréales une aide d'autant plus grande qu'elles sont plus complètes, il convient, pour le prêtre, de n'en pas trop montrer, afin de ne p.109 pas être imité par des voisins à l'affût de tout ce qui contraint ou flatte les puissances célestes.

II fait donc de sa façade une sorte de rébus à l'usage des profanes qui reconnaissent certains détails. Quant à ses collègues, ils ne trouvent que les représentations habituelles, à l'exclusion des plus importantes.

Ogotemmêli n'était pas très explicite sur ces questions et il fallut chercher ailleurs.

Comme l'intention et surtout les paroles du rite jouent un rôle essentiel, on peut supposer que l'exécutant, en peignant des images courantes, y met mentalement et verbalement beaucoup plus que sa main n'en trace.

Mais plus que l'ignorance ou la méfiance, joue un facteur proprement religieux qui vient à l'encontre de l'expression - puisqu'il la supprime - et qui est le frein le plus sérieux à l'expansion de la connaissance : une grande réserve, faite de respect et de crainte, quand il s'agit de prononcer les noms ou de dessiner les formes des puissances surnaturelles.

C'est un fait connu que l'on ne saurait prononcer le nom d'un absent sans provoquer dans l'invisible des mouvements importants. L'explication généralement donnée est que prononcer le nom évoque la chose ou l'être qui le porte, l'oblige en quelque sorte à se présenter, ce qui n'est pas sans inconvénients. Mais on n'a pas insisté sur la raison pour laquelle l'être accourait ainsi à l'appel de son nom.

C'est que jeter un nom, c'est jeter une forme, un support, la forme la meilleure, le support le plus apte à recevoir la force vitale de l'être.

En jetant la parole, l'orateur projette certes une force qui provient de lui, que porte la buée sortie de sa bouche, qui se confond avec la buée. Mais cette force ne fait que 
préfigurer celle de l'invoqué, elle l'informe, elle la met en voix.

Et cette forme, qui sera la meilleure pour l'appelé, va comme piéger sa force vitale, va l'obliger à comparaître, à surgir à la voix.

Les mêmes choses pourraient être dites du dessin. Surtout si la matière avec laquelle on trace est efficace, surtout si les paroles accompagnant les gestes de la main sont explicites et contraignantes.

p.110 Concernant les noms, ces idées conduisent au silence ou à l'euphémisme. Concernant les peintures, elles aboutissent à l'absence de représentation. De même qu'on ne prononce jamais le nom du génie de l'eau, de même on ne trace jamais son image. Ce serait une grossièreté vis-à-vis de lui : le représenter serait l'obliger à se présenter, comme si on le nommait. Ce serait le troubler dans ses desseins, intervenir dans la marche de ses activités de Moniteur de l'univers.

II y a donc lieu, pour chaque prêtre, de ne tracer sur la façade de son temple que les figures se rapportant à son Binou et que celles dont l'usage est général et connu de tous.

Ainsi l'artiste peint-il, autour d'un bélier invisible, maître de la germination, à la toison de feuilles et de cuivre, une série d'accessoires célestes ou terrestres, en désordre, où seuls les initiés lisent un système continu du monde. 


\section{Dix-huitième journée}

\section{Le culte du Lébé}

@

C'était jour de marché, les perturbations habituelles s'annonçaient. Des braiements de nuit, puis d'aurore, avaient secoué l'ouest. L'esplanade du marché avait surgi à la lumière, comme chaque matin, mais vêtue des agitations préliminaires.

Chez Ogotemmêli, il y avait conseil commercial entre le maître et un homme de bon sens accroupi sous les niches des ancêtres.

Koguem et l'étranger s'étaient assis à leur place habituelle, écoutant les deux hommes.

- Ogotemmêli, dit Koguem, annonce qu'il veut manger la tête du bœuf. II a convoqué Dyougodyêh pour le charger d'acheter la tête. Dyougodyêh explique qu'il a payé une tête, autrefois, 75 francs, qu'il l'a fait cuire, qu'il a mangé à sa faim et revendu ensuite pour 91 francs de viande.

- Le bénéfice est insuffisant, dit Ogotemmêli. II faut acheter la tête à un autre homme, pour l'avoir à meilleur marché.

Un autre moyen était d'injurier le boucher qui avait vendu trop cher :

- p.111 La preuve qu'il le mérite, dit l'aveugle, c'est que je lui ai acheté autrefois une tête et quatre pattes de bœuf.

II les avait placées dans une peau et le boucher lui avait volé I'une des pattes:

- En revenant, je n'ai trouvé que trois pattes.

II convenait de se méfier de ce genre d'homme.

- Je sais, poursuivait-il, que l'un de mes frères a acheté un bœuf vivant et qu'il va le revendre aujourd'hui. II faut lui demander la tête. Avec lui, ce sera sûr. En plus, on va maudire le faux boucher. 
Sauf pour la malédiction, Dyougodyêh était d'accord sur tout :

- Ce n'est pas la peine, disait-il, de gagner moins de cinquante francs pour avoir le soleil sur le crâne toute la journée et faire cuire une tête de bœuf pendant 6 heures.

Mais quant au faux boucher, il ne le maudirait pas, il l'injurierait seulement.

- J'avais aussi acheté une tête de bœuf à 110 francs, dit Dyougodyêh, en prenant congé, et comme se parlant à lui-même. Au même boucher. Or après avoir mangé j'en ai revendu pour 85 francs. Ai-je mangé pour 25 francs ? Non, à peine 10 ! J'ai perdu !

L'homme grommelait encore en traversant la cour.

- Maudis-le! cria Ogotemmêli, maudis-le par le «parent pétri »!

C'était la plus irrémédiable des malédictions. L'homme se retourna et dit :

- L'injurier suffira.

Puis il cracha sur le mur et passa le seuil.

Ogotemmêli baissa la voix pour répondre au Nazaréen qui l'interrogeait sur le Lébé, sur le culte actuel et sur son prêtre le Hogon.

Le Hogon habitait à côté, derrière les greniers, et l'infamie eût consisté à être entendu par-dessus le torchis. C'était là sa maison personnelle; sa résidence de fonction était située dans Ogol-du-Haut.

Le Blanc connaissait les grandes lignes du culte de ce plus vieil ancêtre dégluti par le Septième Nommo, Nommo lui-même, Huitième Nommo confondu avec le Septième et pourtant distinct.

Sa pierre d'alliance était issue de son crâne, elle était l'insigne $_{\text {p.112 }}$ de la prééminence sur les huit autres pierres principales et naturellement sur toutes les plus petites, marques des ancêtres venus dans la suite.

Sans entrer dans les chevauchements territoriaux, dans les querelles sans issue, dans les affaires de priorités personnelles, familiales ou tribales, dans les décomptes 
infinis des ascendances des droits et prétentions, on pouvait dire qu'il y avait un Lébé par région, avec un prêtre qui n'était autre que le plus vieil homme, avec un autel situé, pour Sanga, sur la grand-place publique d'Ogol-du-Bas, en un lieu que ne foulait aucun profane et auquel n'accédaient les officiants qu'en des occasions solennelles.

Cet autel, en forme d'ombilic, n'était pas fait de terre ordinaire. Ou plutôt, sa terre avait reçu, à la fondation, une force qui lui venait de loin. Loin dans le temps, loin dans l'espace.

Le Lébé des temps mythiques avait été inhumé dans le champ primordial et les hommes, quand ils se trouvèrent trop à l'étroit dans leurs cantons, résolurent d'emporter ses restes avec eux vers les pays nouveaux qu'ils pensaient découvrir.

Ayant creusé la tombe, leur aîné y trouva les pierres d'alliance et aussi un grand serpent vivant. On nomma cet homme Dyon, c'est-à-dire «creuseur». Dyon en conclut que c'était là une bonne terre puisqu'un corps mort y avait retrouvé la vie. II pensa qu'en empruntant un peu de cette terre, il pourrait transporter dans les districts de l'avenir ce ferment de résurrection, les imprégner de l'essence ancestrale.

Muni de glèbe, Dyon, imité par d'autres, s'éloigna par des chemins mystérieux qui passaient sous terre. II était suivi du serpent, forme vivante de l'ancêtre Septième et du Lébé, qui portait sur son crâne, dans un creux longitudinal, un épi de mil.

La marche souterraine aboutit au sud-ouest des falaises, où Dyon émergea du trou d'un bambou, comme l'indique la devise qu'il donna à ses descendants :

- Creuseurs! poussés par le trou d'un bambou !

D'autres émergèrent à Amani, au bas des éboulis. Un autre au pied du pic de Bamba.

D'autres, par les voies ordinaires, avaient pris la même direction et avaient rejoint les premiers.

A Kani-Bonzon, au sud des falaises, fut fondé par Dyon-Creuseur le premier autel du Lébé : la terre 
transportée fut placée à la base d'une pierre dressée que l'on recouvrit de mortier.

p.113 Dans la suite, chacun des chefs de migration prit un peu de terre sur l'édifice et fonda au loin un autre autel, lequel servait de point de départ à d'autres essaims. Ainsi la vertu du champ primordial se répandait-elle dans les défrichements, faisant reculer l'impureté, aidant à l'établissement des hommes.

Et le serpent Lébé, partout présent, unique et multiple comme un Dieu, suivait chaque fondateur.

Et c'est pourquoi on voyait, sous la table rocheuse d'Ogol-du-Haut, au nord-ouest, la caverne dite «des Femmes Réglées », d'où il sort le soir, et à l'Est, celle qui est dite « du Baobab de Dieu», où il rentre à l'aube. Et c'est pourquoi aussi ceux qui n'ont pas les yeux des hommes ordinaires, pouvaient le voir parfois, par grand soleil, lové, beige brillant, dans la friche dite «lieu de repos » que les hommes laissent dans le champ de son prêtre.

Son rôle est immense. Axe des germinations, protecteur des placenta, pourvoyeur de forces de vie, ses travaux sont quotidiens, avec des paroxysmes aux dates critiques.

- Chaque nuit, dit Ogotemmêli, il se rend chez son prêtre le Hogon, par la ruelle ouest séparant Sodamma de Do. A l'aube, il rentre par l'est entre Guêndoumman et Do. C'est pourquoi le Hogon doit être chez lui de nuit et ne sort pas du village.

- Que fait-il chez le Hogon ?

Ogotemmêli garda un long silence. Puis d'une voix encore plus basse, il dit, ce que tout le monde savait, que le Lébé léchait le corps du Hogon.

- Ainsi, chuchota-t-il, il lui donne la force de vivre pour un jour.

Et cette force profite à tous. Le Hogon est comme le représentant du Serpent auprès des hommes. II est le représentant des hommes auprès du Serpent. II est chargé de la somme de vie nécessaire aux humains et au territoire. 
Car dans la salive du Lébé réside la force de l'humidité, la buée sonore que toute bouche expectore. Pour tout un jour, le vieillard est enduit de parole.

La voix de l'aveugle devenait un souffle; il s'arrêtait pour écouter les bruits des ruelles, pour deviner les présences, pour percer les silences de ceux qui épient sur la plante des pieds, bouche ouverte, dans les angles des édifices.

- C'est pour cela qu'aucune sueur ne doit couler sur le corps du Hogon. Elle emporterait les forces. Et si la sueur sort du ${ }_{\text {p.114 }}$ corps, c'est qu'il a trompé le Lébé, rompu ses interdits. La salive est de la force vitale. Cette force s'en va si l'interdit est rompu et le Hogon meurt.

Quelques semaines auparavant, I'une des Européennes s'était rendue en grande hâte - prévenue à la dernière minute - à l'intronisation du Hogon de Nînou, et avait pu constater les précautions prises pour éviter toute fatigue et sueur à l'impétrant. Le vieillard, consacré dans les cavernes de Kounnou-Sésé, avait été porté jusqu'à son temple à dos d'homme, au travers d'une bousculade de rochers et sur des pentes luisantes à faire réfléchir un piéton.

Interrogé sur cette pratique, Ogotemmêli, déclara qu'en plus de l'affaire de la sueur, il y avait celle du contact avec le sol. et sec.

- S'il avait touché terre, tout le mil serait devenu rouge

Il aurait roussi la terre.

Car le Hogon, procédant en quelque manière de la nature du Lébé, donc du Nommo, donc des puissances célestes, donc de leur feu (puisque les grands Nommo sont les forgerons du ciel), donc du soleil, ne doit pas circuler à pied en dehors du territoire réservé. Ce territoire est le village et la zone hors des murs où s'aventurent les volailles, ce qui fait quelques dizaines de coudées.

- Mais le Hogon pourrait aussi bien roussir le village?

- Oui! mais il porte des sandales. La sandale est réservée aux prêtres et surtout au Hogon. Personne ne peut pénétrer chez le Hogon sandales aux pieds. De même 
personne n'entre dans la forge s'il n'est pieds nus; car le feu de forge a été volé au ciel. II est soleil, comme le Hogon.

- Mettre des sandales, c'est se prendre pour le soleil, dit le Blanc, mais pourquoi empêchent-elles le porteur de mettre le feu à la terre?

- Les premières sandales étaient de fer. Non pas de cuivre, qui est l'eau et aussi le rayon de lumière. Elles étaient de fer car il est couleur de l'ombre.

L'ombre est fraîche. Elle est absence de soleil, Elle aide à lutter contre lui. Le fer couleur d'ombre est une bonne protection pour le sol foulé par des pieds de feu. Sur le plateau, à Nandouli, le prêtre chausse, pendant la minute suprême de la consécration, quand il est totalement identifié au Nommo, les deux sandales de fer placées sur l'autel.

p.115 Mais c'étaient là premiers balbutiements de la technique de la marche. Il fallait des sandales d'usage commode, souples comme le pied. Les premières furent coupées dans la peau usée du soufflet de forge.

- C'est le grand Nommo qui indiqua le cuir, car la peau avait reçu le feu volé au ciel, lors de la descente du forgeron.

La peau était donc à l'épreuve du feu. Elle était de feu elle-même, ou mieux inoculée contre le feu. Elle était l'écran par excellence entre le pied et le sol à protéger.

Ainsi les sandales de cuir permirent à ceux qui tenaient des essences célestes de marcher sur les terres sans nuire à la germination. Elles leur étaient réservées et nul ne pouvait les porter sans usurpation.

Un autre accessoire particulier au Dogon et qui manifeste l'origine de son pouvoir est le bonnet rouge.

- Le bonnet rouge est comme un soleil sur la tête du Hogon. Nul autre que lui ne peut le porter dans Sanga.

Koguem sourit :

- Quand j'étais tirailleur, confia-t-il à l'étranger, je retirais toujours ma chéchia en arrivant sur les limites. 
- Si le Hogon ne sort pas du village, c'est aussi à cause du cuivre.

Lorsqu'un Hogon meurt, on lui passe aux deux chevilles et aux deux bras un anneau de cuivre. Ces anneaux viennent du pays des origines, du champ primordial, de la tombe du Lébé. Ils ont été faits du métal excrété par le Septième après sa déglutition.

Ogotemmêli réexpliquait le cuivre :

- Les rayons tombant des nuages se transforment en cuivre en touchant le sol. Mais non pas à la surface. C'est dans le fond de la terre, et trop profond pour que les hommes puissent le saisir. Celui du Lébé a été trouvé parce qu'il était dans une tombe qu'on a creusée.

Les anneaux qu'on a forgés avec le métal sont la propriété du Lébé ; le Hogon mis en terre en est orné, puis on les lui retire pour les remettre non pas à son successeur, mais au plus vieil homme qui suit ce dernier et qui sera nommé, à son tour, lorsque la place sera vacante à nouveau.

Donc, tout Hogon a, durant le temps de règne de son prédécesseur, gardé les anneaux. II s'est imprégné de cuivre. II est donc comme cuivre et de ce fait ne peut traverser aucune eau, p.116 car c'est là l'un des plus grands interdits du Nommo. Le Nommo étant, en quelque manière, cuivre par son essence céleste et lumineuse, reprend tout cuivre passant sur les lieux d'eau qui lui sont réservés.

L'Européen, personnellement, s'accommodait fort bien de toutes ces représentations, de toutes ces modalités de manipulations de l'invisible par les hommes, des hommes par l'invisible. Mais il songeait à ceux qui, de l'extérieur, auraient un jour la curiosité d'étudier la métaphysique des Dogon et chaque fois qu'il en avait l'occasion, il jetait quelques impedimenta dans les exposés où l'aveugle brassait l'univers.

- Le Nommo, dit-il, est propriétaire du cuivre, il est notamment cuivre, il excrète du cuivre. D'accord. Mais il pourrait reprendre le métal en tous temps et en tous lieux, 
et non pas seulement lorsque le porteur passe près de l'eau.

- Ne vous ai-je pas dit que le cuivre était aussi l'eau ? Passer avec ce métal près de certaines eaux, c'est risquer de le voir retourner à elle, c'est risquer d'être entraîné soimême dans ce retour.

En effet, si le cuivre est lié au Nommo et si celui-ci est l'eau, le liquide et le métal sont de même essence.

Et Ogotemmêli reprenait les explications concrètes des fondements de la pensée dogon :

- Le soleil est une terre cuite entourée d'une spirale de cuivre portée à l'incandescence qui lui donne son mouvement diurne, qui donne lumière et vie à l'univers. Le soleil est comme du cuivre en fusion. La preuve c'est qu'au feu le métal jette des rayons comme ceux de l'astre. Mais ces rayons, je vous l'ai dit, sont pompeurs d'humidité, faiseurs de nuages. Ils sont les chemins de l'eau, ils sont eau. La preuve, c'est qu'on ne les voit que par temps de brumes chaudes et d'orages. Et c'est pourquoi les rayons solaires sont dits mênn di, « eau de cuivre ».

Le Blanc fit volontairement un coq-à-l'âne :

- Mêndi, c'est aussi le nom d'une montagne.

Ogotemmêli releva la tête. Décidément, devait-il penser, les Blancs sont parfois moins sots que ne l'imaginent communément les Noirs.

- Oui, dit-il. Les ignorants disent Mênti. Mais c'est Mêndi qu'il faut prononcer.

p.117 Mêndi s'élevait comme un dôme sur les plateaux du nord, non loin de Tintam, à deux jours de marche de Sanga. L'Européen l'avait aperçu quelque temps auparavant, dans la brume sèche, gonflé comme un soufflard près d'éclater.

- On l'appelle Eau-de-cuivre parce qu'il contient du cuivre et qu'il donne beaucoup d'eau. Et c'est pourquoi les âmes des morts s'y rendent avant d'entreprendre leur voyage vers le sud. Elles y font provision de cuivre qu'elles boivent sur leur longue route. C'est cela leur provision d'eau. 
L'Européen se souvenait de la déposition d'un informateur, en vue de la montagne

- Les âmes des morts y viennent en masse. Elles se pressent à Mêndi. A pied, à cheval, sur des bœufs porteurs. Maintenant, c'est par camions bondés qu'elles arrivent pour chercher l'eau.

- L'utilité du Nommo, conclut Ogotemmêli, c'est d'avoir aussi donné le cuivre aux hommes.

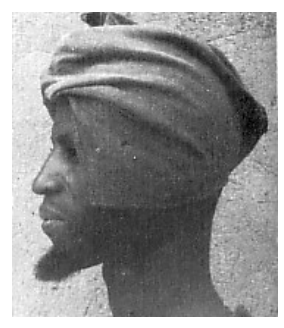

@ 


\section{Dix-neuvième journée}

\section{Le culte des Binou}

On pouvait concevoir que l'institution du Lébé était comme le centre du culte des Binou, de ce pseudo-totémisme auquel pensaient les Blancs depuis plusieurs années.

Les enquêtes menées au cours de ce nouveau séjour n'avaient apporté que des confirmations à ce qui avait été publié jusqu'alors par l'équipe.

Le culte des Binou honore et rend propices aux vivants les âmes des huit ancêtres et de certains hommes prestigieux qui, dans le sillage de ces huit, ont vécu dans la suite des temps.

Après une longue période, après la révélation de la troisième parole et l'organisation moderne du monde, la mort était apparue. Jusqu'à ce moment les hommes étaient immortels ou du moins subissaient, après une longue vie, une métamorphose comparable à celle des huit grands. Ils se rendaient dans la fourmilière, s'y enfonçaient, laissant sur l'orifice l'écuelle témoin de leur corps. Mais au lieu de monter au ciel après avoir pris forme de Nommo, ils restaient sur la terre.

p.118 Quand survint la mort, seuls quelques hommes très vieux purent se transformer selon la même règle. Les autres suivaient la loi de la destruction du corps; les rites nouveaux procédaient à la mise en ordre des forces spirituelles qu'ils libéraient.

A partir de ce moment, ils furent soumis à des dangers inconnus et leurs ancêtres, qui n'avaient pas subi la mort, vinrent à leur secours, revinrent parmi les leurs, d'où leur nom de Binou.

Pour se manifester, le Binou apparaissait à l'un de ses descendants sous une forme humaine ou animale et lui remettait l'une des pierres d'alliance (dougué) trouvées dans la tombe du Lébé. Ces pierres avaient été emportées 
par les vieillards dans leurs migrations, ou avaient été laissées dans la terre, et par des voies mystérieuses, étaient parvenues jusqu'au pays actuel des Dogon.

Muni de cette pierre et de divers accessoires qui faisaient partie de l'attirail de l'ancêtre, l'homme élu édifiait un sanctuaire et fondait un culte dont il devenait le prêtre.

Avant sa mort, il cachait la pierre dans les gorges ou les mares, et son successeur, possédé par le Nommo et par l'esprit du Binou, se mettait en quête, girovaguant dans les roches, fouillant les eaux, jusqu'à ce qu'il l'eût trouvée, donnant ainsi la preuve de la réalité de l'appel céleste.

Aujourd'hui encore, on rencontre dans les villages ces hommes aux yeux luisants qui parfois quittent leurs travaux ou se dressent en pleine nuit pour l'inlassable recherche qui dure souvent de longues années.

Et l'Européen avait pu voir, au quartier de Dodyou Oreil, le postulant à la prêtrise du Binou Ogoïné, l'un des garçons les plus intelligents et les plus instruits de Sanga. II relevait un culte dont le prêtre précédent était mort depuis plus d'un siècle. Personne n'avait retrouvé depuis ce temps le matériel rituel.

Chaque famille, faisant partie de l'un des huit grands groupes ancestraux, a un Binou appartenant à ce groupe. Cet ancêtre peut être commun à des familles dispersées formant des ensembles importants. II arrive encore que le matériel d'un sanctuaire ait été partagé entre plusieurs familles.

Des sacrifices réguliers sont offerts au Binou, lors des semailles, à la récolte. II s'agit pour les ressortissants de p.119 bénéficier de la force de l'ancêtre, force vivante par excellence, puisqu'il n'a pas subi la mort.

Dès le début des enquêtes, qui remontaient à près de quinze ans, l'équipe de chercheurs avait été amenée à étudier cette institution.

Les apparences étaient convaincantes: les animaux surgissaient aux tournants des mythes, crachant les pierres d'alliance que leur avait remises l'ancêtre et 
devenant du fait même interdits, «tabou » comme on dit en sabir européen. Les uns semblaient jouer un simple rôle d'auxiliaire, de porteur de message, de sauveur. D'autres, au contraire, se confondaient avec l'ancêtre lui-même; le mythe du Binou Tiré, ancêtre de la famille d'Ogotemmêli dont le quartier d'origine est Sodamma, d'Ogol-du-Haut, en donnait un bon exemple :

L'ancêtre, devenu vieux, avait coutume, lorsque les adultes étaient au travail, de garder les enfants dans la maison de son fils aîné. Un jour, il se transforma en serpent, ce qui affola les bambins. Mais comme il reprenait son apparence au retour des hommes, on crut à des imaginations enfantines. Pourtant, la chose s'étant renouvelée, le fils aîné, revenant inopinément des champs, surprit le vieillard en pleine métamorphose. Celui-ci, honteux d'être découvert, se mua aussitôt en antilope chevaline pour s'enfuir plus vite. Poursuivi par l'homme, il se précipita dans la caverne dite Kommo Dama, au sud-ouest des Ogol, et s'y enfonça.

L'homme, n'osant le suivre, resta dans l'entrée du trou, écoutant le bruit décroissant du galop de la bête qui se perdait dans les entrailles de la terre. Déjà il allait se retirer, n'entendant plus rien, lorsqu'il perçut une rumeur qui allait en s'amplifiant. La rumeur devint grondement, grandit comme un orage et une vague énorme déferla finalement du fond de l'antre, venant mourir aux pieds de I'homme et se retirant aussitôt.

Regardant au sol, I'homme aperçut une pierre déposée par le flot, qui était la marque d'alliance abandonnée par le vieillard avant sa disparition dans l'autre monde. L'ayant recueillie, il la confia par la suite à un homme de la famille qui se révéla possédé par l'esprit de l'ancêtre et du Nommo et qui devint le prêtre, premier de la série, du Binou Tiré de Sodamma.

On pouvait croire que le totémisme dogon, tout en présentant un caractère particulier, remplissait les conditions imposées par les sociologues.

p.120 De plus, les indigènes eux-mêmes, par abus de mots, aidaient à cette détermination: ils donnaient 
indifféremment le nom de Binou à l'ancêtre et à l'animal interdit.

Pourtant, un doute subsistait : c'était l'ancêtre humain, et lui seul, qui jouait le grand rôle dans le culte. L'animal semblait toujours être un accessoire; les liens entre I'homme et l'espèce n'apparaissaient pas clairement. L'équipe des Blancs en était arrivée à éviter le mot totem, à s'exercer aux néologismes. Dirait-on binouisme?

Tant que ne serait pas réglée la question des rapports entre I'homme et l'animal, on ne pouvait se prononcer.

Ogotemmêli allait apporter une solution, sans doute provisoire, mais si originale qu'elle devait renouveler la question du totémisme dans son ensemble.

II commença pourtant l'entretien par des aphorismes qui n'étaient pas de nature à éclairer le problème.

- L'animal, dit-il, est supérieur à l'homme, car il est de la brousse, et il n'est pas astreint au travail. Beaucoup de bêtes se nourrissent de ce que l'homme cultive avec peine.

II allait même jusqu'à dire que les animaux étaient plus perfectionnés que les hommes, attendu qu'ils n'avaient pas la parole.

Entendait-il par là que la parole, véhicule du progrès, fondement de l'organisation du monde, était finalement une calamité ? Voulait-il dire que la parole était en quelque sorte née du désordre parce que nécessaire au rétablissement de la marche normale des choses? Voulait-il dire que si le monde s'était développé sans heurts sur la base originelle, point n'était besoin de parole, ni de techniques, les deux choses étant étroitement liées ? Voulait-il dire que les animaux étaient à l'abri des désastres humains?

Jamais Ogotemmêli n'apporta de réponse à ces questions.

II apparut, dès ses premières déclarations, que le rôle de l'animal était lié à la gémelliparité originelle, qu'il était de réparation, de réorganisation, de compensation.

- L'homme, se disait à lui-même l'Européen pour rassembler ses idées, a perdu la gémelliparité. Le Nommo intervient, donne deux âmes de sexes différents à chaque 
enfant. Inconvénient: I'être est mâle et femelle. II faut le décider dans un sens ou dans l'autre. Circoncision et excision sont la solution : prépuce et clitoris, où est fixée la seconde âme, sont écartés. Inconvénient : ${ }_{\text {p.121 }}$ une âme va rester sans support. Solution: le prépuce devient le lézard dit «Soleil », le clitoris scorpion. Inconvénient : ces animaux porteurs sont frustes, trop près des créations poursuivies à l'aurore du monde; la seconde âme, qui reste toujours en contact avec l'intéressé, est mal étayée, mal assurée. Solution?

Ogotemmêli méditait. On était à la racine d'une des plus vieilles institutions humaines.

- Quand les huit ancêtres naquirent du premier couple, huit animaux différents naquirent au ciel.

- De qui ?

- Des couples d'animaux créés, dès l'origine, par le Dieu Amma. Ils n'avaient, jusqu'alors, aucun rapport avec la terre. Dès l'apparition des huit hommes, chacun d'eux eut une âme en commun avec un animal, mais l'homme restait sur la terre et son correspondant au ciel. C'est après la métamorphose dans la fourmilière, après leur transformation en Nommo que les ancêtres, montant au ciel, y rejoignirent leur animal, sans pourtant se confondre avec lui.

Quant aux hommes qui vinrent dans la suite, ils se transformaient de la même façon mais ne montaient pas au ciel, restant ainsi indéfiniment séparés de leur homologue, qui naissait en même temps qu'eux, dans l'espèce correspondant à leur famille.

Lorsque survint la mort, le nouveau système du monde était déjà descendu sous la forme du grenier céleste sur lequel figuraient tous les animaux. De ce fait, les ancêtres métamorphosés étaient en quelque sorte représentés par leurs correspondants animaux qui, dès ce moment, vivaient dans les terres non cultivées encerclant les villages et non plus au ciel.

- L'animal, dit enfin Ogotemmêli, est comme le jumeau de l'homme. 
Et c'est de lui que se servait l'ancêtre pour se faire connaître des vivants qu'il voulait aider, car l'animal était comme son jumeau; certes distinct de lui, né en d'autres zones, de forme apparemment hétérogène, mais de même essence et appartenant à la même promotion répercutée jusqu'au ciel.

L'ancêtre, en se manifestant, apportait une aide précieuse aux hommes, aide dont l'un des éléments les plus efficaces était la révélation de ce jumeau inconnu auprès duquel chacun vivait sans le savoir et qui devait être respecté en devenant l'interdit de la famille.

p.122 Ainsi, de révélations en révélations, le peuple dogon tout entier s'installa dans un système nouveau où chaque homme était en possession de deux supports pour sa seconde âme: l'un, dès sa naissance, était constitué par l'animal; l'autre, à la circoncision, était le lézard « soleil ».

Ogotemmêli s'étendait sur le rôle de l'animal, de ce point de vue de jumeau, sur les répartitions du spirituel, sur les devoirs de l'homme vis-à-vis de son homologue, de son interdit, de ce gage de vie déposé hors de lui-même. Mais soudain, le système apparut dans son étonnante complication :

- J'ai dit, remarqua-t-il en reprenant comme de coutume ce qu'il avait exposé, que les premiers enfants et les animaux du ciel n'avaient pas de suite (il voulait dire: pas de rapports). C'est parce qu'on a circoncis et excisé qu'il y a eu rapports. Donc, à chaque naissance d'homme naît un animal interdit. Mais ce dernier a lui-même un jumeau, un animal interdit. Ce dernier aussi et ainsi de suite. Chaque famille d'hommes vient en tête d'une classe entière d'animaux.

II insistait sur ce fait considérable. Chaque famille d'hommes faisait partie d'une longue série d'êtres et l'ensemble des familles était lié au règne animal en entier. Et derrière lui apparaissaient obscurément les séries végétales.

- Quand un homme naît, dit l'aveugle, parce qu'il est la tête (c'est-à-dire: le chef), tous les animaux interdits, tous les interdits d'interdits naissent en même temps. 
Ainsi l'homme, dans chacune des huit familles, était un déclencheur d'êtres, répercutant la vie jusqu'à l'extrémité d'une série intéressant le huitième de la création.

L'esprit qui présida à cette organisation supposait que l'obligation de l'interdit, du point de vue de l'homme, s'étendait à la classe entière. En réalité, la règle ne valut que pour un ou deux animaux et un végétal. Car I'homme se fût trouvé enserré dans un réseau d'impossibilités.

- Quand je suis né, est née une antilope chevaline. L'interdit de l'antilope est la panthère. Une panthère est née, Mais à son tour elle a pour interdit l'antilope.

Ainsi le cercle se fermait.

- Cependant, dit l'aveugle, bien que l'homme ne s'occupe pas de tous les êtres de la série, à chaque accouchement sont déclenchées les naissances de tous les animaux et végétaux liés à sa famille.

p.123 C'était dire que lorsqu'un enfant naît dans chacune des huit familles, toute la création est mise en branle.

L'Européen prit congé; les premiers braiements des ânes rentrant des pâtures s'entendaient en direction de Lulli.

Derrière chaque homme qu'il rencontrait dans les ruelles, il croyait voir les ombres de la huitième partie des règnes animés. 


\section{Vingtième journée}

\section{Le Sacrifice}

En montant par les ruelles d'Ogol-du-Bas, de Dodyou Oreil à Tabda, par Guinna et Amtaba, le Nazaréen pensait à ce mystère insondable des rites qu'est le sacrifice sanglant.

Dans les temples de Binou, sur les autels du Lébé, sur les ombilics de terre aux mille destinations qui s'érigent sans pudeur dans le milieu des cours ou qui se cachent le long des parois, des bêtes mouraient tout au long de l'année, aux époques prévues. Toutes perdaient leur sang pour des liaisons avec le ciel que les hommes s'obstinaient à entretenir. Les poulets le versaient la tête pendante, ailes écartées, pattes retenues par la poigne solide de l'égorgeur. Les moutons étaient passés à bout de bras, pantelants, aux hommes du haut des terrasses, pour être brandis au-dessus des frontons ferrés de crochets et d'enclumes à bras en croix. Les moutons bredouillaient leur sang par leur plaie remplie de bulles, et les flots coulaient sur les façades en traînées garance qui tournaient au brun, comme un fer passe de l'incandescence au sombre.

Quand la victime était trop pesante pour être déplacée du sol où elle agonisait, on recueillait son sang dans les calebasses, au jet de sa gorge, comme à une fontaine, et le sacrificateur répandait les flots, comme un jardinier spirituel, sur tous les plants de fer et les bois consacrés.

On pouvait dire que toutes les bêtes domestiques de Sanga mouraient sur les autels, sauf quelques bovidés débités au marché depuis peu d'années.

Et le Nazaréen, progressant dans l'enchevêtrement des

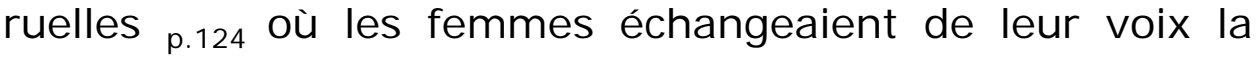
plus douce le salut du matin, pensait à toute l'encre qui avait coulé à cause de ce sang, à toutes les hypothèses émises pour expliquer l'acharnement des hommes à immoler. 
II avait l'impression que les seuls à comprendre, que les seuls à pouvoir s'expliquer étaient justement les seuls à ignorer l'écriture.

Il avait déjà, quelques années auparavant, entrevu le mécanisme de la mort rituelle: un Dogon de quinze ans avait mis sur la voie un membre de l'équipe et brusquement tout s'était éclairé. Sous ses apparences diverses, qu'il soit de consécration, d'expiation, de divination, de purification, d'entretien de l'invisible ou de soi-même, le sacrifice, chez les Dogon, avait un effet constant : redistribuer de la force vitale.

Mais il ne s'agissait pas tellement de prendre à une victime sa force pour la placer ailleurs, pour augmenter celle d'une autre personne visible ou invisible. II s'agissait de créer un mouvement de forces dans un circuit composé du sacrifiant, de la victime, de l'autel et de la puissance invoquée. Dans le cas du service ordinaire d'une puissance comme le Nommo, fils de Dieu, ou comme le Dieu Amma, le mécanisme apparaissait clairement.

Au moment critique, c'est-à-dire quand le sang coule, I'homme formule une prière par laquelle il invoque la puissance - par exemple le Nommo - et explique son geste. Cette prière est prononcée à haute voix; elle est donc elle-même une expectoration de la force qui suit les volutes de buée sortant de la bouche. Cette force va d'une part alerter le Nommo. D'autre part elle va conduire celle qui sort de la gorge ouverte de la victime et qui s'épanche sur l'autel.

Dans l'autel, la vertu nouvelle, fraîche, se joint à celles qu'une longue série de meurtres rituels a déposées.

Car l'autel est un réservoir où s'emmagasinent les forces, où l'homme puise le moment venu et qu'il entretient. C'est aussi le point de rencontre de l'homme et de l'invisible.

Tandis que l'autel est alimenté, que sa puissance est rénovée par l'apport frais, le Nommo, alerté par la parole, vient s'abreuver, se fortifier, entretenir sa vie. Et de fait, le mot dogon désignant le sacrifice vient d'une racine signifiant « faire revivre ». 
Mais en investissant l'autel, le Nommo amène un flux qui est p.125 aussi un apport frais. II suit de là une émulsion, un amalgame bouillonnant dont deux courants vont sortir.

L'un d'eux est capté par le Nommo et constitue son bénéfice. L'autre, le plus important du point de vue humain, remonte le flot coulant de la victime, pénètre dans la gorge ouverte, suit les canaux du sang et va s'emmagasiner dans le foie, organe privilégié, creuset secret de la personne.

C'est alors que la victime est dépecée, préparée, consommée. Mais le foie plein de vertu revient au bénéficiaire du rite, au sacrifiant dont le propre foie se gonfle d'un flux revigorant. Par cette consommation, celuici assimile une part de la force du Nommo, fermant ainsi le circuit ouvert par la parole, laquelle provient justement de son foie.

Le Nazaréen se remémorait tous ces détails qui constituaient l'une des premières explications données par les usagers d'un geste plusieurs fois millénaire, et il constatait que ce qui sortait du foie revenait au foie. L'homme expectorait pour réingurgiter, et dans le cycle de cet entretien spirituel aux apparences alimentaires, se tenaient la victime et l'autel de Dieu.

Mais le cycle se fermait-il vraiment ainsi ?

Ogotemmêli ne s'était jamais beaucoup étendu sur le fonctionnement du sacrifice. II supposait le problème résolu par l'Européen, d'abord parce qu'il le savait renseigné et aussi parce que la chose lui semblait aller de soi.

Il avait des révélations à faire sur l'institution, mais il avait attendu que son interlocuteur fût au courant de diverses pratiques et représentations. Et il était certain que les explications eussent été incompréhensibles sans la connaissance des idées que les Dogon se faisaient du Verbe et de ses effets.

Le Blanc, qui allait pénétrer dans Tabda et prendre le tournant pour se rendre chez l'aveugle, s'arrêta soudain, en faisant signe à Koguem de regarder: dans le coude sombre de la ruelle, un poussin noir, à queue en trapèze 
renversé, poursuivait avec frénésie une chose invisible. II sautait en tous sens, tournant presque sur lui-même en l'air, s'arrêtant brusquement pour s'avancer avec précaution, le bec rasant la terre. Mais comme l'étranger s'était arrêté, l'animal se précipita sur une tache claire qui s'immobilisa quelques instants au mur : c'était le reflet de l'écran jaune fixé à l'objectif que le Blanc portait toujours sur lui.

Dans la cour, Ogotemmêli avançait à pas prudents, dans ses p.126 haillons bruns. Ses pieds connaissaient toutes les bavures de roches et les poussières. II tenait de la main droite son bâton luisant qui lui venait à l'épaule. La main gauche serrait contre lui le sac de cuir noir connu à deux jours de marche alentour et qui contenait des remèdes mystérieux.

Ayant longuement salué, il s'assit à sa place habituelle, dans l'embrasure de la maison à étage. Ce jour-là, sa voix fut à peine perceptible, car il s'agissait encore du Lébé et de son prêtre le Hogon. II voulait enseigner à l'Européen le sens du sacrifice annuel dont la première phase s'opérait sur l'autel extérieur, situé au milieu de la grand-place d'Ogol-du-Haut, dite «terrasse du Lébé ».

II s'agissait d'un ombilic de terre grise que tous les habitants contournaient soigneusement et dans lequel était placée la parcelle de terre prélevée dans les temps anciens sur l'autel de Kani-Bonzon, premier relais dans les migrations des Dogon, formé lui-même avec la terre de tombe apportée du champ primordial. Cet ombilic figure donc en quelque sorte la tombe du Lébé.

Le jour venu, après les cérémonies ouvrant la période des semailles, une chèvre est égorgée sur l'autel :

- Un forgeron est là, dit Ogotemmêli, avec son enclume. Il est placé devant celui qui va manger le foie.

- Qui va manger le foie ?

- Le plus vieux des hommes «impurs ».

Les «impurs» sont les hommes relevés de la plupart des interdits et notamment de ceux qui concernent la mort. Chaque famille en compte plusieurs qui sont 
désignés par la divination. Eux seuls sont habilités à manipuler sans danger les forces émanant des morts.

- Pourquoi un « impur»?

- Parce que le sacrifice a lieu sur une terre de tombe. Et aussi parce que l'« impur » est aujourd'hui, comme fut le Lébé, ni mort ni vivant.

De ce fait, l'« impur» était le plus apte à recevoir temporairement la force qui allait monter de la victime en lui, par déglutition du foie.

- Dès l'égorgement, enchaînait l'aveugle, le forgeron frappe le sol de son enclume. II ne s'arrête que lorsque tout est consommé. En frappant il aide aux déplacements des forces.

La force vitale du Lébé, contenue dans la terre de tombe ${ }_{\text {p.127 }}$ pétrie avec celle de l'autel, monte, au rythme des battements, dans le foie de la chèvre et de là, pénètre dans le foie de l'impur qui le consomme après cuisson.

- Ce sont les coups de l'enclume qui provoquent le mouvement.

II entendait par là que les coups remplaçaient la prière d'alerte et imprimaient sa direction au mouvement. II semblait bien, de plus, que ces coups rappelaient ceux que donnait le Forgeron tombé du ciel tandis que se poursuivaient la résurrection et la déglutition souterraines.

- L'« impur », continuait Ogotemmêli, lorsqu'il mange le foie de la bête, c'est comme s'il mangeait le crâne du Lébé, le crâne de son vieux Père. Car c'est la force du crâne du Lébé qui passe dans la bête sacrifiée.

Ceci rappelait la disposition des pierres vomies dans la tombe par le Nommo Septième, après consommation du Lébé. Alors que les pierres des articulations étaient destinées au culte des Binou, celle qui remplaçait la tête était le signe du culte du Lébé lui-même, en tant que représentant prestigieux du Huitième ancêtre, en tant qu'identifié à lui.

- L'« impur » mange le foie cuit, disait l'aveugle, car le feu en fait sortir tout ce qui est néfaste. La partie 
mauvaise de la bile, contenue dans la vésicule, s'en va dans les flammes et le bon principe reste.

Mais Ogotemmêli, baissant de plus en plus la voix et s'étant assuré que ni la femme du Hogon ni la sienne ne pouvaient entendre, déclara : vie.

- L'«impur», en mangeant le foie, donne sa propre

On était à un tournant de l'enquête. Ogotemmêli cracha et reprit du tabac. Pendant plusieurs minutes, il ne fut question que d'une obscure affaire de champ sis au nord de la dépression de Sammtigou, au droit du rocher dit « Caverne Tâ ». Ogotemmêli parlait avec véhémence. II trouvait l'affaire claire comme le jour et tenait pour des imposteurs les gens du rocher de Go. Il ne voulait pas même prononcer leur nom ; il disait « les gens de Go ».

— L'« impur »? rappela le Nazaréen.

- En mangeant le foie, il devient le Lébé lui-même.

C'est-à-dire celui qui est mort, qui fut dégluti, qui ressuscita pour la réorganisation du monde.

- L'« impur » est comme le Lébé ; il porte dans son foie la ${ }_{\text {p.128 }}$ force vitale du Lébé. II est comme vidé de sa propre vie pour se remplir de celle de l'Ancêtre. Et comme c'est dans le foie que naît la parole, tout ce que dit l'« impur », à partir du sacrifice et longtemps après, est comme dit par le Lébé. En parlant, l'«impur» communique à tous le bon verbe.

Ainsi parcourait-on une autre étape du sacrifice. On avait vu le cycle des mouvements de forces partir du sacrifiant, passer par la puissance invisible, l'autel, la victime et revenir au sacrifiant. On pouvait tenir la chose pour satisfaisante. Mais la pensée dogon ne s'en était pas tenue là. Les vertus mises en branle poursuivaient leur route. Par la parole de I'homme qui s'identifiait au Mort, acteur de la troisième révélation, les forces de vie se répandaient sur l'humanité à portée de voix.

Dans cette action, le plus vieil «impur» n'était pas seul. Il était secondé par d'autres hommes de même qualité que lui et qui mangeaient le reste de la victime. Eux aussi recevaient un pouvoir de parole; mais à un 
moindre degré. Pourtant leur voix était efficace et s'entendait aussi pour le bien de la société.

Cependant Ogotemmêli poursuivait sa déposition. Car il ne se plaçait pas du point de vue du sacrifice en général, mais de celui qu'on offrait au Lébé lors des semailles et qui se continuait le lendemain de l'immolation de la chèvre sur l'autel extérieur.

Le second sacrifice avait lieu dans la maison du Hogon, sur un autel qui ne semblait pas élevé spécialement au Lébé, mais aussi, et peut-être surtout, au Nommo Septième, qui l'avait dégluti.

Cet autel n'avait probablement pas été pétri avec la terre de tombe, car le Hogon, homme «vivant » par excellence, consommait le foie de la victime après avoir prononcé la prière qui résumait l'attente de tout le territoire :

Dieu ! reçois le salut du matin!

Ancêtres! recevez le salut du matin !

Nous sommes au jour choisi,

Nous allons sortir pour ensemencer,

Nous allons sortir pour cultiver,

Dieu ! donne au mil la germination,

Que les huit graines pointent, p.129

Ainsi que la calebasse neuvième.

Donne une femme à qui n'en a pas.

A celui qui a femme sans enfant,

Donne un enfant.

Protège les hommes contre les épines,

Contre les morsures de serpent,

Contre le mauvais vent,

Verse la pluie

Comme on verse la poterie à eau.

Mil ! viens ! »

Ogotemmêli ne dit pas si le Hogon s'identifiait au Nommo Septième. Mais peu importait, car la jonction du Septième, déglutisseur et ressusciteur, avec le Lébé, dégluti et ressuscité, se faisait le jour même: les « impurs » qui avaient, la veille, communié dans la chair du Lébé et dont le plus vieux avait subi une véritable 
transsubstantiation, se présentaient à la demeure du Hogon, au moment du sacrifice, pour demander la non-séparation, l'union continue du Septième et du Lébé, représentant la famille du Huitième ancêtre, c'est-à-dire l'étroite conjonction de la parole et du maître de la parole.

Ainsi assurait-on, par le rite sacrificiel, la continuité de l'ordre établi lors de la résurrection survenue dans le champ primordial, laquelle devait être suivie par la germination des graines mises en terre.

Mais Ogotemmêli ne voulait pas laisser croire que le sacrifice au Lébé lors des semailles avait seul la qualité de permettre l'expansion des bonnes paroles.

- Dans tout sacrifice, dit-il, l'effet est le même que pour celui du Lébé. On se nourrit d'abord soi-même, on se fortifie, puis on rend, par la parole, la force à tous les hommes.

Même dans les sacrifices d'entretien de soi, que chacun offre sur ses autels individuels représentant l'un sa tête, l'autre son corps, le repas du sacrifiant profite à tous.

Et il en est ainsi pour toute la gamme de sacrifices et de libations que les hommes versent sur les autels de fondation de village, sur les autels de quartiers, dans les sanctuaires de famille, sur les poteries de jumeaux, sur celles des ancêtres, sur le grand masque, sur les autels du feu.

Ainsi tous les sacrifices ont les mêmes effets que le rite collectif célébré aux semailles de la communauté : après qu'il a p.130 communié, l'homme parle et son verbe, imprégné des vertus ancestrales, va aux autres :

- L'autel, dit Ogotemmêli, donne à l'homme et I'homme redonne une partie à tous. Un sacrifice sert un peu à soi-même et le reste va aux autres. Les forces du sacrifice rentrent dans I'homme, passent et ressortent. Et c'est ainsi pour tous.

Si bien que chacun donne à tous, mais aussi reçoit de tous. Il y a entre les hommes un échange continu, un mouvement incessant de flux invisibles. Et il est nécessaire qu'il en soit ainsi pour que dure l'ordre universel. 
- La parole, dit Ogotemmêli, est pour tous en ce monde ; il faut l'échanger, qu'elle aille et vienne, car il est bon de donner et de recevoir les forces de vie. 


\section{Vingt et unième journée}

\section{La parole fécondante}

L'entretien de la veille avait fait apparaître la toute-puissance du verbe humain. Par la voix l'homme alerte Dieu ; par la voix il prolonge l'action divine.

Il fallait sans doute s'y attendre, puisque Dieu luimême, par l'intermédiaire du Nommo son fils, avait réorganisé par trois fois le monde à l'aide de trois paroles successives, de plus en plus explicites, de plus en plus répandues. Il y avait eu aussi la régénération des huit hommes, leur renaissance en génies d'eau par la voix du Nommo qui, se parlant à lui-même, se fécondait.

D'où venait cette parole, qui se développait sur les volutes hélicoïdales de la buée de devant le visage ? Quels chemins suivait-elle dans l'être humain ?

II n'était pas dans le génie d'Ogotemmêli de répondre directement à de telles questions.

- Le Nommo, dit-il, qui est eau et chaleur, entre dans le corps par l'eau qu'on boit et il communique sa chaleur à la bile et au foie. La force vitale qui porte la parole, qui est la parole, sort de la bouche en vapeur d'eau, qui est eau et qui est parole.

Comme il l'avait dit la veille, Ogotemmêli rappelait que la p.131 parole sortait du plus profond, du plus secret de l'être, c'est-dire du foie.

Mais il voulait suivre le chemin original de sa pensée et non répondre à des questions.

II rappela que la première parole avait été scandée devant le sexe d'une femme. En effet, le premier cache-sexe, support de la parole, avait été toronné, avait été « parlé » par le Nommo devant sa mère.

- La parole, dit-il, est ensuite sortie de la fourmilière, c'est-à-dire de la bouche du Nommo Septième, c'est-à-dire d'un sexe de femme. 
La seconde parole, incluse dans le tissage, était en effet sortie d'une bouche qui était aussi le sexe primordial où avaient été menées les premières parturitions.

- Sortie d'un sexe de femme, la parole rentre dans un autre sexe qui est l'oreille.

Dans le symbolisme du corps, déjà développé par l'aveugle, l'oreille était un sexe double : le pavillon mâle, le trou auditif femelle.

Mais en réalité, la parole, selon sa qualité, peut entrer par deux ouvertures de la femme : oreille et sexe.

- La mauvaise parole entre par l'oreille, pénètre dans la gorge, dans le foie et finalement dans la matrice. La mauvaise odeur du sexe féminin est la mauvaise parole entendue par l'oreille.

Le phénomène de l'odeur apparaissait comme l'achèvement d'un cycle de paroles.

Au contraire, la bonne parole, tout en étant recueillie par l'oreille, va directement au sexe où elle s'enroule autour de la matrice comme s'enroule autour du soleil la spirale de cuivre. Cette parole d'eau apporte et entretient I'humidité nécessaire à la procréation et le Nommo, par ce moyen, fait pénétrer dans la matrice un germe d'eau. II transforme en germe l'eau de la parole et lui donne l'aspect d'un humain mais l'essence d'un Nommo.

Ou plutôt le Nommo, présent dans le sexe humide comme il est dans toute eau, forme avec les paroles efficaces, qui sont buée et qui se mêlent à la semence féminine, un petit être d'eau à son image.

Donc, à l'origine de l'homme, se trouve un germe céleste qui gît en instance, dans toute matrice de femme féconde. II est ${ }_{\text {p.132 }}$ formé par le Nommo, mais la matière vivante qui le compose est le fait des humains. Toutes les bonnes paroles, qu'elles sortent des bouches des femmes ou de celles des hommes, entrent au sein de toutes les femmes, qu'elles font prêtes pour les unions et les parturitions futures.

Car le germe ainsi pétri d'eau ne saurait se développer. II est fait d'attente. II peut d'ailleurs être défait par les mauvais propos. II est immobile et le flux du bon verbe, 
même s'il était incessant, ne parviendrait qu'à le faire persévérer dans son être. II stagne: il reste à l'aube de lui-même.

Ogotemmêli n'expliquait pas pourquoi ce germe céleste ne pouvait se développer selon son essence. Interrogé sur ce point, il aurait sans doute répondu que le pourquoi des destinées de l'univers n'était pas de sa connaissance et que si les parturientes mettaient au monde des génies célestes et parfaits, ces destinées ne seraient pas ce qu'elles sont.

II faut donc donner au germe un élan nouveau. II faut aussi opérer sa transsubstantiation, car sa nature ne saurait s'accommoder de la vie terrestre.

C'est alors qu'intervient l'homme.

Mais il semble que cette intervention, bien que nécessaire, soit marquée par certains événements originels. La lutte amoureuse du couple humain, où la femme résiste tandis que son partenaire a l'initiative, est l'image de la première lutte menée par le chacal, fils aîné de Dieu, et par sa mère la Terre. L'homme actuel est le chacal creusant la fourmilière, à la poursuite de la fourmi, avatar de la Terre. La femme est la mère incestueuse qui s'avoue finalement vaincue par plus fort qu'elle et qui s'unit à son fils.

L'union du couple, dans l'ombre de la seconde pièce aux quatre poteaux, se consomme sur le terre-plein orienté. L'homme face à l'ouest, couché sur le côté droit; la femme face à l'ouest 1 .

Le lit étant le champ originel et contenant les semences prêtes pour la germination, est rempli de vie en instance.

Au moment de l'union, le Nommo régit la semence masculine qui se met en hélice autour de la matrice comme a fait la parole. Cette semence, venant d'un organe fait de terre, est elle-même symbole de la terre. Elle est aussi terre car elle provient des articulations de l'homme, qui étaient marquées, dans la tombe primordiale, par les pierres d'alliance du vomissement.

\footnotetext{
1 [css : ou face à l'est ?, cf. p. 91].
} 
- p.133 Les pierres, dit l'aveugle, étaient placées aux articulations, car le principal, dans le corps de l'homme, c'est l'articulation.

Le Nommo pétrit cette glèbe avec l'eau du germe, qui, elle, est le produit des paroles enseignées par le ciel.

- L'eau de la femme, dit Ogotemmêli, que le Nommo a formée à son image, il la mélange avec la semence de I'homme qui est terre.

Comme toujours, il procédait par retouches successives de sa première phrase pour cerner les sujets difficiles:

- De même que Dieu a pétri l'homme en terre et eau, de même le Nommo pétrit la semence de I'homme avec l'eau de la femme.

Enfin il ajouta :

- Le Nommo, avec les paroles et la semence féminine, forme un être d'eau à son image. Le semence de l'homme entre dans ce germe comme un homme.

II voulait dire que dans l'être d'essence céleste, en instance dans la matrice, pénétrait tout d'une pièce, « comme un homme », la nature humaine.

Et la semence masculine, provenant des articulations, les transmettait: elle donnait à l'être aux membres souples, comme ceux du Nommo, les coudes et les genoux des hommes.

Ainsi la semence masculine, extraite des huit articulations, se porte, à l'intérieur de l'embryon, aux places analogues de celles qu'elle occupe dans les membres du mâle. Elle marque de cette première manière la nature humaine.

Elle est aussi, par sa qualité terrestre, le rappel et le témoin de la dette que chacun doit à la terre, car c'est de glèbe que fut formé le premier couple. Et cette dette doit se payer, par versement de sang, lors de la circoncision, de l'excision, lors des périodes menstruelles.

Mais Ogotemmêli se réservait de parler de cette dette plus tard. II revenait sur les effets du verbe dans la génération. 
- De jour, la parole entre dans le sein des femmes. Tous les hommes parlant à toutes les femmes aident à la procréation.

En parlant à une femme, on la féconde. Ou du moins en introduisant en elle un germe céleste, on la met en état d'être humainement fécondée.

Et l'aveugle comparait la femme enceinte à l'épi de mil qui commence à gonfler dans sa spirale de feuille. On dit de cet épi p.134 qu'il «a pris sa voix », peut-être par analogie avec la femme fécondée qui, elle aussi, a pris une voix, a pris la voix des hommes.

Mais Ogotemmêli insistait sur la nécessité, pour que la parole soit bonne, de la prononcer de jour.

- La parole diurne est seule bonne. La parole nocturne est néfaste.

Et c'est pourquoi il est interdit de parler haut, de crier, de siffler de nuit dans les villages.

- Les paroles s'envolent. On ne sait où elles vont. Elles se perdent. C'est de la force qui se perd car toutes les femmes reposent, aucune oreille, aucun sexe n'entend.

Où peuvent s'évanouir les paroles sans écho et sans personne pour les recevoir? Était-il bon de lancer par-dessus les murs de clôture, dans les interstices des portes, dans les ruelles désertes, des paroles sans destinataires?

II y avait pire, pourtant, que l'absence d'auditrices. En réalité, il y a toujours, dans un village, des femmes qui ne dorment pas.

- La parole de nuit entre dans l'oreille des femmes. Elles se disent «Qui a parlé ? ». Elles ne le savent jamais. Ce qui est dit de nuit est parole d'inconnu, tombant dans des seins de hasard.

Si donc les femmes étaient ainsi fécondées, l'embryon serait un fruit d'aventure, «comme celui qu'elles recevraient en dormant sans règle avec des garçons ».

Mais la parole nocturne ne féconde pas les femmes, et de même que les coups donnés de nuit sur le sol défont le 
travail de jour mené par le forgeron sur son enclume, de même :

- Le verbe de nuit, pénétrant par l'oreille des femmes, passant par la gorge et le foie, se love autour des matrices dans un sens néfaste, déroulant les spires efficaces de la parole diurne.

La mauvaise parole rendait donc momentanément la femme inapte à la procréation, puisqu'elle détruisait, ou mieux démontait «le germe d'eau» prêt à recevoir l'apport du mâle.

Son action allait plus loin. L'aveugle avait déjà dit que ce verbe mauvais ne faisait pas qu'investir la matrice: il s'en exhalait en effluves qui jouaient aussi un rôle décisif dans les jeux génésiques.

- La mauvaise parole est une puanteur. Elle agit sur la force de l'homme. Elle va du nez à la gorge et au foie, du foie au sexe.

p.135 Elle contribuait à l'éloignement de l'homme. Ogotemmêli en vint alors à l'hygiène féminine qui pouvait combattre, dans une large mesure, les effets des mauvaises paroles. II rappela le grenier céleste, dont le centre était occupé par la poterie sphérique, image de la matrice et du soleil, contenant les pierres d'alliance, elles-mêmes destinées à marquer les articulations productrices de semence humaine.

Sur cette sphère était placée, comme fermeture, une poterie plus petite, remplie d'huile de Lannea acida destinée aux soins intimes, et symbolisant le fœtus. Ce récipient était lui-même surmonté d'un pot plus petit encore, contenant des racines odoriférantes.

Ogotemmêli, s'appuyant sur ce matériel, développa les règles de l'hygiène où entrait la méticuleuse gesticulation des femmes en vue d'attirer les hommes. Le parfum, agissant comme un bon verbe, luttait contre la puanteur issue de la mauvaise parole.

Et de là, il en revint aux jeux des parures et des vêtements qu'il avait longuement exposés déjà.

La boucle se fermait sur le rôle continu de la parole dans les pièges et luttes pour la procréation. Le même 
verbe, qui prédisposait les matrices à l'union, attirait les hommes dans les plis du pagne dont chaîne et trame enserraient dans leurs fils les paroles des huit ancêtres.

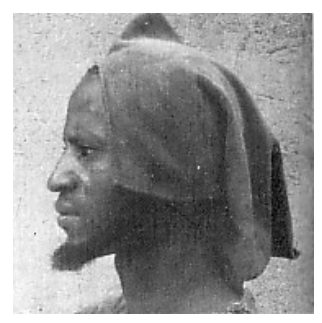

@ 


\section{Vingt-deuxième journée}

\section{Le sang des femmes}

L'Européen avait posé à brûle-pourpoint une question qui semblait n'avoir aucun rapport avec le sujet :

- Pourquoi les huit familles ont-elles des interdits divers ? Pourquoi tous ces animaux ?

Ogotemmêli, qui ne se démontait jamais, donna une réponse qui fit sourire de satisfaction son interlocuteur :

- Les interdits sont différents, car il y a quatre formes de matrices et trois de sexes masculins. Les enfants, déterminés par les combinaisons de ces formes, étaient donc divers. Les p.136 animaux, qui sont comme les jumeaux de chaque sorte d'homme, devaient donc être différents les uns des autres.

II rappela qu'à l'origine le premier couple créé avait mis au monde huit enfants: quatre mâles aînés, quatre femelles. Celles-ci avaient les rangs 5 à 8, auxquels étaient affectées des matrices dont les qualités étaient en rapport avec celles des chiffres.

La forme 5 est dite pobou, par allusion au fruit de l'arbre du même nom.

Ogotemmêli et Koguem riaient sous cape en prononçant ce mot, qui est l'une des plus viles injures à jeter à une femme.

La forme pobou est ovoïde, ronde à sa partie inférieure, plus pointue en haut. Dans l'agencement du grenier céleste elle correspond à la case cinq, c'est-à-dire au grain de haricot, oblong comme elle. Elle est néfaste et son produit est mal constitué, car elle est peu profonde et interdit le développement normal.

Elle porte le chiffre de l'avortement et des enfants souffreteux. 
La forme 6 est dite «pied d'antilope ». Triangulaire (c'est-à-dire aussi de chiffre 3, mâle), elle donne théoriquement naissance à des jumeaux mâles ( 2 fois 3 , c'est-à-dire 2 fois le chiffre de l'homme). Elle est faste, comme les deux suivantes. Elle correspond à l'oseille indigène (Hibiscus).

La forme 7, dite «fendue », est plus allongée et plus mince que la forme 5 . Elle est fendue dans le sens de la longueur, comme le grain de riz auquel elle est liée. Elle donne naissance à deux jumeaux de sexes différents (4 plus 3).

La forme 8 , dite «poitrine », est en trapèze renversé, comme une poitrine. Elle présente quatre côtés, chiffre féminin, et elle produit des jumeaux femelles ( 2 fois 4 ). Elle correspond à la Digitaria.

Les formes mâles, dont l'affectation chez les quatre premiers ancêtres n'est pas connue, sont la « grosse », la «tête de lézard», la «longue». La première, faste, convient surtout aux formes femelles 5 et 8 . La seconde, lancéolée, «pique »; elle est néfaste pour toutes les formes. La troisième convient aux formes 6 et 7 ; elle est néfaste pour les autres.

Bien entendu, ces quatre formes femelles et ces trois mâles se sont répandues dans toutes les familles. Mais à l'aube de l'humanité elles furent à l'origine des classifications.

p.137 Cette idée dogon éclairait-elle l'origine de ce que les linguistes nomment les classes nominales ? Ce système repose sur une répartition des êtres, des objets, des gestes, des manières d'être, en catégories dont chacune dispose, dans les langues noires bien conservées, d'une classe de noms à caractéristique spéciale. La langue dogon, à première vue, ne semble pas présenter cette division. Mais elle offre par contre des exemples étonnants de catégories d'êtres, de choses ou d'abstractions apparemment disparates portant les noms de même racine et parfaitement liés dans la mythologie, dans le rite comme dans l'idée même des usagers. Ainsi les entretiens avec Ogotemmêli avaient-ils fait apparaître non seulement dans les mots, mais dans les choses et actes, l'étroite 
parenté tissu-vêtement-parole-parure-sept, soleil-vachemère-lézard(avatar du prépuce)-quatre, et grenierdérober.

On pouvait aussi, avec quelque hardiesse il est vrai, du point de vue linguistique, proposer le rapprochement Digitaria exilis-menstrues et voix-hélice-cuivre-pluie, qui sont à la base même du système religieux des Dogon.

Mais ces idées ne faisaient que passer en trombe dans la tête du Blanc qui suivait les confidences données à voix basse ou chuchotées, selon les bruits venus de la ruelle:

- Après que Dieu eut fait la femme, il lui donna un sang mauvais dont le flux revint chaque mois.

On pouvait expliquer cet inconvénient comme une punition permanente de l'inceste primordial qui avait uni le chacal à sa mère la Terre. Le chacal avait porté la main sur le cache-sexe de sa mère que le Nommo avait tressé. Jusque-là, les fibres du vêtement étaient de couleur claire. Par la suite, elles devinrent pourpres.

- Le rouge des fibres, dit Ogotemmêli, c'est celui du sang menstruel qui vint à la Terre. Mais il est irrespectueux de parler des règles de la Terre. On dit qu'il avait plu, que les fibres étaient humides et qu'il avait fallu les mettre au soleil pour les faire sécher.

On devait parler plus tard des conséquences de cette exposition sanglante.

Le flux de sang menstruel est le produit de l'union entre le fils et la mère. II est le produit de la chose défendue.

Par ailleurs, Ogotemmêli comparait ce sang à celui de la p.138circoncision qui est considéré comme une dette payée à la terre :

- La femme, ayant été pétrie dans la Terre, doit lui payer son dû. Dieu a mis dans la femme une dette de sang; elle doit verser "l'eau du sein de Dieu pour la Terre ».

C'est ainsi qu'il nommait le sang menstruel, par respect pour les femmes. 
- La Terre ne tient quitte de cette obligation que durant la grossesse et l'allaitement. Car l'enfant est aussi un paiement.

Durant cette mauvaise période, la femme doit s'éloigner de la communauté. Son contact souillerait les hommes, sa présence dans les lieux habités affaiblirait les autels. Elle vit en bordure du village dans une maison ronde, symbole de la matrice, dont elle ne sort que pour les ablutions nocturnes. Encore suit-elle un itinéraire réglé qui ne conduit qu'aux eaux permises. Le passage en tout autre lieu polluerait la région, bouleverserait les mares, ferait bouillonner des têtes de torrent.

- Car la femme est alors le plus grand interdit du Nommo. II désire du sang faste et non ce flux mauvais. II fuit à l'approche de la femme.

Et c'est pourquoi les pas de la femme, en état d'impureté, vident de toute vie les lieux qu'elle ne doit pas fouler.

Elle-même, en une certaine manière, est le siège de perturbations comparables à celles qu'elle produirait si elle s'écartait de la loi: le flux dont elle souffre est le trop-plein de sang que pousse du dedans une bile surabondante :

- La bile, dit Ogotemmêli, est faite des mauvaises paroles qui ont pénétré dans la femme.

Non seulement elles déroulent la spirale fécondante des bonnes paroles, mais elles s'emmagasinent dans la vésicule et font pression sur le sang.

Tout se passe comme si le Nommo, présent dans le foie, et ne pouvant le quitter sans causer la mort, rejetait au dehors le sang indésirable, symbole lui-même du mauvais verbe.

- Au contraire, dit l'aveugle, la grossesse est le signe que les bonnes paroles sont entrées, qu'elles n'ont pas été déroulées de la matrice. Elle est le signe de la bonne marche des choses. 


\title{
Vingt-troisième journée
}

\author{
Le sang des femmes \\ et le battage de Digitaria
}

p.139 Les institutions des Dogon étaient remplies d'énigmes inentamées, défendues de partout par des mystères, des correspondances, des symbolismes sans fin.

Avant le contact avec Ogotemmêli, un travail considérable avait été mené ; de grands pans de cette civilisation avaient été découverts, étudiés dans le détail. Le fonctionnement des Masques était connu; le culte des morts, certains mécanismes sacrificiels, le culte du Binou, du Lébé avaient été démontés. Les enquêtes menées par des équipes spécialisées avaient tracé dans l'immense champ des faits, des avenues qui semblaient converger en un haut-lieu central où gisaient les très secrets mobiles des hommes, les enchaînements du réseau, les pourquoi et les comment, les fins mécanismes de la pensée dogon.

Mais ce haut-lieu apparaissait tantôt comme un roc impénétrable, tantôt comme un brouillard sans consistance.

Ogotemmêli avait accompli le miracle de dévoiler ce centre prestigieux auquel tout se rattachait. De plus, il dessinait les liens transversaux qui joignaient les institutions les unes aux autres, rite par rite, loi par loi.

Avec lui, la civilisation dogon apparaissait comme un corps immense dont chaque organe avait sa fonction propre et locale comme aussi celle de contribuer au développement général de la société. Et dans ce corps entraient toutes les institutions. Aucune ne restait en marge et les unes après les autres les plus aberrantes en apparence, les moins expliquées prenaient place dans un système dont la charpente se montrait chaque jour avec plus de netteté.

Depuis de longues années, le Nazaréen se trouvait devant le problème de la Digitaria exilis nommée fonio 
dans le sabir occidental, graminée dont la culture ne ressemblait à aucune autre.

Il y avait quinze ans que pour la première fois il avait entendu, à la tombée du soleil, sonner les trompes du battage de nuit.

D'abord une corne de vache avait mugi dans le champ Ba Diguilou, face aux murs de Dodyou. Elle lançait des «toulou » 140 voilés qui faisaient sortir les jeunes gens des ruelles, chacun armé d'un bâton court. Puis la troupe s'était enfoncée en direction de Gôna, dans les derniers rayons du soleil, pour revenir tard dans la nuit, annoncée de très loin par les trompes en corne d'antilope aux deux notes déchirantes qui semblaient surgir du plus profond des temps.

La Digitaria, aux grains ronds minuscules, se moissonne en toute hâte au moment où elle est juste mûre. Sa tige, qui arrive au mollet, se couche au moindre vent dès qu'elle est sèche, et les graines tombent. II convient donc de former rapidement les meules et de les battre, si possible, le jour même. Pratiquement, ce travail s'opère dans les premières heures de la nuit, et comme il doit être mené en hâte, les jeunes gens se rassemblent par quartier et vont battre successivement, durant plusieurs semaines, la moisson de chaque chef de famille. Les jeunes filles sont associées à cette corvée : elles balaient les grains sur le rocher à mesure qu'ils tombent et elles rapportent sur leur tête les peaux de chèvres remplies par la moisson. Certaines d'entre elles, parmi les plus robustes, s'intercalent entre les jeunes gens pour manier le fléau.

A certains détails, ces travaux semblaient présenter un caractère spécial; durant la moisson, effectuée par des adultes que des femmes aidaient en transportant les tiges coupées, étaient échangés entre les sexes des chants d'une impudeur inaccoutumée. D'autre part, certaines ruées des moissonneurs vers la limite du champ ou à la rencontre de ceux qui venaient les aider, mettaient dans ce travail une note particulière.

Mais l'usage de la graine était surtout une énigme. Elle était l'interdit d'un très grand nombre d'hommes. Seuls les «impurs » pouvaient la consommer impunément. Les 
hommes «vivants » ordinaires pouvaient être relevés de cette obligation dans certains cas. Au contraire, son simple contact souillait gravement les prêtres et si le Hogon était intouchable, c'était en partie parce qu'on aurait pu conserver sous les ongles et lui communiquer quelque poussière de fonio.

Ce n'était d'ailleurs pas une petite affaire que d'obliger une femme légitime à le piler. II lui fallait le vanner hors des murs, en des lieux-dits particuliers. Et c'était une dure et minuscule graine, donnant peu de nourriture pour un grand travail. On citait des femmes qui avaient demandé le divorce pour fuir cette préparation.

p.141 Enfin la graminée était l'un des plus sévères interdits du Génie de l'eau.

Aussi la curiosité du Blanc fut-elle piquée au vif lorsqu'Ogotemmêli lui déclara tranquillement que Digitaria et menstrues étaient une seule et même chose.

II avait parlé, la veille, de la dette de sang des femmes et rien ne laissait prévoir un tel tournant de l'information.

- Fonio et menstrues, répéta-t-il, c'est tout un.

Les deux mots, en dogon, étaient de même racine.

- Cette fois, pensa l'Européen, la liaison entre les deux choses va être difficile.

Car il nourrissait la plus grande méfiance pour les linguistes qui se contentent de travailler sur les mots sans s'intéresser à tout ce qu'ils recouvrent.

Ogotemmêli était assis, comme de coutume, sur son seuil, le visage vers la terre et les mains croisées au-dessus de sa tête. II ne s'animait jamais au cours des entretiens que pour abominer les coqs ou se mettre à l'unisson des hommes qui lui criaient ses devises. II ne ressentait apparemment aucun émoi en parlant des confins des temps ou de la pensée. Entre ses mains, la poterie sphérique devenait un soleil à huit spires de cuivre, le vieux panier un univers. Tout cela lui était familier.

Il parla de la Digitaria à voix très basse, comme il convenait pour une graine interdite ayant un rapport avec la vie intime des femmes. 
L'affaire remontait très haut dans le temps et dans l'espace. Elle datait du séjour des huit ancêtres dans les cieux, après leurs métamorphoses en Génies Nommo.

- Au ciel, les huit Nommo nouveaux devaient vivre séparés. Mais le premier, qui devint plus tard le Forgeron, fréquentait le troisième, ancêtre des gens de caste. Ils ont rompu ainsi l'interdit.

Étant devenus impurs de ce fait, ils durent se séparer des autres et Dieu, pour leur permettre de vivre, leur donna les huit graines, dont la Digitaria.

C'est alors que le premier déclara solennellement devant tous les autres, qu'il ne mangerait jamais de cette petite graminée. II la remit à son ami le troisième. Mais ayant un jour consommé les sept autres, il en fut réduit à mendier la nourriture qu'il avait méprisée. Malgré les observations du troisième qui lui rappelait son engagement, il passa outre et consomma la graine sur laquelle il avait prononcé de mauvaises paroles.

p.142 II demanda à son compagnon de n'en rien dire et tous deux se jurèrent fidélité et alliance sur le fonio, priant Dieu de tuer le parjure. Mais les autres soupçonnèrent la chose ; considérant qu'un Nommo, même impur, ne devait pas revenir sur sa parole, ils eurent honte pour lui de manger la graine et ils en firent leur interdit.

- Mais pourquoi fut-elle mise dans le grenier qui descendit sur la terre?

- Elle était là pour la mauvaise parole. Elle était la mauvaise parole.

Il fallait que dans le nouveau système du monde figurât le néfaste. Ogotemmêli voulait dire que la mauvaise parole ne pouvait plus ne pas exister, ne pas être intégrée dans l'organisation du monde, puisqu'elle avait été expectorée à plusieurs reprises. Et rien mieux que la graminée ne pouvait la représenter: c'était sur elle que l'ancêtre premier avait proféré les propos dont il s'était dédit; c'était sur elle qu'il avait prononcé le serment de dissimulation.

- Elle était le symbole de la mauvaise parole qui flatte la femme et l'empêche de procréer, qui déroule les spires 
du bon verbe autour de la matrice et s'enroule à sa place. Elle était le symbole du sang menstruel, signe de la stérilité temporaire qu'engendre ce mauvais enroulement.

Et c'est pourquoi la Digitaria fut versée dans le huitième compartiment du grenier, dont le rang est celui de la parole et qui correspond, dans l'organisme, à la vésicule biliaire.

Mais il fallait entendre aussi que la graine conservait en outre la bonne force, la bonne parole, que Dieu y avait introduite en la créant. Elle se comparait à la vésicule, dont le contenu est néfaste quand il est en excès, mais dont l'enveloppe est une chose faste puisqu'elle contribue à la marche normale de l'organisme.

Et il fallait aussi remarquer que le rang du compartiment où elle était placée était celui de la matrice dite «poitrine », qui engendre les jumeaux parfaits.

Le meilleur et le pire étaient donc en même place et au même rang.

Et il était bon que le meilleur et le pire puissent être appréhendés dans le même support; il était bon qu'ils puissent y être dissociés par un même geste, à la fois attracteur et apotropaïque : le battage nocturne.

p.143 On allait voir à quels paroxysmes s'élevait la subtilité de cette pensée, à quels cheminements logiques elle savait s'astreindre.

La graine étant donnée dans l'univers, il fallait l'utiliser. Bien plus, il convenait de l'employer dans le rôle même qui lui était assigné touchant la procréation.

Ainsi furent institués la culture et surtout le battage de la Digitaria.

Lorsque les trompes du rassemblement sonnent sur les abords, tous les jeunes hommes et les jeunes filles du quartier sont alertés. Aucun ne doit manquer, sous peine de forte amende versée au chef de la classe d'âge des aînés.

Et c'est pourquoi, pour une part, est choisie l'heure du coucher du soleil : on est sûr que tous les habitants sont 
rentrés des travaux extérieurs et qu'aucun des obligés ne peut se dérober.

Les garçons partent d'abord et se rendent sur le lieu du labeur où ils commencent à frapper la meule de leurs bâtons. Placés en cercle, ils abattent leurs bras selon une cadence à trois temps, un tiers du groupe frappant à chaque temps, ce qui donne l'impression d'un lent galop de cheval. Ils s'accompagnent de couplets divers, dont certains rappellent les chants obscènes proférés dans la journée par les hommes et les femmes adultes qui ont moissonné ensemble. De temps à autre, deux garçons s'écartent pour laisser une des filles qui viennent d'arriver s'intercaler dans le cercle.

Coups sur les tiges et chants ont le même but :

- Frapper les graines, dit Ogotemmêli, c'est frapper brutalement les forces, c'est-à-dire la parole, qu'elles contiennent. La bonne parole reçue lors de leur création sort et se mêle aux chants.

Ainsi les chants forment un réseau sonore dans lequel vient se prendre la force bénéfique, la bonne parole extraite par la violence. Ils en sont renforcés; ils n'en seront que plus efficaces pour enrouler les matrices de leurs spires fécondantes, d'autant que le sens des mots est clair, que les sexes sont constamment évoqués.

Ces chants sont le récipient sonore qui reçoit la bonne force sortant des graines et dans lequel le groupe de filles et de garçons va la transporter au village, dans l'exaltation des trompes p.144 qui alertent de loin les hommes et les femmes restés au foyer. - La bonne force des graines sort et suit les paroles et les chants des frappeurs.

Les coups sourds du battage, les chants, le son des trompes concourent au même but :

- Ils donnent comme une production d'enfants. Bien qu'ils soient nocturnes, ils ont sur les matrices le bon effet des paroles de jour.

L'Européen, pourtant, avait cru trouver une fissure dans le déroulement ordonné de cette gesticulation visible et invisible. Le «bien qu'ils soient nocturnes » ne lui avait 
pas échappé et il saisit l'occasion d'une question insidieuse: n'était-il pas interdit. en temps ordinaire, et sauf pour certains jeux ou rites, de frapper le sol, de crier, de chanter, de sonner de nuit ?

- D'habitude, dit Ogotemmêli, frapper le sol est interdit. Une amende punit le coupable; avec son produit on achète une victime qui est sacrifiée sur l'autel de fondation du village. Car cet autel honore aussi le territoire occupé et l'on rend au sol, par le sang, la force qu'on fait sortir indûment de lui en le heurtant. Mais les coups donnés par les jeunes gens ne sont pas des coups ordinaires.

Ogotemmêli se tut un instant. II avait cru que des pas s'étaient arrêtés dans la ruelle. II reprit d'une voix très basse :

- Le frappement du fonio, c'est comme si un homme égorgeait une victime sur un autel.

Le Blanc écoutait, retenant son souffle :

- C'est un geste de sacrifice.

Mais où était le sang? Par quels détours de la symbolique pouvait-on aboutir à cette comparaison ?

- La huitième graine, reprit Ogotemmêli, est le symbole de la bile et du sang menstruel.

II rappelait ce qu'il avait exposé au début de l'entretien. La graine, qui figurait dans le huitième compartiment (vésicule biliaire) du grenier céleste, contenait bonne et mauvaise parole. Ce qu'elle avait de bon en était extrait et mêlé aux chants; ce qui était mauvais restait en elle, tombait au sol avec elle sous les coups des fléaux, tombait comme un sang.

Comme dans le sacrifice, il y avait là séparation des principes spirituels de la victime; avec les chants était captée la bonne vertu; dans les graines répandues restait le mauvais principe, le sang menstruel représentant la dette due à la terre :

- p.145 Le frappement des graines, dit Ogotemmêli, c'est comme une femme qui fait boire son sang à la terre. 
Le sacrifice symbolique de la Digitaria frappée à mort avait donc deux aspects :

d'une part il payait l'amende due pour les coups nocturnes donnés par les fléaux,

d'autre part il payait à la terre la dette originelle des femmes.

Et ce dernier résultat était complémentaire de l'œuvre de fécondité que poursuivait la bonne parole extraite des graines. En effet, si les chants grossis de cette parole mettaient les femmes en état de procréer, c'est-à-dire en situation de ne plus subir le flux mensuel, il fallait parfaire le geste symbolique en payant à l'avance la dette de sang à la terre.

Ainsi les femmes, pendant la durée du battage des graines, étaient-elles baignées dans une atmosphère propre à la génération et tous les jeunes gens et jeunes filles, espoir de la société, devaient contribuer à ces travaux et à ces chants où eux-mêmes puisaient des forces pour les futures amours. Et l'amende qui les frappait pour une dérobade visait moins la perte de travail que le manque à profiter de la ranimation commune des forces de génération. 


\section{Vingt-quatrième journée}

\section{La double âme et la circoncision}

Les moissons étaient terminées depuis longtemps. Les hommes avaient rabattu une à une les tiges à hauteur de visage, avaient coupé l'épi ou la grappe et avaient laissé remonter le support délesté. Les champs n'avaient plus été peuplés que de hautes cannes jaunissantes qui peu à peu étaient tombées sous les couteaux. Par bottes énormes balancées sur les têtes d'hommes, par meules amoncelées sur l'échine des petits ânes qu'elles engloutissaient, elles s'en allaient dans les ruelles en raclant les torchis, pour s'affaler au milieu des cours et gonfler les fumiers.

La courte période était morte où les longues cannes sèches étaient dérobées par les bambins nus qui couraient les villages p.146 en brandissant ces lances immenses auxquelles flottaient comme banderoles des feuilles crissant au vent. Ils s'attroupaient à cing ou six et cernaient les chiens dans les impasses pour les rosser. Pendant une bonne semaine, ceux-ci fuyaient en rasant les murs dès qu'ils apercevaient au bout des places le plus petit enfant.

Ces jeux avaient cessé faute de lances: les piétinements des moutons et des hommes les avaient brisées, intégrées aux fumiers des cours. Les enfants avaient peu à peu versé dans un autre cycle : celui du guet clandestin pour la chute prématurée des fruits de baobab.

- Les incirconcis, disait Koguem, ne rêvent que désordre et embarras.

II voyait la chose simplement. Pour Ogotemmêli, l'état de l'enfance était plus complexe. On comprenait, à l'entendre, la sollicitude inlassable des adultes pour les petits, l'émotion des hommes et des femmes devant ce que certains sociologues ont appelé l'«invasion de barbares » qui submerge chaque année la société par le moyen des naissances. 
Les enfants, en effet, sont comme en marge du groupe. Ils ont leur vie à eux, leurs sentiers, leur matériel, leurs troupeaux de coléoptères et de sauterelles aux ailes brisées par précaution. Ils connaissent la valeur du fétu, du caillou rond, de la tige de nénuphar comme chalumeau. Étant nus, ils n'ont aucune honte. Le danger les laisse indifférents. Une vétille les terrorise. Ils montrent aussi une mystérieuse inclination pour la mort.

- Rien en eux n'est fixé, dit Ogotemmêli.

Et il expliqua longuement que comme toutes choses, celle-là remontait à l'origine de la création.

- La règle, dit l'aveugle, pour que tout soit bien, serait d'être deux. La source de tous les désordres est la solitude du Chacal, premier-né de Dieu. On ne peut dire que le Chacal ne soit pas une mauvaise chose, car sa solitude l'a poussé vers sa mère. Pour cela, pour éviter la solitude, à chaque accouchement le Nommo demande à Dieu une double naissance. Mais sa prière n'est pas toujours exaucée. Et c'est pourquoi il a donné deux âmes à chaque nouveau-né.

De fait, il avait toujours semblé étonnant à l'Européen que le nom de l'âme - pour employer un terme de la nomenclature traditionnelle - soit composé d'une répétition du même vocable: kinndou-kinndou, qu'il faudrait traduire par « âme-âme ».

- p.147 Le Nommo, pour un seul être, crée deux âmes jumelles.

Car le Nommo assiste à la parturition qui se déroule dans la seconde chambre de la grande maison, entre les quatre poteaux de soutènement. La femme est assise sur un siège bas, ou sur un mortier renversé ; deux matrones l'aident. L'enfant arrive sur le sol qu'il lui faut toucher de ses quatre membres.

Car le Nommo a dessiné sur la terre le contour de deux âmes, deux silhouettes à forme humaine. La première tracée est femelle, la seconde mâle. Et quand le nouveau-né prend contact, les deux âmes l'investissent.

- Il est seul dans son corps, mais il est deux dans le spirituel. 
Sur l'origine de ces âmes, sur le réservoir sans limite ou renouvelé dans lequel puisait le Nommo pour ses dons incessants, Ogotemmêli ne s'expliqua pas.

Donc l'enfant arrive au monde nanti de deux principes de sexes différents et théoriquement il appartient autant à l'un qu'à l'autre ; le sexe de sa personne est indifférencié. Pratiquement, la société, par anticipation, lui reconnaît dès l'abord le sexe qu'il porte en apparence. Toutefois, par des détails du symbolisme, l'androgynie spirituelle reste présente.

C'est ainsi que la mère, après délivrance, reste recluse durant quatre semaines (de cinq jours). Elle sort ensuite dans le village, le nouveau-né au dos, et durant trois semaines porte à la main une flèche pour un garçon, un couteau pour une fille, apparemment dans un but de protection contre les dangers visibles et invisibles.

Ces deux périodes de 4 et de 3 semaines ont le chiffre de la femelle et du mâle.

- Pendant les quatre premières semaines, dit Ogotemmêli, l'accouchée d'une fille file du coton.

Ainsi rappelle-t-elle le travail principal auquel est destinée la future femme qu'elle vient de mettre au monde. L'accouchée d'un garçon file également, mais moins; il s'agit seulement de manifester la solidarité de I'homme tisserand et de la femme fileuse.

Fuseau féminin manié dans l'ombre de la chambre, flèche masculine exhibée dans les ruelles par la mère d'un garçon se rejoignent pour une démonstration de l'origine céleste de l'humanité :

- Lorsqu'une fille vient au monde, dit Ogotemmêli, la mère p.148 tient son fuseau pour rappeler que le grenier venu des cieux était attaché à un fuseau fiché dans la voûte. Le fil qu'elle tourne est celui qui s'est déroulé dans la descente.

Quant à la mère d'un mâle, la flèche qu'elle porte à la main est celle que tenait le forgeron pour se défendre en traversant l'espace.

Mais les deux objets ont le même sens, car les flèches du forgeron étaient des fuseaux munis de pointes. Et celle 
qu'il décocha dans le grenier devint l'axe dont l'édifice luimême était l'énorme fusaïole.

Les gestes et objets dont on entoure la naissance rappellent donc la réorganisation du monde; ils signifient l'intégration du nouveau-né dans le système révélé par le forgeron et par le Nommo Septième. Ils sont la manifestation de la nature humaine faite pour le travail.

- Mais, dit l'Européen, quand la naissance est double ?

A cette question immense, convenait une longue réponse. Ogotemmêli la réserva. On aborderait plus tard le culte fondamental des jumeaux.

Pourtant, l'Européen apprit qu'à leur venue chacun des jumeaux recevait deux âmes et que les mêmes habitudes étaient observées pour eux que pour les enfants uniques. Cependant, détail important, si la réclusion était de même durée, la sortie « en armes » de la mère était portée à quatre semaines, ce qui faisait huit semaines avant la reprise de la vie normale. Car huit est le chiffre de la perfection, comme Ogotemmêli l'avait déclaré déjà.

Muni de ses deux âmes, l'enfant poursuit sa destinée. Mais ses premières années sont marquées par l'instabilité de sa personne. Tant qu'il conserve son prépuce ou son clitoris, supports du principe de sexe contraire au sexe apparent, masculinité et féminité sont de même force. II n'est donc pas juste de comparer l'incirconcis à une femme ; il est, comme la fille non excisée, à la fois mâle et femelle. Si cette indécision où il est quant à son sexe devait durer, l'être n'aurait jamais aucun penchant pour la procréation.

En effet, le clitoris qu'a reçu la fille est un jumeau symbolique, un pis-aller mâle avec lequel elle ne saurait se reproduire et qui, au contraire, l'empêcherait de s'unir à un homme. De même que Dieu a vu se dresser devant lui l'organe de la terre, de même l'homme qui s'unirait à une femme non excisée serait ${ }_{\text {p.149 }}$ " piqué » et l'opportunité de sa présence discutée par l'organe qui se prétendrait son égal.

L'individu, d'autre part, ne peut se conduire normalement sous une double direction. II est nécessaire 
que l'un des principes prenne définitivement le pas sur l'autre.

- L'enfant ne peut rien faire de sérieux, et on ne peut rien lui faire de sérieux tant qu'il n'est pas circoncis.

C'est ainsi qu'il ne peut ni recevoir sa devise, ni assurer un culte, ni supporter de remèdes donnés par les guérisseurs contre les maladies, ni utiliser d'amulettes. Ces pratiques, en effet, supposent des va-et-vient de force vitale trop violents pour un être dont l'âme n'est pas encore «fixée ».

Mais la dualité de l'individu n'est pas la seule cause de son instabilité : Dieu l'ayant fait avec la glèbe, I'homme a contracté envers la terre une dette qu'il doit payer en sang. Il lui faut se sacrifier lui-même sur celle dont il procède :

- L'écoulement du sang de la circoncision, dit l'aveugle, est comparable au fait d'offrir une victime aux autels. Et c'est la terre qui vient boire le sang.

Tant que ce compte n'est pas en règle, l'âme n'est pas stable, l'individu n'en est pas propriétaire.

- Dès la naissance, l'enfant est comme attaché à la Terre par un lien dit «fil de Dieu », partant du prépuce ou clitoris et pénétrant dans le sol. II est fixé au moment où le nouveau-né prend contact avec la Terre ; il est de sang. II se déplace et pénètre toujours le sol aux pieds du porteur. Il est coupé à la circoncision.

- Qui donc est la Terre ?

Ogotemmêli ne répondit pas directement :

- L'écoulement du sang, c'est pour renvoyer à la Terre la chose prêtée. Mais ce n'est pas seulement la terre qui reçoit son dû. Le Nommo vient boire et il appelle le Lébé qui le suit et vient boire aussi. Cependant, le sacrifice ne leur est pas destiné ; il est fait pour la Terre et pour tout ce qui est terre, c'est-à-dire aussi pour le premier couple pétri par Dieu.

- Mais le Nommo ? le Lébé ?

- La place où était le vieil homme (c'est-à-dire la tombe du Lébé), la glèbe avec laquelle Dieu a pétri 
I'homme, le Lébé ressuscité en terre, ces trois choses sont une.

Ogotemmêli énonçait là le principe de l'unité de I'univers. La tombe de la résurrection est de glèbe ; I'homme est de glèbe ; p.150 le vieil homme ressuscité était de glèbe et c'est dans la glèbe qu'il fut vomi vivant. Enfin le ressusciteur, mort lui-même, inhumé sous la forge, ressuscita dans la glèbe.

- Mais pourquoi blesser l'homme dans son sexe ?

- Parce que le prépuce et le clitoris supportent l'âme qui doit s'éloigner. Parce qu'aussi c'est par le sexe que commence le fœtus.

Dans le sein, l'être est d'abord un sexe auquel se joint la tête. Le corps se développe ensuite. Le sexe est «le maître-autel de fondation de l'homme ». Ainsi Dieu, pour tout être, procède comme il fit lors de la première création et il dresse l'« autel » de I'homme comme un fondateur dresse l'autel de fondation d'un village.

Mais ce n'est pas seulement le corps qui est de terre. Quelques-uns disent que Dieu a pétri les âmes comme les corps, et c'est sur le sol qu'est dessinée l'âme, au moment de la naissance.

II semble aussi qu'à l'idée de dette se joint une idée de force néfaste prise par la personne en même temps que sa condition terrestre. D'où la nécessité de se débarrasser, à la fin de l'enfance, de cet élément que l'on renvoie à son lieu d'origine.

Ce sont donc des raisons diverses qui expliquent la circoncision et l'excision : nécessité de débarrasser l'enfant d'une force mauvaise, nécessité pour lui de payer une dette de sang et de verser définitivement dans un sexe. A cela, il convient d'ajouter que l'homme doit, par solidarité, souffrir dans son sexe comme la femme.

L'opération est préparée dès la naissance, et comme il s'agit de fixation de l'âme, les autels de famille sont utilisés pour la retenir au plus près de l'enfant.

- La flèche que tient la mère d'un garçon, dit Ogotemmêli, est posée dans la huitième semaine après la naissance sur l'autel de la petite famille. Le père égorge 
une victime en disant : «Dieu !reçois ce sang et fais sortir la chance de mon fils. »

Dès ce moment les âmes des ancêtres, qui sont venues boire à l'autel, aident l'enfant dans son assimilation spirituelle et lui communiquent une part de leur force qu'elles déposent dans le foie de la victime qu'on lui fait goûter.

- La veille de la circoncision, on demande encore devant l'autel la fixation de l'âme. Et au moment où le prépuce est coupé, l'âme mâle se rend dans cet autel. Elle y séjourne pendant tout le temps de la retraite. Après guérison, lorsque l'enfant revient, $p .151$ on égorge une autre victime pour lui et il en mange le foie. A ce moment, cette âme retourne en lui.

Ainsi la circoncision a-t-elle pour effet premier un éclatement du spirituel : d'une part le prépuce sectionné, support de l'âme femelle, se transforme invisiblement en lézard dit «soleil ». L'enfant est ainsi libéré de la féminité. D'autre part son âme mâle, agissant comme celle d'une victime, s'éloigne de son corps et va séjourner dans l'autel de famille. Durant toute la retraite que subit le circoncis, il est privé de ses principes spirituels, et celui qu'il doit reprendre attend avec les morts. Le circoncis est comme mort lui-même.

- Lorsque le circoncis retrouve son âme dans l'autel de famille, est-il complètement délivré de l'âme femelle partie avec le lézard?

- Non ! dit Ogotemmêli ; il garde encore son ombre qui est une âme féminine réduite et qu'il a en commun avec le lézard. Cette ombre est sotte, tandis que l'autre âme est l'intelligence.

Là encore, le système de spéculation Dogon apparaissait comme une suite d'actions et de compensations juxtaposées.

- p.152 Le lézard « soleil », continuait Ogotemmêli, est le symbole du prépuce femelle qui entoure le pénis mâle. Mais sa queue courte ressemble au pénis. Elle est rouge et c'est pourquoi il se cache de la lumière, car il ne veut pas lui être comparé. 
De fait ce lézard vit en terre et il se montre rarement.

- Le lézard est femelle, dit Ogotemmêli, mais il ressemble à un pénis par l'arrière de son corps. II est prépuce, mais il est aussi comme un pénis découvert.

Entouré de cette femelle qui est «soleil», rouge et sphérique comme l'astre qui est lui-même féminin, le pénis finit par être gagné à la féminité.

Et dans cette symbolique on peut entendre que le circonciseur, en tranchant la chair, libère et découvre le pénis, c'est-à-dire le soleil femelle.



SISTRE DE CIRCONCIS

- Quel est le sens du sistre de calebasse que portent les circoncis pendant la retraite?

Le sistre est fait d'une baguette dans laquelle sont enfilées des rondelles de calebasse, symbole de la féminité, dont les bords sont dentelés. Les enfants les agitent pour éloigner les mauvais esprits et les femmes.

- La baguette du sistre, dit Ogotemmêli, est le sexe délivré du prépuce. Les cercles de calebasse, en nombre égal à celui des circoncis, représentent les prépuces de la promotion. L'enfant agite le sistre d'une main ; de l'autre il tient un bâton de marche orné d'une hélice à huit spires marquée dans l'écorce. Le bâton est le génie de l'eau, qui guide ses pas; I'hélice rappelle la spirale enroulée et déroulée autour du soleil.

Ainsi l'enfant tient dans ses mains la féminité, l'eau et la lumière. 


\section{Vingt-cinquième journée}

\section{Les autels personnels}

Le camp était empêtré dans les bêtes. De nuit, des ravageurs inconnus remuaient les plats oubliés, faisaient basculer les barrières, s'enfuyaient devant des ombres de plus grande taille. On pouvait fort bien ne pas attribuer ces effervescences à des p.153 animaux ordinaires. Mais c'était la calamité contre laquelle nul ne pouvait rien.

S'ajoutaient des troubles intérieurs dont on connaissait le remède, sans l'appliquer jamais.

- Si vous possédez un coq provenant d'un cadeau, maugréait l'Européen, mangez-le dans la journée. Ou couvrez-le d'une natte, avec un poids dessus. Sinon, il vous réveille dès quatre heures!

Depuis une semaine, un coq à cri acide triomphait chaque nuit de tous les obstacles, et bien avant l'aurore claquait des ailes hors les caisses, murs et claies dont on l'entourait chaque soir.

- II est pire, disait le Blanc, que n'a été le bélier de Douneyrou.

Le bélier offert par Douneyrou, chef de canton, portait la tempête dans sa crinière. Dès qu'on l'avait lâché dans la cour, il avait avisé, droit devant lui, sans un regard pour le reste du monde, le mur de clôture. II avait reculé lentement de quelques pas, sans dévier, comme sur un rail, et soudain il avait bondi pour une charge sans merci. Profitant d'un ressaut du torchis, il avait franchi l'obstacle non comme un cheval, mais comme une panthère. II avait disparu, entraînant à sa suite deux hommes vociférant tous bras levés et une marmaille qui n'en demandait pas tant.

Il ne pouvait être question de rejoindre ce tourbillon. Ce ne fut que le soir, à l'heure où la nature entière se calme, que la toison et les cornes réapparurent, au bout d'une corde. 
- Il a d'abord mangé le mil du lieu-dit Bâ Diguilou qui est cultivé par le futur successeur du Hogon. Puis il passa dans Ogo Digou, qui appartient au Hogon lui-même. II a mangé le mil. Il est entré à Dodyou Oreil. II est allé tout droit chez Ongnonlou et a tué un agneau en le bousculant. Il a terrorisé Dodyou Oreil toute la journée. Le voilà.

On pouvait penser que l'animal allait être dépecé sur I'heure. II n'en avait rien été. La veulerie humaine l'avait relâché chaque matin dans le même concert de vociférations.

II y avait aussi les menus incidents provoqués par les crapauds. On s'appelait pour se montrer du doigt, et en silence, celui qui s'était blotti comme un poing dans une espadrille, cet autre qui résidait dans la boîte à savon.

II fallait également se taire et marcher avec précaution, dans p.154 certains recoins, pour laisser un couple de mange-mil gros comme le pouce organiser son nid dans une poche de veston. On profitait de leur départ pour transporter les herbes et les fils dans une chaussette pendue au même endroit. Mais peu de temps après, on retrouvait les herbes à nouveau dans la poche.

- Les mange-mil, dit Ogotemmêli mis au courant de ces menus faits, aiment les vêtements. Ils font aussi leur nid dans les sacoches, dans les pots suspendus.

II connaissait leur devise et leur interdit, comme d'ailleurs ceux de tous les oiseaux, de tous les animaux sauvages et domestiques. C'était un monde inconnu qu'il évoquait et dont il parlait volontiers, ayant été chasseur durant de longues années.

Le Nazaréen eût bien voulu entrer à sa suite dans cette vie des bêtes et des plantes de brousse, où chacun a son rôle, ses effrois, ses passions. Mais le temps pressait; il fallait suivre les grandes lignes de la doctrine ogotemmêlienne et reporter aux enquêtes ultérieures les développements des institutions.

Dans les niches rongées par la pluie et le vent de la façade étaient placées, parmi quelques objets misérables, des boules de terre tassées sur des pierres plates. Les unes comportaient une cupule noyée dans la masse; sur d'autres étaient plantés des crochets de fer, des petits bois 
fourchus ou munis d'encoches. C'était l'attirail des autels personnels de la famille d'Ogotemmêli. Leur nombre indiquait qu'il avait eu beaucoup d'enfants et que, contrairement à l'habitude, il n'avait pas détruit le matériel lorsqu'ils étaient morts.

Ces autels personnels, auxquels Ogotemmêli avait très souvent fait allusion et qui étaient bien connus de l'Européen, sont au nombre de deux pour chaque individu : l'autel de crâne et l'autel de corps.

Le premier est pétri par le père du garçon quelques jours avant son départ pour le lieu de la circoncision; la boule modelée est mise en contact avec la tête de l'intéressé et consacrée par une libation de bouillie de mil qu'accompagne la prière suivante :

L'enfant va partir en brousse,

Autel, prends ton eau et bois,

Que la bonne force ne parte pas avec le sang

Que la mauvaise force parte!

p.155 Puis l'autel est aspergé du sang d'un coq ou d'une poule qu'on égorge. Des bêtes ouvertes, le foie et le cœur sont extraits et grillés ; une parcelle est prélevée et jetée sur la boule de terre tandis que le reste est consommé par l'intéressé.

Pour une fille, l'autel de tête est constitué par son père, dans sa demeure à lui, au moment où elle s'en va pour habiter avec son mari.

Quant à l'autel de corps, il est composé d'une boule de terre qui a été malaxée avec des rognures d'ongles, des cils, des sourcils, des cheveux et quelques gouttes de sang prélevées sur le patient. Le père le consacre généralement avant l'autre autel, dès que, par suite d'incidents, le corps du garçon a besoin d'être fortifié, et lorsque, pubère, la fille est susceptible de se marier.

A première vue, ces deux autels constituent une sorte de dépôt extérieur, de réserve de soi sur laquelle l'individu peut agir, qu'il augmente par des sacrifices et des libations. Pour le Dogon du commun, sacrifier sur son autel de tête revient à sacrifier sur son propre crâne, siège de sa pensée et de sa volonté, partie la plus importante de son corps. 
- Quand la tête est en santé, dit-on, tout le reste va.

Aussi les Dogon sacrifient souvent sur ces autels, selon un rythme régulier, correspondant en partie au cycle religieux de la communauté, et encore selon l'occasion. Une maladie, une impureté contractée par rupture d'interdit, une déperdition de force, par exemple à la procréation, sont compensées par le flux vivifiant déterminé dans les autels par l'aspersion de sang ou de bouillie, flux dont profite par contrecoup le propriétaire qui communie en quelque sorte avec lui-même en consommant la victime qu'il offre.

Mais cette économie, admise par le commun, semblait incompréhensible à l'Européen.

- Comment peut-on s'offrir un sacrifice à soi-même ? se disait-il. Si l'on retranche une part de soi pour l'ériger en autel extérieur, le sacrifice n'attire aucune force. II y a bien celle de la victime, mais un poulet mangé rôti produirait le même effet, augmenterait les forces du sacrifiant aussi sûrement.

Il se décida donc à poser à Ogotemmêli la question habituelle dans cette sorte d'enquête :

- Qui vient boire le sang du sacrifice offert sur les autels de tête et de corps ?

Cette question, qui paraît bénigne, avait été la plus difficile à p.156 trouver, dans toute la carrière ethnographique de l'Européen. Car il faut méditer la forme de la question avant de faire les trouvailles. Elle était tellement simple que personne n'y avait pensé.

La première fois que l'étranger l'avait posée, elle avait fait purement et simplement fuir l'informateur. II s'agissait d'un homme pusillanime qui avait horreur d'évoquer l'invisible. Dans la suite, la question avait fait fortune et l'enquêteur la projetait comme un brandon dans le fouillis des réticences, mensonges et cachotteries de ses interlocuteurs. Elle n'appelait que deux réponses: la fuite ou la vérité.

Pour Ogotemmêli, initiateur volontaire d'un Blanc, il n'y avait là rien que de naturel. 
- Quand on égorge sur les autels personnels, dit-il, ils sont deux à venir boire : le premier homme créé par Dieu et le Lébé.

II ajouta qu'en un sens le premier homme et le Lébé mort et ressuscité étaient la même personne. Mais le Blanc se réservait de sonder cette subtilité plus tard.

- Pourquoi l'un est-il la tête et l'autre le corps ?

- Lorsqu'on égorge une victime sur l'autel de tête, c'est la force du crâne du premier homme et du crâne du Lébé qui remonte le sang et pénètre dans le foie. Si le sacrifice est offert sur l'autel du corps, c'est la force du corps du premier homme et du corps du Lébé qui emplit le foie mangé par le sacrifiant.

C'était donc que l'on pétrissait les deux autels au nom du premier homme et du Lébé, et non seulement au nom du bénéficiaire.

- Quelle est la formule prononcée à la consécration ? demanda le Blanc.

- En pétrissant l'autel de tête, répondit Ogotemmêli, et en le faisant toucher au front de l'enfant, le père demande au vieil homme de l'aider.

- Quel vieil homme?

- Le premier homme créé, et aussi le Lébé.

Ogotemmêli en revenait à cette identité. II citait la formule de consécration :

- Toi, crâne du vieil homme, viens et aide !

Pour l'autel de corps, le rite était comparable, mais l'appel n'était plus adressé au crâne :

- Toi, corps du vieil homme, viens et aide!

Le Blanc avait donc reçu réponse complète à sa question. p.157 Mais ce n'était qu'un pas vers la lumière. Pourquoi cette séparation du crâne et du corps ? Pourquoi ces autels personnels puisque de grands autels publics recevaient aux dates réglées les libations et les sangs de la communauté ?

- En pétrissant ces choses, dit Ogotemmêli, on rappelle l'affaire du Lébé. 
II voulait dire la résurrection du Lébé, son vomissement par le Nommo Septième, sous la forme de la silhouette de pierres.

On pétrit l'autel de tête à part de l'autel de corps parce que, dans la tombe du vieil homme, on a trouvé une pierre à la place du crâne et les huit pierres et les autres plus petites à la place du squelette.

De même que la pierre remplaçant la tête était à part des autres et avait le rang 9 , réservé à la chefferie, de même on fait l'autel de tête à part. On ajoute aussi du cuivre pour rappeler l'excrément du Nommo après qu'il a dégluti le vieil homme.

Une autre complication surgissait: la pierre de rang 9 que le Nommo avait vomie à la place du crâne avait eu sa destinée particulière; elle était devenue le signe de la fonction du Hogon, prêtre du culte du Lébé. Symboliquement donc l'autel de tête pouvait représenter le Lébé. Mais les pierres des articulations, celles qui avaient dessiné la silhouette du ressuscité, avaient, elles aussi, suivi une destinée propre: elles étaient devenues les signes de fonctions des prêtres de Binou.

- Si l'autel de tête est le Lébé, dit Ogotemmêli, I'autel de corps remplace les Binou.

Ainsi dans ce culte pour l'entretien de soi, chaque homme avait à sa portée et pour son usage personnel un système de Lébé et de Binou, un résumé du système du monde expectoré dans la tombe du champ primordial.

II disposait en somme de l'image de la tombe elle-même sous forme de ces deux boulettes de glaise plaquées sur des pierres plates. Et il pouvait, sans mettre en branle le mécanisme social, sans troubler la sérénité propre au maître autel dressé dans les sanctuaires, travailler à la défense de ses humbles intérêts, manipuler dans le privé les forces bénéfiques, promouvoir le cosmique, les pieds dans le fumier de sa cour.

Mais il fallait aller plus loin encore. A la lueur de certaines allusions faites dans d'autres entretiens, le Nazaréen comprenait pourquoi l'intéressé introduisait dans les autels ses ongles et p.158 ses cheveux, pourquoi il touchait l'autre de son front. Si l'autel de tête représentait 
le crâne du premier homme, du Lébé et de l'homme actuel, si l'autel de corps était leur corps à tous trois, c'est qu'il y avait identité de nature entre le premier créé, le premier mort ressuscité et l'homme d'aujourd'hui.

C'est pourquoi sur les ongles, cheveux et cils de ce dernier on dressait un autel dédié aux deux autres. Et lorsque le sacrifiant consommait la victime égorgée sur une partie de lui-même, il communiait, en réalité religieuse, avec la première œuvre humaine de Dieu. II communiait aussi avec l'ancêtre ressuscité comme puissance céleste et dont le corps avait servi à dessiner le nouvel ordre des choses. C'est-à-dire qu'il assimilait la force vitale de l'un et de l'autre, assurant par là, dans sa vie privée et pour sa part, le déroulement de la destinée terrestre.

On pouvait voir ainsi comment, dans la magistrale et minutieuse économie dogon, tout est dans tout ; comment des cultes considérables se fragmentent jusqu'à la poussière individuelle et comment cette poussière, par le jeu des symboles, contient l'immensité de l'organisation du monde humain. 


\section{Vingt-sixième journée}

\section{Invention de la mort}

@

Dans les entretiens avec Ogotemmêli, la mort n'apparaissait pas encore. Tous les événements mythiques relatifs à la révélation des trois paroles réorganisatrices s'étaient déroulés au temps de l'immortalité des hommes. La mort du Lébé, la mort du Nommo Septième n'avaient été que des artifices de la providence divine. II n'y avait eu là qu'apparence et la double résurrection avait fait reprendre le cours des choses.

Depuis de longues années, l'équipe d'Européens connaissait les mythes d'invention de la mort et le fonctionnement des institutions qui avaient fait face à cette calamité. Mais il restait encore, dans le réseau de renseignements, des obscurités.

Le Blanc savait que tout s'enchaînait dans l'immense déroulement des événements universels et que la fin physique de l'homme était déjà en germe dès les

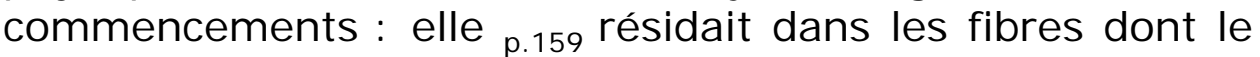
Génie de l'eau avait fait un cache-sexe à sa mère la Terre.

Un mythe considérable concernait les aventures des fibres à travers le monde. Rougies par le sang menstruel apparu après l'inceste qui unit la terre à son fils le chacal, elles furent mises à sécher sur la fourmilière. Elles étaient d'un rouge si lumineux qu'un passant, en les voyant, s'écria :

- Est-ce le soleil ? est-ce le feu ? quelle chose étonnante !

Une voix sortant de la fourmilière avait répondu :

- Ce n'est pas le soleil, ce n'est pas le feu, c'est une chose fraîche !

Puis les temps s'étaient écoulés. Dérobées, les fibres avaient été mises à la portée des humains. Une femme s'en était emparée, s'en était vêtue, avait semé la terreur 
autour d'elle, avait régné, grâce à cette parure éclatante que personne n'avait jamais vue. Les hommes avaient enfin dépossédé la femme, s'étaient parés à leur tour de ce vêtement de domination et l'avaient interdit à l'autre sexe à quelques exceptions près. Tous les jeunes hommes dansaient vêtus de fibres rouges, et les femmes devaient se contenter de les admirer.

Pourtant, cette possession réalisée par la force recelait en elle-même sa sanction : ceux qui avaient dépouillé la femme avaient caché leur exploit au plus vieil homme, rompant ainsi avec une tradition de respect et de soumission vis-à-vis du chef naturel. Le vieillard étant arrivé au terme de sa vie humaine, avait, comme les anciens, subi sa métamorphose en génie Nommo; mais, selon la règle, il n'était pas monté au ciel et continuait sa vie terrestre sous forme de grand serpent. Un jour que les jeunes gens avaient revêtu les fibres cachées dans les cavernes et se rendaient au village, le serpent se trouva sur leur passage et leur barra le chemin. Dans sa colère d'avoir été bafoué, il leur adressa en langue dogon, compréhensible pour eux, les plus violents reproches. C'est ce qui causa sa perte.

En effet, puisqu'il avait quitté la forme humaine dont la langue était la troisième parole révélée, il devait prendre le langage réservé aux génies dans le monde desquels il était parvenu, c'est-à-dire la première parole, En s'adressant aux hommes dans les termes qui leur étaient familiers, il rompait un interdit, il se séparait du monde surhumain dont il devenait un élément impur et dans lequel il ne pouvait plus vivre. II ne lui était pas ${ }_{\text {p. } 160}$ possible non plus de retourner chez les hommes. En conséquence, il mourut sur-le-champ.

Cette mort était donc l'effet d'une rupture d'interdit, elle-même causée par une faute contre la règle. C'était là événement universellement connu. Toutes les religions ont leur perte d'immortalité dans le péché causant le désordre. Mais quel était, pour les Dogon, le mécanisme de la calamité ? Que devenaient les forces contenues dans l'ancêtre-serpent? Par quel effet avaient-elles été déplacées ? 
- Les fibres portées par les jeunes gens, dit Ogotemmêli, étaient sèches.

Les explications de l'aveugle commençaient souvent par un propos énigmatique, point de départ d'un enchaînement qui se rattachait logiquement aux principes connus.

- Elles étaient le symbole des fibres rougies par le sang à la suite de l'inceste de la terre et qui avaient été placées sur la fourmilière pour sécher au soleil. Mais elles étaient aussi le symbole des fibres mouillées à l'origine par le Nommo et qui rafraîchissent le sein des femmes. C'était une mauvaise chose donc que de les mettre ainsi à la chaleur et à la lumière, car elles doivent être toujours humides pour protéger le sexe et favoriser la procréation.

II insistait sur cette obligation de l'humidité.

- Les fibres mouillées sont rafraîchissantes. Elles ne doivent pas sécher. Fibres sèches rendent la femme sèche.

C'est-à-dire stérile.

L'Européen se demandait où son interlocuteur voulait en venir, comment il en arriverait à la mort :

- Actuellement, continuait celui-ci, chaque fois qu'un homme revêt la jupe de fibres pour aller danser en place publique, il l'arrose d'un peu d'eau avant de s'en ceinturer. II l'arrose en disant : «Longue parole des hommes ! »

On entendait rappeler par là qu'on obéissait à une ancienne parole des ancêtres, à une très vieille coutume.

- Verser l'eau sur la jupe de danse est bon pour les femmes. C'est comme leur mettre de l'humidité dans le sexe, ce qui les aide à engendrer.

Le rôle des hommes allait plus loin : ils ne faisaient pas que manifester la condition essentielle de la procréation :

- p.161 Quand les hommes revêtent les fibres, c'est comme s'ils s'habillaient en femmes, car ces parures représentent le sexe féminin.

Bien plus, s'exhiber ainsi, c'était s'exhiber non en femme quelconque, mais en femme féconde. 
- Les hommes, quand ils mettent les fibres, c'est comme s'ils mettaient sur eux l'humidité du sexe des femmes.

Ogotemmêli semblait attacher une certaine importance à persuader le Blanc de cette nécessité de I'humide.

- Mises au soleil, les fibres devinrent chaudes et sèches. On les prit pour du soleil ; on les prit pour du feu. Elles ne contenaient plus d'eau, car l'astre l'avait bue. Mais elles contenaient encore un peu de force assoiffée, prête à attirer, à reprendre l'humidité.

Elles étaient, en quelque sorte, absence et désir de vie.

Mais elles étaient impures du fait de leur teinte due au sang menstruel et sans doute ne pouvaient-elles qu'absorber de l'impur, de la force en rupture d'interdit.

- Quand le vieil homme-serpent invectiva les jeunes, les fibres burent sa parole; elles burent le souffle qui venait à elles et qui venait à cause d'elles, puisqu'elles étaient l'objet de la réprimande.

Or ce peu de force qui demeurait dans les fibres était un reste d'eau, c'est-à-dire du Nommo.

- Parce que l'eau du Nommo restait un peu, lui, le Nommo, a bu la force du vieux. Il a bu le sang du vieux. Cette force bue, ce sang, suivait la parole du vieux qui allait de sa bouche aux fibres.

Ainsi mourut le serpent, asséché par les fibres, bu par le Nommo.

De même que l'humidité de la terre est bue par le soleil, de même celle du vieillard passa aux jupes de danse.

Tout se déroula comme si I'humidité des paroles avait été aspirée par le soleil de fibres.

Le serpent gisait en travers du chemin, mort. Les jeunes hommes effrayés s'enfuirent au village, en revinrent avec les vieillards. On décida de porter le cadavre dans une caverne et de l'envelopper des fibres, cause de sa fin. Mais c'était solution d'apparence valable pour l'apparence des choses. Elle ne réglait pas l'invisible. Du corps inanimé s'était enfuie l'âme du vieillard accompagnée de ce qui lui restait de force non bue par les 
p.163 fibres. Tandis que la putréfaction achevait son œuvre, les principes spirituels libérés cherchèrent un support. Ils le trouvèrent en la personne d'une femme grosse qui, pour des raisons obscures, était vêtue d'une jupe rouge comparable à celles qui enveloppaient le corps du serpent. La femme accoucha d'un enfant rouge comme les fibres et tacheté comme le reptile qui ne devint normal qu'après sa consécration à l'ancêtre dont la disparition avait été causée par la désobéissance des humains.

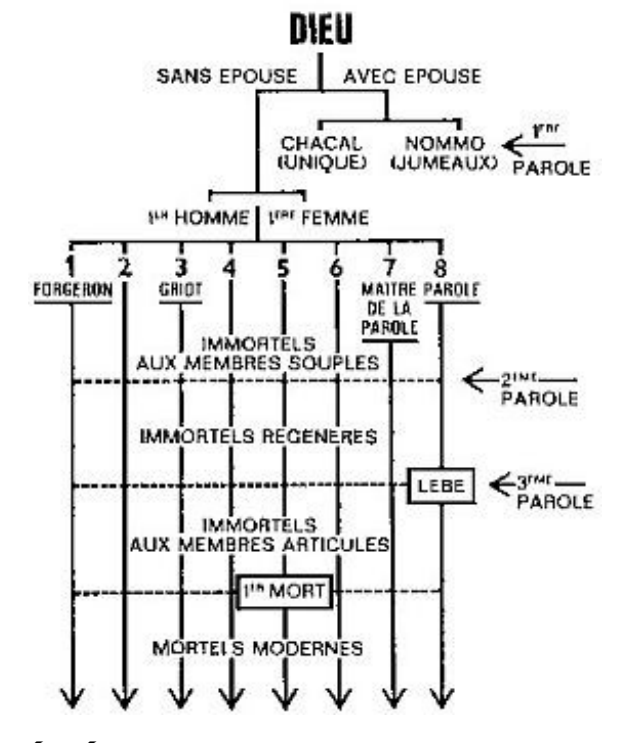

\section{GÉNÉALOGI E DU PEUPLE DOGON}

Cette consécration fut célébrée au cours d'une longue retraite que subit l'enfant dans son adolescence. Elle coïncidait avec la taille d'un grand bois, en forme de reptile, peint aux couleurs du disparu, dans lequel, par un sacrifice approprié, furent attirés les principes spirituels que ne pouvait plus supporter l'enfant. En revanche, celuici était attaché au culte que la société des hommes devait à l'ancêtre.

C'étaient là événements et gestes de grandes conséquences. Le Blanc y réfléchissait longuement, tandis qu'Ogotemmêli s'absorbait dans la sérieuse tâche consistant à prendre du tabac.

Avec la mort de l'ancêtre, prélude à la fin des hommes. apparaissait la sujétion où étaient les vivants de fournir à tous les morts qui allaient suivre un support pour les âmes et forces libérées. II leur fallait aussi trouver parmi eux un 
enfant responsable du culte qui était institué dans chaque cas. Dans toute sa complexité, le monde des morts allait s'organiser. II allait peser lourdement sur les vivants, déclenchant les arts par la taille des images de bois représentant les disparus, puis par celle des masques d'animaux qui périssaient eux aussi, tués de la main des hommes; déclenchant les inquiétudes individuelles par le réseau de plus en plus dense de règles et d'interdits enserrant chacun. On pouvait dire que la suite de fautes et de ruptures dont l'aboutissement était la mort, avait amené un nouvel ordre des choses, où non plus seulement les groupes, mais les individus avaient leur rôle. Tout en maintenant les responsabilités globales de la nature humaine, ces ruptures dans lesquelles on pouvait grossièrement reconnaître les premières formes du péché, obligeaient l'humanité à l'exil individuel, divisaient à l'infini, réduisaient à la taille de chacun les charges d'expiation ou de maintien d'un ordre nouveau.

II n'entrait pas dans les vues de l'Européen de reprendre avec son informateur le détail des nombreux rites, comportements et représentations nés de la perte de l'immortalité par les p.164 hommes. Les institutions concernant les morts étaient bien connues; mais pour chacune la question de l'origine se posait et seul un homme comme Ogotemmêli pouvait aider à la résoudre.

L'une d'elles, par son ampleur, par les grandioses manifestations qu'elle déclenchait, s'imposait à l'attention. II s'agissait d'une fête célébrée tous les soixante ans par le peuple entier, et qui, durant une longue période, agitait successivement, d'année en année, toutes les régions dogon. Ce rite ambulatoire, nommé Sigui, partait de la région de Yougo.

II intéressait toute la falaise et le plateau, du nord-est au sud-ouest. II donnait lieu à de longues journées de danses et de gesticulations rituelles; le rassemblement des denrées consommées exigeait de grands mois d'efforts. Toutes les familles du territoire dont c'était le tour de manifester vivaient longtemps à l'avance dans la fièvre et la peine.

Deux actes essentiels étaient accomplis au cours de ces journées: taille d'un long serpent de bois dans un seul 
tronc d'arbre (un des exemplaires rapportés par le Blanc, aux Musées de p.165 France, mesurait dix mètres); beuverie de bière de mil, les buveurs étant assis sur un siège spécial dit «siège de masque » réservé pour cette seule occasion.

Le sens de la taille du bois était clair: il s'agissait de renouveler le support des principes spirituels du premier mort, toujours présents dans le monde des hommes. En effet, le bois du premier « grand masque » sculpté par les anciens avait vieilli; d'autre part l'homme qui avait été affecté à son entretien était mort. Ces deux faits remettaient en question la tranquillité de la société humaine : à l'esprit de l'ancêtre il fallait un autre contenant; pour son culte il fallait un nouvel initié. On avait donc choisi un enfant dans la descendance de celui qui était né marqué par le mort et qui était devenu en quelque sorte le répondant des hommes auprès de lui. On l'avait initié, en même temps que plusieurs autres camarades, dans la caverne où était placé le grand masque ; on l'avait consacré, par sacrifice sanglant, au nouveau bois qui luimême, par rites et prières appropriés, avait relevé I'ancien.

Ainsi avait-on procédé par la suite, tous les soixante ans. Et dans les villages anciens, on pouvait voir, alignés au plus profond des cavernes, les grands mâts des soixantenaires dont les plus récents gardaient encore leur peinture, dont les plus vieux se délitaient, tombant en poussière sous la main.

Mais si la taille périodique du grand masque et le renouvellement des initiés s'expliquaient, il n'en était pas de même de cette consommation de bière, par rang d'âge, où tous les mâles de la région s'asseyaient sur un siège de forme inhabituelle. Certes la consommation elle-même avait son sens mystique: il s'agissait d'une communion générale à laquelle prenaient part le nouveau grand masque ruisselant de libations et l'ensemble des hommes, depuis le vieillard à peau sèche jusqu'au nouveau-né du jour même. II y avait consécration au mât de la société entière qui prenait à son compte aussi bien l'expiation de la faute commise envers l'ancêtre que le culte du nouveau support. 
Par contre, rien n'avait jamais éclairé le sens du « siège de masque », sorte de courte béquille en $\mathrm{Y}$, aux deux branches très écartées, souvent presque horizontales,

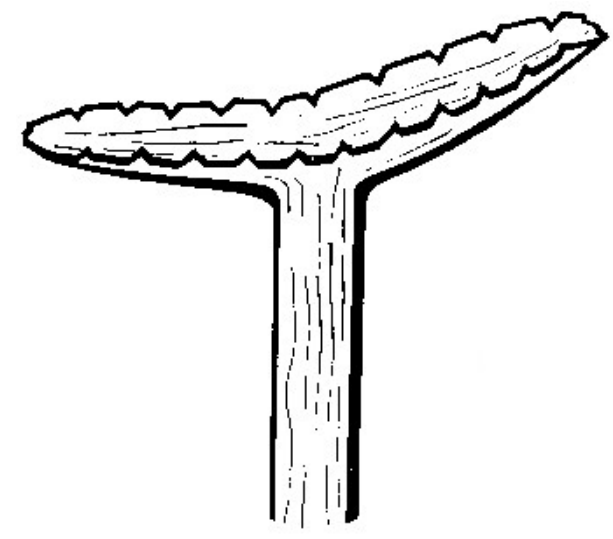

\section{CROSSE-SI ÈGE DES FÊTES DU SI GUI}

amincies et de pourtour dentelé. La communion n'était valable que si l'intéressé était assis sur ce siège qu'une libation spéciale consacrait auparavant.

- Le siège de masque, dit Ogotemmêli, c'est l'image du Génie de l'eau.

p.166 A nouveau, il fallait remonter très haut dans les temps mythiques.

- Avant sa métamorphose en Nommo, l'ancêtre qui mourut le premier s'était longuement querellé avec un homme de sa classe d'âge à propos de préséance. Ils voulaient chacun avoir le pas sur l'autre et chacun prétendait être le plus fort.

Tous deux appartenaient à la cinquième famille aujourd'hui fixée à Yougo. Ils parvinrent au temps de leur métamorphose sans se réconcilier.

- Lorsqu'ils furent transformés en serpent, ils reprirent la querelle, chacun criant, dans la langue des génies: «C'est moi le plus fort! » Finalement, ayant lutté, le premier tua l'autre et le mangea.

C'est à cette époque que survint l'aventure avec les jeunes gens: le serpent mourut impur. A ce moment l'ennemi qu'il avait dégluti, et qui n'avait été tué qu'en apparence, ressortit du corps de son vainqueur. Mais comme il avait été en contact avec le cadavre, comme il 
ressuscitait d'un mort, il périt lui aussi, par contagion. Cependant, sa fin n'était pas comparable à celle de l'autre. Son vainqueur avait péri impur; lui-même disparaissait sans souillure, par simple contagion, comme devaient par la suite faire la plupart des humains.

- De celui-ci on rassembla le squelette, que l'on crépit et dont on fit un autel. Vous pouvez en voir un modèle au-delà du champ de Samtigou, près du nouveau village de Go.

Le Blanc connaissait bien cette haute borne rouge sur laquelle il avait vu, des années auparavant, une bête sacrifiée, ouverte, pattes en croix, vidée par les rapaces. Pendant des mois, il avait essayé de trouver la bonne fissure, dans le bloc silencieux formé par la famille Sangabinou, gardienne du mystère. Des bribes disparates, sans intérêt, avaient été la récompense de son acharnement. Les Sangabinou, tantôt toutes dents dehors, tous vieillards hérissés, tantôt dos ronds, œil absent, avaient résisté autour de la glaise insigne couverte de sang coagulé.

Les Sangabinou, dans la région, formaient un groupe minoritaire, de la tribu Arou. Ils se disaient les plus anciens, ce qui était vrai. Depuis des siècles ils possédaient Go, qu'ils avaient abandonné pendant plusieurs décades, pour y reconstruire à nouveau un village. Ils montraient avec orgueil, non loin de leur abri pour le conseil, un amas de pierres qui était le plus vieil p.167 autel de la région, qui avait été dressé par les Tellem, ces anciens habitants repoussés paisiblement par les Dogon.

- Cet autel leur vient de Yougo, où se trouve celui qui fut fondé dans les temps anciens.

C'était là comme une tombe. Mais cet édifice, très important pour l'ensemble du peuple dogon, n'en était pas moins confié à une famille particulière. Un autre objet, symbole de l'ancêtre, devait au contraire figurer en effigie dans les mains de tous les hommes participant aux fêtes du Sigui : cet objet était un piquet de fer au haut duquel était fixée par le milieu une languette en forme de côte de melon, aux pointes mousses. 
- Le piquet, dit Ogotemmêli, c'est le bas du corps du Nommo, en forme de reptile. Le fer plat transversal forme les bras légèrement relevés du génie. La tête est absente. pent ?

- Mais l'ancêtre n'était-il pas mort sous forme de ser-

- Oui ! les deux ancêtres ennemis sont morts sous forme de serpent. Mais c'était la forme invisible du génie Nommo. En réalité, ils avaient la forme invisible du génie Nommo.

- S'ils avaient la même forme invisible, pourquoi avoir taillé un long bois pour le premier et un siège de masque pour le second?

- Le premier est mort impur pour avoir rompu l'interdit de parole. On lui a donné une forme terrestre de serpent. L'autre n'est mort que par contagion. De plus, c'était lui qui avait le pas sur l'autre. II était le plus vieux. Pour cela, il est plus près que le premier de la forme céleste du Nommo. On lui a donné dans le fer une forme de Nommo sans lui forger la tête.

- Mais cette tête ?...

- On ne l'a pas forgée parce que cet objet est un siège et qu'on ne saurait s'asseoir sur la tête d'un vieillard. Car chacun a taillé dans le bois un siège imitant le modèle de fer.

- Pourquoi cette forme de siège ?

- Lorsque l'homme boit, assis sur le siège, la bière du Sigui, il est le vieillard lui-même. C'est comme si l'ancêtre était là. Le siège est le corps, aux bras ouverts, et I'homme assis est la tête du Nommo mort. Chacun est une résurrection du vieil homme.

Ogotemmêli semblait fatigué : il avait pris froid la nuit précédente, ayant dormi sur le rocher sans se couvrir. Sa voix, de temps à autre, se voilait.

- La femme de l'ancêtre au siège, continua-t-il, était celle qui ${ }_{\text {p.168 }}$ découvrit les fibres rouges. C'est aussi pour cela que cet ancêtre était plus important que l'autre. La femme, à la fin de sa vie terrestre, s'est, elle aussi, transformée en génie Nommo, comme tous les vieillards 
notables. Son symbole est la calebasse que porte chaque homme pendant les fêtes du Sigui et dans laquelle il boit la bière.

Ainsi durant la célébration du rite soixantenaire, les buveurs qui dansaient la marche serpentante des génies, honoraient dans le nouveau grand mât l'ancêtre vainqueur de la querelle. Et ils brandissaient dans leurs mains le siège de bois et la calebasse: la calebasse-femme dans laquelle ils allaient boire l'humidité vivifiante, le siège-ancêtre dont ils figuraient la tête. Présentant les deux Nommo morts, ils en mimaient la résurrection.

En rentrant par le chemin situé entre les deux Ogol, le Nazaréen passait devant le baobab dans les branches duquel était dressé le grand masque durant les fêtes du Sigui. II traversait les lieux-dits où les danses et les beuveries communielles réunissaient la société entière des hommes. II s'enfonçait dans un abîme de réflexions.

II connaissait depuis longtemps le sens de ce grand rite ambulatoire que chaque région célèbre à son tour. Mais il venait seulement de découvrir le symbolisme du siège de masque qui éclairait brusquement l'ensemble de tout le système religieux, équilibré entre la vie et la mort, fait de va-et-vient incessants de l'un à l'autre.

Côté vie, il y avait eu alliance, intime union alimentaire de deux êtres dont l'un était céleste et l'autre humain. Tous deux avaient resurgi d'une mort apparente et l'un par l'autre, l'un avec l'autre, distincts et confondus, ils avaient manifesté une organisation nouvelle du monde.

Aujourd'hui, tous deux animaient un culte de vie et figuraient matériellement sur les sanctuaires; I'un mangé sous forme d'homme, vomi en silhouette de pierres, était le serpent ondulé pétri dans le torchis des façades, vivant, buvant les bouillies et les sangs des sacrifices. Il était le Lébé luisant, glissé chaque nuit dans les ruelles pour les tâches d'entretien spirituel.

L'autre sommait les frontons, enclume à deux bras en croix, à tête pointée vers le ciel. Vivant, il accrochait dans

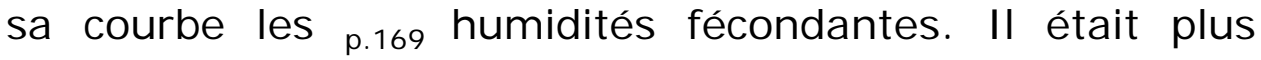


céleste que le Lébé, qui avait été dégluti comme corps humain.

Côté mort, il y avait eu combat entre deux génies de même famille, l'un avait dégluti l'autre. L'un, le vainqueur, était mort impur et avait été représenté sous sa forme de serpent, par un grand bois taillé tous les soixante ans. L'autre, de forme plus céleste, était ressorti vivant des entrailles pour mourir aussitôt. On le représentait sous la même forme que celui des frontons des sanctuaires de vie, avec deux bras et un corps, mais sans tête. Cette tête, tous les soixante ans, était l'homme lui-même, buvant la bière du culte des défunts.

Il y avait, dans le monde des morts, une réplique au monde des vivants. 


\section{Vingt-septième journée}

\section{Le culte des morts, les boissons fermentées}

A chaque marché, des ivrognes titubaient dans les ruelles et grognonnaient par-dessus les murs des phrases sans suite. La plupart étaient des hommes d'âge et nul ne se formalisait de leur tenue ni de leurs propos. Au contraire, une certaine considération, mêlée de crainte, semblait les entourer.

Interrogés, les Dogon avaient répondu qu'il n'était pas décent pour les jeunes de boire avec excès de la bière de mil, mais qu'il n'y avait aucun inconvénient pour les adultes, et surtout pour les personnes âgées, à revenir ivres du marché ou des beuveries familiales. En tout cas, on n'injuriait jamais un homme pris de boisson, même lorsqu'il prononçait des paroles désobligeantes, ce dont il ne se faisait pas faute.

A certains sourires, le Blanc avait été amené à demander ce que disaient les ivrognes.

- Ce que disent les gens qui ont trop bu de bière ? lui répondit-on, ils disent: «Les morts, eux, meurent de soif ! »

Cela ressemblait à une plaisanterie. D'autre part, on ne voyait pas comment cette déclaration aurait constitué une très grave injure si elle avait été le fait d'un homme lucide.

Il ne s'agissait pourtant de rien de moins que du culte des p.170 ancêtres et de son contrôle par les buveurs de boisson fermentée. Sur cette boisson, il y avait d'ailleurs beaucoup à dire. Dans les rites, elle était réservée aux choses de mort, « aux choses de brousse ». Au contraire, les ancêtres, considérés comme des êtres vivants, recevaient le sang et la bouillie de mil. Jamais leurs autels n'étaient directement aspergés de bière.

- Si ces autels recevaient la bière, dit Ogotemmêli, les ancêtres s'enivreraient, car ils sont vivants. Seuls les 
autels élevés aux «impurs », qui sont des morts-vivants, peuvent la recevoir.

Cette règle supposait un abîme d'explications. Ogotemmêli les donna toutes. Le Blanc, bien qu'il eût I'habitude de cette logique, de ces agencements implacables, de ces nuances méticuleuses, restait étonné devant la pensée sans fissures qui s'étendait chaque jour devant lui.

Mais il voulait en venir au sens profond de l'injure des ivrognes : Les morts, eux, meurent de soif !

II savait que l'âme d'un homme le quitte souvent très longtemps avant sa fin; elle ne revient qu'à ce moment critique pour habiter la maison mortuaire durant toute la période du deuil, close par un rite funéraire qui provoque le départ de l'âme, libérant famille et société des interdits pesant sur elles. A cette occasion, de grandes dépenses de nourriture et de boisson sont faites, des masques sont confectionnés. D'une manière générale, l'importance du rite est fonction de l'âge et de l'importance du défunt. La parenté est tenue d'offrir aux deuilleurs d'autant plus de denrées que le défunt a célébré lui-même un plus grand nombre de levées de deuil.

La partie la plus importante du rite est constituée par une danse masquée sur la terrasse du mort. Sur l'étroit rectangle de terre, qui symbolise les régions célestes, l'ensemble des masques, qui résume le monde des animaux et des humains, les fonctions sociales, les métiers, les peuples voisins, intègre dans son activité l'âme du disparu et l'entraîne hors du domaine terrestre.

Quelques jours plus tard, des rites rompent les dernières attaches du défunt qui de la qualité de mort passe à celle d'ancêtre dès que l'enfant qu'il a désigné pour héritier de sa force vitale érige la poterie-autel dans laquelle il viendra désormais boire.

Toutes ces cérémonies, minutieusement ordonnées, ont donc ${ }_{\text {p.171 }}$ pour effet de régler l'instable situation du défunt, du defunctus, qui s'est acquitté de la vie, qui est sorti de fonction et qui erre dans l'incertitude. La société a intérêt à les célébrer dans les délais prévus pour assurer la paix et 
l'ordre religieux. Pourtant elle ne le fait pas toujours. Les familles doivent en effet engager de grandes dépenses pour l'organisation de la levée de deuil.

- Dans les familles, dit Ogotemmêli, on attend toujours qu'il y ait eu plusieurs morts pour célébrer la levée de deuil et poser les poteries-autels.

Ainsi les frais se trouvent-ils répartis. Mais le résultat de cette procédure est d'accumuler les cas de défunts insatisfaits, dont le statut n'est pas réglé et qui continuent à séjourner dans le monde terrestre, incertains et méfiants.

- Dans cette attente, les morts sans autel s'exaspèrent, mettant le désordre dans les villages.

Ogotemmêli entendait par là que les familles vivaient de ce fait dans un état d'insécurité morale qui entravait le déroulement normal de la vie. Dogon.

- L'affaire de la pose des autels, disait-il, préoccupe le

II était pris entre le désir de contenter les défunts et celui de se tirer au mieux des embarras causés par la dépense.

Mais le désagrément de cette alternative ne suffisait pas à expliquer les malaises individuels ni le malaise social. Les sentiments internes, chez les Dogon, ont presque toujours, en matière religieuse, des moteurs externes.

Il fallait d'abord connaître la raison de cet état de mécontentement latent chez les défunts instables.

- Les défunts, dit Ogotemmêli, sont impurs du fait de la mort.

Du fait de la mort, les principes spirituels de l'individu explosaient pour ainsi dire. L'âme était séparée de la force vitale dont elle était la volonté et la conscience. Cette force vitale elle-même s'écartelait. Elle était en effet composite, formée de parcelles provenant de la force des géniteurs, de celle d'un ancêtre "parrain » et des divers ancêtres de groupe et de tribu. Elle avait été entretenue, dans le cours de la vie, par des sacrifices aux autels élevés à ces différentes personnalités religieuses. Tout en formant un amalgame cohérent permettant l'action de son porteur, 
elle restait liée, du fait de ses origines diverses, à tous ceux qui l'avaient octroyée.

L'un des effets de la mort était de disperser la force vitale, p.172 de renvoyer aux autels respectifs les parcelles dont elle était formée. Et dans un certain sens, c'était cette dislocation de force, ce dépouillement de l'âme qui constituaient l'impureté de la mort. Mais il fallait convenir, à ce propos, que le mot d'impureté était incommode, impropre, trompeur. II n'en existait pourtant pas d'autre.

L'âme donc, placée dans un état d'anxiété, de désarroi, cherchait à retrouver son équilibre, à réunir les forces qui lui avaient échappé, à reformer un ensemble, à regagner cette «pureté » qu'est la vie par rapport à la mort, à regagner cette présence de vie.

- Étant impurs, dit Ogotemmêli, les défunts mettent partout le désordre.

Ce désordre n'est d'ailleurs qu'avertissement adressé aux vivants, le but des âmes anxieuses n'étant pas la vengeance, mais l'alerte donnée aux humains, l'appel à la mise en ordre des disparus.

Étant impurs, étant provisoirement choses de mort, les défunts emploient, pour créer ce désordre d'alarme, une chose qui, rituellement, est réservée aux morts, c'est-à-dire la bière de mil.

Ne recevant pas encore de culte, errant dans la période de deuil, l'âme vient se désaltérer d'elle-même dans les bières en fermentation que la parenté prépare pour les usages profanes ou religieux. Partout où s'élèvent les fumées et vapeurs des grands pots remplis d'eau et de mil, les âmes accourent.

- Elles viennent se poser sur le support à ferment.

Cet objet est fait de fibres tressées en forme de bonnet allongé, ou de sphère grossière, auxquels pendent parfois de petits pompons. On le trempe dans le bouillon de mil pour y déterminer la fermentation.

Posés sur le support, les défunts l'imprègnent du peu de force qui leur reste. Cette force se mêle à celle de l'eau et du mil, entre dans la boisson pour lui donner son pouvoir énivrant; elle est assimilée avec la bière par le buveur; 
elle est assez puissante pour provoquer en lui un désordre, mais non pas pour le rendre lui-même impur. II y a comme une lutte entre elle et celle de l'homme.

- Le ferment de désordre que les défunts ont introduit dans la bière agite le buveur. Mais la force de celui-ci résiste et finalement elle expectore ce qui est impur.

p.173 Le buveur rejette l'élément perturbateur par des paroles elles-mêmes désordonnées mais efficaces.

- II renvoie l'impureté à ceux qui l'ont placée dans la bière, mais aussi et surtout à ceux qui sont coupables d'obliger à une trop longue attente les défunts sans autels.

Et les paroles vont, par-dessus les murs, au travers des portes, atteindre les retardataires. Qu'ils bredouillent des mots sans suite, qu'ils chantent ou qu'ils injurient, les hommes trébuchant dans les ruelles sont entendus de tous, car tous ont des deuils à lever, des comptes funèbres à régler. Et même s'ils ne les crient pas distinctement, leurs paroles sont bien comprises de tous les insouciants dont les greniers ne sont pas assez pleins pour l'ouverture des rites, de tous les pauvres dont les efforts sont vains :

- Les morts, eux, meurent de soif !

Et lorsque la conscience familiale est par trop chargée, tout malaise, tout incident fâcheux est interprété comme le second avertissement sensible, pressant, donné par ceux qui attendent.

- Ceux qui tombent malades, ceux dont les bêtes dépérissent vont consulter les devins. On leur apprend alors qu'il faut lever le deuil, qu'il faut poser les poteries où les morts viendront boire.

Car du fait même de l'établissement de son culte, le défunt recevra une aide régulière des siens et dès la première offrande il réunira ses forces, attirera à lui toutes les parcelles de lui-même dispersées par la mort. II sortira de la mort et reprendra son état de pureté. De défunt impur, il deviendra ancêtre vivant.

Ainsi l'ivresse est-elle un état efficace. 
- Les hommes ivres créent, par leurs paroles, un mouvement favorable à la pose des autels, ce qui satisfait les défunts.

- Alors, il faut boire de la bière en excès ?

- Pour les vieux, s'enivrer est comme un devoir. Car c'est un désordre apparent qui aide au rétablissement de l'ordre.

Les morts vivants

Mais cette institution de la boisson fermentée, de l'ivresse religieuse, n'était pas jugée suffisante pour assurer le rappel des devoirs envers les disparus. Celle des « impurs », des p.174 morts-vivants, permettait au contraire de satisfaire constamment à la règle.

Après que le corps du premier mort eut été transporté dans la caverne, on l'avait imité en taillant un grand serpent de bois, le grand masque, et l'enfant désigné par le disparu avait été consacré à sa garde ainsi que plusieurs compagnons.

Du fait qu'un culte avait été établi, qu'un support nouveau lui était donné, le défunt, d'impur qu'il était au moment où il avait rompu l'interdit, était devenu un ancêtre vivant. Bien que présidant au culte des morts, il avait donc suivi une destinée normale. Mais son état d'impureté avait eu une influence décisive sur la personne des jeunes initiés qui avait acquis, elle aussi, cette qualité. Le fait qu'il y avait eu, dans la suite, changement d'état du grand masque, n'avait en rien modifié la situation des enfants. Ceux-ci devaient, toute leur vie, conserver la qualité d'« impurs », c'est-à-dire, en un certain sens, de morts.

- Les initiés, dit Ogotemmêli, sont de même nature que l'ancêtre du grand masque. Mais alors que cet ancêtre est devenu « vivant » dès qu'on lui posa une poterie-autel, les initiés sont restés «impurs», car ils ont été formés auprès du mort lorsqu'il était encore « impur ». 
Et ils devaient, à leur mort, devenir les «parrains » d'autres enfants. Ainsi, aujourd'hui, chaque famille compte un nombre important de membres «impurs», relevés de la plupart des interdits imposés aux autres hommes qui sont dits « vivants ». Ils jouent un rôle essentiel dans tous les cultes. Mais ils assument une fonction permanente qui leur est dévolue de par leur nature même :

- Les « impurs » sont les remplaçants du premier mort au moment où il n'avait pas encore d'autel. Les «impurs » et l'homme mort «impur» qui est devenu le grand masque, c'est tout un. Pour cela, ils sont aussi les remplaçants de tous les morts qui n'ont pas d'autel.

Si bien que tout le bien qu'on leur fait profite aux défunts. Et notamment les faire participer aux sacrifices revient à nourrir tous les disparus qui errent à la recherche d'une nourriture :

- Les «impurs», quand ils consomment la chair et la bière des sacrifices, c'est comme si buvaient et mangeaient les morts dont on n'a pas encore établi les autels.

Ainsi les «impurs » sont comme des morts que l'on nourrirait p.175 en permanence pour que les disparus insatisfaits laissent en paix les villageois.

- Mais c'est une tromperie, dit Ogotemmêli.

Il entendait par là qu'on ne pouvait se contenter de désaltérer et nourrir les «impurs. II fallait finalement et réellement poser les autels de ceux qui n'étaient plus et qui souffraient de leur état incertain. II fallait établir les cultes et promouvoir les ancêtres.

- Ces « impurs », que deviennent-ils après la mort ?

- Ils sont comme tous les autres. Quand la famille a posé leur autel, ils deviennent ancêtres.

Ainsi ces hommes qui vaquaient comme tous les autres à leurs occupations, qui criaient au marché sur les viandes trop chères et peinaient dans les champs, étaient des morts, buvaient pour les morts. 
Ils ne devenaient vivants que lorsqu'ils étaient promus au rang d'ancêtres, lorsque leurs corps s'étaient desséchés dans les nécropoles. 


\section{Vingt-huitième journée}

\section{La danse}

@

A diverses reprises, au cours des entretiens, Ogotemmêli avait parlé de la danse. Masquée ou non, elle était souvent, dans des rites divers, un axe de travail religieux. Notamment dans le culte funéraire, soit pour l'inhumation, soit pour la levée du deuil, elle apparaissait comme la gesticulation par excellence.

Son origine remontait aux premiers temps du monde, où l'inceste de la terre muée en fourmi avait rendu le chacal maître de la jupe de fibres et hostile à Dieu.

- Vêtu de la jupe, le chacal s'était rendu sur la terrasse de son père qu'il croyait mort.

Le père du chacal était Dieu et Dieu s'étant passagèrement endormi, son fils, qui était aussi son rival, l'avait cru mort. Préfigurant l'un des gestes essentiels des rites funéraires qu'allaient plus tard instituer les hommes, l'animal était monté sur la terrasse de son père pour le pleurer.

- p.176 S'étant vêtu des fibres prises à sa mère, le chacal dansa. En dansant il parlait. Car les fibres étaient pleines d'humidité et de parole. Elles contenaient la première parole révélée par le Nommo à la terre. C'étaient cette eau et ce verbe qui faisaient parler l'animal.

Le fils de Dieu parlait sa danse ; ses pas laissaient dans la poussière de la terrasse des traces qui dessinaient le sens de son verbe.

- En dansant, dit Ogotemmêli, il a laissé trois traces en long et trois en large qui représentaient la terrasse de Dieu, l'intérieur de la maison de Dieu et le réduit où l'on pose l'autel des morts ; il a planté de petits bois, placé des pierres et tracé des signes. 
Le fils de Dieu, en célébrant la mémoire de son père qu'il croyait mort, gesticulait, parlait et traçait le monde et son avenir.

- Il parlait la première parole et il dévoilait l'avenir du monde. Par colère, il révélait les secrets de Dieu.

Car il honorait et bafouait son père. II avait pris les fibres de sa mère, pleines de verbe, lequel contenait les desseins des puissances célestes.

- La terrasse où a dansé le chacal a été la première table de divination. Les hommes l'ont ensuite imitée dans le sable, autour des villages.

II voulait parler des rectangles de sable passés au lissoir sur lesquels les devins marquent leurs questions et que les chacals, attirés par des appâts, viennent piétiner de nuit, inscrivant la réponse.

Ainsi la première danse attestée avait-elle été de divination ; elle avait projeté dans la poussière les secrets du verbe contenu dans les fibres portées par le danseur. Elle était aussi danse de mort car c'était pour honorer et bafouer son père apparemment mort que le chacal l'avait inventée.

De longues périodes s'étaient écoulées. Les hommes avaient fait leur apparition et la révélation de la troisième parole avait agité le ciel et la terre. Ogotemmêli avait rapporté comment, au rythme de l'enclume et des soufflets de forge, le Nommo Septième s'était relevé de la mort, comment il avait étendu et replié les bras, progressant dans le monde souterrain avec des gestes de nage.

Cette danse de résurrection avait conduit le maître du verbe ${ }_{\text {p. } 177}$ à la tombe de l'ancêtre représentant de la parole. Elle avait abouti à une déglutition suivie d'un vomissement rythmé qui avait projeté dans le sépulcre la silhouette du nouveau système du monde.

Et tous ces prodiges avaient eu pour scène le champ primordial qui avait reçu le grenier céleste et au nord duquel était établie la forge.

Tout ce décor, ce matériel sonore, cette gesticulation devaient se retrouver dans la vie des hommes, s'enrichir de sens, de mouvements nouveaux. 
Inventeur de la première cadence de résurrection, le forgeron trouva d'autres rythmes correspondant à de nouvelles figures. Enclume et soufflets étaient unis dans ce labeur ; mais bientôt ils furent symboliquement projetés dans l'ensemble instrumental de base: révélés par le Nommo Septième, les tambours prirent la place des soufflets, les clochettes de fer celle de l'enclume, la baguette celle de la masse. Au début, seuls les forgerons frappaient les peaux, mais peu à peu d'autres hommes les remplacèrent.

- Battre le tambour, dit Ogotemmêli, c'est faire marcher le soufflet, qui est le symbole du soleil.

Le tambour-soleil, comme l'astre, jette de la chaleur, de la vapeur d'eau chaude et sonore sur les danseurs.

- Les danseurs sont chauffés sous les aisselles qui respirent comme le nez. La chaleur pénètre dans la bile et de là se répand dans tout le corps. C'est pour aider son action que les assistants crient: «Ardent! ardent! ardent ! » Et cette chaleur est aussi la parole des ancêtres révélée par le tambour. La sueur qui coule des aisselles et du corps, c'est le trop-plein de la parole des ancêtres qui déborde.

Ainsi enflammés, les danseurs masqués, ceinturés de fibres rouges, deviennent des morceaux de soleil.

Certains mouvements imitent ceux du soleil. La danse sommo est celle qui les rappelle le plus. La danse gôna vient ensuite. Quand le haut masque dit «maison à étage », qui symbolise la maison de famille, la couverture du mort et la chaîne du métier à tisser, tourne à I'horizontale, c'est le soleil lui-même qui montre sa forme ronde.

Le porteur avait aussi une autre mimique qui le mettait à genoux, face à l'est. II abattait son mât vers l'avant, le relevait et le rabattait en arrière, vers l'ouest, la tête comme brisée.

- p.178 L'abattement et le relèvement du mât, c'est la marche diurne d'est en ouest. L'homme est la spirale de cuivre qui donne le mouvement. 
Mais c'était là perfectionnement des premières figures, lesquelles étaient plus simples.

- C'est le Nommo Septième, dit l'aveugle, qui apprit la danse aux hommes.

II avait d'abord répété son premier mouvement rythmé qui l'avait animé dans les régions souterraines.

II dansait du haut du corps, dressé sur sa queue de serpent.

Au début, les hommes dansèrent sur place, tournant sur eux-mêmes ou mimant les gestes de nage. Mais ces mouvements étaient épuisants. Peu à peu, on se déplaça en agitant les jambes. On imita la marche lente du caméléon, qui a reçu toutes les couleurs du Nommo, c'est-à-dire de l'arc-en-ciel. Les mouvements devinrent plus rapides.

- La figure gôna rappelle le vomissement du Nommo dans la tombe. Danser soulage, comme vomir.

Puis les hommes sautèrent en déchargeant une jambe après l'autre.

- La jambe que l'on détend, pendant qu'on est en l'air, c'est la queue de reptile sur laquelle était dressé le Nommo.

Et pour se rendre sur les lieux, les danseurs, courant en file indienne, forment une ligne serpentante aux segments brisés.

- Le chemin en chevrons, dit Ogotemmêli, symbolise celui du Nommo, c'est-à-dire une rivière pleine d'eau qui coule.

Les danses avaient d'abord été exécutées sur le champ primordial, devant la forge qui les orchestrait. Ce champ fut la première grand'place.

- Aujourd'hui le champ de danse est la grande place du village, située au nord et que borde la forge.

Ainsi le corps de ballet, son orchestre et son décor reproduisent les lieux et les acteurs des origines. Pour rappeler l'union du son clair du fer et des halètements sourds du soufflet, des clochettes ont été accrochées aux tambours. Et lorsque la baguette, image de la masse, 
frappe la peau, les roulements et tintements rappellent les bruits et rumeurs de l'atelier mythique. La batterie de tambours est soufflerie et enclume, activant et frappant les fragments de soleil qui dansent.

- Et le corps de ballet, la société des masques, est l'image du monde entier.

p.179 Car tous les hommes, toutes les fonctions, tous les métiers, tous les âges, tous les étrangers, tous les animaux sont taillés comme masques ou tissés comme cagoules.

- La société des masques, c'est le monde entier. Et lorsqu'elle s'ébranle en place publique, elle danse la marche du monde, elle danse le système du monde.

Ainsi l'ensemble de l'orchestre, du corps de ballet, de la grand'place est une image de la forge rythmant le mouvement de l'univers.

- Mais, dit Ogotemmêli, le spectacle de la grand'place est passager.

II voulait pourtant trouver des avantages à ces scènes animées.

- Sur la grand'place, dit-il, c'est le système du monde en couleurs et remuant.

Il demandait au Blanc s'il avait bien vu cela, aux cérémonies de levée de deuil.

- Oui, disait l'étranger, j'ai vu celles de Monsé, le chasseur mort le 20 octobre, il y a quinze ans. Et j'en ai vu beaucoup depuis.

Dans sa mémoire passaient les scènes inoubliables de la place et des terrasses mortuaires. II se rappelait la file des cent cinquante danseurs masqués des Ogol qui avait surgi des grès tremblants de mirage et s'était engagée dans la poussière des pistes traversant les champs. Presque tous ceinturés de fibres écarlates qui s'ouvraient sur des fibres noir luisant ou jaune paille, les hommes portaient sur la poitrine les faux seins noirs ou les bandes de cauris cousus, éclatants de blancheur. Les visages se cachaient sous les cagoules tressées dont certaines se crêtaient d'un court plumet beige ou d'un cimier rouge, à la romaine. Ils 
représentaient les jeunes gens, les forgerons, les Peuls, les Saman, les cordonniers, les tambourinaires, les Maures, les voleurs rituels, les chasseurs. D'autres portaient les masques en bois taillés et peints des trois couleurs fondamentales, rouge, noir, blanc. Antilope chevaline, cervidés, oiseaux picoreurs, « déployeurs d'ailes de brousse » à la haute croix de Lorraine, enfin les longs mâts dits « maison à étage ».

Tous tenaient en main des branchages verts, sorte de témoignage de leur essence fraîche. Depuis des mois ces hommes travaillaient dans les creux de roches et les halliers, loin des femmes. Ils étaient partis munis de leurs seuls couteaux et p.180 hachettes. Ils avaient taillé, meurtri, roui, tissé les fibres, les écorces, les troncs. Ils avaient écrasé les couleurs, les avaient étalées avec les pinceaux de poils d'âne. Ils avaient plaisanté sur la teinture rouge des jupes qui avait souillé leurs paumes; ils l'avaient comparée aux flux des femmes. Partis dans leurs vêtements de paysans, arrachés par les épineux, effrangés par l'usage, ils revenaient éclatants dans la brousse terne, casqués et muselés de coiffes et de visages du monde des morts, ceinturés de la jupe écarlate, symbole du soleil.

Sur la grand'place d'Ogol-du-Bas, ils se lançaient par petites files de même costume, chasse-mouches ou vannerie colorée en main, exécutant leurs figures propres ou les danses générales, rythmées sur les tambours et les cloches de fer, au milieu des poussières, encouragés par les chants en langue vulgaire et les déclamations en langue sacrée :

Versez des larmes pour mon père mort !

L'eau tombe, tombe de mes yeux!

Et sur la terrasse mortuaire où ils accédaient par les encoches des troncs servant d'échelles, ils piétinaient dans l'étroit espace, entrecroisant leurs silhouettes rouges et noires, tandis que la veuve, torse nu, bras levés, psalmodiait dans la ruelle, les yeux humides:

La colonne de fourmis est montée sur la terrasse,

La colonne de fourmis a ruiné la maison

Est montée sur la terrasse

Ce sont les fourmis qui ont ruiné la maison du père. 
Elle rappelait, par allusion voilée et licite, la danse du chacal, fils de Dieu, qui s'était vêtu des fibres prises à sa mère transformée en fourmi et qui avait tracé, sur la terrasse mythique, la première table de divination.

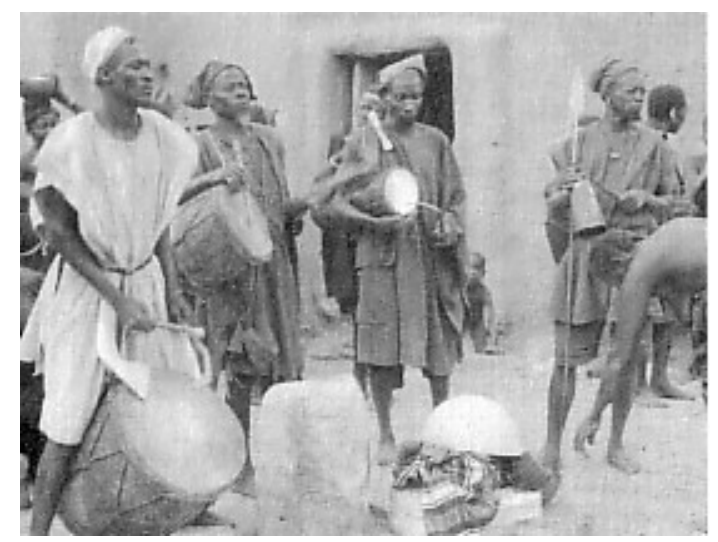

Sur la grand'place, selon Ogotemmêli, on voyait le système universel en couleurs et en mouvement.

Sur la terrasse, les masques, comme avait fait le fils de Dieu, traçaient l'avenir du monde.

Mais ces mouvements et ces couleurs étaient éphémères ; il fallait, pour le fonctionnement de l'univers, une aide permanente.

- p.181 Sur la façade des sanctuaires de Binou, dit Ogotemmêli, vous voyez les peintures blanches du soleil et de la lune, des étoiles, des hommes, des animaux, du matériel. Ces peintures demeurent. Elles aident constamment le monde à continuer.

Car ces peintures représentent, elles aussi, le cadre de la vie des hommes. Elles sont, au repos, et en blanc, la réplique des mouvements et des couleurs qui animent la grand'place et la terrasse du mort. 


\section{Vingt-neuvième journée}

\section{Le culte du feu}

Le culte des morts n'était pas, pour les Dogon, la seule occasion de représenter symboliquement des événements mythiques. Certains masques jouaient, dans un culte mystérieux, un rôle que le Blanc n'avait pu s'expliquer.

Quand on se déplace dans les champs des plateaux, ou des éboulis, on voit, plantés en bonne place à même la terre ou dressés sur des rochers dominant les cultures, des bois noircis grossièrement taillés en tête d'animal à gueule largement fendue. Les uns semblent des coqs monstrueux, enfouis, le cou seul émergeant, bec ouvert sur les céréales. D'autres sont comme de longs chiens tordus, la gueule menaçante.

Selon la croyance populaire, tout homme qui commettrait un vol, dans un champ ou sur un arbre protégé par ces bois noirs serait foudroyé tôt ou tard.

Ces objets provenaient notamment d'un sanctuaire situé dans une caverne de Dyamini et dont un prêtre sur lequel on ne savait rien, assurait le service.

Dès les premiers entretiens, quand Ogotemmêli avait décrit la descente dans l'espace du grenier céleste, ces bois avaient fait leur apparition; pour punir le vol d'un fragment de soleil commis par le forgeron, le couple de grands Nommo avait foudroyé l'édifice.

- Pendant la descente, dit Ogotemmêli, les Nommo du ciel ont lancé deux coups de foudre, la femelle d'abord, le mâle ${ }_{\text {p.182 }}$ ensuite. C'est ce qui a précipité la course du grenier. C'est pour cela qu'il y a eu choc à l'arrivée et que les bras et les jambes du forgeron ont été brisés.

La foudre était tombée par deux fois à côté du soufflet contenant le fragment de soleil. 
- Le forgeron a éteint l'incendie avec l'eau de son outre et il a trouvé deux bois noircis, taillés en forme de gueule ouverte. Le mâle s'est appelé Anakyê, la femelle Badou.

Mais il y avait une autre raison à ce foudroiement. Comme la descente sur la terre avait été organisée par les huit Nommo ancêtres, les deux grands Nommo fils de Dieu avaient voulu être présents dans les cultes qui allaient s'instituer :

- Anakyê et Badou sont les symboles des deux génies. Le forgeron confia le culte à la famille du quatrième ancêtre.

Depuis, d'autres familles en profitèrent.

- Mais pourquoi ces bois en forme de gueule ?

- La bouche du Badou rappelle celle du bâton du voleur dans laquelle le forgeron avait saisi le fragment de soleil.

II s'interrompit.

- p.183 Vous devriez demander à Aninyou, grand-père du prêtre d'Anakyê. Il sait toutes ces choses.

Le Blanc avait déjà interrogé Aninyou, vieillard réticent d'Ogol-du-Haut, et précisément à la suite de cette enquête il s'était décidé à faire parler Ogotemmêli sur ce sujet. II ne répondit pas à cette suggestion et l'aveugle continua, comme se parlant à lui-même :

- Le forgeron est allé voler avec son bâton-de-voleur. C'est dans la bouche de ce bâton qu'a commencé le feu. C'est cela que le forgeron a donné au monde.

Et il ajouta :

- C'est à cause de cela que le vol rituel a été institué.

Les voleurs rituels s'observaient dans tous les éboulis et sur le plateau. A Sanga, chaque patriarche avait cette qualité et l'on pouvait voir, accrochée dans un coin enfumé de la grande maison, une crosse de vol. C'était un bois recourbé en crochet terminé en bouche très ouverte et muni, dans sa courbe, d'une paire d'oreilles pointues. Le long du manche, et formant comme une crinière, courait une ligne chevronnée. On pensait à une fine tête de cheval stylisée. 
Cet objet était une réplique du bâton avec lequel le forgeron avait accompli son vol et le patriarche, trop vieux pour courir les villages lorsque les expéditions rituelles étaient déclenchées, déléguait ses pouvoirs à un plus jeune. Celui-ci était chargé, avec ses collègues, de procéder à des rafles de petit bétail qui était consommé en commun dans des conditions déterminées.

Le piquant de cette institution était qu'elle fonctionnait seulement lors de la mort d'un des membres de cette sorte de conseil. La troupe des remplaçants se mettait aussitôt en branle et se rendait dans les villages voisins pour y surprendre le bétail mal surveillé. Lorsqu'une chèvre était capturée, on la rapportait à la maison mortuaire et on l'égorgeait sur la terrasse dans laquelle était pratiqué un trou donnant sur la chambre où reposait le cadavre; une tige de mil, placée sur sa poitrine, montait verticalement jusqu'à l'ouverture et guidait le sang qui coulait de la gorge tranchée. Par ce canal, une partie de la force vitale du patriarche remontait dans le bâton-de-voleur du disparu qu'on avait placé contre le trou. L'objet était ensuite reporté dans la grande maison de famille près des autels d'ancêtres et devenait la propriété du successeur.

p.184 II s'agissait là, en quelque sorte, d'un rite de reversement. En effet, selon Ogotemmêli :

- Lorsqu'on devient patriarche, on reçoit, entre autres, une parcelle de force vitale provenant du bâton-de-voleur placé près des autels. Cette crosse rappelle celle du vol du feu céleste.

Mais la partie valant le tout, c'est finalement le forgeron lui-même qui est représenté par l'objet.

- Dans tous les autels de famille, le forgeron, ancien Nommo, aîné de la lignée des huit fils du premier couple humain, est présent. II donne sa force au nouveau patriarche, qui la rend à sa mort, par l'intermédiaire de la crosse.

Le patriarche, durant son règne, est donc, entre autres, un représentant du Nommo forgeron, voleur du feu.

Dans chaque village, la règle eût voulu que la troupe fût composée de cinq voleurs. 

vole.

- Cinq, dit Ogotemmêli, sont les doigts de la main qui

Mais ce nombre était toujours dépassé. II y avait autant de voleurs que de familles.

La raison de cette institution, d'après Ogotemmêli, était la commémoration du geste du forgeron volant le feu au péril de sa vie pour le donner aux hommes : au lieu de feu, on dérobait des moutons et des volailles.

- Le bâton-de-vol est comme une hyène qui mange de la viande fraîche et rouge. Cette viande rappelle la braise volée dans le soleil.

Pour rappeler l'embrasement et la prise de viandes saignantes, on dessinait parfois, sur les façades des sanctuaires, des crosses à mâchoires rouges.

- La ligne chevronnée, le long du manche, est le chemin du Nommo, celui par lequel le forgeron s'est enfui du ciel.

Développant cette institution, une technique de répression du vol reposait sur les deux coups de tonnerre vengeurs qu'avait reçus le premier coupable. Les foudroiements s'étaient matérialisés en deux bois taillés à la ressemblance du bâton. Ils avaient la forme même du corps du délit. Ils avaient été confiés à deux prêtres qui les multiplièrent et les distribuèrent à leur parenté pour éloigner les pillards des champs et des arbres. Car il ne s'agissait plus de dérober les braises des foyers, comme avait fait le forgeron céleste.

Ils étaient comme des feux éteints mais capables d'attirer la foudre sur les coupables. Ils étaient, de plus, doublés dans leur p.185 rôle par des masques rouges, en écorce de Lannea acida, représentant aussi les feux morts des coups de foudre que le forgeron avait parés.

Dans sa cagoule oblongue que sa tête gonflait comme un épi de maïs gonfle son étui de feuilles, l'homme masqué, en parcourant les vergers, jetait la terreur parmi les femmes et les enfants.

Tous ces feux éteints avaient, à Sanga, deux sanctuaires : un pour le Badou, à l'ouest de Dyamini ; un 
pour Anakyê, feu mâle, sis en bordure est du quartier de Guêndoumman, dans Ogol-du-Haut.

Le sanctuaire du Badou était construit à l'orée d'une vaste caverne occupée en grande partie par des maisons de Binou. II était entouré d'une petite enceinte de pierres sèches dans laquelle étaient entassés de nombreux bois noircis. L'édifice se composait d'un cube de torchis où un homme n'aurait pas eu ses aises, et sur la surface duquel s'étalaient des lignes de chevrons rouges et blanches.

Le temple d'Anakyê était au contraire établi à ciel ouvert, à même le rocher luisant déversé sur la dépression séparant les deux Ogol. Il était composé d'un cylindre de trois coudées de diamètre, et d'autant de hauteur, recouvert d'une terrasse. Sa porte, hermétiquement close, ne s'était jamais ouverte, pas plus que celle du Badou, devant l'Européen.

II avait appris pourtant de sources sûres et dont les renseignements étaient recoupés, que l'autel intérieur de ces deux édifices était surmonté de deux cupules noyées dans le mortier de terre. C'était là que le prêtre versait les offrandes au couple foudroyeur des Nommo célestes.

C'était là aussi que tous les bois de protection étaient apportés chaque année après les récoltes pour y puiser une nouvelle force au cours d'un rite dont la partie essentielle était la mise en scène du vol du feu.

A Dyamini, comme aux Ogol, deux masques représentaient les feux mâle et femelle. Un homme jouait le rôle du forgeron et brandissait une torche, poursuivi par les deux premiers. A Dyamini, la scène se déroulait dans les rochers, entre la caverne et une petite cuvette de terre couverte d'herbes sèches que le fuyard incendiait, pour rappeler comment le feu du grenier céleste, après le contact, s'était répandu sur la terre.

Aux Ogol, une course s'organisait entre le sanctuaire d'Anakyê ${ }_{\text {p.186 }}$ et un point situé en bordure d'Ogol-du-Bas. Le parcours traversait ainsi le champ situé entre les deux villages, dans la dépression aux baobabs.

L'homme à la torche partait de l'édifice, déboulait sur la pente luisante et courait à travers chaumes, secouant son 
brandon d'où tombait une pluie d'étincelles et de petites braises.

- Car le forgeron, au ciel, courait et perdait du feu, le ramassant avec sa crosse, s'enfuyant, le reperdant et le reprenant.

Le coureur, lorsqu'il avait atteint la bordure d'Ogol-du-Bas, revenait sur ses pas et remontait au sanctuaire dont il repartait aussitôt. Ce manège était répété trois fois et, durant toutes ces courses, les deux masques poursuivaient le fuyard en brandissant un couteau. Ils symbolisaient les deux coups de foudre lancés contre le coupable par les Nommo et ne rejoignaient jamais le porteur de torche qui, à la fin du troisième trajet, atteignait le sanctuaire. II en faisait trois fois le tour en brandissant son feu.

- Ces trois tours, dit Ogotemmêli, rappellent la course du forgeron qui, dans son trouble, cherchait une issue pour monter sur le grenier et cacher les braises.

Car le sanctuaire rond d'Anakyê représentait, dans ce rite, le grenier céleste.

Ainsi se terminait la poursuite qu'un forgeron scandait en frappant le rocher avec son fer d'enclume.

Et le feu vif, pourchassé par les feux morts, redonnait leur force aux foyers de ce monde et aux bois noircis gardiens des récoltes et des fruits des arbres. 


\section{Trentième journée}

\section{Les jumeaux et le commerce}

@

- Moi, répondit Apourali, avec un large sourire, je n'ai rien eu. Je ne suis pas sorti du village; je n'ai pas eu le temps. Je n'ai rien eu du tout !

- Et toi ?

- Moi ! Trente francs ! dit Ambara. J'ai eu trente francs dans la famille de ma mère, à Mendéli.

- p.187 Et moi, dit Koguem, je suis allé à Dyamini, dans la famille de ma mère qui est Dandoulou. J'ai reçu 400 cauris et 110 francs ! En arrivant, j'ai dit : « La vache a eu deux veaux! »

Depuis trois mois, une grande partie du peuple dogon s'agitait sur les pistes pour cette affaire des veaux jumeaux de Mendéli. L'événement était survenu en septembre et la nouvelle s'était répandue avec célérité d'un village à l'autre, sur tout le plateau et dans les éboulis. Elle avait atteint le tréfonds des gens; tous étaient intéressés par le prodige, vieux et jeunes, tous ceux qui pouvaient parler et simplement dire : « La vache a eu deux veaux! »

Car cette mise bas déclenche un mouvement extraordinaire: tous les gens en état de marcher et de parler se rendent dans la famille de leur mère pour y porter la nouvelle et recevoir un cadeau en espèces. Autrefois, seules les femmes étaient sollicitées et versaient des cauris. Aujourd'hui, tous les membres du groupe sont joints et donnent le plus souvent de l'argent. Quant aux vieillards qui ne peuvent se déplacer, ils se contentent de visiter les parentes mariées dans le village ou de guetter celles qui viennent au marché.

Mais pour être lié à une lignée utérine, on n'en est pas moins, en revanche, l'utérin de quelqu'un. Si bien que, finalement, l'argent reçu après avoir peiné sur les pistes 
est restitué, lors du retour, aux demandeurs qui viennent annoncer la même nouvelle.

- On rend ce qu'on a reçu et comme on a eu en route des occasions de dépenses, le résultat est une perte. Quant à celui qui ne se dérange pas, il perd, car il donne sans recevoir. Mais tout cela fait circuler l'argent.

Ainsi, pour des veaux jumeaux, une foule courait les sentes, gagnait et dépensait. Ce n'était pas pour honorer les veaux eux-mêmes, mais pour fêter, en soi, la naissance gémellaire, dont le culte est répandu dans toute l'Afrique.

A vrai dire, la plupart des entretiens avec Ogotemmêli avaient roulé en grande partie sur les jumeaux, sur la nécessité d'être deux, sur les dépôts de vie formant le double de chacun.

Les huit premiers ancêtres étaient en réalité huit paires :

- Les quatre hommes et les quatre femmes, disait Ogotemmêli, à cause de leur bas (de leur sexe) sont les huit doubles. Les quatre mâles étaient homme et femme, mais c'était l'homme le plus fort. Chez les femmes, la femelle était la plus forte. p.188 Eux-mêmes se sont accouplés; chaque femelle de chaque couple est devenue enceinte, a mis au monde des enfants.

Mais dès cette génération, les humains naquirent le plus souvent uniques. L'organisation religieuse, la métaphysique des Dogon exprimaient cette hantise de la perte originelle de la gémelliparité. Les puissances célestes, elles-mêmes, étaient deux, et dans leurs manifestations terrestres, elles intervenaient constamment par couples: le Lébé et le Nommo Septième formaient un couple vivant; les ancêtres du grand masque et du siège-de-masque étaient un couple mort. On pouvait même croire - mais aucun Dogon n'avait émis pareil blasphème - que le premier malheur, dans la marche universelle des choses, avait été l'unicité de Dieu.

Dans la pratique, une naissance de jumeaux est un événement considérable. Elle est, en quelque sorte, un 
rappel des temps fabuleux, où tous les êtres venaient par deux, symboles des équilibres divins et humains. Elle répète la parturition de la première femme et la transformation de son clitoris en scorpion. Le scorpion aux huit pattes est un symbole de deux nouveau-nés aux huit membres. Il est aussi leur protecteur: nul ne les touchera sans s'exposer à sa piqûre.

Cette naissance gémellaire marque le début d'une série de pratiques et de rites exceptionnels. C'est seulement huit semaines (chiffre des jumeaux) après l'événement, que la parturiente cesse sa retraite. A la fête des prémices qui suit, les enfants sont rasés par des jumeaux adultes et la parenté procède à la pose de poteries spéciales dans l'autel de famille. Car ces enfants vont, dès leurs débuts dans la vie, recevoir un culte, d'ailleurs inclus dans celui que le groupe rend aux ancêtres.

Ce culte semblait bien indiquer que l'on prêtait aux jumeaux une ascendance particulière. Dans le peuple, on pensait que leur mère avait été «touchée », durant sa grossesse, par un génie que l'on n'osait nommer Nommo, le terme étant dangereux, trop grand pour une bouche humaine. Les enfants étaient donc d'une qualité incomparable à celle des autres.

Mais ces faits sont universellement connus et le Blanc n'était pas désireux d'insister sur toutes les modalités des rites célébrés en pareil cas. Au demeurant, des enquêtes antérieures avaient apporté toutes les précisions désirables et il était soucieux p.189 d'attirer les confidences d'Ogotemmêli sur un détail du matériel qui lui paraissait chargé de sens : les poteries réservées aux jumeaux.

Ces poteries ont une forme particulière: chacune est faite de deux cupules rondes de cinq à six centimètres de diamètre, aplaties, soudées l'une à l'autre par le bord comme un coquillage bivalve entièrement ouvert. L'objet figurait dans le grenier céleste, au sommet des poteries superposées qui étaient placées au croisement des cloisons inférieures; il recouvrait le petit récipient à parfums intimes fermant le pot à huile, symbole du fœtus, lequel surmontait la grande poterie-matrice. 
Dans cette position, il était dans le climat de la génération; il était comme un appel à la création par paires, dont il était le symbole.

- Les deux cupules accolées, dit Ogotemmêli, sont, comme les jumeaux, de taille et de grosseur égales.

Le jour où les enfants sont rasés, le père se procure quatre cupules doubles qu'il établit dans l'autel de la famille et deux petites pièces trapézoïdales de cuir sur chacune desquelles on coud huit cauris. Ces objets sont consacrés par un sacrifice sanglant de huit poulets, les deux pièces de cuir devenant ensuite des pendentifs que les enfants portent au cou comme signe de leur qualité. Les poteries, elles, recevront les offrandes régulières de la parenté et, plus tard, celles des intéressés eux-mêmes.

- La double cupule, dit Ogotemmêli, est le symbole des jumeaux : ils ont taille égale, grosseur égale, parole égale.

De même qu'une des cupules est égale à l'autre, de même les jumeaux sont interchangeables.

- A cause de cela, dit Ogotemmêli, le commerce a commencé par eux.

II insistait sur cette idée d'égalité, qui donna naissance à celle d'échange :

- Les jumeaux ont la parole juste, égale. Ils sont de même valeur. Ils sont la même chose. L'homme qui vend, I'homme qui achète, tous deux sont aussi la même chose. Ils sont deux jumeaux.

Et de l'idée de personnes échangeant, il passait à celle de choses échangées :

- Le commerce, disait-il, vendre et acheter des espèces différentes de choses, c'est échanger des jumeaux.

p.190 II entendait par là que les choses échangées devaient être de même valeur, qu'elles devaient se balancer exactement, sans que l'une l'emporte sur l'autre, que cet échange soit un troc ou qu'il s'agisse d'un acte où intervient la monnaie.

- Les jumeaux qui ont inventé le commerce sont de la sixième famille; ils furent les premiers à naître après la 
descente sur la terre du grenier contenant le système du monde. C'est leur père qui avait découvert, dans la tombe du Lébé, les cauris devant servir au commerce.

Les coquillages avaient été placés là où se trouvaient les doigts du mort.

- Le Nommo Septième avait placé les cauris à l'endroit des mains parce que les hommes comptent avec les doigts. Il en avait mis huit par main et, à l'origine du commerce, on comptait par huit.

Ogotemmêli avait son idée sur les comptes. Les Dogon employaient bien le système décimal, car ils avaient utilisé, dès l'origine, les dix doigts, mais c'était en réalité huit qui se plaçait à la base. On retrouvait ce nombre dans ce qu'ils appelaient en français la centaine et qui correspondait à quatre-vingts. Quatre-vingts marquait la fin d'un compte. On entamait ensuite une nouvelle série.

Aujourd'hui, le nombre de ces séries était de dix, et de ce fait, le mille européen correspondait à huit cents chez les Dogon.

Mais Ogotemmêli était d'avis qu'à l'origine les hommes comptaient par huit - nombre des cauris à chaque main , qu'ils avaient bien introduit les dix doigts pour obtenir quatre-vingts, mais qu'à nouveau le huit apparaissait pour donner six cent quarante $(8 \times 10 \times 8)$.

- Six cent quarante, dit Ogotemmêli, c'est le bout du compte.

Dans son idée, c'était six cent quarante pierres d'alliance que le Nommo Septième avait vomies pour dessiner la silhouette dans la tombe du Lébé.

Donc, les cauris trouvés en terre par le père des jumeaux, en buttant le mil lors de la deuxième culture, étaient une prémonition du commerce.

Pourtant ce n'avait pas été le cauris qui avait servi de monnaie d'échange dans les tout premiers temps. On avait commencé par troquer des bandes d'étoffe contre des animaux ou des objets.

L'étoffe était la monnaie. L'unité était la palme de bande de ${ }_{\text {p.191 }}$ deux fois quatre-vingts fils de largeur. Un 
mouton valait huit coudées de trois palmes. La petite mesure de mil valait une coudée. Ensuite, la valeur des choses a été fixée en cauris par le Nommo Septième, maître de la parole. La poule valait trois fois quatre-vingts cauris ; la chèvre ou le mouton trois fois huit cents ; l'âne quarante fois huit cents; le cheval quatre-vingts fois huit cents ; le bœuf cent vingt fois huit cents.

Mais au début, il y avait peu de cauris. Les trente-deux coquillages trouvés aux mains et aux pieds du Lébé avaient été donnés aux jumeaux nés peu après la découverte; sur ce nombre, huit avaient été utilisés par chacun d'eux pour orner le pendentif de cuir qui manifestait leur qualité. II restait donc huit cauris à chacun.

Selon une variante, ces cauris auraient d'abord été échangés avec d'autres hommes contre des poulets, quatre pour une bête. Dans la suite, les poulets se seraient reproduits et d'autre part les cauris, qui étaient choses vivantes, se seraient multipliés dans les mains de leurs possesseurs.

- Pour le premier échange, les jumeaux se sont placés sur une fourmilière. L'un fut le vendeur, l'autre l'acheteur. Ils prirent comme témoin la fourmi. On dit aussi que le premier échange déplaça des cauris et des bandes d'étoffe.

C'était donc devant le sexe de la terre et devant la fourmi, avatar de la terre, que s'instituait le premier acte de commerce. Mais les objets de l'échange avaient la qualité de vie: les cauris étaient des coquillages vivants ; l'étoffe était remplie de verbe.

- Le Nommo Septième, dit Ogotemmêli, avait recommandé de placer les objets en face les uns des autres. Les paroles pour l'échange devaient être prononcées devant eux. C'est comme si les objets parlaient. Ils parlaient par la bouche de leurs possesseurs, ils s'entendaient eux-mêmes sur leur échange.

La voix de l'aveugle était forte. II était droit dans l'embrasure et non abîmé sur lui-même, selon son habitude, lorsque l'entretien portait sur des sujets religieux. 
- C'est pour être sûr, dit-il, que les objets soient d'accord.

II semblait bien que l'important était là.

- Le principal, dans l'échange ou dans l'achat-vente, c'est la parole, les paroles échangées entre les deux parties, la discussion du prix. C'est comme si le tissu et les cauris parlaient. Les marchandises s'entendent par la bouche des hommes.

Car il y a accord entre la force vitale de l'objet et celle de ${ }_{\text {p.192 }}$ son propriétaire. Celle des cauris leur vient du Lébé dont ils sont l'émanation, et le Lébé distribue la sienne aux hommes. Dans la bande d'étoffe, le tisserand vendeur, dans le temps qu'il enserre la parole des ancêtres, introduit la sienne propre. II en est ainsi pour tout objet confectionné par l'homme; un peu de sa force passe dans le travail de ses mains. Et le fait même de posséder introduit dans la matière des forces qui représentent en quelque sorte le propriétaire.

Lorsqu'on a emprunté une chose qu'on ne peut rendre, sa force, qui est celle du propriétaire, crée des difficultés à l'emprunteur.

Dans le cas d'achat ou d'échange, la force, étant compensée, ne peut rien contre le détenteur. II semble même qu'il y ait déplacement des deux forces en présence, qu'elles prennent chacune la position de l'autre, ce qui supprime tout danger pour les nouveaux possesseurs.

Ogotemmêli termina l'entretien par une phrase énigmatique.

- Avoir des cauris, c'est avoir des paroles. 


\section{Trente et unième journée}

\section{Les jumeaux et le commerce (suite)}

Sur la place vide du marché, où le Nazaréen s'était rendu pour procéder à certaines vérifications, une pierre longue se dressait, fichée dans une fente et consolidée par des éclats de grès. Avant de continuer l'enquête sur le commerce, les renseignements avaient été pris sur cet autel, dit «Lébé du marché », dont le gardien était un nommé Allêguê, de Barna.

Les conversations avec ce personnage n'avaient pas été sans heurts et la seconde fiche portait une note catégorique: "Allêguê est un fieffé menteur, comme paraît-il, tous les gens de Barna!»

Allêguê portait la culotte classique serrée au-dessous du genou, une veste ample à manches, ouverte sur le côté et un bonnet aux deux pointes avançant jusqu'aux joues. L'étoffe brune, au crépuscule, se confondait avec le torchis

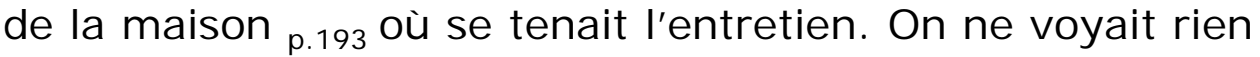
de son visage qu'une ligne de dents et de son corps que les paumes claires de ses mains, lorsqu'il les ouvrait pour les affirmations.

Allêguê avait d'abord soutenu que la pierre d'autel avait surgi d'elle-même des lieux «sans qu'on sût qui l'avait envoyée ». II pensait, par cette nouvelle, contenter la curiosité de l'Européen. II avait ajouté que le même prodige était survenu à Bongo de Sanga-du-Bas mais que la chose n'avait pas réussi.

- Bongo a eu aussi un marché à autel, mais les affaires ont mal tourné. Finalement, on a joint les deux pierres sur le marché près de Barna.

Allêguê aurait désiré s'étendre longuement sur les procédures, prérogatives et organisations obscures qui concernaient cette union de deux pierres aux origines mystérieuses. II restait bien entendu que la plus petite était celle de Bongo, que les droits de Barna étaient les 
plus considérables, que les vieillards de Sanga-du-Bas n'étaient pas assez fous pour croire à la plus petite chance de dominer en cette affaire.

Ces discours, qui parfois amenaient quelque propos de poids, furent interrompus par une seule question :

- Lorsqu'on égorge sur le Lébé du marché, qui vient boire le sang?

Cette phrase avait suffi pour plonger Allêguê dans un abîme de réflexion. Et l'affaire en était restée là.

Pourtant le Nazaréen en avait appris assez pour jalonner les déclarations d'Ogotemmêli qui reprirent sur la dernière phrase de la veille.

- Avoir des cauris, c'est avoir des paroles.

On a commencé par échanger, contre des cauris, des bandes de tissu, c'est-à-dire la parole des ancêtres, et notamment celle du Septième, maître de la parole. Ces cauris émanaient du Lébé, issu lui-même du huitième ancêtre, qui avait le chiffre de la parole.

Les cauris avaient donc fait leur apparition sous le signe du verbe; ils étaient verbe eux-mêmes en tant que signifiant des chiffres et représentant par là un langage. Ils étaient moyens d'expression, et peut-être qu'à l'aurore des relations entre les hommes ils ont servi, au même titre que les mots parlés, à échanger des idées. Peut-être était-il arrivé jusqu'aux Dogon, par ceux qui les leur apportèrent, un écho des usages lointains des cauris ?

p.194 Évoquant cette obscure période, Ogotemmêli déclarait :

- A l'origine, les cauris ont servi aux échanges de paroles en même temps qu'aux échanges de marchandises. Celui qui n'avait pas de cauris ne pouvait pas parler ou parlait moins que les autres.

II n'était pas possible de pénétrer plus à fond cette pensée millénaire, usée dans les mots qui l'avaient transmise, mais vivante encore derrière les deux yeux éteints d'Ogotemmêli. 
Les cauris étant la parole, il leur fallait, comme la parole, circuler entre les hommes, et Ogotemmêli répétait à ce propos ce qu'il avait déjà dit au sujet du sacrifice.

- La parole est pour tous. Pour cela il faut échanger, donner et recevoir.

Et il reprenait l'image de la bande de coton en formation sur le métier, sa chaîne figurant les pays déserts, sa trame étant le verbe, la lumière et l'humidité qui les pénètrent :

- Le Nommo a dit que lorsqu'on offre des cauris pour acheter une marchandise, le vendeur meurt s'il refuse. C'était pour obliger à échanger. De même que la bande d'étoffe s'allonge pendant le tissage, de même que la culture s'étend sous le fer du paysan, de même les cauris doivent circuler.

Les cauris portent en eux-mêmes la force de cette loi et cette force agit sur celle des marchandises comme sur celle de l'homme: la blancheur des cauris attire l'œil de I'homme et le tente. Leur force entre dans celle de I'homme et augmente son désir de commerce.

C'était sans doute pour manifester cet appel constant au commerce que les jumeaux portaient sur la poitrine le pendentif aux huit coquillages. Et par choc en retour, cette qualité des jumeaux d'être liés au commerce et à son signe monétaire en fait les commerçants par excellence.

De fait, ils sont réputés pour réussir, mieux que quiconque, toutes les affaires qu'ils entreprennent, et l'on répugne souvent à traiter avec eux, dans la certitude où l'on est que tous les avantages leur sont acquis d'avance.

- Si vous allez à Mopti vendre vos oignons en compagnie d'un jumeau, vous pouvez être sûr que les acheteurs préfèrent sa marchandise, même si elle est moins belle. Son tas de monnaie augmente plus que le vôtre et si vous faites de mauvaises affaires, c'est que vos cauris sont allés chez lui.

II ne faisait aucun doute pour personne que les biens des p.195 jumeaux se multiplient beaucoup plus vite que ceux des autres et la raison en était simple : 
- Ils offrent sur leur autel à huit cupules un sacrifice que les gens ordinaires ne peuvent effectuer. Ils disent aux huit ancêtres : «Voici votre bête! Merci pour hier ! que le reste prolifie demain! »

Dès qu'ils atteignent trois ou quatre ans, leurs parents leur achètent des animaux avec les cauris qu'ont versés à leur mère leurs tantes maternelles et avec lesquels on s'est procuré de l'huile de Lannea acida. De cette huile tirée de l'arbre du Nommo, on les a oints en entier pour manifester l'humidité permanente nécessaire à la prolification, si bien que les animaux, liés à l'huile, se multiplient.

- Personne ne prend en garde de tels animaux : eux seuls engraissent et se reproduisent; les autres périclitent.

Et cette propension à la réussite gagne les proches. Avant de se rendre au marché, la mère des jumeaux se présente devant leur autel et demande aux huit ancêtres protection et chance. "Ancêtres jumeaux, dit-elle, venez me conduire, mettez-vous devant moi. »

Connaissant cette pratique, peu de femmes se risquent à suivre une telle mère, sur les pistes qui mènent au marché. La plupart s'écartent et prennent des chemins détournés, sûres de voir l'autre profiter de toutes les bonnes affaires.

Ce privilège de la naissance gémellaire est d'ailleurs matérialisé par le supplément gratuit qu'est tenu de donner tout vendeur à un jumeau acheteur. Ce supplément, de petite valeur aujourd'hui, était beaucoup plus considérable à l'origine: le vendeur devait, pour le même prix, donner le double de la marchandise demandée.

De même, lorsqu'un cadeau est fait à un jumeau, il convient de le présenter en deux parts égales. Sinon, il ne saurait l'accepter.

II résulte de toutes ces coutumes et habitudes que le jumeau, concernant les affaires commerciales, est considéré comme exerçant une dangereuse attraction sur les richesses. Pourtant, nul ne refuse d'entrer en relations 
avec lui et, au contraire, chacun lui fait volontiers des dons.

- On donne aux jumeaux, dit Ogotemmêli, pour acquérir un peu de leur chance. On pense qu'on recevra par la suite plus qu'on a donné.

p.196 C'est ainsi qu'à la cérémonie de la pose de leur autel, les enfants reçoivent solennellement les dons en cauris de toute la parenté utérine et masculine, qui s'assure ainsi un contact avec la chance. Dans la cour de la maison du père, la grande couverture de famille, aux carreaux noirs et blancs, dans laquelle on enveloppe les morts, est étalée sur des nattes; la mère et la fille qui l'aide y prennent place, tenant chacune un des enfants. Au rythme dit « de la chefferie » joué par un tambourinaire, tous les parents défilent et déposent leur offrande, en deux tas, celui de droite étant réservé à la femme, celui de gauche à son mari.

Chacun donne des deux côtés, en faisant toutefois une part plus grande à son parent direct.

- Les deux tas doivent être égaux, car ils symbolisent un acheteur à droite et un vendeur à gauche. Et la couverture du mort, sur laquelle ils sont placés, est aussi le symbole du commerce. Car les jumeaux qui ont commencé les échanges étaient assis dessus et elle est faite de carrés égaux, noirs et blancs en nombres égaux. Le commerçant qui porte une couverture de mort, ses affaires vont bien.

Mais quoique liée au commerce, la couverture n'est pas une monnaie. Elle est la plus représentative des richesses et ne doit pas circuler. La plus grande honte, pour une famille, est de vendre la couverture des morts et celui qui n'en possède pas en emprunte secrètement pour ses défunts, afin de ne pas laisser croire que le groupe en est dépourvu.

A l'inverse des cauris, dont la loi est la mobilité, la couverture est stable et immobile. Elle est comme l'aboutissement de l'économie familiale, l'étape finale de la formation de la richesse. Et c'est dans l'orgueil et l'exaltation que la famille, aux funérailles, étale ses 
couvertures sur la façade de la maison, publiant ainsi son avoir inaliénable.

C'est donc assise sur le capital de famille que la mère exhibe le couple d'enfants et préside à l'acte symbolique de commerce où deux amas de monnaie s'équivalent.

C'est assise sur le symbole de la terre cultivée, aux carreaux multipliés, qu'elle préside, après avoir fait acte exceptionnel de fécondité, à la prolifération des cauris.

Et la cérémonie solennelle se déroule selon un protocole identique, même si l'un des enfants a disparu.

- On ne dit jamais qu'un jumeau est mort. On dit qu'il a pris son élan, qu'il s'est envolé.

p.197 Dans ce cas la mère seule est présente avec le survivant. Si le couple est mort, la fête est célébrée pour l'enfant né après eux, qui est considéré comme lié à ses deux aînés.

- Il est comme le résidu des jumeaux, dit l'aveugle. On l'appelle « cendre d'homme ».

Car il importe de marquer le témoignage de la gémelléité retrouvée et de propager à tout le groupe le bénéfice, même éphémère, de l'état primordial.

Après avoir été le centre de la multiplication des cauris, les enfants, imprégnés de commerce et d'abondance, sont portés au marché, vers le milieu du jour, à l'heure où la place est pleine, où la foule fait entendre une grande rumeur.

- Le bruit confus des voix, c'est la voix des génies des eaux transformés en personnes humaines et qui vont faire leurs emplettes.

C'est à cette heure que des belles filles, inconnues de tous, fendent les groupes affairés et disparaissent sans laisser de traces. C'est à cette heure que dans les paniers des marchands et sans que nul au monde ne s'en doute, des Nommo se muent en tomates indigènes.

A ce moment propice, les jumeaux sont présentés à la foule et aux invisibles; devant l'autel du marché le groupe s'arrête pour la consécration des enfants au Lébé et aux huit ancêtres : 
- Au Lébé du marché, nous confions les jumeaux, qu'il les protège, qu'il les conduise !

Puis la parenté, par trois fois, leur fait exécuter le tour de la place, enfermant ainsi les groupes humains venus de toutes les régions dans la zone bénéfique où circulent intensément les denrées et la monnaie.

Le centre de cette zone est l'autel de pierre élevé à ce Lébé dont la silhouette vomie par le Nommo est formée des huit ancêtres, des huit couples d'ancêtres, patrons des jumeaux. Ce sont eux qui boivent le sang des sacrifices, et avec eux viennent les jumeaux morts de tous les temps, dont les deux premiers, inventeurs du commerce; vient aussi le couple suprême de Nommo jamais incarnés.

C'est sous le signe permanent de la gémelliparité terrestre et céleste que les hommes ont placé les lieux des échanges.

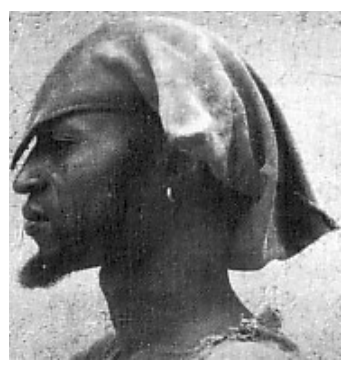

(a) 


\section{Trente-deuxième journée}

\section{Les signes du Zodiaque}

p.198 Au cours de ces journées remplies par les entretiens avec l'aveugle et par cent autres travaux, au cours des nuits de réflexion et de mise au point, le Nazaréen avait songé, obscurément d'abord, et de plus en plus nettement dans la suite, à certains détails de la cosmologie dont l'ensemble lui paraissait surprenant.

Le rôle des jumeaux ne l'avait pas étonné : il avait déjà rencontré maints exemples du culte de la double naissance dans les pays noirs. L'apparition du bélier casqué d'une calebasse-soleil, qui se doublait d'un taureau de même allure, avait commencé à l'intriguer. Les béliers coiffés d'une sphère gravés sur les roches de l'Afrique du Nord, avaient fait couler beaucoup d'encre. Selon les uns, ils venaient d'Égypte; les autres proposaient le sens inverse. Beaucoup avaient identifié le soleil dans ce cercle d'entre les cornes. Toutes ces spéculations, qui restaient dans le domaine de l'hypothèse, se trouvaient brusquement éclairées d'un jour nouveau et venant de contrées dont l'intervention dans un tel problème n'était pas prévisible.

Jusque là, le Nazaréen se trouvait devant des questions posées de longue date. L'affaire du scorpion, résultat de l'excision, le plongea dans la perplexité; elle sortait de l'ordinaire. Jumeaux, bélier, taureau, scorpion. Le Blanc pensa au Zodiaque. Mais il garda cette idée à part lui : il voulait que le système apparût sans heurt, de lui-même, dans les entretiens du seuil où le maître s'asseyait.

Chaque jour, il se demandait quelles révélations allaient sortir de ce vieillard ployé dans l'embrasure, nettement détaché sur le fond noir. Chaque jour lui apportait une pâture nouvelle, des joies profondes comme jamais il n'en avait éprouvées dans sa carrière de chercheur. Dans cette harmonie, l'idée du Zodiaque n'était qu'un jeu entre mille, mais elle mettait pourtant une note piquante. Les Noirs avaient-ils leur explication cohérente du symbole du 


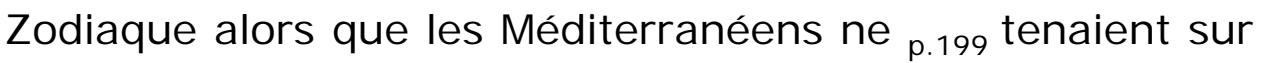
son compte que des propos enfantins? Car on ne peut admettre sérieusement que les Anciens aient reconnu dans le ciel un scorpion, des jumeaux, des poissons et que la position des étoiles ait dicté douze signes abracadabrants où une vierge voisine avec une balance, un crabe avec un lion.

Jumeaux, bélier, taureau, scorpion. Le Blanc s'était demandé un jour si les douze signes ne figuraient pas dans le grenier céleste que le forgeron avait conduit le long de l'arc-en-ciel.

Ce grenier était lié au système stellaire. II était luimême fait de ciel, de lune et de soleil ; d'autre part, chaque escalier était en rapport avec un point cardinal et un groupe d'étoiles.

Les jumeaux y paraissaient du fait que l'ancêtre forgeron était double et que d'autre part il représentait le mâle et le grenier la femelle, bras et jambes levés soutenant le ciel.

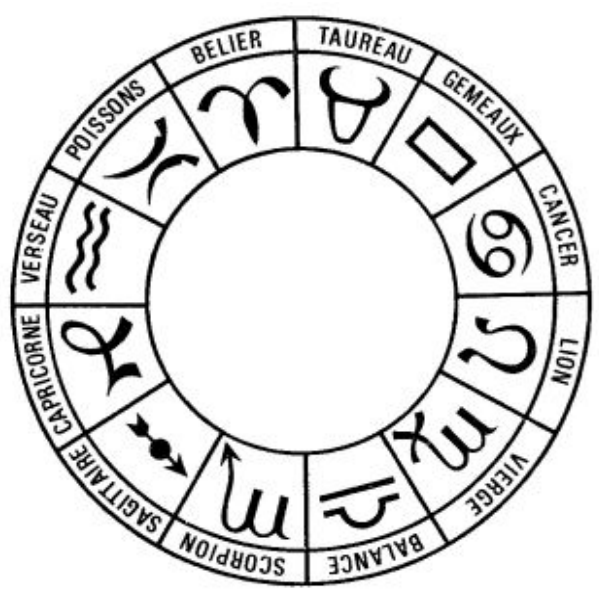

Le bélier et le taureau occupaient les degrés du sud : le scorpion le dessous du plancher, lequel était le soleil. Quant à l'animal nommé nay, c'est-à-dire « soleil », il ne s'agissait pas d'un cancer, mais d'un lézard de forme particulière. II se tenait à côté du scorpion.

Le lion apparaissait en bonne place, sur l'escalier occidental, à l'échelon 9, chiffre de la chefferie. Ogotemmêli insistait sur le fait que le lion est gémellipare, 
qu'il n'avait pas perdu les avantages primordiaux ainsi d'ailleurs que le scorpion.

La Vierge ne figurait que sous la forme de la calebasse féminine placée sur la tête du bélier ou du taureau. II fallait remarquer de plus que la licorne souvent accolée dans ce signe, avait une curieuse réplique sous la forme du bélier dont le second sexe se dressait entre ses cornes et fécondait la vierge-calebasse.

La balance avait longtemps paru absente au Blanc. Au dire de tous les indigènes, c'était là un appareil récent de l'économie dogon. Aucune trace ne s'en trouvait dans le grenier. Pourtant, l'enquête sur les jumeaux avait été un trait de lumière : la double cupule, aux valves égales, qui représentait deux valeurs interchangeables, était un symbole de balance. Elle était placée au centre de l'édifice, sur la pile de poteries.

Le sagittaire était évident : le forgeron, voleur du soleil, lançait des flèches non seulement pour se défendre mais encore pour organiser sa descente. II avait décoché un projectile dans la voûte des cieux, un autre dans la terrasse du grenier.

Le capricorne pouvait à la rigueur être représenté par la p. 200 chèvre de l'escalier méridional, mais ce n'était pas très satisfaisant, d'autant que la chèvre du Zodiaque a souvent une queue de poisson.

Le verseau était dans le fil déroulé de l'énorme fuseau formé par le grenier. II se libérait en une hélice qu'Ogotemmêli comparait à une ligne de chevrons.

Quant aux poissons, ils pendaient au nombril de leurs jumeaux, hommes et femmes, sur l'escalier septentrional.

II semblait donc bien au Blanc que, sans présenter un système constitué du Zodiaque, la cosmologie et la métaphysique des Dogon offraient du moins une place de choix à la plupart de ses signes. Cette place se remarquait certes dans le système du monde descendu des cieux sous l'égide du forgeron, mais elle était plus visible encore dans les institutions elles-mêmes.

Au cours de cette dernière journée de travail avec son initiateur, l'Européen avait voulu, à l'occasion d'une 
récapitulation générale, faire le point pour cette question, entre quelques autres.

Et il était arrivé à la conviction que le symbolisme du p.201 Zodiaque exprimait deux principes fondamentaux : celui de l'eau, essence des êtres, et celui de la gémelléité.

Ces deux principes étaient liés dès la plus haute époque: le couple de Nommo, génies de l'eau, premiers enfants réussis des œuvres de Dieu, était pétri en eau. La semence de Dieu, faite d'eau, après un premier échec qui avait donné un être unique, donc incomplet, avait produit la paire céleste qui devait devenir la monitrice du monde :

- Si ce n'est le couple de Nommo, disait Ogotemmêli, personne ne peut réorganiser le monde.

Le rôle des jumeaux avait surgi dans toute son ampleur au cours des entretiens: il permettait de démonter des institutions considérables. Mais pour en revenir au Zodiaque, le Blanc avait tenté d'expliquer, par jeu, le carré ou le rectangle qui les représente souvent. Cette figure à quatre côtés exprimait probablement la personnalité quadruple du couple dont chaque élément est muni, à la naissance, de deux âmes. Ce nombre est par ailleurs celui de la féminité, c'est-à-dire de la fécondité. Ogotemmêli avait souvent dit que le couple idéal était composé de deux femelles et de signe huit, le même que celui de la parole créatrice.

Mais si les jumeaux étaient d'eau, l'eau était-elle double?

II convenait de remarquer que les Verseaux du Zodiaque étaient généralement deux. Les Dogon, eux, emploient fréquemment la ligne de chevrons seule. Sur les façades des sanctuaires, sur les poulies de métier à tisser, sur les vases de bois, sur les masques, sur les bâtons-de-voleur, sur les portes des greniers, elle figure presque toujours seule. Elle est unique également dans la danse dite " chemin en chevrons », comme dans la trame de l'étoffe, où elle symbolise le cheminement de la parole et de l'eau.

Mais son rôle profond apparaissait sur certains sanctuaires et sur les masques : elle séparait et unissait à la fois deux zones qui souvent étaient peintes de couleurs 
diverses; en elle s'emboîtaient deux lignes de dents. Pourtant, c'était surtout dans le geste primordial du tisserand qu'elle livrait son secret : elle était l'union de la droite et de la gauche sans cesse équilibrées, sans cesse progressant sur la chaîne.

II convenait d'aller plus loin encore: la ligne de chevrons de la trame, symbole de la progression de I'humidité dans les régions incultes, aboutissait à la bande de carreaux égaux, noirs et blancs; huit bandes formaient la couverture des morts. Or, p.202 c'était sur une couverture que les jumeaux avaient inauguré le commerce où se présentent, pour l'échange, des marchandises égales, comme sont égaux, en nombre et en surface, les carrés noirs et les carrés blancs.

Gémelliparité et eau étaient donc liées dans leur essence et dans leurs symboles, gémeaux et verseaux.

L'Européen, éclairé par les ultimes récapitulations, passait en revue les diverses figures et institutions qui donnaient une clé du système méditerranéen du Zodiaque bien que - détail piquant - ce système fût inconnu comme tel des Dogon. II retrouvait, dans la plupart des signes, l'expression des deux grands principes sur lesquels était fondée en grande partie leur pensée.

Le bélier, avatar du grand Nommo mâle, est casqué d'une calebasse-soleil, avatar du grand Nommo femelle. Son chanfrein est la lune mâle et par sa toison de cuivre il est aussi émanation du soleil. II est donc en réalité un couple et l'on peut même dire que symboliquement, il le manifeste au moins deux fois : il exhibe deux sexes mâles et il est deux fois femelle, par la sphère solaire dont il est coiffé, et par la toison dont il est recouvert.

II est aussi l'éjecteur d'eau-semence par excellence : d'une part, il féconde la féminité d'entre ses cornes; d'autre part, il urine les pluies sur le monde. Sa toison est de cuivre, donc d'eau, et sous sa queue terminée en tête de serpent s'érige un épi de mil. Il est l'humidité de la végétation.

S'il n'est plus aujourd'hui figuré en entier sur les façades des sanctuaires, du moins est-il présent au 
fronton, sous la forme du crochet double de ses cornes, auquel se prennent les nuages pluvieux.

Le taureau, doublet du précédent, s'explique de la même façon. Quant à la chèvre, elle est l'avatar du génie de l'eau pour les œuvres néfastes. La queue de poisson du capricorne s'explique peut-être par le fait qu'il s'agit d'un animal apparaissant toujours dans l'eau.

Au cancer correspond le «soleil », sorte de lézard, avatar du prépuce, support de l'âme femelle, jumelle de I'homme né apparemment unique. Cet animal est d'ailleurs lui-même double : sa queue courte se compare à sa tête et symbolise le pénis mâle alors que l'ensemble du corps est l'avatar du prépuce femelle. Et il faut remarquer que le cancer du Zodiaque est représenté p.203 par un signe double, disposé tête-bêche, qui conviendrait à un tel lézard. Il est d'autre part la réplique au scorpion, jumeau mâle de la femme. Le scorpion, supposé gémellipare, est le protecteur des jumeaux et ses pattes, au nombre de huit, symbolisent leurs membres. Il est deux fois lié à l'eau : il a recueilli dans son dard celle de la parturition de la première femme et il est, comme le lézard, avatar d'un organe sexuel humide.

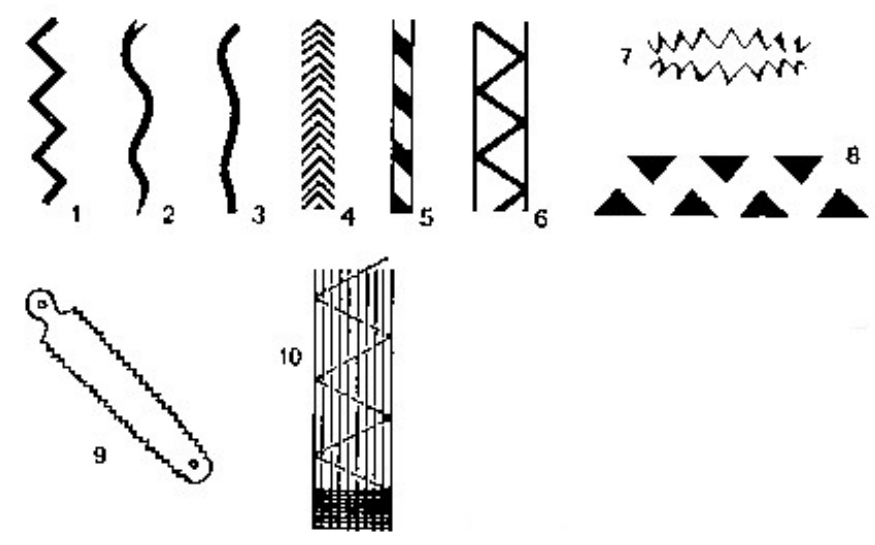

1. Chemin de l'eau (dessin de sanctuaire). -2 . Dessin de serpent. -3 . Toron de fibres. -4 . Scarifications. -5 . Hélice du bâton de circoncis. -6 . Chemin de l'eau (dessin de masque). - 7.Ligne des dents. - 8. Ornements architecturaux. - 9. Rhombe de fer dentelé. - 10. Fil de trame.

Le lion, comme le scorpion, est supposé gémellipare. II est placé sur le neuvième degré de l'escalier occidental du système du monde, parce qu'il symbolise la chefferie, dont le nombre est neuf. La chefferie est confiée au Lébé, dispensateur des pluies, moniteur de la végétation. 
La vierge s'incorpore au bélier sous la forme de la calebasse-soleil. Le signe correspondant du Zodiaque, sorte de $\mathrm{m}$ dont le dernier jambage est sectionné, pourrait être rapproché de celui du scorpion, dont le dernier jambage est au contraire terminé souvent par une pointe. Le premier représenterait la vierge excisée, le second le résultat de l'excision, l'animal armé du dard rappelant l'organe coupé.

p.204 La double cupule, qui se présente comme les deux plateaux d'une balance, est le symbole des jumeaux interchangeables. Elle est destinée à recevoir le sang et l'eau des libations et sacrifices.
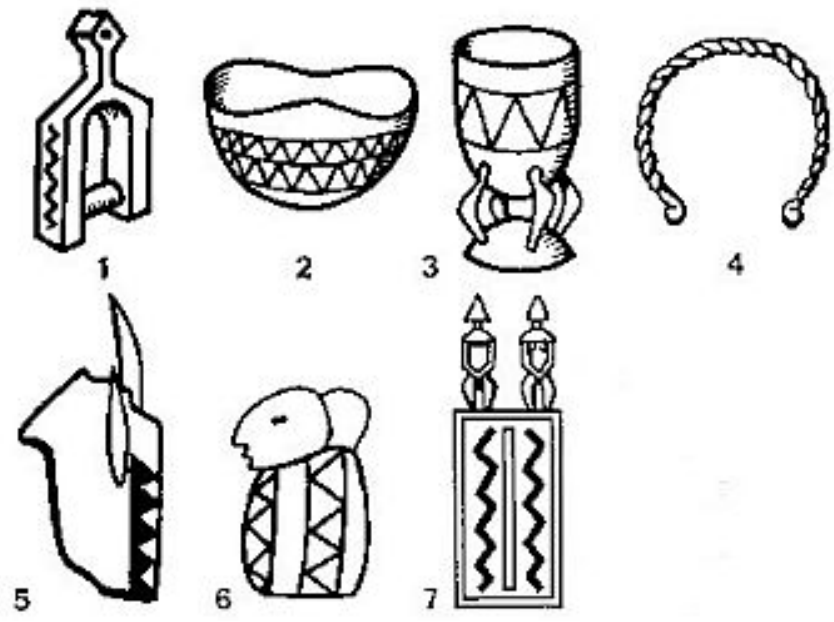

1. Poulie de tisserand. -2 . Calebasse rituelle. -3 . Vase de chef. -4 . Bracelet de prêtre. - 5. Masque antilope. - 6. Andoum Boulou. - 7. Serrure.

Le sagittaire est rappelé par le forgeron armé de l'arc et dressé sur le grenier céleste qui est aussi sa jumelle aux quatre membres levés, sorte de monture renversée soutenant le ciel. II est lié à l'eau, puisque Nommo, et c'est avec l'eau de son outre qu'il a éteint les feux lancés contre lui.

Le signe correspondant du Zodiaque, la flèche munie d'une boule placée au milieu du fût, est sans doute le fuseau transperçant la fusaïole. Les flèches décochées par le forgeron dans le ciel et dans le grenier étaient des fuseaux; celui de la voûte des cieux servait de point d'attache au fil de descente, lequel se déroulait de l'axe fiché dans la terrasse de l'édifice. Cet édifice lui-même 
était une énorme fusaïole qui avait servi de cible à la flèche.

Les poissons du Zodiaque, jumeaux liés par une banderole ou par un conduit qui leur sort de la bouche, symbolisent p.205 également l'eau. I Is figurent sur l'escalier septentrional du grenier céleste, accolés aux Bozo. Poissons et hommes sont jumeaux, et le Bozo lui-même est le symbole de l'eau, étant le premier pêcheur du Niger et maître du fleuve. Le Bozo, qui soutient avec le Dogon ce qu'il est convenu d'appeler des rapports de «parenté à plaisanteries », est classiquement traité, par ce dernier, de « poisson qui se promène dans la plaine ».

II semblait donc que, vu au travers de la métaphysique et de la cosmologie dogon, le Zodiaque des méditerranéens pouvait s'expliquer. Mais le Blanc ne se faisait aucune illusion sur l'accueil que recevrait une telle argumentation de la part de certains spécialistes accrédités dans les milieux choisis de l'érudition. Certes, il y avait de consolantes exceptions: de brillants esprits, voués pourtant aux études classiques, s'ouvraient avec étonnement et sympathie aux civilisations lointaines. Des amateurs éclairés, venus au Noir par l'art, des philosophes hardis, venus aux spéculations inhabituelles se penchaient passionnément sur ces problèmes. Mais ils étaient perdus dans la foule.

N'était-il pas entendu, une fois pour toutes, que le Noir ne pouvait rien apporter, qu'il ne pouvait pas même refléter des formes anciennes de la pensée du monde? N'avait-il pas été, de tous temps, relégué au niveau de l'esclave? "Voyez les bas-reliefs taillés par les grandes civilisations de l'Antiquité ! Où sont les Nègres ? A leur place! Parmi les gens de peu! Quelle influence voulez-vous leur prêter ? - Mais il ne s'agit pas, pour le moment, d'influence exercée, il s'agit d'influence reçue et conservée! »

Discussion inutile. Encore faut-il s'estimer heureux de n'essuyer qu'un mépris souverain englobant le chercheur et l'objet de son étude. La haine inconsciente s'observe fréquemment. 
A songer à ces incompréhensions volontaires, à ces refus de connaître, le Blanc, devant l'aveugle courtois qu'il allait quitter le lendemain, éprouvait quelque honte. II eût voulu exprimer son hommage à cet homme privé de lumière et dont la parole était lumière, selon son dire.

Il eût voulu s'excuser pour tous les mépris d'Europe et d'Amérique, pour toutes les ignorances.

Mais la sérénité d'Ogotemmêli, dans sa cour où montait l'ombre des greniers, était hors du temps des Blancs, hors du remords des hommes.

Déjà il s'inquiétait du départ de son ami, de son voyage aérien p.206 dans ce qu'il nommait un «alpilani ». Il eût voulu en connaître les dangers, pour les partager en pensée avec le Nazaréen qui avait vécu, comme lui, sur la paille de sa maison. II recommandait la prudence, comme il eût fait à l'un des siens partant pour le travail des champs:

- Quand nous allons aux champs, dit-il, nous trouvons des épines, des serpents et des vents pernicieux.

Un poussin piaillait près de lui ; il l'écarta d'un geste de la main.

Puis il se dressa de toute sa hauteur dans ses haillons et il donna le salut du soir. 


\section{Trente-troisième journée}

\section{Adieu à Ogotemmêli}

Le soleil du dernier jour de travail se levait. Le lendemain, à pareille heure, le camp serait vide.

Le Blanc ne se rendit pas chez Ogotemmêli comme il le faisait chaque matin. II était pris par les derniers préparatifs, par les derniers contacts avec les gens de la région.

La moisson de l'expédition était d'une ampleur inespérée. La documentation linguistique, patiemment édifiée au travers des conversations, des chevauchées, des enquêtes matérielles, faisait apparaître une langue riche, aux nuances infinies, concrète. Les travaux les plus subtils des puissances d'eau s'exprimaient en images claires. D'une région à l'autre on reconnaissait les parlers élégants: dans chaque région les villages s'échelonnaient selon l'aisance de leur phrase, les subtilités du vocabulaire. Dans les villages, chaque quartier plaisantait le voisin sur son accent, sur la moindre particularité dialectale. Enfin, telle famille, et dans son sein tel homme, passaient pour l'arbitre du bon parler.

La jeune Européenne chargée de la linguistique, en dépistant les meilleurs informateurs, avait découvert qu'Ogotemmêli était respecté pour avoir le plus pur parler des gens de Sanga-du-Haut, auprès desquels ceux de Sanga-du-Bas faisaient figure de paysans balourds.

p.207 L'enquête sur l'organisation territoriale, sur les familles, sur les rites agraires, sur le culte des ancêtres avait apporté des vues nouvelles sur maints problèmes.

Par ailleurs les travaux sur les Bambaras avaient décelé des cosmologies et des métaphysiques inattendues. Là aussi le verbe et l'eau étaient à la base de la vie spirituelle et religieuse. Là aussi des mythes cohérents donnaient la clé des institutions et des coutumes, et à maints indices, on pouvait penser que sous les apparences variées de 
leurs rites et de leur comportement, les divers Noirs de ces régions cachaient les grandes lignes d'une même religion, d'une même pensée concernant l'organisation du monde et des personnes.

De toutes manières l'expédition marquait un tournant des études africaines. Ses résultats étaient la récompense de quinze années de recherches persévérantes; ils s'étaient étagés harmonieusement et la clé de voûte du système apparaissait avec six ans de retard imposés par la guerre.

L'Européen refaisait ce bilan en se rendant, en fin d'après-midi, par les chemins habituels, chez Ogotemmêli.

II lui avait offert, la veille, un coq d'un bon prix pour un sacrifice de clôture auquel tous les étrangers étaient conviés. Le cœur serré, il se présentait pour la dernière fois devant la petite porte sonore comme un gong. Le seuil franchi, il se trouva dans la cour qui semblait en état d'alerte. Ogotemmêli était assis sur la pierre creuse où venaient boire les poulets. Il morigénait à la cantonade, mais sans passion. Sa femme était montée sur un mortier et regardait dans la cour du Hogon, par-dessus le muret séparant deux greniers. Son frère épiait de même, côté nord, les allées et venues de bêtes sur la grand'place.

- Le coq s'est enfui ! dit une voix.

Cette grave affaire devait dominer les adieux. Le Blanc n'en était pas mécontent : elle mettait quelque gaieté aux poignantes minutes qu'il passait là. Lorsqu'on quitte un Dogon, sait-on quand on le reverra? La vie des hommes est si fragile en ces pays.

Ogotemmêli était sur sa pierre, les mains aux genoux, le visage vers le sol. A voix basse il donna l'ordre à son frère de prendre un autre poulet. Les Européens s'étaient alignés le long du mur de l'autre côté duquel courait la ruelle. Aucun indiscret ne regardait par l'échancrure ni par aucune brèche des torchis : on savait qu'il y avait sacrifice chez Ogotemmêli et les gens p.208 passaient sans tourner la tête, par déférence pour l'acte religieux du prochain.

Sur la planche d'une vieille porte gisant à terre, des colliers de cuir sombre et deux masses oblongues, noires, étaient posés. Celles-ci figuraient sans doute une partie de 
I'autel de chasseur qu'Ogotemmêli avait hérité de son père et qui provenait, par apports successifs de terre, de l'autel primordial qui avait servi de tombe à l'ancêtre inventeur de la chasse.

Ogotemmêli avait donné à l'étranger des précisions sur ce sujet, mais il était difficile de solliciter d'autres confidences sur ce matériel vu pour la première fois. Déjà le vieillard tendait à son frère le couteau pour l'égorgement d'un poulet gris, étique, qui remplaçait le beau coq.

Peu importait pour l'invisible; un sang est toujours un sang; la vie est toujours la vie, qu'elle coule d'un poulet maigre ou d'un homme ou d'un taureau gras. II n'y avait d'ennui que sur le plan humain : la fuite de la victime ne permettait pas d'honorer l'étranger comme il le méritait.

Ogotemmêli prononça des prières. II alertait les cieux ; il préparait des chemins sonores aux forces de grâces. II acquittait sa dette envers les gens de l'Eau dont il avait peut-être trop parlé à l'étranger venu des pays septentrionaux. II demandait aussi une heureuse issue à la longue marche inverse que cet homme allait entreprendre. II faisait face au nord, aux pays où vivent les Blancs, dit-on. C'était l'heure propice où l'ombre monte dans les cours et profile les moindres rebords des terrasses, I'heure où le soleil adouci boit moins vite que les âmes le sang répandu.

Déjà le sacrificateur, ayant ensanglanté le matériel, avait jeté la victime sur le sol. Dans le silence; elle agonisait, marquant la fin des travaux. Tous pensaient à cette mort, valable comme toutes les morts, d'un poulet gris, égorgé faute de mieux.

Le frère d'Ogotemmêli, sans bruit, ouvrit la porte de la grande maison. Par-dessus le seuil familier où l'aveugle s'asseyait chaque matin, il tendit la main dans la pénombre, vers la cage d'où s'était enfui le coq du sacrifice. II resta ainsi quelques instants, pour fixer aux yeux des Blancs, en cette heure solennelle, les causes premières, les raisons suprêmes de l'immolation à demi honorable: il indiquait le panier vermoulu dont le prototype avait, dans les temps mythiques, servi de modèle au système du monde. 


\section{Septembre 1947}

@

p.209 Achevé en juin dernier, ce livre contient l'essentiel de la doctrine dogon. Dans l'esprit de l'auteur, il était aussi le témoin du premier contact avec Ogotemmêli et il devait être suivi d'autres ouvrages dont la matière aurait été fournie par de nouveaux entretiens.

II ne pourra en être ainsi.

Au début de ce mois, l'auteur recevait de Sanga une lettre datée du 10 août. En voici les passages essentiels :

«... Cela vous étonnera et vous mettra dans une grande tristesse... C'est celui que vous avez trouvé le plus dévoué, le plus franc et sincère et l'un des plus savants dans nos coutumes dogon qui est tombé dans le sommeil éternel. C'est votre vieil Ogotemmêli.

II est mort le mardi 29 juillet 1947, vers deux heures du soir. Et c'était le jour du marché de Sanga. Avant sa mort, une petite sécheresse commençait à flétrir nos pieds de mil; le jour même, avant son enterrement, il y eut une moyenne pluie qui sauva nos semences. Vous savez pourquoi. C'est qu'il était possesseur d'une « pierre de pluie » que vous devez bien connaître.

Enfin ne comptez plus le revoir prochainement. Que son nom reste immortel dans vos travaux!

... Cette mort est une dure perte pour les sciences humaines. Non pas que le vieil aveugle ait été le seul à connaître la doctrine de son peuple. D'autres notables détiennent les grands principes, d'autres initiés continuent à s'instruire; mais il était l'un de ceux qui comprenaient le mieux l'intérêt des recherches poursuivies par les Blancs.

Peut-être a-t-il laissé derrière lui les paroles vivantes qui permettront à d'autres de renouer le fil des révélations. Il avait tant d'ascendant que peut-être d'autres voudront suivre son exemple. 
Mais quoi qu'il advienne, personne n'aura la noble. démarche, personne la voix profonde, personne le visage triste et lumineux d'Ogotemmêli, grand chasseur d'Ogol-du-Bas. 


\section{TABLEAU DE CORRESPONDANCE}

\begin{tabular}{|c|c|c|c|c|c|c|c|c|}
\hline Nombre & 1 & 2 & 3 & 4 & 5 & 6 & 7 & 8 \\
\hline Qualité & Forgeron & Cordonnier & Griot & & & & $\begin{array}{l}\text { Maître de la } \\
\text { parole }\end{array}$ & Parole \\
\hline Sexe & $\begin{array}{c}\text { Mâle } \\
\text { Impair }\end{array}$ & $\begin{array}{l}\text { Mâle } \\
\text { Pair }\end{array}$ & $\begin{array}{c}\text { Mâle } \\
\text { Impair }\end{array}$ & $\begin{array}{l}\text { Mâle } \\
\text { Pair }\end{array}$ & $\begin{array}{l}\text { Femelle } \\
\text { Impair }\end{array}$ & $\begin{array}{c}\text { Femelle } \\
\text { Pair }\end{array}$ & $\begin{array}{l}\text { Femelle } \\
\text { Impair }\end{array}$ & $\begin{array}{c}\text { Femelle } \\
\text { Pair }\end{array}$ \\
\hline Situation & Droite & Gauche & Droite & Gauche & Droite & Gauche & Droite & Gauche \\
\hline Corps & Bas & Bas & Haut & Haut & Bas & Bas & Haut & Haut \\
\hline Membre & Haut & Haut & Haut & Haut & Bas & Bas & Bas & Bas \\
\hline Grenier & $\begin{array}{c}\text { Bas } \\
\text { Droite } \\
\text { Devant } \\
\text { N.O. } \\
\end{array}$ & $\begin{array}{c}\text { Bas } \\
\text { Droite } \\
\text { Derrière } \\
\text { S.O. }\end{array}$ & $\begin{array}{c}\text { Bas } \\
\text { Gauche } \\
\text { Derrière } \\
\text { S.E. }\end{array}$ & $\begin{array}{c}\text { Bas } \\
\text { Gauche } \\
\text { Devant } \\
\text { N.E. }\end{array}$ & $\begin{array}{l}\text { Haut } \\
\text { Droite } \\
\text { Devant } \\
\text { N.O. } \\
\end{array}$ & $\begin{array}{l}\text { Haut } \\
\text { Droite } \\
\text { Derrière } \\
\text { S.O. }\end{array}$ & $\begin{array}{c}\text { Haut } \\
\text { Gauche } \\
\text { Derrière } \\
\text { S.E. }\end{array}$ & $\begin{array}{c}\text { Haut } \\
\text { Gauche } \\
\text { Devant } \\
\text { N.E. }\end{array}$ \\
\hline Êtres vivants & $\begin{array}{c}\text { Hommes et } \\
\text { animaux } \\
\text { sauvages, } \\
\text { végétaux }\end{array}$ & $\begin{array}{c}\text { Animaux } \\
\text { sauvages, } \\
\text { Végétaux, } \\
\text { animaux } \\
\text { domestiques }\end{array}$ & $\begin{array}{c}\text { Animaux } \\
\text { domestiques, } \\
\text { oiseaux }\end{array}$ & $\begin{array}{l}\text { Oiseaux, } \\
\text { hommes }\end{array}$ & $\begin{array}{l}\text { Hommes et } \\
\text { animaux } \\
\text { sauvages, } \\
\text { végétaux }\end{array}$ & $\begin{array}{c}\text { Animaux } \\
\text { sauvages, } \\
\text { Végétaux, } \\
\text { animaux } \\
\text { domestiques }\end{array}$ & $\begin{array}{c}\text { Animaux } \\
\text { domestiques, } \\
\text { oiseaux }\end{array}$ & $\begin{array}{l}\text { Oiseaux, } \\
\text { hommes }\end{array}$ \\
\hline Constellations & $\begin{array}{c}\text { Pléiades et } \\
\text { Grande } \\
\text { queue }\end{array}$ & $\begin{array}{l}\text { Grande } \\
\text { queue et } \\
\text { Orion }\end{array}$ & $\begin{array}{l}\text { Orion et } \\
\text { Vénus }\end{array}$ & $\begin{array}{l}\text { Vénus et } \\
\text { Pléiades }\end{array}$ & $\begin{array}{l}\text { Pléiades et } \\
\text { Grande } \\
\text { queue }\end{array}$ & $\begin{array}{l}\text { Grande } \\
\text { queue et } \\
\text { Orion }\end{array}$ & $\begin{array}{l}\text { Orion et } \\
\text { Vénus }\end{array}$ & $\begin{array}{l}\text { Vénus et } \\
\text { Pléiades }\end{array}$ \\
\hline Organes & Estomac & Gésier & Cœur & Petit foie & Rate & Intestins & Grand foie & Vésicule \\
\hline Graines & Petit mil & Mil blanc & Mil d'ombre & Mil femelle & Haricot & Oseille & Riz & Digitaria \\
\hline Couleurs & Jaune & $\begin{array}{c}\text { Rouge et } \\
\text { blanc }\end{array}$ & Rouge & Blanchâtre & Bronze & Noir & Rose & $\begin{array}{c}\text { Vert et } \\
\text { blanc }\end{array}$ \\
\hline Tambours & Kounyou & $\begin{array}{c}\text { D'aisselle } \\
\text { (petit) }\end{array}$ & D'aisselle & Petit & Moyen & Calebasse & Tambour & Grand \\
\hline $\begin{array}{l}\text { Forme des } \\
\text { tambours }\end{array}$ & $\begin{array}{l}\text { Sein de } \\
\text { femme }\end{array}$ & $\begin{array}{l}\text { Homme et } \\
\text { femme }\end{array}$ & $\begin{array}{l}\text { Homme et } \\
\text { femme }\end{array}$ & $\begin{array}{c}\text { Petits } \\
\text { hommes }\end{array}$ & Lion & Parturiente & Iguane & Vache \\
\hline Langues & Toro 1 & Toro 2 & De Mendeli & De Sanga & Toro 3 & Bamba & D'Ireli & Pour tous \\
\hline $\begin{array}{l}\text { Instruments } \\
\text { à vent }\end{array}$ & Mirliton & Corne kan & $\begin{array}{c}\text { Corne kan } \\
\text { tolo }\end{array}$ & $\begin{array}{c}\text { Corne kan } \\
\text { koulou }\end{array}$ & $?$ & $?$ & $?$ & $?$ \\
\hline $\begin{array}{c}\text { Forme des } \\
\text { instruments à } \\
\text { vent }\end{array}$ & Génies & Ane & Bœuf & Gazelle & $?$ & $?$ & $?$ & ? \\
\hline Sexes & Pénis(gros) & $\begin{array}{l}\text { Pénis(tête } \\
\text { de lézard) }\end{array}$ & Pénis (long) & $?$ & $\begin{array}{l}\text { Matrice } \\
\text { pobou }\end{array}$ & $\begin{array}{c}\text { Matrice pied } \\
\text { d'antilope }\end{array}$ & $\begin{array}{l}\text { Matrice } \\
\text { fendue }\end{array}$ & $\begin{array}{l}\text { Matrice } \\
\text { poitrine }\end{array}$ \\
\hline $\begin{array}{l}\text { Forme des } \\
\text { sexes }\end{array}$ & En battant & Lancéolée & & & Ovoïde & Triangulaire & Navette & Trapézoïdale \\
\hline Doigts & Majeur & Index & Pouce & Annulaire & Auriculaire & Pouce & Index & Majeur \\
\hline $\begin{array}{c}\text { Maison de } \\
\text { Conseil } \\
\text { (piliers) }\end{array}$ & $\begin{array}{c}\text { N.O. } \\
\text { Gauche } \\
\text { Avant }\end{array}$ & $\begin{array}{c}\text { O. } \\
\text { Gauche } \\
\text { Milieu }\end{array}$ & $\begin{array}{c}\text { S.O. } \\
\text { Gauche } \\
\text { Derrière }\end{array}$ & $\begin{array}{c}\text { S.E. } \\
\text { Droite } \\
\text { Derrière }\end{array}$ & $\begin{array}{c}\text { E. } \\
\text { Droite } \\
\text { Milieu }\end{array}$ & $\begin{array}{c}\text { N.E. } \\
\text { Droite } \\
\text { Devant }\end{array}$ & $\begin{array}{c}\mathrm{N} . \\
\text { Centre } \\
\text { Devant }\end{array}$ & $\begin{array}{c}\text { S. } \\
\text { Centre } \\
\text { Derrière }\end{array}$ \\
\hline Régions & Daga & Ende & Mendeli & Sanga & Yanda & Bamba & Ireli & $\begin{array}{l}\text { Toutes } \\
\text { régions }\end{array}$ \\
\hline Techniques & $\begin{array}{c}\text { Forge et } \\
\text { poterie } \\
\text { Articulations }\end{array}$ & Tannage & $\begin{array}{l}\text { Poésie } \\
\text { Chant }\end{array}$ & Danse? & $\begin{array}{c}\text { Sculpture } \\
\text { Peinture } \\
\text { Mort }\end{array}$ & Commerce & $\begin{array}{c}\text { Tissage, } \\
\text { musique, } \\
\text { parure, } \\
\text { langage }\end{array}$ & Agriculture \\
\hline
\end{tabular}




\section{BIBLIOGRAPHIE SOMMAIRE}

(9)

CALAME-GRIAULE Geneviève - Ethnologie et Langage. La Parole chez les Dogon, Paris, Gallimard, 1965.

Dictionnaire dogon, dialecte toro. Langue et civilisation, Paris, Klincksieck, 1968.

DIETERLEN Germaine - Les Ames des Dogons, Paris, Institut d'Ethnologie, 1941.

GANAY Solange de - Les Devises des Dogons, Paris, Institut d'Ethnologie, 1941.

GRIAULE Marcel - Masques dogons, Paris, Institut d'Ethnologie, 1938.

Jeux dogons, Paris, Institut d'Ethnologie, 1938.

GRIAULE Marcel et DIETERLEN Germaine - Le Renard Pâle, Paris, Institut d'Ethnologie, 1965.

LEIRIS Michel - La Langue secrète des Dogon de Sanga, Paris, Institut d'Ethnologie, 1948.

PALAU-MARTI Montserrat - Les Dogon, Paris, PUF, 1957. [Monographies ethnologiques africaines.]

PAULME Denise - Organisation sociale des Dogon, Paris, Domat-Montchrestien, 1940.

N.B. Une bibliographie complète des travaux de Marcel Griaule a été publiée dans le Journal de la Société des Africanistes (XXVI, 1956). 


\section{INDEX}

A B CDEFGH IJ KL M NOPRSTUVZ

@

Abri des hommes : 94, 95.

Accouchement (parturition) : 21, 46, 62, 90, 147, 188.

Agriculture :

origine de I' : 44, 54, 79 ;

culture, symbolisme de la : 71-73, 91 ;

voir aussi Tissage.

Ame :

double: $20,22,145 s$;

et circoncision : 20, 145-152 ;

des morts : 56, 117, 163, 170-175.

Amma : voir Dieu.

Ancêtres :

et animaux : 107, 119-122;

ancêtre forgeron et construction du monde : 29, 37-42, 98, 177, 181, 182, 199, 200 ;

culte des: voir Autels ;

les huit : 22-24, 28, 42, 45, 55, 56, 69, 87, 99, 117-123, 141 ;

et maison de famille : 87-89;

voir aussi : Binou, Lébé, Nommo.

Animaux :

et ancêtres : 107, 119-122 ;

interdits : 107, 119-122 ;

et jumeaux : 120-122, 187, 195 ;

dans le système du monde : 31 ss, 121,122 ;

voir aussi noms spécifiques, Sacrifice.

Arbres, dans le système du monde : 32.

Arc-en-ciel : 38, 40, 47, 105, 106, 178.

Arou : 61, 166.

Articulations : 40, 41, 44, 47, 51, 133.

Autels :

de fondation : $82,92,129$;

des ancêtres : 87, 89, 92, 129, 166, 171, 175, 188-189 ;

du Lébé : 112, 126, 128, 192-193, 197

personnels : 81, 99, 129, 152-158, 196 ;

voir également: Sacrifice.

Autruche : 106.

Bambaras : 5. 
Baobab : 32, 53, 62, 83, 113, 146, 168.

Baudrier d'Orion, constellation : 30.

Bélier céleste : 80, 99, 102-105, 108, 110, 198, 202 ; voir aussi Eau.

Bière : 165, 167 ;

et culte des morts : 169-173.

Binou,

ancêtre : 95-97, 110 ;

culte du : 117-123, 157.

Bois noircis : 181-184; voir aussi Feu, Vol.

Bonnet : 19, 74, 115, 121.

Bozo, peuple: 4, 32, 33, 205.

Bruit : voir Interdit.

Calebasse : 67, 102, 103, 106, 168, 199, 203.

Cauris :

dans le système du monde : 49, 50, 55, 98 ;

monnaie : 190-192 ;

et Parole : 192-194.

Chacal (Thos Aureus)

fils de Dieu : 16, 20, 23, 24, 146 ;

et désordre : 16, 19, 20,41,132, 137, 175, 176 ;

voir aussi : Inceste.

Champ :

primordial : $41,43,46,79,98,112,115,129,177$;

cultivé : 72, 108.

Chants obscènes : 140, 143.

Chasse : 13, 208.

Chef de famille (patriarche) : 32, 61, 107, 183, 184.

Cheveux : 77.

Chevrons, ligne de : 18, 64, 96, 106, 107, 178, 200, 201, 203, 204.

Circoncision : 120, 133, 138 ;

et l'âme double : 20-22, 145-152 ;

voir aussi Ame, Excision.

Classification des choses : 31-36, 136, 137.

Clitoris, termitière : 16,23 ; voir aussi Excision, Scorpion.

Coiffures : voir Cheveux.

Commerce : voir Jumeaux.

Correspondances, système des : 122 ;

table des : 210.

Coton : 25-26, 38, 44, 64, 67-69, 91.

Couleurs, symbolisme des : 47-50, 74, 75, 137, 179.

Couverture des morts : 68, 74, 88, 89, 91, 94, 107, 196, 201.

Crochets de fer : 98-101, 106, 202.

Crosse,

de jet : 106 ; 
des voleurs rituels : 106, 182, 184 ;

crosse-siège : 66, 164-165.

Cuivre : 17 ;

et Eau : 103, 116, 117 ;

et le Hogon : 115, 116 ;

ornements de : 74, 76, 115 ;

et le Soleil : 15, 67, 103, 116 ;

et Tambours : 61,62 ;

Rouge : 15 ;

Blanc : 15 ;

voir aussi Nommo.

Culte : voir Ancêtres, Binou, Feu, Lébé, Morts.

Culture : voir Agriculture.

Damiers : 88, 107, 108.

Danse : 175-181.

Dents :

limage des : 75

de Nommo : 25.

Dieu (Anima) :

et la création de l'univers : 15, 16, 22-27, 121, 130, 162, 201 ;

père du Chacal : 16, 175-176 ;

voir aussi Nommo.

Digitaria exilis : 28, 35 ;

et la menstruation : 141-145 ;

battage de : 139-145;

et interdits : 140.

Divination : 20, 24, 126, 176, 180.

Dogon, peuple: généalogie : 22, 112, 113, 162, 166.

Doigts, valeur numérique des : 50 .

Droite et gauche : 51, 91, 102, 196.

Dyon, homme mythique : 112.

Eau :

génie de I': 16ss, 35, 46, 75, 79, 80, 91, 96, 99, 102, 105, $130,131,141,152,159,165$;

et Nommo : 17, 54, 116, 161, 201 et passim ;

et Procréation : 16, 17, 24, 91, 130, 132, 133, 201, 202 ;

voir aussi : Bélier, Humidité, Parole.

Escaliers : voir Monde.

Etoiles : 15, 30, 102, 103, 106, 181.

Excision : 16, 21, 23, 120, 133, 148, 150, 203 ;

voir aussi Ame, Circoncision. 
Féminité : 16, 20, 38, 74, 103, 148, 151, 152, 201, 202 ; voir aussi Fourmilière, Termitière.

Femmes : 75-77, 131 et passim ; travail des femmes : $67,147$.

Feu, culte du feu : 40, 181-186 ; voir aussi Bois noircis, Foyer, Vol.

Fibres, jupes de : symbolisme des 18-19, 137, 159-161, 175 ; et Parole. 18-19, 63, 176.

Filage : 26, 27, 67, 69, 147.

Foie : $35,125,130,131,134,138$; consommation du foie : 125-128, 151, 156.

Force vitale : 81, 82, 124-126, 171, 172, 184,

Forge : 37, 41, 42, 46, 78-82, 92, 99.

Forgeron : 5, 78-82 ; ancêtre : 37-42, 44, 46, 62, 81, 98, 177, 181, 182, 199, 200, 204 ; et le culte du feu : 40, 181-186; et Nommo : 38, 42, 184 ; fonctions rituelles du : 81, 126, 127, 186

Fourmilière : 16, 26, 38, 44, 131, 132, 191.

Foyer : 80, 90 ; voir aussi Feu, Forge.

Funérailles : 46, 170ss, 175ss ; voir aussi Sacrifice.

Gémelliparité : 16, 20, 21, 57, 201, 202 ; et animaux : 120-122 ; voir aussi : Jumeaux, Nommo.

Graines : les huit : 23, 24, 28, 35, 47, 141 ; voir aussi Digitaria exilis.

Grenier, comme modèle du système du monde : 33-38, 43, 67, 68, $79,81,199$.

Grossesse : 138.

Hogon, chef religieux : 56, 57, 59, 71, 111, 113-116, 126-129, 140, 153, 157 ; voir aussi Lébé.

Humidité : 17, 64, 72, 76, 99, 107, 113, 160, 161, 168, 176, 201, 202 et passim.

Hygiène féminine : 135, 138. 
Immortalité : 45, 117, 163.

Impurs, hommes : 81, 126-128, 140, 173-175.

Inceste : 19-23, 132, 137, 146 ; voir aussi Chacal.

Initiation : 163, 165.

Insectes, dans le système du monde : 32 .

Interdits : 116, 126, 138, 140, 154 ;

animaux : 107, 120-122 ;

bruits : 64, 82, 134 ;

travaux de nuit : 70,82 .

Ivresse : 169-173.

Jumeaux,

naissance et mort des : 20,146, 148, 188, 196, 197 ;

et animaux : 120-122, 187, 195 ;

et commerce : 186-197, 199, 202 ;

cupule double des jumeaux : 35, 36, 189, 195, 199, 204 ;

et cosmogonie : 199-201, 204 ;

et l'eau : 201, 202 ;

voir aussi Gémelliparité, Nommo.

K

Kouroumba, peuple : 5 .

Langage,

origine du : 18,19 ;

des tambours : 61-64 ;

voir aussi Parole.

Lannea acida : 32, 35, 36, 71, 92, 102, 103, 135, 185, 195.

Lébé, le vieil homme : 45, 53-58, 156 ;

avalé par Nommo : 45, 46, 53, 55, 56, 158 ;

culte du : 110-117, 126, 156 ;

serpent : 113 ;

tombe du: 45, 46, 54, 68, 71, 92, 98, 112, 115, 126, 149

résurrection du : 46-52, 57, 92, 157 ;

voir aussi Hogon.

Lézard «Soleil » (Nay) : 20, 21 37, 44, 121 137, 151, 152, 199, 202.

Lion : 31, 62 199, 203. 
Lune: 30, 103, 106, 181, 199 ;

et poterie : 15,85 .

Maison : 26 ;

de famille : 85-95, 108 ;

des femmes : 92,138 ;

symbolisme : $90,91$.

Marché : 58, 59, 64, 110 ;

voir aussi Commerce.

Masques: 13, 89, 96, 106, 107, 170, 175-181, 185, 201 ;

Grand Masque : 81, 165-167 ;

siège de : 165-168.

Matrice : 24, 35, 36, 74, 131-133, 135, 138, 142-144 ; classification : 135, 136.

Menstruation : 20, 133, 135-138, 141145, 159.

Monde, système du : 14-15, 27-40, 102, 103, 108, 110, 121, 122, $157,200,205,208$; vomissement du : 46-52, 157.

Monnaie : 190, 191 ; voir Cauris.

Mort, la : 45, 46, 117, 126, 158-169;

Morts, des jumeaux : 196, 197.

culte des : 158-175, 179-181, 183 ; voir aussi Autels, Bière, Couverture.

Morts-Vivants : voir Impurs.

Naissance, unique : 16, 20, 22, 146ss, 188, 201 ; double: 16, 21, 120-122, 146, 148, 188 ; rites de la : 147, 148 ; voir aussi Accouchement, Gémelliparité, J umeaux.

Nay : voir Lézard.

Nombres, symbolique des: 25, 47, 52, 190 ; trois : $24,74,136,147$;

quatre : $20,24,74,90,147$;

sept : $24,26,42,45,75,136$;

huit : $17,35,41,45,57,87,95,148,190$;

neuf : 52, 58, 157, 199 ;

dix : 25, 190 ;

quatre-vingts : 25, 41, 75, 190.

Noms, prononciation des : 109, 110.

Nommo,

création : 16ss ;

bélier : 102, 103, 202 ; 
et cuivre : $17,103,104,114-117$;

et le dessin de l'âme : 20, 22, 147 ;

et eau : $16,17,54,116,130$ et passim ;

forgeron céleste : 38, 40, 42, 80, 114 ;

et le Hogon : 114, 129 ;

jumeaux : 16-20, 201 ;

et parole : $17,18,25,42,45,55,130,131$;

et tissage : $18,22-27,62,67-70$;

et tambours : 60-62 ;

voir aussi : Eau, Jumeaux, Lébé.

Nuages : voir Crochets.

Odeur, et parole : 131, 134, 135.

Ogotemmêli,

personnalité : 4, 10-14;

adieux à : 207, 208 ;

mort d' : 209.

Oiseaux, dans le système du monde : 32 .

Or : 103, 105.

Oreille, signification sexuelle de l' : 76, 131.

Panier, système du monde : 29, 30, 37, 208.

Parole : 17, 45, 55, 61-64 109, 130 ;

et fibres : $18,63,131$;

rôle de la parole : 24, 25, 55, 61, 120, 135, 191 ;

et procréation : 24, 130-135 ;

et tissage : $22-27,63,65-70,131$;

maître de la : 24, 42, 43, 45 ;

et odeur : 131, 134 ;

et vêtement : 75 ;

voir aussi : Langage, Nommo, Rédemption.

Parturition : voir Accouchement.

Parure : 59, 75-78, 135.

Peintures : 96-97, 100-110, 181.

Pierres,

d'alliance : 46-49, 55, 105, 107, 111, 118, 119 ;

vomissement des : 47, 54, 119, 127, 132, 157, 190.

Pleïades, constellation : 30.

Pluie : 44, 54, 103, 104, 106, 202.

Poissons dans le système du monde : 32, 200, 205.

Poterie : 83-85 ;

poteries d'ancêtres : voir Autels ;

et forge : 80,84 ;

et lune : 15,85 ; 
et soleil : $15,84,85,116$;

dans le système du monde : 35, 36, 58, 78, 84, 85, 135.

Prêtre : 47, 95, 105-108, 112-114, 118 ; voir aussi Hogon.

Prière : 124.

Procréation : 64, 69, 91, 103, 131-134, 160 ;

voir aussi Parole.

$\mathrm{R}$

Rédemption : 22, 53-58.

Résurrection souterraine : 54, 60, 62, 150, 168, 176.

Sacrifice : 97, 98, 118, 123-130, 144-145, 155, 156, 174, 208 ; voir aussi Autels.

Sanctuaire :

du feu : 185 ;

totémique : 95-110 ;

peintures du sanctuaire : 100-110, 201.

Sandales : 105, 106, 114, 115.

Sang, menstruel : 20, 133, 135-144,159, 161 ; voir aussi Sacrifice.

Scarifications : 76, 203.

Scorpion : 21, 37, 44, 121, 199-203 ; voir aussi Clitoris.

Sépulture : 42, 45, 46 ; voir aussi Lébé.

Serpent :

ancêtre : 159-168 ;

Lébé : 112-114;

Nommo: 42, 43, 45 ;

dans les peintures : 96-98, 106.

Sexuels,

organes: 135, 148, 203 ;

symbolisme des : 131, 148-152;

voir aussi Circoncision, Excision, Lézard, Oreille, Scorpion.

Sexuels, rapports : 19, 21, 69, 74, 77, 91, 132-134.

Sigui, rite : 164-168.

Sistre de circoncision : 151, 152.

Société, organisation de la : 47-52.

Soleil : 14, 15, 20, 30, 66, 80, 85, 89, 103, 104, 116, 152, 161, 177, $181,199,203$ et passim ; voir aussi Lézard.

Sorko : voir Bozo. 
Tambours : 60-64, 101, 177 ;

voir aussi Parole.

Taureau : 199, 202.

Temple : voir Sanctuaire.

Termitière : 16, 44.

Terre,

création de la : 15 ;

mère du Chacal : 16, 18, 22, 132, 137, 138 ;

cultivée : 41, 44, 54, 71, 201 ;

voir aussi Agriculture, Champ.

Thos aureus : voir Chacal.

Tissage,

et parole : 22-27, 61, 63-70, 75 ;

et culture : 71-73;

et Nommo : 18, 22-27, 67-70.

Tombe : voir Lébé, Sépulture.

Tortue : 32, 107.

Totémisme : 95, 96, 117-120.

Unités de mesures, création des 29, 33, 37.

V

Vénus, planète : 30.

Verbe : voir Parole.

Village : 10, 92-94;

schéma du : 93, 108.

Vol :

du feu : 38-40, 90, 181, 185-186 ;

rituel : 106, 182-184.

Zodiaque, signes du : 198-206. 